STABLE VANAGEMENT AND EXERCISE

\title{
A BOOK FOR HORSE-OWNERS 8 STUDENTS
}

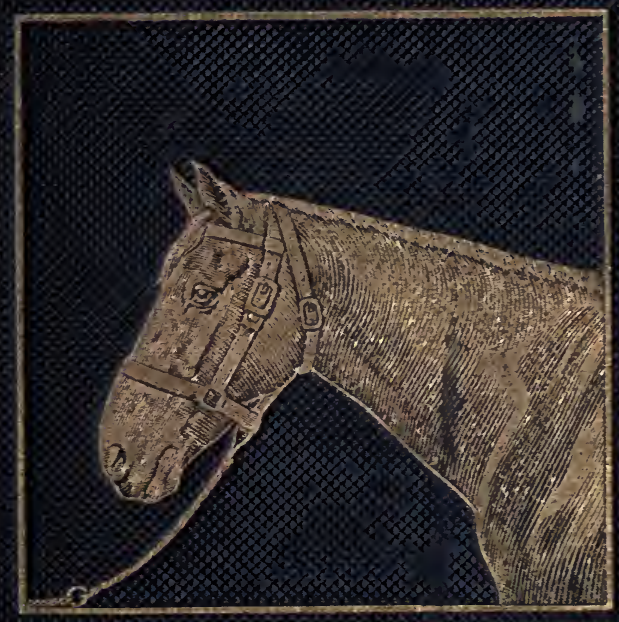

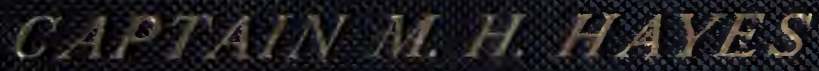



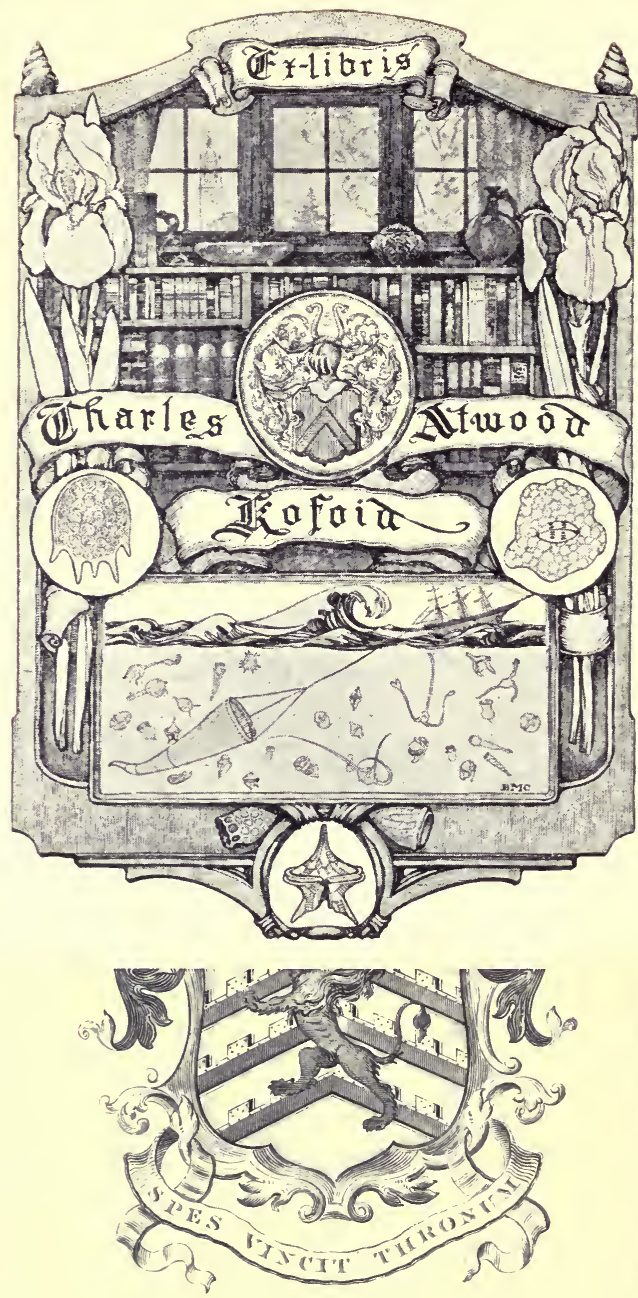

Firederic Winthrop. 


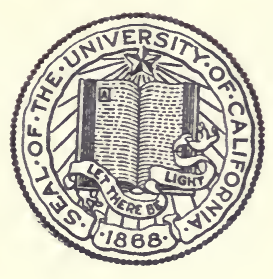

THE LIBRARY OF

THE UNIVERSITY OF CALIFORNIA

PRESENTED BY

PROF. CHARLES A. KOFOID AND

MRS. PRUDENCE W. KOFOID 

STABLE MANAGEMENT AND EXERCISE 




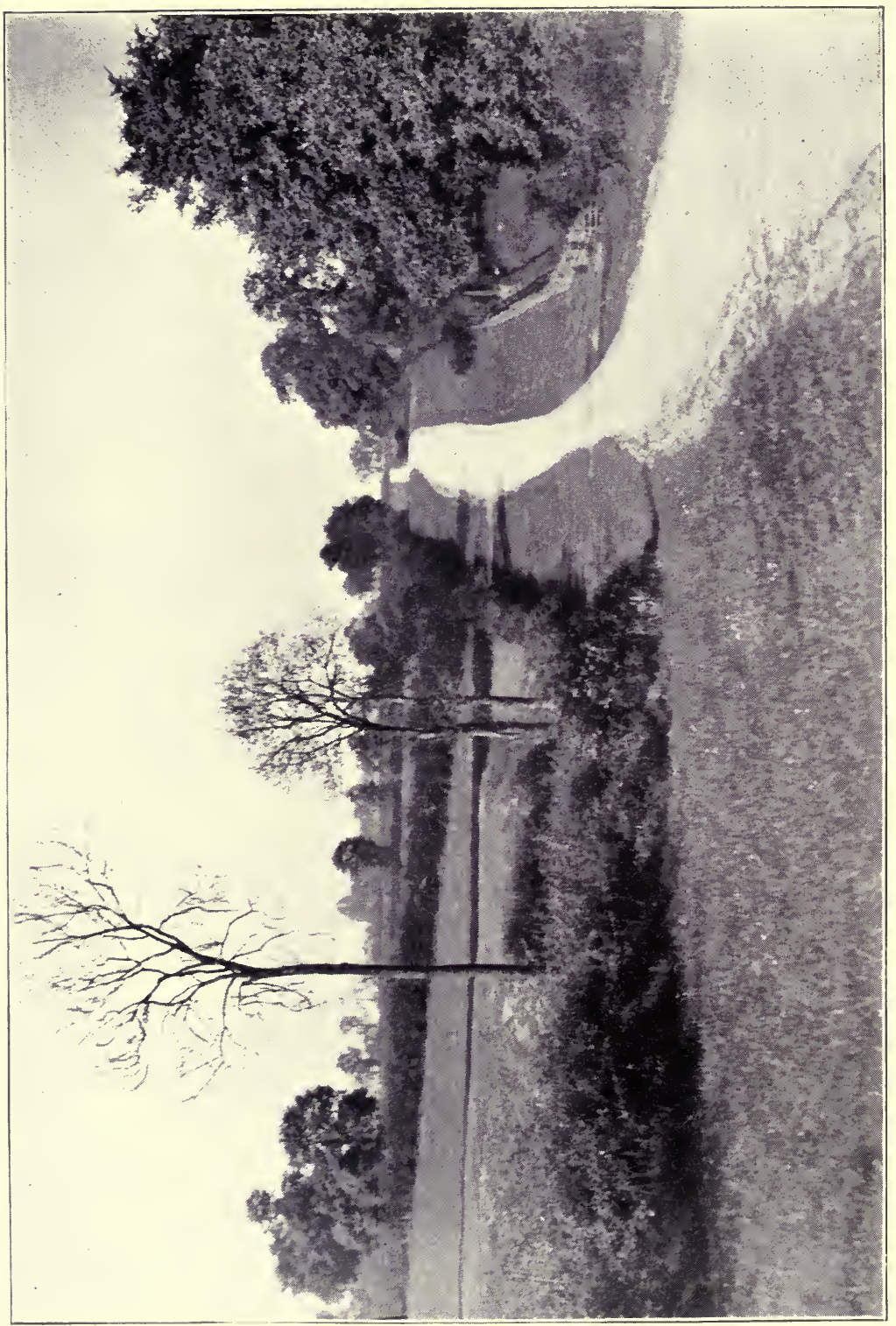

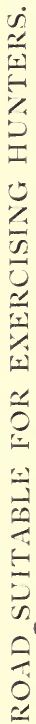

气ับ 


\section{STABLE MANAGEMENT}

AND

\section{EXERCISE}

A Book for Horse-Owners and Students.

BY

M. HORACE HAYES, F.R.C.V.S.

Late Captain "The Buffs"

Author of "Points of the Horse," “Veterinary Notes for

Horse-Owners," “Illustrated Horse-Breaking," etc

SECOND EDITION.

LONDON

HURST AND BLACKETT, LIMITED

I 3 GREAT MARLBOROUGH STREET

1900

All rights reserved 
PRINTED BY KELLY'S DIRECTORIES LIMITED, LONDON AND KINGSTON. 


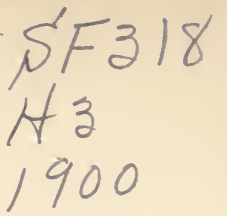

P RE F A C E.

A QUARTER of a century's experience in writing technical books on horses proves to me that the reading public, which becomes better educated every day, values opinions only when they are supported by valid reasons. Therefore, while giving full prominence to practical details, I have tried to explain their principles in a scientific manner, and have been greatly helped in this endeavour by many eminent authorities whose names I have mentioned in the text of this book. Without their valuable and kindly assistance and advice, it would have been impossible for me to have obtained all, or even the most part, of the information of which I was in search.

I am much obliged to Messrs. Sutton and Sons for the grasses and clovers, of which I have taken photographs; to Messrs. Champion and Wilton and Mr. T. U. Clarke for help about saddlery and harness; and to Mr. Arthur Richards for notes on the cleaning of carriages and gear, and on stable servants.

A large portion of this work appeared in articles which I wrote for the Live Stock Journal. I have had thus the advantage of seeing them in print and rewriting them before putting them into book form.

Yew Tree House, Crick, Rugby. Ist July, I900. 


\section{O N T E N T S.}

CHAP.

PAGE

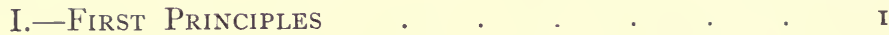

II.-Theory OF EXercise AND WORK . . . $55^{\mathrm{I}}$

III.-Theory of Feeding . . . . . . . . 6 I

IV.-Theory and Practice of Watering Horses. I 28

V.-VARieties of Food . . . . . . . . 146

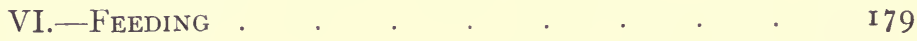

VII.-STABLES . . . . . . . . . . $\quad$ I92

VIII.-BEDDING . . . . . . . . . 260

IX.-Clothing . $\quad . \quad$. $\quad . \quad$. $\quad . \quad 285$

X.-Handling and Leading Horses . . . 308

XI.-GROOMING . . . . . . . . . 316

XII.-Clipping, Singeing, and Trimming • . $35^{\circ}$

XiII.-Cleaning Gear, Carriages, etc. . . . 359

XIV.-Management of Horses on Board Ship . $37 \mathrm{I}$

XV.-Stable Routine . . . . . . . . . $33^{82}$

XVI.-Summering Hunters and Wintering Polo

PONIES • .

XVII.-Exercise for Conditioning Hunters • • 39I

XVIII.-Stable Servants . . . . . . . . . 396 


\section{L L U S T R A T I O N S.}

Frontispiece-Road suitable for exercising hunters.

FIG.

PAGE

I. Teeth of horse

2. Transverse section of skull of horse, immediately in front of his back teeth . . . . . . 77

3. Transverse section of skull of horse, showing position of back teeth when the animal is chewing on the left side of his mouth

4. Jaws of horse placed evenly together . . . $\quad 79$

5. Lower jaw moved to the left, as in Fig. 3 . . . 80

6. Wood meadow grass; Italian rye grass; perennial rye grass ; yellow trefoil

facing $p$.

I 74

7. Red fescue; meadow fescue; rough stalked meadow grass

facing $p . \quad$ I 76

8. Hybrid cow clover ; alsike ; great bird's foot trefoil ,,

178

9. Bird's foot trefoil ; broad red clover ; sainfoin ,

I 80

ı. Sheep's fescue; fine-leaved sheep's fescue; smoothstalked meadow grass; hard fescue

facing $p . \quad \mathrm{r} 82$

I I. Crested dogstail; meadow foxtail ; timothy; suckling clover; tall fescue; yellow oat grass facing $p . \quad 184$

I 2. Rough cocksfoot ; lucerne ; sweet-scented vernal," $\quad$ I86

I3-I4. Methods of ventilation . . . . . . 203

I5-18. $" \quad, \quad$. . . . . . . 205

19-23. " " $"$. . . . . . 207

24. Stable with sliding doors . . . . . 223

25. One door to two loose boxes . . . . 225

26. Rack chain . . . . . . . $24 \mathrm{I}$

27. Water bucket fixed to door of box . . . . 245

28. Skep or dung basket . . . . . . 253

29. Side elevation of tricycle adapted to corn crusher . 255

30. Ground plan , , , , , , , , . 257 
FIG.

PAGE

3I. Good moss litter . . . . . . . $\quad 269$

32. Bad , , . . . . . . . $27 \mathrm{I}$

33. Cotton grass in peat. . . . . . . 273

34. Ends of straw bedding twisted-in, with stable fork laid across them . . . . . . . 277

35. Twisting-in ends of straw bedding . . . . 279

36. Racehorse in clothing . . . . . . 293

37. Arrangement to prevent the roller pressing on the withers . . . . . . . . 295

38. Manner in which a horse slips his head-collar . 297

39. Head-collar without a front . . . . . 298

40. Anti-slipping head-collar . . . . . . 299

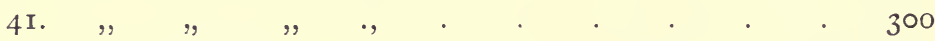

42. Foal's head-collar . . . . . . $30 \mathrm{I}$

43. Webbing halter . . . . . . . 302

44. Improvised halter . . . . . . . 303

45.,$\quad . \quad . \quad . \quad . \quad . \quad . \quad 3 \circ 3$

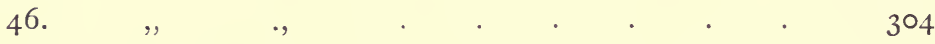

47. $\quad, \quad, \quad . \quad . \quad . \quad . \quad . \quad . \quad . \quad 305$

$48 . \quad, \quad, \quad . \quad . \quad . \quad . \quad . \quad . \quad . \quad 305$

49. $\quad$ 4. $\quad . \quad$. $\quad . \quad . \quad . \quad . \quad . \quad . \quad .305$

50. $, \quad, \quad . \quad . \quad . \quad . \quad . \quad 306$

5 I. Leading a horse into a stable . . . . . . . 3 I I

52. Adjustment of snaffle for leading a horse, when mounted . . . . . . . . $33^{\mathrm{I}} 3$

53. Hand-rubbing the body . . . . . . 324

54. " " " " . . . . . . . 325

55. Grooming tools . . . . . . . . 327

56. Brushes . . . . . . . . 329

57. Half-moon sweat scraper, with india-rubber band . 333

58 to 61 . Making a hay pad . . . . . 335

62. Watling Street Road facing $p . \quad 396$ 


\section{STABLE MANAGEMENT.}

\section{CHAPTER I.}

\section{FIRST PRINCIPLES.}

State of Nature-Gregariousness-Composition of the Animal Body-Composition of Plants Consumed by Horses-Circulation of Blood and RespirationBodily Supply and Removal-Reciprocal Action of the Organs of ExcretionEnergy in Plants and Animals-The Animal Body as a Machine-Duties of the Skin-Causes which affect Epidermal Growth-Maintenance and Regulation of Bodily Temperature-Reaction and Chill-Absorption of Fluids by Solids-Absorption of Gases by Solids-Radiation of Heat-Protection against Heat by Colour-Conduction of Heat-Protection by the Coat against Cold and Chill-Ability of Horses to bear Extremes of Temperature-Influence of Damp on Horses in the Open-Influence of Sunlight on HorsesInfluence of Altitude on Horses-Acclimatisation-Stable Impurities-Soap.

THE explanation in this Chapter of some of the principles which should guide us in the stable management of horses, will, I trust, save much repetition when discussing later on, the "why and the wherefore" of various practical details.

\section{STATE OF NATURE.}

The theory of evolution teaches us that the special organisation of an animal has been produced by the gradual action which surroundings (climate, soil, food, etc.) have had on the animal's ancestors through the course of ages. As health is the ordinary condition of the body, we may conclude that it can be best preserved by the surroundings which have effected the final result, and in which the animal is popularly said to be in his "natural state" of life. We find this to be 
true even among varieties of the same species which habitually exist under respective surroundings that are widely different from each other, as we may see among Arctic dogs and those that are natives of tropical climates, neither of which could bear with impunity a mutual change of country. It is evident that an alteration in the natural state of an animal will continue to be more or less detrimental to its health, until the functions of the animal have accommodated themselves to the new surroundings. Although young horses fresh off grass, as a rule, at first feel the bad effects of a change of surroundings, when put into a stable; they become so well accustomed to their new conditions of life, that after some time an abrupt return to the old order of things is not always safe. In our efforts to obtain a maximum of strength or speed, we may succeed to some extent in making special breeds and certain individual horses tolerant, for instance, of food which is much more stimulating than that found by them in their "natural" state. At the same time, experience proves that such apparently tolerant horses are abnormally liable to disease. Therefore, while endeavouring to regulate the stable management of our horses, so as to enable them to meet our civilised requirements, we should keep them in a state as near that of Nature as is practicable. Even among human beings, civilisation is not free from danger to health. The wellintentioned, though extremely ill-advised attempt to make the remnant of Tasmanian natives participate in the supposed blessings of wearing clothes, sleeping in beds, eating cooked food, and practising other forms of comparatively modern hygiene, resulted in their speedy destruction.

\section{GREGARIOUSNESS.}

Gregariousness (love of association) is largely developed in horses, which consequently as a rule thrive best under conditions of companionship with their fellows. Among semi- 
wild horses, like those on the Kirgis steppes and Montana ranches, each stallion has his kossiak or "bunch" of brood mares, and the other mares and geldings live in amity together. I have known a horse in the open, failing association with one of his own kind, seek the companionship of a cow, whose side he would rarely quit. Two horses which work as a pair, or which are close stable companions, as for instance when separated only by a swinging-bail, frequently contract for each other a strong friendship, which one or other will often manifest by loss of appetite and restlessness during his partner's absence. It is evident that in a stable, a stallion should be kept rigidly separated from other horses, and especially from mares. I have pointed out in Illustrated Horse-breaking, that horses recognise mankind far more by the voice than by the appearance, and are quick to perceive differences of meaning conveyed by changes of tone. Hence, a stableman who wishes to be companionable to a horse in his charge, should speak to him as occasion may offer, and should use an invariable tone and an invariable form of words for each respective verbal communication.

COMPOSITION OF THE ANIMAL BODY.

The chemical elemerits found in the body and their general compounds are shown in the two following tables :

CHEMICAL ELEMENTS OF THE BODY.

$\begin{array}{lll}\text { Oxygen } & \text { Potassium } & \text { Iron } \\ \text { Hydrogen } & \text { Sodium } & \text { Magnesium } \\ \text { Carbon } & \text { Sulphur } & \text { Fluorine } \\ \text { Nitrogen } & \text { Chlorine } & \text { Iodine } \\ \text { Calcium } & \text { Silicon } & \text { Lithium } \\ \text { Phosphorus } & & \end{array}$

CONSTITUENTS OF THE BODY.

Water

Nitrogenous matter

Fat
Mineral matter Carbo-hydrates Acids

Water supplies from about two-fifths to four-fifths of the 
entire weight of the body; the percentage being affected by various conditions, of which age is as a rule the principal. The proportion of water is highest at birth, and lowest in old age.

Nitrogenous matter is that in which nitrogen is found. It is divided into several classes, the discussion of which comes more within the province of physiology than within that of stable management. One or more of these forms of nitrogenous matter enter into the composition of every tissue (muscles, nerves, and glands for instance) and fluid (blood, saliva, and gastric juice for example) which are actively engaged in vital work, and into that of bones, cartilage, tendons, ligaments, skin, hair, hoofs, etc. The nitrogenous matter of muscle has, according to Hoppe-Seyler, the following composition :

$\begin{array}{lcrrr}\text { Carbon } & \text { from } & 51.5 & \text { to } & 54.5 \\ \text { Hydrogen } & , & 6.9 & , & 7.3 \\ \text { Nitrogen } & , & 15.2 & , & 17.0 \\ \text { Sulphur } & , & 0.3 & , & 2.0 \\ \text { Oxygen } & , & 20.9 & , & 23.5\end{array}$

Fat, the amount of which varies greatly in different animals, has the following average composition:

$\begin{array}{lllllll}\text { Carbon } & \cdot & \cdot & \cdot & \cdot & 76.5 & \text { per cent. } \\ \text { Hydrogen } & \cdot & \cdot & \cdot & \cdot & 12.0 \quad, \\ \text { Oxygen } & \cdot & \cdot & \cdot & \cdot & \frac{11.5}{100.0}\end{array}$

Mineral matters form about one-twentieth of the entire weight of the body, and are chiefly found in the bones, seveneighths of the mineral matter of which consists of phosphate of lime, the remainder being carbonate of lime, with traces of magnesia, fluoride of lime, and common salt (sodium chloride). Small quantities of lime exist in the muscles and other soft tissues and in the fluids of the body. The percentage of lime in the body varies directly as the age of the animal. In fact, 
age may be regarded as the gradual calcification of the organism, which in extreme senility renders the performance of the vital functions impossible. Although salts of potash and those of soda (chiefly in common salt) constitute only about $\frac{1}{3000}-$ th of the entire weight of the animal, they play an indispensable and active part in nutrition; and as they become rapidly excreted, a continued supply of them is necessary for health. Chlorine, besides being a component of common salt, is also one of hydrochloric acid ( $\mathrm{HCl})$, which is found in gastric juice. Silica appears in minute traces in the body; its chief office being to give hardness to the tissues in which it is present. Although iron does not add more than one ounce to the entire weight of the horse, its presence in the colouring matter of the blood is essential to life; and its duc supply, to health.

The principal carbo-hydrates, which are found only to a small extent in the body, are animal starch (glycogen), dextrose (grape sugar), and milk sugar. We find traces of grape sugar in the blood, and considerable quantities of glycogen in the cells of tha liver, from which it is removed by the blood in the form of grape sugar. The grape sugar preserves its identity in the circulation for only a short period.

Phosphoric acid and lactic acid, in small quantities, are the chief acids which are distributed throughout the tissues and fluids of the body. Hydrochloric acid, as just stated, is found in the gastric juice.

There are other organic compounds which are met with in the system; but their quantity is so insignificant, that they need not be mentioned.

COMPOSITION OF PLANTS CONSUMED BY HORSES.

Plants contain all the chemical elements found in animals, and in nearly similar combinations. 

CONSTITUENTS OF PLANTS CONSUMED BY HORSES.
Water.
Woody fibre.
Nitrogenous matter. Vegetable acids.
Crude fat. $\quad$ Mineral matter.
Starch and sugar.

The chemical composition of the constituents of food eaten by horses, will be discussed on page 62 et seq.

\section{CIRCULATION OF BLOOD AND RESPIRATION.}

The circulation of blood is carried out by the heart, which is a hollow muscle that acts like a force pump, and by tubes (blood-vessels) which are respectively classed as arteries, capillaries, and veins. The arteries convey blood from the heart; the veins take blood to the heart; and the capillaries, which are of very minute calibre, form a connection between the arteries and veins. There are two systems in the distribution of blood, namely, the general circulation, and the lung (pulmonary) circulation. In the general circulation, the nutritive matter is carried by the arteries to the capillaries, through the extremely thin walls of which it passes to nourish the various tissues; and the capillaries take up from the tissues waste material, which is brought by the veins to the heart, and which consists chiefly of carbonic acid, water, and broken-up nitrogenous matter. Having completed the round of the general circulation, the blood, which is now loaded with impurities, is carried by the pulmonary arteries to the air-cell capillaries of the lungs, where most of its carbonic acid escapes into the air cells, and is conveyed from them into the outer air by the bronchial tubes, windpipe and air passages of the head. While passing through the capillaries of the air cells, the blood absorbs oxygen from the air that is in these minute cavities, and carries it through the heart to the capillaries of the general circulation, which give it out to a greater or less extent to the tissues, where it is used for purposes of combustion (oxidation). Hæmoglobin, which 
is the colouring matter of the blood, acts as the air-carrier of oxygen to the tissues. On meeting with oxygen (as in the air cells), it forms oxyhæmoglobin, which on being brought into the presence of carbonic acid (as in the capillaries of the tissues) parts with its oxygen. The bright red colour of arterial blood of the general circulation, as when an artery of the external muscles is cut, is due to the oxyhæmoglobin in it. When hæmoglobin is uncombined with oxygen, it is of a purple hue, as we may see in ordinary venous blood.

Under usual circumstances of health, the quantity of blood in the body is more or less evenly distributed throughout the system. As this supply of blood is just sufficient for the requirements of the animal, it follows that if there is an unusually large accumulation (congestion) of blood in one part, there will be too little blood (ancemia or bloodlessness) in the remainder of the system; and vice versâ. Such local changes can be borne with impunity, if they are restricted within comparatively moderate limits of time and extent. It is, however, impossible to fix the limits which divide congestion and anæmia from health and disease. Cold sets up anæmia by causing contraction of the blood-vessels of the part. Heat and exercise have the opposite effect. As a rule, there is less blood near the surface of the body than in the deeper-lying tissues, owing to the cooling effect of the atmosphere, and to the fact that the work done by the internal organs is more continuous than that of the superficial muscles. Although the terms anæmia and congestion are generally connected with disease, we may correctly apply them to certain healthy conditions, as for instance, the anæmia of the brain during sleep, and the congestion of the blood-vessels of the stomach during the digestion of food in that organ.

BODILY SUPPLY AND REMOVAL.

The living body suffers constant loss of substance in the performance of its functions, and to make up for this loss and 
to obtain materials for its other requirements, it receives nutrition in the form of food, water and oxygen. Food to be utilised has to be digested, water and soluble salts are absorbed unchanged, and oxygen, as we have just seen, is taken into the system by the lungs from the air.

Regarding the body as practically made up of water, nitrogenous matter, fat, and mineral matter; we find that the water and soluble salts which have served their purpose, or which are in excess of the requirements of the system, can be removed (excreted) without change. Water is discharged chiefly from the kidneys, lungs and skin; and mineral matters from the kidneys and to a slight extent from the skin, especially in the case of common salt. The kidneys act as filters which have selective power in removing waste material along with water from the blood. This impure water (urine) is carried by two tubes (the ureters) from the kidneys into the bladder, from which it is finally discharged through the urethra. The insoluble mineral matters of the body, though fairly stable, gradually undergo change by becoming converted into soluble salts. Broken up nitrogenous matter yields compounds which are removed along with the urine, and fat which by uniting with the oxygen brought to the tissues by the blood, is changed into grape sugar and finally into carbonic acid and water; the carbonic acid being given off by the lungs into the atmosphere. The fat which has accumulated in the tissues undergoes the same changes, when it becomes broken up, as the fat which results from the disintegration of nitrogenous matter. A portion of the waste fat, as we all know, is excreted unchanged in perspiration and in other secretions. As many of the waste materials have a poisonous influence on the body; it is necessary for the maintenance of health that the organs (lungs, kidneys, intestines, skin, liver, etc.) which excrete them, should be in perfect working order, and that the system should have a 
full supply of oxygen and water, which is necessary for dissolving out and carrying away hurtful products.

The skin, like the lungs, gives off carbonic acid, although in very much smaller quantities; and it absorbs a minute quantity of oxygen from the air. In man, the lungs expire about 200 times the amount of carbonic acid given off by the skin.

\section{RECIPROCAL ACTION OF THE ORGANS OF EXCRETION.}

In the lowest forms of animal life, the functions of absorption and excretion have no special organs, but are performed by the entire surface. Insects breathe through openings (stigmata) which are distributed all over the body. In frogs, according to Bischof, the function of breathing is about equally divided between the lungs and skin. As we ascend the scale, we find that the processes connected with absorption and excretion become more and more localised. Thus, in the horse as in man, the absorption of oxygen from the air is practically confined to the lungs; and that of food and water, to the stomach and intestines. In excretion, the lungs carry away by far the greater part of the carbonic acid; the kidneys remove waste nitrogenous matter (urea, hippuric acid, etc.), along with the urine ; the kidneys, lungs, and skin get rid of the used up water; and the bowels expel the unabsorbed portions of food.

This tendency to the localisation of the functions of absorption and excretion are in no case complete. Thus, atthough the lungs are the special organs for the excretion of carbonic acid, the skin, as already mentioned, exhales it to a slight extent. Bouley was of opinion that his experiments proved that this transpiration from the skin (cutaneous expiration) was essential to the life of the lower animals. Of two horses, the skins of which he had shaved and covered with tar, one died in nine days, the other in ten days, and a third horse, which had been treated in the same way, 
except that before the tar was put on, he got a thick preliminary coating of glue, succumbed in nine hours. In all these cases the symptoms were those of gradual suffocation (gradual cutaneous asphyxia, as Bouley termed it), namely, the breathing became slow and deep, and the pulse weaker and weaker; the mucous membranes of the eyelids and nostrils assumed a purple hue; and the body and expired air became colder and colder. Bouley's conclusions on the subject appear to have been confirmed by the experiments of Colin, Becquerel, and others. Against this view, some physiologists (see Kirkes' Physiology) argue that such cases of death are caused by cold and not by asphyxia. As, however, they admit that this varnishing of the skin does not seem dangerous to human beings, and as men are far more susceptible to a low temperature than horses; it may not be unreasonable to conclude that Bouley and his followers were right, and that the skin of the horse exhales a larger quantity of carbonic acid than that of man. In any case, experience shows that when the nature of the work done by a horse, imposes a severe strain on his lungs, we should do our utmost to keep his skin in good working order.

In the discharge of water from the system, we have an admirable instance of reciprocal action; for in cold weather when the skin is inactive, far more urine is passed by the kidneys, than in hot weather when the skin is in full work.

The skin aids to a small extent in the excretion of urea, which, on reaching the surface, becomes rapidly converted into carbonate of ammonia (p. 46).

\section{ENERGY IN PLANTS AND ANIMALS.}

The scientific meaning of energy is the capacity of doing work; and work may be defined as the movement of weight. Thus, a unit of work is reckoned as a weight of one pound raised through a space of one foot. 
There are several forms of energy (heat, motion, electricity, and attraction, for instance), all of which can mutually reproduce each other. We may divide attraction into gravitation, cohesion and chemical affinity. Gravitation is the power of attraction which all bodies in the universe have for each other. Cohesion and chemical affinity act only when the bodies (molecules or atoms) which are influenced by them, are very close together. Electricity, as we all know, can generate motion, light and heat. Heat by means of the steam engine, for example, can produce motion and electricity. Motion produces heat when we rub the palms of our hands briskly together; electricity and heat, when we rub a stick of sealing wax on a silk handkerchief; and light and heat, when, by using a flint and steel, the small particles of stone which are broken off, violently impinge against each other, and thus produce sparks. The principle here involved is termed the correlation of forces, and means, as Grove expresses it, "that any force capable of producing another may in its turn be produced by it."

Energy exists either as active energy, which is energy at work, or passive energy (potential energy), which is energy at rest. If we wind up a clock without the works being put into movement, the active energy in the form of motion which we transferred from our muscles to the machinery, will remain as passive energy until the pendulum begins to swing. Then, as long as the works keep going, their motion will become converted into heat. If we throw a stone straight up into the air, the active energy possessed by the stone on quitting our hand, will gradually become converted into passive energy by the force of gravitation, until the highest point of its trajectory is reached, at which moment it will be at rest. During its descent, it will gradually lose its accumulated passive energy, until on striking the ground, its active energy of motion, due to gravitation, will become converted into heat. 
A similar case of the conversion of attraction into heat is seen, when water comes in contact with quicklime, and slaked-lime is produced. Some bodies which have a strong chemical affinity for each other, require an impetus to effect their union. Thus, the carbon in the materials (wood, coal, charcoal, or peat) for a fire, will not combine with the oxygen of the air without being set alight. Here we have a case somewhat analogous to that of a stone which, instead of being thrown up in the air and coming down again, sticks in the foliage of a lofty tree during its ascent. It would then require an impetus or shove-off, in order to convert its potential energy into active energy.

We have seen that by pouring water on quicklime, chemical affinity is converted into heat; but if we apply heat to slaked-lime, we shall have a portion of the heat changed into chemical affinity by the water being driven off. A similar action takes place in a lime kiln during the conversion of limestone (carbonate of lime) into quicklime.

When the water in a kettle is boiled over a fire under ordinary conditions, neither the water nor the steam rises above boiling point $\left(2 \mathrm{I} 2^{\circ} \mathrm{F}\right.$.) ; because the surplus heat is occupied in keeping the particles of steam separate from each other. While accomplishing that work, heat is said to be latent (inappreciable by the senses). If, however, we check the expansion of the vapour by means of pressure, as in a digester, the heat which is unutilised for keeping the particles of steam apart, will tend to raise the temperature of both the water and the steam above $212^{\circ} \mathrm{F}$. But the moment the artificial pressure is removed, the surplus heat will become converted into latent heat, with the result that the steam will expand, and its temperature and that of the water will fall to boiling point. The cooling effect which the evaporation of perspiration has on the skin, is due to the conversion into latent heat of a portion of the 
heat that was present in the skin. The raising of water from the surface of the earth in forming clouds is an everyday instance of work done by latent heat.

The food of those plants which are not parasites consists of carbonic acid $\left(\mathrm{CO}_{2}\right)$, water $\left(\mathrm{H}_{2} \mathrm{O}\right)$, mineral salts (such as phosphates, nitrates and sulphates of lime, potash and magnesia), and small quantities of oxygen and ammonia. Tubercles on the roots of plants appear to exert a strong influence in facilitating the absorption of nitrogen either simple or combined. By means of the energy received in the form of heat and light from the sun, plants are able to carry on their vital functions and to store up substances which are possessed of energy in the form of chemical affinity for oxygen. In the manufacture of these substances (e.g. woody fibre, starch, oil, and vegetable albumen) by a plant, the oxygen-containing compounds which are absorbed by the plant (carbonic acid and water, for example) are deprived more or less of their oxygen, which the plant gives off into the atmosphere. Thus, in order to manufacture Io parts by weight of woody fibre, the plant requires I6.3 parts of carbonic acid gas and 5.5 parts of water, the loss being II.8 parts of oxygen. Hence, when woody fibre is burnt, its potential (stored-up) energy, in the form of chemical affinity for oxygen, is productive of a considerable amount of heat. As starch has the same chemical composition as woody fibre, it yields to the animal which eats and digests it the same amount of energy as woody fibre produces in a fire; for in both we have the act of combustion, which is oxidation. The chemical reaction in both cases is expressed as follows :-

$\underset{\begin{array}{c}\text { (Carbonic } \\ \text { acid.) }\end{array} \mathrm{CO}_{2}}{\text { (Water.) }}=\underset{\begin{array}{c}\text { (Starch or } \\ \text { woody fibre.) }\end{array}}{\mathrm{C}_{6} \mathrm{H} \mathrm{H}_{10} \mathrm{O}_{3}}+\underset{\text { (Oxygen.) }}{\mathrm{I}_{2} \mathrm{O}}$

In vegetable oils and fats the proportion of oxygen is still less, and consequently they possess more stored-up energy. 
In the animal body, the oxygen which is required for the combustion of food is obtained, as we have seen, from the air breathed in by the lungs.

The nitrogenous compounds formed in plants by the agency of the rays of the sun, also possess energy in the form of chemical affinity for oxygen, though to a much less extent than fat or starch, as we may learn from their composition (approximatively, 53.5 parts carbon, 7 parts hydrogen, 23.3 parts oxygen, and 16.5 parts nitrogen), and from the fact that chemical affinity is stored up in urea and hippuric acid, in which products almost all the nitrogen contained in the plant food of the horse leaves his body. The life of plants which are eaten by horses (non-parasitic plants) is a process of deoxidation; that of animals, one of oxidation.

The absorption of carbonic acid gas in plants is effected by chlorophyll, which is the green colouring matter of plants and which is formed only in sunlight. Hence, plants which have no chlorophyll, are unable to obtain their carbon from the carbonic acid of the air, and are consequently obliged to feed on other plants or animals. Fungi (mushrooms, toadstools, etc.) and bacteria (the disease germs of glanders and tuberculosis, for instance) are varieties of such parasitic plants.

\section{THE ANIMAL BODY AS A MACHINE.}

The movements of the body do not appear to be produced in a manner similar to those of a mechanical machine, as for example, a steam engine, in which the chemical affinity of the fuel for oxygen is converted into heat; and the heat, into motion to a greater or less extent. In the first place, the energy required for the movements of the animal machine is not obtained directly from the fuel. (the food), but from the machine itself (the tissues); the fuel being employed to build up and repair the component parts of this living mechanism. Secondly, the heat which is evolved does not seem capable 
of being utilised for the production of muscular activity; for no useful effect in that direction is obtained by attempting to prevent the dissipation of that heat into the atmosphere. It may therefore be not unreasonable to conclude that the motion for muscular work is got directly from chemical affinity, and that the evolved heat is the remaining product of that source of energy. This heat is necessary, not for muscular work, but for the performance of the vital functions, which cannot be carried on in a state of efficiency unless the system is maintained at a temperature, in the case of horses, of about $99.5^{\circ} \mathrm{F}$; the surplus heat being carried off by evaporation from the skin, lungs, etc., and by radiation and conduction. In health, when the usual supply of heat is not sufficient to maintain the body at its normal degree of temperature, the nerves stimulate the process of combustion in the system, so that more heat is produced. Hence in cold weather, animals require more food than in warm weather, and at that time, food can be more or less supplemented by clothing. The nerves also perform the duty of preventing the temperature of the body from unduly exceeding its normal standard; for when the heat production is high, as during fast work, the nerves cause an increased supply of blood to go to the surface of the body, with the result that the process of evaporation is proportionately stimulated. The regulation of the internal temperature is therefore under nervous control.

DUTIES OF THE SKIN.

The following are the chief duties of the skin :

I. To act as an organ of feeling (or touch).

2. To assist in removing carbonic acid and other noxions products from the body.

3. To give off perspiration, which is a fluid that consists of about ninety-nine parts of water and one part of various other substances. This secretion is called insensible perspiration, 
when it cannot be seen on the skin by the unaided eyes; and sweat or sensible perspiration, when it is thus visible. The term, perspiration, is applied generally to both forms. The secretion of perspiration is regulated by the quantity of blood supplied to the skin, and also by direct stimulation of the nerves of the glands that secrete this fluid; both forms of control being exercised by the nervous system. Perspiration may be excited by muscular exercise, external heat, various poisons (including those of certain diseases), emotion, and other kinds of nervous disturbance, which may be indicative of bodily weakness or ill health. The drinking of water tends to promote perspiration by increasing the volume of the blood. On the other hand, as drinking water is generally much colder than the body, the ingestion of the former will as a rule lower the temperature of the latter. Hence, the warmer the water which is drunk, the more will the secretion of perspiration be excited; and vice versâ. Speaking generally, we may say that the appearance of sweat is compatible with health only when it has been brought on by an increased supply of blood. When sweat breaks out independently of the circulation, the skin, as a rule, being free from an excess of blood and being cooled down by the process of evaporation that is in action on its surface, will be unusually cold; hence we may regard the existence of a "cold sweat" as a sign that the health of the animal is more or less upset. The hot and dry condition of the skin in certain stages of intermittent fever, for instance, is an example of the arrest of perspiration by a poison (toxin) produced by the presence of disease germs in the system.

We have seen ( $p .12$ ) that evaporation has a cooling effect on the surface from which it takes place; because a liquid to be converted into vapour, has to acquire a certain quantity of heat, which it naturally absorbs from its surroundings.

Evaporation is dependent on the capability of the air to 
absorb water. When air hàs absorbed all the moisture it can hold, it is said to be saturated, and then evaporation cannot go on. The degree of humidity in the atmosphere varies between the limits of absolute dryness and saturation point, neither of which are ever attained in nature. The degree of saturation varies according to the temperature; hence, the warmer the air, the more moisture it is capable of absorbing. Also, the drier the air, the more rapidly does evaporation take place, and consequently, the greater is its cooling effect. Dry atmospheric heat can therefore be far more easily borne than moist heat. The difference which the presence of moisture in the air makes on the rate of evaporation, is well exemplified by a comparison drawn between the condition of the skin of a man or horse in a hot moist climate like that of, say, Singapore, and in a hot dry one like that of the Arabian desert. In the former, the skin remains more or less wet from sweat which is unable to escape into the nearly saturated air ; but in the latter, its usual condition is one of extreme dryness.

It is evident that the cleaner the skin and the shorter the coat, the more freely will evaporation take place from the surface of the body.

In addition to the evaporation of perspiration, there is an evaporation of moisture which passes through the skin mechanically, in the same way as it would do from a freshly killed dead body. This evaporation, which is far less than that from perspiration, has also of course a cooling influence on the system.

4. To secrete oil, which serves to lubricate the skin and hair. This oil is necessary to keep the skin in a pliable condition; for we find that when a large proportion of it has been removed, especially from those parts which are subjected to a good deal of bending (flexion and extension), the skin is liable to crack, as in cases of "cracked heels" and mud fever. This oil gives to the skin a polish, which naturally helps to check loss of 
bodily heat by radiation, and thus protects the body to some extent from chill. As a full supply of this oil is not secreted in many diseased conditions, the presence of the gloss which it gives to the coat is justly regarded as a valuable indication of good health. The more blood is brought to the skin by exercise and good grooming, the more plentiful will be the secretion of this oil.

5. To form epidermis, which is the general term for hair, cuticle, and horn, all of which are varieties of the scaly material (epithelium) formed by the true skin. Epidermis acts mechanically in protecting the body from injury. The short hair of the body of a horse is a protection against cold, and to some extent against irritating objects, such as flies. The duty of the long hairs of the tail, mane, and forelock is chiefly defensive, especially against insects. The long hairs of the muzzle serve almost entirely as feelers.

Dandruff consists of loose scales of the outer skin (cuticle), and of oil secreted by the skin. The cuticle and its dandruff act like hair in protecting the skin against cold and against irritation from external objects. Dandruff, on the other hand, forms a comfortable nest for insects.

\section{CAUSES WHICH AFFECT EPIDERMAL GROWTH.}

Comparison between the winter and summer coats of horses and other animals, proves that cold, which reduces the supply of blood in the surface of the body, has a stimulating effect on the growth of the epidermis. In seeking for an explanation of this apparent anomaly, we must examine the manner in which cold affects the respective processes of supply and removal of this structure. Epidermis receives its nourishment from lymph (fluid portion of the blood) supplied by the blood vessels of the true skin. As it possesses no blood vessels, its removal cannot be effected by means of the blood; but is accomplished by exfoliation, and by contact with 
external objects, as we may see in the flaking off and wearing down of the hoofs of an unshod horse. The exfoliation of hair is accomplished naturally by the shedding of the scales which cover the hairs, as we may observe by the thinned-out condition of their ends. The exfoliation of epidermis is hastened by the action of perspiration. Thus, cuticle can be far more easily rubbed off the skin of a man who is sweating freely, than off that of a man whose body is cool. Also, vigorous grooming tends to make the coat both fine and short. Contrary to the general opinion that brushing stimulates the growth of hair, we have the fact that the Sikhs, who have longer hair than any other people in the world, keep their hair as a rule closely coiled up on their heads, and undo it, for purposes of cleaning, only after long intervals of time. I may explain that their religion forbids them to cut their hair. When stationed in the Punjab, which is the country of the Sikhs, I have seen many of them making their, probably, annual capillary toilette, and have often noticed among them, instances of the hair reaching to the ground, while the owners were standing upright. In fact, it is no uncommon occurrence to find Sikhs with hair $6 \mathrm{ft}$. long ! I think we may safely attribute the extraordinary length of their hair to comparative absence of friction, and to the protection against the action of perspiration afforded by the compact condition which the hair is made to assume on the head.

The horns of animals which wear this kind of epidermal growth, are almost always more massive in cold countries than in hot ones, among members of the same species, as we see in reindeer, ovis ammon, and ibex. Also, observations in the respective countries will show us, that the hoofs of Tibet and Finnish ponies are thicker than those of Indian horses. We must here bear in mind that the colder a climate, the dryer it is, other things being equal. 
The beneficial effect which oil has on the growth of hair, is apparently due to the protection against moisture (including perspiration) and against friction which it affords the hair. Both in this case and in that of cold, the overgrowth is due to waste being less than supply. The increased growth of the skin and hair produced by a blister, appears to be caused by an excessive supply of nutritive material (lymph), which escapes through the walls of the small blood vessels during the resulting congestion and inflammation.

Pressure, such as that arising from saddle and harness gear, causes epidermal thickening by increasing the supply of lymph to the part. We see a similar process of epidermal growth on the soles of the feet and on the palms of the hands of men who respectively walk and row a great deal. In human beings, congestion due to pressure when carried to excess by the wearing of tight boots, produces corns. The more evenly pressure is distributed, the less violent are its effects, as we find in the difference between walking over gravel in thin boots, to that in thick ones. As congestion in excess is liable to become developed into inflammation, we should be careful to distribute the pressure of harness and saddlery as evenly as possible over the surface on which it falls. We are all aware of the stimulating action which pressure has on the frog of a horse's foot. I am indebted to Professor Halliburton for the hint that epidermal overgrowth, like accumulation of fat, is simply a case of supply being in excess of waste.

Dr. W. H. Willcox has kindly pointed out to me that various forms of disease are characterised by overgrowth of epidermis. Thus, in human tuberculosis, the hair of the scalp and the eye-lashes tend to grow long; the skin gets coarse and thick; and the body often becomes covered with fine downy hair. In cases of myxœdema with weak circulation, and in those of congenital heart disease, the skin is thick and the hair coarse. 
MAINTENANCE AND REGULATION OF BODILY TEMPERATURE.

The chemical changes which take place throughout the system during the process of waste and repair, are accompanied by the production of heat, and consequently render the temperature of the body higher as a rule, than that of the surrounding air. On the other hand, radiation, evaporation (principally from the lungs and skin), and conduction of heat by contact with objects of lower temperature, reduce this heat. The balance between these respective processes of heating and cooling is not left to chance, but is maintained within narrow limits by the nervous system. Although the temperature of the surface of the body is subject to extensive fluctuations, that of the interior cannot be kept higher than say $104^{\circ} \mathrm{F}$. or lower than $96^{\circ} \mathrm{F}$. for even a few hours without grave disturbance of health ensuing. The power of the regulating action of the nervous system on the temperature of the body is by no means absolute; for we find that by prolonged exposure to great atmospheric heat in the tropics, the nervous system may lose its power of control, and heat apoplexy may ensue with a sudden and abnormally high rise (say, over $107^{\circ} \mathrm{F}$.) of temperature. As the rapidity of evaporation, in circumstances of equal atmospheric temperature, varies in inverse proportion to the quantity of moisture in the air ; heat apoplexy occurs among horses as a rule, only in hot damp climates, like that of Calcutta for instance. We should here note that the evaporation of perspiration and not the mere pouring out of that fluid on the skin by the sweat glands, is an effective means for cooling the surface. The glare of a tropical sun seems to exert a very disturbing influence on the heat-controlling power of the nervous system; for we find that a thick shade to the eyes (preferably made of a bad conductor of heat, like pith or wood for example) affords great protection from sunstroke to animals which work under the 
rays of a tropical sun. In this respect, it is much more effective than pith sun-protectors placed over the top of the head, poll, and loins. We should bear in mind that the connection between the brain and the eyes by the optic nerve and its expansion, the retina; is short and direct. Most persons who have lived in the tropics must have felt the cooling effect on the entire system produced by the wearing of blue, green, or neutral-tinted glasses in the open on a very hot sunshiny day. As evaporation implies loss of fluid, a full supply of drinking water is an effective means for cooling the body of an animal exposed to great heat.

Exercise raises the temperature by increasing tissue change, as we learn from the fact that it causes the lungs to give off much more carbonic acid than they do during rest. At the same time, it stimulates the evaporation of moisture from the lungs and skin; and the nerves preserve the balance of healthy temperature.

When the influence of any cooling process, such as that of external cold, is greater than the influence of normal heat production, there will be undue bodily waste owing to increased chemical decomposition being necessary to obtain the extra heat. Consequently, when horses are "turned out" in cold weather, they will require more food to keep them in "condition" than if they were comfortably housed.

\section{REACTION AND CHILL.}

The term reaction, when applied to conditions of health, signifies the more or less rapid readjustment of a functional balance which has been recently disturbed, as for instance, by going out for a few moments into sharp, frosty air, or by taking a plunge into cold water. If the action of cold on the skin in either of these cases produces a healthy glow over, respectively, the surface of the face or that of the body, we have healthy reaction, which is often accompanied by 
increased functional activity. If, however, the application of cold is too violent or too prolonged for the reaction to take place, chill, with its well-known bad results, will probably ensue. The greater the previous functional activity, the quicker will be the reaction, and the less will be the danger of chill taking place. Hence, when a horse is hot from recent exercise, he will have less chance of catching a chill from, for example, drinking cold water, or being made to swim in a river, than after he has cooled down. Although I have never known or heard of any harm having been caused to a horse by drinking cold water when he was in a heated state from exercise, the fact remains that men have dropped dead from nervous shock in similar circumstances.

When a horse "breaks out" into sweat after he has become cool, he is far more liable to chill, than when he returns to his stable hot from work; because, in the former case, his skin is colder than in the latter. "Breaking out" is caused chiefly by influences which-like hot stables and too much clothing-stimulate the sweat glands more than they increase the temperature of the surface of the body. Removal of the cause, exercise and vigorous friction to the coat, are evidently the appropriate remedies.

Disease set up by chill is a result of a change in the quantity of the local blood supply being carried beyond a healthy limit, as often happens when the surface of the body is rendered more or less bloodless by the continued action of a cold current of air, with consequent congestion of one or more of the internal organs. A cold draught playing on a horse in a stable is far more likely to give him a chill, than exposure to an equally cold and equally strong current of air in a field, where the effect of the wind would be much more general, and where he would have an opportunity of equalizing the distribution of blood in his body by exercise.

When the blood vessels have been deprived of their normal 
supply of blood for a considerable time, the blood, if suddenly restored to them, appears to act more or less as an irritant to their walls; the only safe way of overcoming the difficulty being to gradually accustom them to its return. Thus, in frost-bite, if the blood, after having been driven away by cold, is allowed to suddenly return, violent inflammation, which may be followed by death of the part, will ensue. Here, the proper treatment will be the adoption of means, such as rubbing with snow, which will permit of only a very gradual return of a full supply of blood. The usual effect, however, of cold is, as we have seen, to produce anæmia (not inflammation), and the special danger to be feared is congestion of the deep-lying parts. Hence, when horses are over-heated from exertion, we should have them walked about, or should have vigorous and prolonged friction applied to their skin by two or more strappers to each animal, so that the healthy congestion of the muscles of the limbs and of the superficial muscles of breathing may not be relieved too quickly; and we should stimulate the sweat-glands by giving a liberal supply of water. Neglect of these precautions is a frequent cause of congestion of the lungs, especially among unfit hunters which have to return by rail to their stable after having been out with the hounds. In a typical case of this kind, when the animal is pulled up and is freed from his burden, the blood vessels of his limbs and of the surface of his body are filled with blood which has been brought in response to the stimulus of exercise. This healthy congestion soon becomes changed to anæmia by cold air, and especially by a cold wind acting on a horse which is standing still in a railway horse box, or perhaps in a more exposed situation, and the internal organs now become congested. Probably, when the horse gets into his stable, the amount of grooming he receives will not exceed that which is sufficient to put his coat "straight"; he gets very little water; and we need not be surprised if by bedding-down time he is 
"blowing," and is in need of the prompt attendance of a veterinary surgeon to treat him for congestion of the lungs. In these cases of congestion from chill, the more an internal organ has been weakened by severe exertion or other causes, the more liable will it be to suffer. Thus we find in India that chill often produces congestion of the liver; but rarely that of the lungs; the opposite being the case in England. I may explain that the climate of India, differing from that of this country, is as a rule, very favourable to the well-being of the organs of breathing, but is highly detrimental to that of the liver. In India, acute attacks of liver disease are frequent just after the rainy season, in localities where there is a considerable fall in the temperature of the air at night, as in places close to the hills. This tendency is increased by the practice pursued by many of the native grooms, who are generally but ill-provided with garments, of removing the horse's clothing to use as their own bedding. It is easy then to conceive how the horse gets derangement of the liver; for the cold, acting on the surface of the body, contracts the superficial blood-vessels, and thereby drives the blood to the internal organs.

\section{ABSORPTION OF FLUIDS BY SOLIDS.}

Books on physics tell us that if a solid body is placed in contact with a fluid which is capable of moistening it, the fluid will mount up to a certain height on the surface of the solid body. If we immerse one end of a glass tube of small diameter in water, we shall find that the water will rise to a much greater height on the inside of the tube than on the outside of it. Experiment shows that the height water is capable of ascending inside a tube, varies inversely as the diameter of the tube. Thus, water will rise ten times higher in a tube of $\frac{1}{100}$ inch in diameter, than in one of $\frac{1}{10}$ inch diameter. This force, which has more power over water than over any other 
fluid, is termed capillary attraction. Some fluids, mercury for example, not only refuse to obey it, but even exhibit capillary repulsion. The smaller and more numerous are the tubes or interstices contained in a solid body, the more water will it be capable of absorbing; supposing that no chemical combination (as occurs with quicklime and water, for instance) takes place between the fluid and the solid. Hence, if we dip into water two sponges of the same size, but of different degrees of closeness of texture, we shall find after we have withdrawn them from the water and have allowed enough time to let all the extra moisture drain away, that the sponge which has the smaller interstices will have retained more water than the other.

As far as stable management is concerned, the subject of the absorption of fluids by solids applies chiefly to questions of bedding, stable construction, clothing and food.

\section{ABSORPTION OF GASES BY SOLIDS.}

"The surfaces of all solid bodies exert an attraction on the molecules of gases with which they are in contact, of such a nature that they become covered with a more or less thick layer of condensed gas" (Ganot). As a great rule, the absorbability of a solid for gases varies according to the extent of its external and internal surface. Consequently the more porous a body is, the greater power it usually has for absorbing gases. In almost all cases, the easier a gas can be liquefied by pressure, the greater capacity has it for being absorbed by solids. For instance, one volume of boxwood charcoal will absorb about 90 volumes of ammonia, 35 of carbonic acid, and 8 of air.

\section{RADIATION OF HEAT.}

Radiation, in the sense used here, is the transmission of rays of heat, or rays of heat and light, by a body without raising 
the temperature of the surrounding air. All bodies, no matter what their temperature may be, constantly radiate heat; the loss thus entailed being more or less made up by absorption of radiated heat from other bodies, and in some cases by conduction of heat from bodies in contact with them. The ray's of the sun are composed chiefly of rays of light, and, to a smaller extent, of rays of heat; the former being capable of becoming converted into the latter and vice versa. If, during summer in a hot country, we ascend a mountain, say to a height of $16,000 \mathrm{ft}$., we shall find that the rays of the sun are as powerful as in the plains, but that the temperature of the air is below freezing point. We may therefore conclude in such a case, that the heat of the air in the plains is due to contact with the ground, buildings, and other objects which have become heated by the rays of the sun; but not to radiation. Heat received by means of radiation is partly absorbed and partly reflected. Thus, when a horse is placed in a cold stall, his body by conduction (p. 30) raises the temperature of the air which surrounds it, and radiates heat that warms the partitions, walls, etc. upon which it falls. These objects in their turn warm the air with which they are in contact, and radiate heat to other objects, including the horse, until finally the temperature of the atmosphere of the stall becomes more or less raised, and more or less equalised. In the open, almost all the heat radiated by a horse is lost, as far as he is concerned, in his surroundings, and consequently during cold weather the temperature outside is lower than in the stable.

The light rays of the sun (luminous rays) are capable of easily going through ordinary window-glass, which offers a considerable obstacle to the passage of the heat rays (obscure rays). Consequently, when sunshine falls on the - panes of a closed stable window, the heat rays are more or less taken up by the glass, and the light rays enter the 
building. These light rays on coming in contact with the surfaces inside the stable, become converted for the most part into heat rays, which are radiated throughout the building, but are unable to escape outwards, except through an open door or open window, and to a slight extent through the glass, which, on becoming heated by the direct rays of the sun, radiates heat inwards as well as outwards. Hence, the temperature of the air in the stable becomes more and more raised according as the rays of light continue to enter. This heating effect caused by the feeble power which heat rays possess of passing through glass, is well shown in the case of a green-house, the temperature of the atmosphere of which on a sunshiny day will be much higher than that of the air outside. If, therefore, we wish to keep our stables cool, we should avoid the employment of much glass, and should keep the windows open when the sun is shining in their direction.

\section{PROTECTION AGAINST HEAT BY COLOUR.}

We learn from the study of physics that the radiating power of the body is equal to its heat absorbing power, and that its heat absorbing power is in inverse proportion to its heat reflecting power. Hence, bodies that reflect heat well, like those which are polished, radiate heat feebly. We therefore find that a horse with a gloss on his coat, other things being equal, will bear exposure to cold better than an animal with a dull coat. Also, light-coloured surfaces radiate heat slower than dark ones, and we have every reason to believe that the change from a dark colour to a light one which the coats of many Arctic animals undergo on the approach of winter, acts beneficially in protecting them from cold, as well as in adapting them to their surroundings. The observations I have made in cold countries lead me to think that light-coloured horses usually stand cold 
better than dark ones, but having no exact data to offer, I give the opinion merely for what it is worth.

I have frequently noticed in hot climates, that white horses which have little or no pigment in their skin (equine albinos' as we might term them) bear exposure to hot sunshine far worse than other kinds of horses. I may explain to readers who have not made a special study of horses, that the great majority of white and grey horses, and all coloured horses, have black skins. I have also observed, though not to such a convincing degree, that the darker a horse's coat is, the better, as a rule, will he ward off the bad effects of the sun. General Daumas in his book, Les Chevaux du Sahara, was, I believe, the first to record this supposed fact, which he states is accepted by the horsemen of the Algerian desert. It appears that the presence of pigment in the skin of negroes and other inhabitants of tropical climates helps to protect the body, when it is exposed to severe solar heat. We learn from experience that in such a case, the skin of a black man, under similar conditions of health, will feel colder to the touch than that of a European or an American. We know that sunlight plays an essential part in the formation of pigment, especially in plants; and it is significant that the colouring of tropical animals as a rule is darker and more brilliant than that of Arctic animals. In horses, melanotic tumours, which are characterised by the formation of a very large amount of pigment, are with few exceptions confined to grey horses, and in such cases they almost always appear after the animal is at least nine years old, at which age the coat begins to turn white. Also, although I have no statistics to bear out the assertion, I feel convinced, from personal observation, that melanosis is a much more common disease among grey horses in hot climates, than in cold or temperate ones. We may reasonably hazard the conjecture that susceptibility to mela- 
nosis is due to the poor protection against over-stimulation by sunlight, afforded by the white coat to the cells which form pigment.

Dr. Pembrey suggests to me, that the rôle which pigment plays in protecting the body from the direct rays of the sun, consists in preventing their deeper penetration. It would then act in a manner somewhat similar, though of course far less effectively, to that in which a blanket wrapt round a block of ice checks the tendency of the ice to melt during warm weather (p. 3I). It would also shelter the sweat nerves from the injurious action which very bright light might have on them. On page 2I I have alluded to the powerful influence which intense light exerts on the nerves. The treatment of lupus by means of the luminous rays of the sun concentrated by a lens, will be suggestive to medical readers. Dr. Pembrey also points out that sun-burn is a protection against the further action of the sun's rays, and that farmers in the South of England generally prefer black pigs to white pigs; because they find that the former are less affected by a hot sun, than the latter. When going by sea from England to tropical countries, I have often remarked that exposed parts-such as the face, neck and arms-of fair-skinned sailors or passengers were much more liable to become blistered by the sun, than those of their dark-skinned ship-mates. Although we have undoubtedly strong grounds for believing that pigment protects the body against heat, this supposition has not up to the present been proved by experiment.

\section{CONDUCTION OF HEAT.}

If a piece of charcoal or stick of sulphur is burning only at one end, we shall find that we can painlessly lift it up by the other end with our fingers; because charcoal and sulphur are bad conductors of heat ; that is to say, their respective powers of transmitting heat through their mass are feeble. On the 
other hand, the conductivity of metals is high, as we may learn by placing our hand on the middle part of a poker which has one end red hot.

Knowledge of the conductive powers of substances can be utilised in various practical ways. Thus, by enveloping a piece of ice in several folds of a blanket or woollen rug, we prevent the ice to a great extent from melting, even during a summer's day; because the protecting material is unable to conduct from the outside a sufficiency of heat to melt the ice. An instance of obstruction to the outward transmission of heat is afforded by the "Norwegian stove," which consists of a box lined with thick felt, and which is used to keep food hot for several hours. It loses its heat so slowly that if a pot containing the raw materials of a stew or soup is brought to boiling point and then put into this box, the process of cooking will proceed without interruption, and will become completed in a few hours with only a small loss of temperature.

The transmission of heat is similar to that of light and sound, in that its intensity varies inversely as the square of the distance travelled. Thus, the light of a candle or the sound of a note of music is four times as strong at a distance of I yard as it is at a distance of 2 yards. Consequently, we may infer that a rug $I$ in. thick would be four times as warm as a rug half an inch thick, both being of the same material.

The nature of the sensation of heat or cold produced by contact is greatly dependent on the conductivity of the body that is touched. For instance, among substances of the same temperature, a bad conductor of heat, such as wool or wood, will feel warmer to the touch than a better conductor, such as iron or stone; a fact which accounts for the not uncommon idea of persons unacquainted with physics, that the former class of objects are habitually of a higher temperature than the latter, under similar conditions of heat.

The following table of the comparative heat-conducting 
powers of certain substances may be studied with advantage :-

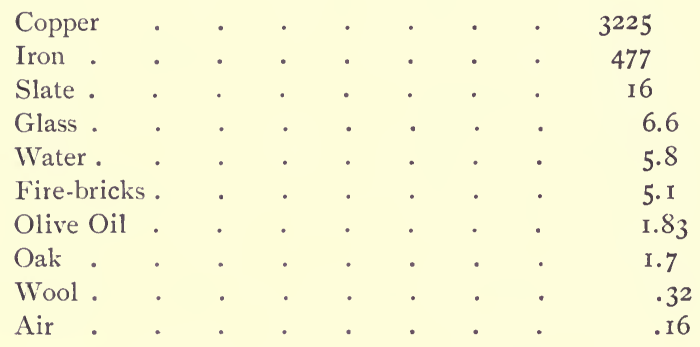

"The conductivity of snow is about $\frac{1}{7}$ th that of moist clay" (Ganot). The order of superiority in conductive power possessed respectively by linen, cotton, silk, and wool, is the same as that in which they are here written. The conductivity of hair may be regarded as the same as that of wool ; for the latter substance is merely a variety of the former which has undergone a modification of shape, but not of composition or structure.

The great difference between the respective conductive powers of snow and water seems to be due chiefly to the large quantity of air contained in snow. Bark has less conductive power than wood, apparently from the fact of its containing more air.

Ordinary manufactured silk conducts heat better than pure silk, owing to its adulteration with certain agents such as salts of iron and tin ; and common horse rugs are better conductors of heat than those which are "all wool," on account of their being made partly of cotton. The presence of water and air modifies the apparent powers of conduction of many substances. For instance, the fact that a woollen cloth holds imprisoned between its fibres a larger quantity of air than a cotton cloth of similar size and weight would do, makes the former material a worse conductor of heat, as compared to the latter, than the knowledge of the respective conducting powers 
of wool and cotton would lead us to suppose. As air conducts heat more feebly than wool, it follows that the more air a piece of cloth retains, the less will be its conducting power; therefore, very closely woven cloth is a better conductor of heat than it would be if its texture were more porous. It is evident that the limit of porosity in this case must not be so great as to allow air to circulate freely through the material. We find that in the case of "cellular cloth" the heat-retaining capacity of the cotton is much heightened by having the cloth loosely woven, and that, with a given weight of clothing, we obtain a somewhat similar effect by increasing the number of thicknesses, between each of which a more or less perfect layer of air is imprisoned. Thus, two rugs will be warmer than one which is as thick as both of them put together, and which is of similar material and structure. Probably most men know from experience that the addition of an ordinary cotton shirt worn over a flannel one will be almost, if not quite, as effective in protecting the body from cold as that of a second flannel shirt. In our own cases, as a protection from cold, it is better to put a cotton shirt over a flannel shirt than a flannel shirt over a cotton shirt, which would be apt to stick to the skin, and would thus prevent the formation of a layer of air between the skin and the shirt. By employing cotton with horses' clothing in the manner indicated, economy in weight and expense may be obtained without much loss of heat-retaining power.

When two bodies are in contact, each of them transmits heat to the other independently of any difference there may be between the respective temperatures. If one of these bodies be colder than the other, the balance of heat transmission gained by it, at any given moment, will be equal to the difference of temperature between the two. Hence, the rate of loss of heat by the warmer body will decrease according as the temperature of the colder one becomes raised. 
Thus we find that when a horse is placed in a cold atmosphere he will lose heat faster when the air is in motion than when it is still ; because, instead of one layer of air remaining close to the skin, and becoming gradually raised in temperature with comparatively little loss of heat by the animal, there will be presented to his skin a more or less rapid succession of layers of cold air. We have this effect heightened in the animal body by the stimulus given to the evaporation of moisture from the skin. Agreeably to these facts, we find that a temperature of $-20^{\circ} \mathrm{F}$. during a Russian winter, for instance, is easier to bear when the atmosphere is still, than one of, say, $10^{\circ} \mathrm{F}$. ( $30^{\circ}$ higher), when a strong wind is blowing. Under the former condition, one experiences no inconvenience from walking about in ordinary clothes and without an overcoat, provided one's hands and ears are well covered; for the circulation of blood is comparatively torpid in these parts of the system. When the temperature in the shade is higher than that of the body (normal temperature of man being about $98.5^{\circ} \mathrm{F}$., and that of the horse about $99.5^{\circ} \mathrm{F}$.), the substitution in question is that of air which is hotter, but also is drier than the removed air. The cooling effect of the stimulus to evaporation of perspiration given by the comparatively dry air is, however, so great, that when the temperature in the shade is even at $120^{\circ} \mathrm{F}$., the effect of a current of air is very refreshing to man and beast.

\section{PROTECTION BY THE COAT AGAINST COLD AND CHILL.}

The coat of the horse being composed of a material (hair) which is a bad conductor of heat, and being capable of holding between the hairs a large amount of air, which is a still worse conductor of heat, it affords an admirable protection to the body against external cold, when it is sufficiently long and thick, and when it is dry. As the presence of dandruff aids in this form of protection, and as grooming tends to 
remove dandruff and loose hairs from the coat; the less a horse is groomed, the better will he stand cold. When the coat becomes soaked with water, its conductivity is increased, probably, at least twenty times, as we may infer from a comparison between the conducting powers of water, wool, and air. Horses which have long coats, and which remain in the open during cold weather, suffer very little from lying out on dry snow; for the coat is such a bad conductor that it allows the heat of the body to melt only a small amount of the snow with which the coat is in contact, and consequently the portion of the coat that is next the skin remains dry. The skin of the horse, like other kinds of leather, conducts heat far better than hair.

Besides protecting the body from cold by being a bad conductor of heat, the coat guards it from chill, by reason of its great capacity for absorbing and retaining moisture. Therefore, when a horse with a long coat perspires freely after exercise, the sweat, by the action of the heat of the body, quickly leaves the surface of the skin and accumulates near the ends of the hairs, from whence it evaporates slowly, and consequently the animal does not run much risk of getting chilled. With a short coated or clipped horse in similar circumstances, the sweat would be more or less in contact with the skin, which would cool much more rapidly, on account of the sweat (practically water) being a far better conductor of heat than either hair or the air that is imprisoned between the fibres of a long coat. If, however, we placed a rug over the animal, the sweat would become speedily transferred to the woollen material, which, like the outer portion of the hair of a long coated horse, would help to prevent chill by giving off the moisture slowly. In our own cases, a flannel shirt acts in a similar manner.

The efficiency of the unclipped coat as a protection against cold is well shown by the immunity from chill displayed by 
cab horses in Russia during winter. These animals, which are not clipped, are driven fairly fast in their work, and often, when reeking with sweat, are pulled up and kept standing in the street for a considerable time. In such cases, the perspiration becomes quickly frozen on the outside of the coat into particles which are kept well away from the skin by the hairs being long, and consequently the formation of this icy layer produces little or no bad effect on the horse's health. If these animals were exposed in anclipped condition to such a trial, they would rarely escape a cough or a cold, if not more serious disease; unless they were covered over with warm clothing the moment their work was stopped, which is a precaution I have never seen taken in that country, except with match trotters. Its neglect does not appear to be accompanied by any bad result; for the coats being left long, the horses keep in health. According to the present regulations in St. Petersburg, when the temperature of the air goes down to $-10^{\circ} \mathrm{R}$. $\left(9.5^{\circ} \mathrm{F}\right.$.), each cab driver is obliged to provide his horse with a warm loin-cloth, which is not removed during work. The question of the influence of a long coat on work, will be discussed under the heading of "Clipping" (p. 350).

\section{ABILITY OF HORSES TO BEAR EXTREMES OF TEMPERATURE.}

Experience teaches us that horses in the open keep their health better, especially as regards their organs of breathing, and possess greater immunity from infective diseases, than stabled horses, other things being equal. Mr. Miller tells us (p.390) that when polo ponies are turned out during the winter in England, they prefer to sleep outside at night, even when snow is on the ground, than to seek the shelter of a comfortable hovel provided for them. The ponies to which he alludes were well-bred and well-fed animals. I have noted 
at Mr. Miller's place that the judiciousness of their choice was amply justified by their robust health and good condition.

The horses reared on the steppes of Little Russia for the Russian dragoon regiments have a strong dash of Arab and thoroughbred blood; yet they show no ill effects, as far as their health is concerned, from having lived in the open during the extreme cold (often below $-30^{\circ} \mathrm{F}$.) of their winter, provided they get a sufficiency of food. In England, a temperature of $5^{\circ} \mathrm{F}$. would be regarded as extreme cold. In almost all cases, before these intended remounts are taken up and finally selected for cavalry purposes, they have much difficulty in obtaining grass in winter, and consequently they are stunted in growth. In fact, the minimum dragoon height for remounts, which are "taken up" when they. are either three off or four off, is only 15 h. $3 / 4$ in. During an official tour I made to the Dragoon Remount Depôts in 1898 , I learned that when these young animals are well supplied during winter with hay, the effect of cold on their growth is not apparent. Even those which are not thus artificially fed, show excellent "bone," and are compact and very useful saddle animals. All the remounts for the fifty-four Russian Dragoon regiments and for all the Cossack cavalry regiments, are taken from horses reared in the open, and the bigger horses required for the twelve cavalry Guard regiments, are brought up in ordinary horse-breeding studs. From the principles already discussed, we know that as the internal temperature of horses has to be sustained by the combustion of food in the body, the severer the cold to which they are exposed, the better should they be fed. The lowest temperature which has been recorded in Arctic regions is $-58.7^{\circ} \mathrm{C} .\left(-73.6^{\circ} \mathrm{F}.\right)$. We may regard $-35^{\circ} \mathrm{R} .\left(-47^{\circ} \mathrm{F}\right.$. $)$ as an extreme degree of cold in Russia.

Mr. T. B. Drybrough, in Polo, tells us that "Montana has a perfect climate for eight months of the year, but the weather of 
January, February and March is sometimes intensely severe, $-40^{\circ} \mathrm{F}$. being not uncommon and $-60^{\circ} \mathrm{F}$. being occasionally recorded. At these times, horses can paw away the frozen snow and so reach the grass underneath, but cattle have not this instinct; they merely plough with their noses, which become so painfully lacerated where there is a hard crust on the snow, that the poor brutes lose heart, give up the vain attempt, and stand miserably awaiting death. In the winter of I886-7, 90 per cent. of the whole cattle stock perished in this way." As this instinct of scraping away the snow when in search of grass, is, as far as I can learn, possessed by all horses; it does not seem unreasonable to regard them as animals which have been evolved under conditions of severe cold.

Even groomed horses which are picketed outside at night, and which are consequently deprived of the means of keeping themselves more or less warm by exercise, show great tolerance of cold. I have never seen the slightest harm result to Arabs and well-bred Australasian army horses which were picketed in the open, as the custom is, with only the protection of a rug over their backs and loins, during the cold weather of Northern India, where sharp frosts are not unfrequent towards the end and beginning of the year. These artillery and cavalry animals appeared to be in about the same working condition as the stabled chargers and hacks of the officers, with the exception that the greater length of their coats during the cold weather lessened to a small extent their capacity for performing fast work. The experience gained from military campaigns - for instance, that of the Crimea, during the winter of which the cold was intense-proves still more strongly that exposure to frost and snow will very slightly, if at all, impair the efficiency of well-fed horses. It is true that the mortality among the army horses of Napoleon I. during the retreat from Moscow was appalling: but these unfortunate animals were in 
a more or less starving condition. The comparative immunity from the effects of cold shown by the more or less well-bred horses we have been considering, is of course surpassed by that possessed by animals which have no Eastern blood, and which have been inured from their birth to very low temperatures, like the Kirgis, Himalaya and Manchuria ponies.

A form of cold which the skin of a horse can badly withstand, is that which is produced by using common salt to melt snow, as is sometimes done during winter, in order to clear snow from streets, so as to save the trouble and expense of carting it away. A combination of snow and common salt acts as a freezing mixture, which with, say, equal weights of these two substances, has at the time of melting a temperature of about $0^{\circ} \mathrm{F}$. Consequently, if such a fluid comes in contact with the feet and pasterns of a horse, it will be liable to produce frost-bite by the direct application of great cold to the skin of the part. In ordinary circumstances, water cannot be colder than $32^{\circ} \mathrm{F}$. Hence, when a horse is travelling over ground covered with snow, its particles will be prevented from coming in contact with the skin, by the hairs of the part forming an obstacle to the entrance of these solid bodies. Also, the air imprisoned between these hairs will greatly aid in the defence of the skin, by the fact of air being an extremely bad conductor of heat. Besides, the air contained in the snow, as we have already seen (p. 32), renders snow a far worse conductor of heat than water, or than ice which is more or less free from air. Therefore, horses which travel through a solution of snow and salt, will be much more liable to frost-bite of their extremities, than if, under similar conditions, they were to go through snow, say, of a temperature of $-20^{\circ} \mathrm{F}$., which is a degree of cold far below that ever experienced in England. I have found in Northern Europe during winter, that when the temperature of the air falls below, say, $5^{\circ} \mathrm{F}$., snow which had been subjected to traffic, 
assumes more or less the form of dry dust, and will neither penetrate through nor adhere to the hairs of the pasterns. It is evident that the greater the length of these hairs, the more effectively will they protect the skin which is covered by them.

Horses of all breeds suffer little from extreme climatic heat, provided that they are protected from the direct rays of the sun (by, for instance, the shade of trees or by a thick roof overhead), and that they are in an airy situation void of adjacent objects which might impede the free circulation of the surrounding atmosphere. By the expression extreme heat I mean anything over $110^{\circ} \mathrm{F}$. in the shade. The highest atmospheric temperature $\mathrm{I}$ have felt was $125^{\circ} \mathrm{F}$. in the shade in Sindh. I have known the temperature of the air to be $109^{\circ} \mathrm{F}$. at nine o'clock at night in Mian Mir in the Punjab. In England, the temperature of the atmosphere very rarely exceeds $90^{\circ} \mathrm{F}$. in the shade. In confined positions or when unprotected from the direct rays of the sun, and especially if put to hard work, horses which are exposed to great climatic heat are very susceptible to fever and even to sunstrolke.

\section{INFLUENCE OF DAMP ON HORSES.}

Damp is peculiarly unfavourable to the well-being of horses, especially when it is combined with heat. In damp hot climates-such as those of Lower Bengal, Lower Burma, the Malabar and Coromandel coasts of India, Southern China, the low-lying seaboard of Ceylon and of the Malay Peninsula, and the Gold Coast-successful horse-breeding and horserearing are impossible; for in such places there is great difficulty in rearing young stock, and if they happen to grow up, they will be no good. Proximity to the sea or to the Equator, in itself, does not appear to have any connection with this failure; for we find that the fact of England and Ireland being surrounded by the sea does not injuriously affect stud operations in these countries; and that one of the 
hardiest and strongest breeds of ponies for their size, namely the Deli ponies, comes from the north of Sumatra. Although climatic cold diminishes the bad effect which damp has on the muscular development of horses, its good influence in this respect appears to be obtained at the cost of increased susceptibility to diseases connected with the organs of breathing. Thus we succeed in breeding in England, big, powerful horses ; but unfortunately many of them, Shires, Clydesdales, and thoroughbreds, "make a noise," and are much more liable to coughs and colds than horses which live in warm climates. The bad effects of damp on horses are shown not only constitutionally, but also in the quality and formation of the animals' feet, which, when kept under its influence, become weak, flat, and often diseased. The fact therefore remains that the horses which have the greatest immunity from roaring and other diseases of breathing, and which have the strongest feet, are those that are bred and brought up in dry climates.

\section{INFLUENCE OF SUNLIGHT ON HORSES.}

Sunlight, to the extent which we experience it in England, has a direct and an indirect influence for good on the health of horses. In human beings it apparently improves the quality of the blood, seemingly by its action on the red corpuscles. The "sun cure" has therefore been prescribed with more or less success for various diseases of mankind. From experience, I think we may safely assume that sunlight directly promotes the health of horses; supposing that its intensity is not tropical. Respecting its indirect action as a destroyer of disease germs there can be no doubt. Thus, Arloing tells us that sunlight impedes the growth of the bacilli of anthrax; Hewlett states that direct sunlight destroys the bacilli of tetanus in from fifteen to eighteen hours; and Sherrington mentions that the microbes of glanders are killed by sunlight in about three days. It is sup- 
posed that this action of sunlight is due to the fact of its giving rise to the formation of ozone or peroxide of hydrogen, both of which are germ destroyers.

\section{INFLUENCE OF ALTITUDE ON HORSES.}

The chief effects of altitude on the atmosphere are to make it lighter, drier, and colder, and to decrease the percentages of carbonic acid gas and dust in it. Dryness and diminution of carbonic acid and dust are conditions which promote the health of horses. The benefit to be obtained from cold produced by altitude, is dependent on the latitude, other things being equal. Thus in India, Sumatra, and Belgium for instance, the Spiti ponies, Deli ponies, and Ardenne mountain horses are respectively far stronger for their size than their relatives in the plains. A difference in altitude (say, of $7,000 \mathrm{ft}$.) which would be highly beneficial to equine life in hot countries, would, by decrease of temperature, be equally prejudicial in cold ones. We may therefore take for granted that cold limits the favourable influence of altitude on the atmosphere. In Tibet, at a latitude about the same as that of Syria, the hill ponies, which are very sturdy animals, live and thrive at an altitude up to at least 14,000 $\mathrm{ft}$. Altitude by rarefying the air, within healthy limits, strengthens the lungs by increasing their work, and in this way often produces a good effect in the early stages of human consumption.

The beneficial influence of altitude in checking the development of many disease germs is apparently due, as a rule, to cold and diminution of humidity in the atmosphere; damp heat being generally favourable to their growth. We find that Horse Sickness in South Africa is practically unknown in places which are at least 6,000 ft. high, unless it has been introduced by affected stock. At similar altitudes in India, bursatee (a disease characterised by ulcers which somewhat resemble the "Delhi boils" of man) becomes spontaneously cured. 
The observations I have made, chiefly in the Himalayas, on the distressing effects of high altitudes, lead me to think that they do not manifest themselves more severely on horses than on men. On leaving the plains in India and going to a height of, say, I0,000 ft., one experiences as a rule no new sensation, except a slight exhilaration of spirits. Ponies of all breeds, when taken from the plains and run on race-courses at Simla, Mussooree and Kujear (near Dalhousie), at altitudes of from 5,000 to 7,000 $\mathrm{ft}$. above the level of the sea, show all their accustomed spirit and endurance. At an altitude of over, say, $15,000 \mathrm{ft}$. in the Himalayas or Tibet, human beings, especially new-comers, become more or less affected with giddiness, breathlessness, faintness, depression, headache, and other more or less painful symptoms of a deficiency in the supply of air to the lungs, which symptoms are naturally aggravated by muscular exercise. Horses in similar circumstances also exhibit exhaustion and distress, though probably, in such cases, they are handicapped by the severe toil they are as a rule enduring.

Fleming (Veterinarian, May, June, July and August, I868) has drawn attention to the fact that horses are said to suffer from various respiratory diseases caused by crossing mountain ranges in Mexico and Peru. In fact it would appear from these reports, that horses are peculiarly susceptible to disease brought on by high altitudes, which is a supposition that cannot be accepted without further proof. My own experience leads me to infer that going over even the highest passes of the Himalayas does not predispose horses to disease. I have bought several and examined many Yarkund ponies which came to Kangra Valley viâ Chanchengmo, and have never seen more healthy animals.

Residence in places of high altitudes, confers a large degree of immunity against the distressing symptoms brought on by the breathing of highly rarefied air. 


\section{ACCLIMATISATION.}

The effects of acclimatisation (the process of inuring an animal to a foreign climate) may be divided into (I) those produced on the emigrant, and (2) those made manifest in its descendants; the latter changes being much better marked than the former. Whether the new climate be bad or good, its influence on the progeny of imported stock tends to render them like unto the type peculiar to the adopted country. Thus, the English-bred offspring of Arabs lose, even in the first generation, a large portion of the characteristics which distinguish the sons and daughters of the Desert; and in India, English blood quickly assumes a "country-bred" appearance. The effects of soil and climate in developing special equine types may be easily seen by comparing even Irish with English horses, or Shires bred in Norfolk with those produced in the Midlands, to say nothing of comparisons made between Australians and Arabs, for instance. Horses and their progeny support in an admirable manner a change from a hot or temperate climate to a cold one, such as that from Arabia to Russia, where the Arab Smetanka, imported in I775 and united with Danish, Dutch and English mares, was the founder of the famous breed of Orlof trotters. The hardy and well-shaped remounts which are bred in the bitterly cold steppes of the Don and Volga, are to a large extent AngloArabs. Many of the excellent saddle horses of Montana are pure or nearly pure English. A change from a cold or temperate climate to a very hot one is, on the contrary, badly borne, at least by the descendants, and especially if the new climate is damp as well as tropical. The heat of Queensland, where good horses are bred, might be taken as the maximum for successful breeding. In a climate as hot as India, it is impossible to continue to breed good stock, without frequent importations of fresh blood, and even then it is impossible to 
get a sufficiency of bone and substance for weight carrying and heavy draught purposes.

The accommodation of the system to new surroundings is well illustrated by the readiness with which the skin responds to the stimulus of cold, or to the sedative action of heat, in the growth of the epidermis. A striking instance of this fact is afforded by the change in the order of shedding the coat which takes place among Australian horses that are imported into India. These animals, which, in the Antipodes, get their winter coat in the spring, and their summer one in the autumn, at first suffer during the Indian hot months from wearing a coat which is abnormally heavy for the climate of their new place of residence. However, in a comparatively short time, say, in a couple of years, the order of shedding the coat changes to that of Indian horses, with an improved state of health.

\section{STABLE IMPURITIES.}

I am indebted chiefly to Dr. W. H. Willcox, B.Sc., A.I.C., for the details connected with chemistry in this section, which has been written for readers who are acquainted with that science.

Stable impurities may be classed as follows :-

I. Exhalations which are given off from the lungs and skin, and which consist chiefly of carbonic acid and water.

2. Urine, dung, and the products formed by their decomposition.

3. Bacteria (germs of decomposition and disease), which are adventitious bodies.

The decomposition of urine may be explained as follows :-

According to Is. Pierre the urine of the horse is composed, on an average, of 90.5 per cent. of water, 4 per cent. of mineral matter, and 5.5 per cent. of organic matter, which 
is composed chiefly of urea $\left(\mathrm{CON}_{2} \mathrm{H}_{4}\right)$ and hippuric acid $\left(\mathrm{C}_{6} \mathrm{H}_{5} \mathrm{CO}\right.$. $\left.\mathrm{NHCH}_{2} \mathrm{COOH}\right)$. Z. Roussin suggests that during work, the former is converted into the latter by the increased action of the organs of breathing; for at such times the percentage of the hippuric acid is raised and that of the urea diminished; the converse being the case during rest. The decomposition of both urea and hippuric acid is effected by bacteria.

The Urea $\left(\mathrm{CON}_{2} \mathrm{H}_{4}\right)$ breaks up under the influence of the micrococcus urea, and uniting with a portion of the water $\left(\mathrm{H}_{2} \mathrm{O}\right)$ becomes converted into ammonium carbonate $\left(\mathrm{NH}_{4}\right)_{2} \mathrm{CO}_{3}$. Thus :-

$$
\mathrm{CON}_{2} \mathrm{H}_{4}+2 \mathrm{H}_{2} \mathrm{O}=\left(\mathrm{NH}_{4}\right)_{2} \mathrm{CO}_{3} .
$$

The ammonium carbonate remains partly in solution, and being volatile, partly escapes into the air. In both cases it becomes decomposed into ammonia gas $\left(\mathrm{NH}_{3}\right)$, carbonic acid gas, and water. Thus:-

$$
\left(\mathrm{NH}_{4}\right)_{2} \mathrm{CO}_{3}=2 \mathrm{NH}_{3}+\mathrm{H}_{2} \mathrm{O}+\mathrm{CO}_{2} .
$$

The hippuric acid is decomposed by bacteria probably as follows :-

$$
\begin{aligned}
& \mathrm{C}_{6} \mathrm{H}_{5} \mathrm{CO} \text {. } \mathrm{NHCH}_{2} \mathrm{COOH}+\mathrm{H}_{2} \mathrm{O}=\mathrm{C}_{6} \mathrm{H}_{5} \mathrm{COOH}+\mathrm{NH}_{2} \mathrm{CH}_{2} \mathrm{COOH} \text {. } \\
& \text { (Hippuric acid ) } \\
& \text { (Water.) (Benzoic acid.) (Amido acetic acid.) }
\end{aligned}
$$

The benzoic acid. would unite with the ammonia derived from the urea, and would form ammonium benzoate; and the amido acetic acid, by the action of bacteria, would partly break up into ammonia and acetic acid $\left(\mathrm{CH}_{3} \mathrm{COOH}\right)$; and the acetic acid would become converted into ammonium acetate.

The principal products of the decomposition of urine would therefore be: Ammonium carbonate, ammonia, ammonium benzoate, amido acetic acid, and a small quantity of ammonium acetate. 
As the dung consists chiefly of cellulose and other insoluble substances, its products of decomposition are unimportant; the chief ones being indole, skatole, lactic acid, and a trace of carbolic acid. Indole and skatole are complex ammoniacal bodies, from which the dung derives its smell. The dung, mixed with the alkaline fluid resulting from the decomposition of the urine, forms an excellent breeding ground for bacteria, the growth of which is unaffected by the small quantity of carbolic acid which is present. The ferments secreted by some of the bacteria have, like those of pus, the power of dissolving albumen, and consequently they eat away those portions of the horses' hoofs that come in contact with the decomposing urine and dung. The fact of this liquid manure being alkaline, also helps in the destruction of horn; for the matrix (chiefly mucin, which is nearly of the same composition as albumen) of the cells of the horn is soluble in alkaline fluids. Prolonged maceration, even in water, also causes disintegration of mucin, and consequent destruction of horn. As ordinary water is not alkaline, and as it is not a good medium for the cultivation of bacteria, its action on horn would be far less destructive than that of a mixture of decomposing urine and dung. Besides its comparatively slow action on mucin, it softens, loosens, and consequently favours the breaking down of horn cells.

The ammonia in the air of the stable is an irritant to the eyes and organs of breathing of horses.

The ammonia has a bad effect on carriages, harness, and saddlery, which are exposed to its influence, by dissolving resin and fat with which it forms a soap. It also, like soda and potash (p. 49) darkens brown leather, by combining with the tannic acid which is in the leather. The varnish on carriages is made by dissolving certain resins in spirit, or in fixed or volatile oil, so that when the solvent evaporates, it leaves a thin film of resin or shellac, for instance, behind. 
As alkalies have the property of dissolving resins, waxes, and fat, all of which are chemically allied to each other ; ammonia in the air will spoil the varnish of a carriage, and will tend to remove fat and bees'-wax from leather, and will consequently make it dry and liable to crack. Coachbuilders remove the varnish from carriages in the same way by using a solution of ammonia, caustic soda, or caustic potash.

To take the case of the removal by ammonia of bees'-wax (which consists mostly of myricyl palmitate), or of a varnish containing bees'-wax, we have the following equation :-

$$
\begin{aligned}
& \mathrm{C}_{30} \mathrm{H}_{61} \mathrm{C}_{16} \mathrm{H}_{31} \mathrm{O}_{2}+\mathrm{NH}_{4} \mathrm{HO}=\mathrm{NH}_{4} \mathrm{C}_{16} \mathrm{H}_{31} \mathrm{O}_{2}+\mathrm{C}_{30} \mathrm{H}_{61} \mathrm{OH} \text {. } \\
& \text { Myricyl palmitate. Ammonium Ammonium Myricyl } \\
& \text { hydrate. palmitate. alcohol } \\
& \text { (a soluble soap). (soluble). }
\end{aligned}
$$

With the exception of the watery vapour, the products of the decomposition of urine and dung do not appear to have any injurious effect on steel. Besides the removal of fatty matters, ammonia has seemingly no destructive action on leather, which, however, falls a ready prey to bacteria, in the event of their reaching it, by, for instance, its becoming soiled with decomposing dung or urine.

In the manufacture of leather, the skins are placed for a brief period in "dung bate," which is a mixture of dung and water, and which, owing to the action of bacteria, will destroy the skins if they are left too long in it. This action of bacteria, and the property ammonia has of removing fat and darkening leather, account for the fact that keeping saddlery and harness exposed to the emanations of a stable has a bad effect on them.

SOAP.

Ordinary soap is formed by the chemical union of certain fatty substances with soda or potash. In tallow, which is used to make common hard soap, the fatty substances consist of 
stearin (a solid) and olein (a liquid). When making this soap, the tallow is dissolved in a weak solution of soda; the result being that soap and glycerine are produced. The soap is separated from the water by an addition of common salt, which is capable of performing this office, because soap is insoluble in a solution of salt. The soap is then removed from the "ley" and dried. Soft soap is made by dissolving a liquid fat (for instance, fish oil, which is largely composed of olein) in a solution of potash; the resulting products being potassium oleate, 4 to 5 per cent. of glycerine, and probably some free potash or some free oil. Economy being a matter of great importance in such an industry, it is natural to suppose that there would be nearly always an excess of free potash. As the addition of common salt to a solution of potassium oleate would cause the formation of ordinary hard (soda) soap and potassium chloride, salt cannot be used here for purposes of separation, and consequently the soft soap is obtained by evaporating the solution. Hence, soft soap contains glycerine and all the impurities that were in the pan. Yellow soap differs from ordinary white soap, by the fact of its possessing a considerable percentage of resin, which, by rendering it harder, and by decreasing its solubility in water, makes it more economical to use. Glycerine soap is a mixture of about equal parts of soap and glycerine.

The darkening effect which the continued application of soap has on leather, appears to be chiefly due to the action which the free alkali of the soap has on the tannic acid in the leather. The addition of either soda or potash to a solution of tannic acid turns it brown; the colour becoming deeper from exposure to the air. As soft soap contains more free alkali than ordinary white or yellow soap, its darkening effect on leather will be more marked.

The solution of soap in water causes its decomposition (hydrolysis) into its fatty acids and its alkali. "Its cleansing 
power is ordinarily explained by this reaction; but it is difficult to see why a solution which has just thrown off most of its fatty acids should be disposed to take up even a glyceride. It is more likely that the cleansing power of soap is due to the inherent property of its solution to emulsionise fats" (Encyclopadia Britannica). 


\section{CHAPTER II. \\ THEORY OF EXERCISE.}

Definition-Exercise in Relation to Health and Development-Rest-Fatigue-

Nature and Duration of Healthy Exercise.

\section{DEFINITION.}

EXERCISE may be defined as "exertion or labour of the body for purposes of health or development of the natural powers" (Lloyd's Encyclopedic Dictionary); and work, as exercise undertaken for purposes extraneous to the horse. In training, the term "work" is often used for "exercise."

EXERCISE IN RELATION TO HEALTH AND DEVELOPMENT.

In writing of exercise under this heading, I assume that the bodily exertion is not carried to an extent which would produce fatigue.

As the animal body has been evolved under conditions of frequent movement, exercise is necessary for maintaining it in health, that is to say, in its ordinary condition. In other words, as "the function makes the organ," the existence of an organ is dependent on the exercise of its function, as we may see in cases of paralysis. For instance, when certain muscles of the larynx suffer from the form of paralysis which causes "roaring," they gradually waste away, and at last become converted into fibrous tissue. Exercise is therefore needed for maintaining the balance between bodily waste and bodily repair. The effect of the exercise of the limbs is not confined to the muscles of movement and their adjuncts (tendons, 
ligaments, and bones), but extends to the entire system. Exercise quickens the circulation of the blood, by which means development of tissue is promoted, and secretion and excretion are stimulated. By stimulating the circulation of blood in the surface of the body and by quickening the action of the lungs, exercise entails a loss of water from the system proportionate to its severity, as we may see from the following results obtained from experiments made by Grandeau :-

Amount of water evaporated per day.

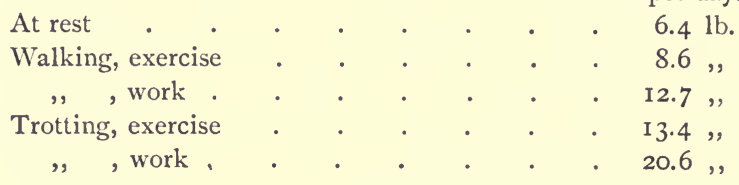

These amounts would of course be greatly influenced by differences in temperature. Under ordinary conditions, the quantity of water removed from the system by the kidneys (in the form of urine) is on an average about double that given off by the lungs and skin; a difference which exercise tends to reverse. For instance, during severe exertion, the skin of a man may give off two and a half times the quantity of water which is discharged in the urine. The increased activity of the skin and lungs during exercise is essential to health, for removing the extra heat and carbonic acid caused by work. Exercise increases the bodily temperature, which may experience a rise even up to $5^{\circ} \mathrm{F}$. from severe work in hot weather; such an increase of heat being naturally accompanied by more or less exhaustion. As the drinking of water promotes perspiration; we may conclude, especially as theory in this case is backed up by practical experience, that horses during labour should not be deprived of water for a long time. We all no doubt have enjoyed the refreshing effect of a drink of water or of a fluid largely consisting of water, when we 
have been hot and tired after severe exercise, and have felt that the skin, which had been previously hot and dry, became moist and cool from perspiration almost immediately after the fluid had been swallowed. The rapidity of this effect, and the fact that after a copious sweat, the drinking of a large quantity of water will be followed by a comparatively small increase in the amount of urine discharged, show that a considerable portion of the water lost during exercise, is a necessary part of the solids and fluids of the body, and consequently no avoidable delay should occur in its replacement. A full supply of water is not only necessary for removing heat by evaporation, but also for keeping the bowels, kidneys, and other organs in good working order. As the necessity for the cooling effect of evaporation from the skin is proportionate to the exercise taken, other things being equal, the severer and more prolonged the exercise, the cleaner should be the skin and the shorter should be the coat, so that as little impediment as possible may be offered to the escape of perspiration into the air.

As long as exercise is continued, there is practically no danger of chill. But if a horse is pulled up when hot from work and is kept standing in a cold atmosphere without anything being done to protect him from its bad effects, he will be specially liable to catch cold; because the cooling process of evaporation will continue to remain unduly active for a longer or shorter period, during which, the supply of extra heat to the skin from the action of the muscles will be cut off.

Exercise improves the quality of the structures affected by it, and disuse has the opposite effect. Thus we find that a horse out of training is peculiarly liable to injury from unwonted exertion; not only because the muscles, tendons, ligaments and bones of his limbs are wanting in strength and resistance, but also because he will suffer far more severely 
from fatigue, than a horse in hard condition would do; on account of the comparative inactivity of his powers of excretion. Lymphangitis and azoturia are diseases which are closely connected with want of exercise.

Muscular development "is due in part to the growth of the pre-existing fibres, and in part to the formation of new fibres" (Halliburton).

Owing to the fact that horses when in a state of nature spend a considerable, if not the greater, part of the twentyfour hours in movement, their limbs cannot bear long enforced idleness without becoming more or less unsound. Hence we find that stabled horses which have too little exercise are liable to get swelled legs, especially behind; because the hind legs being farther from the heart than the fore ones, the circulation of blood in them is more torpid. Also, from want of pressure, the growth of the frog becomes diminished, and consequently its secreting membrane becomes liable to inflammation, which is made manifest by thrush. The habit of standing on cold stones appears to be a not unfrequent predisposing cause of navicular disease. Long continued standing, as on board ship (p. 37 I), is a fertile exciter of laminitis (fever of the feet). It seems probable that this variety of laminitis is set up by waste nitrogenous material (pp. 56, I22 and I23), the deposition of which would be favoured by the slowness of the circulation in the feet of an unexercised horse, and by their coldness.

As the tissues can utilise the nutritive materials which they receive from the blood only at a slow rate; exercise for both health and development should be long continued during the day, and from day to day.

REST.

As the energy (p. Io) expended by the body, even during slow walking, is greater than that obtained from the blood in 
the same time, the system requires rest proportionate in length to the effect which the exertion has had on it,'so 'as to allow time for the assimilation of the necessary potential energy and for the removal of poisonous products (p. 56). Although the heart, which is a hollow muscle, appears to be in constant work, it has a succession of brief periods of rest and of labour, the former being about twice as long as the latter.

\section{FATIGUE.}

We may define fatigue as exhaustion from too much exercise or from too much work. Bunge aptly states that "the sensation of fatigue is one of the safety valves of our nature," which is a remark we may also apply to horses. If an extract of fatigued muscle be injected into the muscles of a healthy and unfatigued animal, it will produce symptoms of fatigue, which fact tends to prove that the feeling of fatigue is due to the formation, during exercise or work, of a poison or poisons in the system. Bodily exertion carried to the extent of fatiguing an animal, interferes with the healthy performance of excretion; the blood becomes loaded with carbonic acid, on account of the lungs not being able to give it off into the air with sufficient quickness for the requirements of health; breathlessness ensues; and congestion of the lungs may supervene in extreme cases. Ordinary breathlessness is therefore the poisoning of the body with carbonic acid which the action of the muscles causes to be produced at a faster rate than the lungs can remove from the system. In less violent work, fatigue may take place without breathlessness occurring. By practice, the organs of breathing acquire the ability to regulate their action, so that breathlessness may be prevented as far as possible.

The nitrogen of the broken-up nitrogenous matter which is taken into the blood, is normally found almost entirely in the 
form of urea $\left(\mathrm{CH}_{4} \mathrm{~N}_{2} \mathrm{O}\right)$, which is very soluble in water (dissolving in its own weight of even cold water), and is consequently a harmless product which the kidneys can readily remove from the system, supposing that these organs are in good condition. From the investigations of Roussin (see Colin's Physiologie Comparée) it appears probable that during fatiguing exertion, a portion of the urea in the blood becomes replaced by hippuric acid $\left(\mathrm{C}_{9} \mathrm{H}_{9} \mathrm{NO}_{3}\right)$, which is sparingly soluble in water. Uric acid $\left(\mathrm{C}_{5} \mathrm{H}_{4} \mathrm{~N}_{4} \mathrm{O}_{3}\right)$, which is another form of nitrogenous waste, is regarded by Haig as the poison in the blood which gives rise to the feeling of fatigue in mankind. Colin tells us that it is present in abnormally large quantities in the blood of animals which are suffering from inflammatory diseases. Uric acid when comparatively abundant in the blood of man, produces great depression, and also gives rise to rheumatic affections, chiefly in the joints, by becoming deposited in these parts, or by uniting with the sodium of soda salts that are in the blood, and forming "chalk-stones" composed of hydrosodium urate. This salt and uric acid dissolve only to a small extent in water, and their comparative insolubility increases according as the temperature of the blood becomes lowered. Halliburton considers that fatigue is caused by the presence of sarco-lactic acid $\left(\mathrm{C}_{3} \mathrm{H}_{6} \mathrm{O}_{3}\right)$. Whatever may be the poison in question, the fact remains that the imperfect elaboration of nitrogenous waste is an injurious result of fatigue, and that a plentiful supply of drinking water is necessary for the removal of products thus formed.

The degree of thirst brought on by fatigue is a reliable measure of the need which the system of a tired horse has for water. We find, in training either a man or horse, that the thirst after hard exercise or hard work gradually diminishes as "condition" is attained, which fact is a proof that exercise purifies the system. 
In mankind, salicylic acid and also salicylate of sodium act well in removing the depression caused by fatigue, and in reducing the temperature in fever. . Haig, Latham and others attribute their good effects in such cases to their power of removing uric acid from the blood by converting it into a soluble form. Whitla (Pharmacy, Materia Medica and Therapeutics) has obtained equally good results in the horse from $1 / 2 \mathrm{Oz}$. doses dissolved in water and given from three to six times during the twenty-four hours. Salicylate of sodium, which is the best form of the drug, would certainly be preferable to the time-honoured ball of physic that is often given to horses out of condition, before putting them into work. Haig recommends that during four or five days before the commencement of violent work in the case of a man, uric acid should be cleared out of the system by salicylate of sodium, so as to obviate the ill results of fatigue. The administration of this drug should be stopped for at least a day before the work begins. The comparatively high price of salicylate of sodium is an objection against its employment in a stable, except, of course, in the case of valuable horses.

The poisonous influence of fatigue injuriously affects all the functions of the body. Hence we find that when a horse is tired, his powers of digestion are more or less impaired. Consequently he should get less food than usual, and the food should be of an easily digestible nature.

\section{NATURE AND DURATION OF HEALTHY EXERCISE.}

A stabled horse keeps his health and strength best when the duration of his exercise is about equal to that which his ancestors experienced in the open, and when the degree of the exercise is proportionate to the amount of energy received from the food. We should here bear in mind that corn given to horses which are at grass, acts on them as a stimulant to take exercise. In fact, the assimilation of potential energy 
within healthy limits excites the nervous system to give the signal for movement. Somewhat similar to appetite for food and thirst for water, there seems to be a craving for exercise in the animal organisation, especially during youth, at which time exercise is particularly required for development. As horses in the open, even when fed on corn, take the larger portion of their daily exercise at a walk, we may safely follow the same plan with stabled horses. Although exercising a horse chiefly at faster paces and only once during the day economises time and paid labour, it does not produce such a good effect on the health and strength of an animal as giving the bulk of the exercise at a walk, and taking him out twice daily, which as a rule will be as often as can be usually managed. I think that a sound horse should not get less than three hours' exercise daily, and that it would be better to give him four hours of it, divided into two and a half hours in the morning, and an hour and a half in the afternoon.

The speed of a horse can be largely affected by habit. Thus, a hack or trapper which is accustomed to be walked and trotted in a slovenly slow style, loses his speed at these paces to a greater or less extent, in the same manner that a horse practised in a riding school becomes slow at a gallop in the open. A fast hunter which passes for the first time into the hands of a heavy weight, will after a season or two, considerably improve in his weight-carrying powers, but with a proportionate loss of speed. In seeking to gain speed, the distance over which the animal is extended should never be so long as to cause fatigue; for in that case, the rate of the "spin," and especially the rate of its concluding portion, will be comparatively slow, and an injurious impression will be made on the horse's speed, to say nothing of the depressing effect which the consequent fatigue will have on the nervous system.

Disuse has a well-marked depressing effect on speed, 
especially with horses that have passed their youth, which is essentially the period of speed. Hence we often find that if fast racehorses are put out of work for a considerable time, they generally suffer a far greater loss of speed than could be accounted for by increased age. The poor form shown by the once famous Signorina on her return to the turf, after having proved a failure at the stud, is a good case in point. Experience proves that speed in either man or beast can be maintained after youth has passed, only by constant practice. In this connection, the names of Reindeer, Herald, Tommy Tittlemouse, Regal and Gamecock will occur to racing men; those of Flora Temple and Highflier to trotting men; and those of Jackson the American Deer, Choppy Warburton, Williamson, Hindle, and Harry Kelly to lovers of pedestrianism and rowing. Flora Temple did her fastest mile when she was seventeen years old, Williamson was running in Sheffield Handicaps up to the age of forty-five, and Jackson was able to beat fifty-five minutes for ten miles when he was over fifty; but all these horses and men kept continually on the track during their respective careers. Therefore, if we wish to preserve a horse's speed, we should on no account throw him out of work, unless we were forced to do so, as for instance by his becoming unsound.

Dr. Vaughan Harley (Lancet, I 884, Vol. i., p. I 199) points out that less muscular work can be done at 9 a.m. than at I I a.m. ; that muscle power rises from the former hour to the latter; and that there is a notable fall in it at 4 p.m. I am inclined to think that the same rule holds good with horses. The daily decline in strength appears to be due to the accumulation of waste nitrogenous matter in the blood, and consequently fatigue is then produced with abnormal readiness. It is evident that the best time for giving strong daily exercise is at an hour when the bodily strength is at its highest degree. 
60 THEORY OF EXERCISE.

The chief lesson, as far as stable management is concerned, which we learn from the foregoing considerations, is that the more severe the exercise or work, the greater is the necessity for keeping the excretory organs in healthy action, and for supplying the animal with pure air and plenty of good drinking water. The skin is the only one of these organs which we can safely stimulate artificially for a prolonged period, and then only by grooming and by a moderate amount of clothing. 


\section{CHAPTER III.}

\section{SKETCH OF THE THEORY OF FEEDING.}

Objects of Food-Chemical Analyses of Foods-Reliability of Chemical Analysis as a Guide to the Feeding Value of Food-Ferments in GrainOrgans of Digestion-General View of Digestion, Absorption and Assimilation-Digestibility and Wholesomeness of Food-Taking Food into the Mouth-Drinking-Mastication-Digestion in the Stomach-Digestion in the Intestines-Water for the Digestive Juices-Absorption-Nutritive and Digestive Functions of the Constituents of Food-Nutritive Ratio of Food -Appetite and Digestive Power-Variety in Food-Comparative Nutritive Values of different Foods-Causes affecting the Nutritive Value of Vegetable Food-Stowage of Forage-Cleaning of Food-Preparation of Food-Food in Relation to Work-Food for Young Horses-Ill Effects of too much FoodCombining Foods according to a Standard-Maximum Amount of Nitrogenous Matter in Food-Hunger and Thirst.

\section{OBJECTS OF FOOD.}

THE objects of food, under which term we may include water and oxygen, are to furnish materials for the repair of bodily waste; for development; and for supplying the system with energy for the production of movement and heat. We may therefore divide food into (I) substances which, like nitrogenous matter, fat, starch and sugar, can supply energy and can build up tissue; and (2) those which, like water and mineral salts, serve only to build up tissue, and are not sources of energy. We shall see further on that there is a third class of food (fibre) which aids in digestion, but does not supply, to any marked extent, either energy or building-up material.

\section{CHEMICAL ANALYSES OF FOODS.}

In the following tables, the analyses marked by "Wa" are taken from Warington (Chemistry of the Farm); by "Wo" 
from Wolff (Farm Foods, translated by Cousins); by " $\mathrm{H}$ ", from Henry (Feeds and Feeding); and by " $\mathrm{C}$ ", from Church (Food Grains of India).

\begin{tabular}{|c|c|c|c|c|c|c|}
\hline FOODS. & Water. & $\begin{array}{l}\text { Nitro- } \\
\text { genous } \\
\text { matter. }\end{array}$ & $\begin{array}{c}\text { Soluble } \\
\text { carbo- } \\
\text { hydrates. }\end{array}$ & $\begin{array}{c}\text { Crude } \\
\text { fat. }\end{array}$ & $\begin{array}{l}\text { Woody } \\
\text { fibre. }\end{array}$ & Ash. \\
\hline $\begin{array}{l}\text { GREEN FOODS. } \\
\text { Pasture grass }\end{array}$ & & & & & & \\
\hline $\begin{array}{l}\text { Pasture grass (Wa) } \ldots \ldots \ldots \ldots \ldots \\
\text { Timothy in different stages }(\mathrm{H})\end{array}$ & $75 \cdot 3$ & 4.0 & II. 5 & 0.9 & $5 \cdot 9$ & 2.4 \\
\hline $\begin{array}{l}\text { Timothy in different stages }(\mathrm{H}) \\
\text { Perennial rye grass (Wo) }\end{array}$ & 61.6 & 3.1 & 20.2 & 1.2 & 11.8 & 2. I \\
\hline $\begin{array}{l}\text { Perennial rye grass }(\mathrm{Wo}) \ldots \ldots \\
\text { Italian rye grass }(\mathrm{Wo})\end{array}$ & 70.0 & 3.6 & 12.8 & 1.0 & 10.6 & 2.0 \\
\hline Kentucky blue grass $(\mathrm{H})$ & $73 \cdot 4$ & 3.0 & 12.1 & 1.0 & 7.1 & 2.8 \\
\hline Oat fodder $(\mathrm{H})$............. & $\begin{array}{l}05.1 \\
62.2\end{array}$ & $\begin{array}{l}4 \cdot 1 \\
3.4\end{array}$ & $\begin{array}{l}17.0 \\
19.3\end{array}$ & $\begin{array}{l}1.3 \\
1.4\end{array}$ & $\begin{array}{l}9.1 \\
I I .2\end{array}$ & $\begin{array}{l}2.8 \\
2.5\end{array}$ \\
\hline Vetch in bloom (Wo).. & 82.0 & $3 \cdot 5$ & 6.6 & 0.6 & $5 \cdot 5$ & 1.8 \\
\hline Lucerne quite young (Wo) & 81.0 & $4 \cdot 5$ & 7.2 & 0.6 & 5.0 & I. 7 \\
\hline Lucerne just in bloom (Wo)... & 74.0 & $4 \cdot 5$ & 9.2 & 0.8 & $9 \cdot 5$ & 2.0 \\
\hline Sainfoin just in bloom (Wo)... & $8 \mathrm{I} .4$ & 4.2 & $7 \cdot 3$ & 0.7 & 5.2 & 1.2 \\
\hline $\begin{array}{l}\text { Red clover before blooming } \\
\text { (Wo) }\end{array}$ & & & & & & \\
\hline Red clover in full bloom (Wo) & $\begin{array}{l}83.0 \\
80.4\end{array}$ & $\begin{array}{l}3 \cdot 3 \\
3.0\end{array}$ & 8.9 & 0.6 & $\begin{array}{l}4 \cdot 3 \\
5.8\end{array}$ & $\begin{array}{l}1.5 \\
1.3\end{array}$ \\
\hline Alsike just in bloom (Wo) ... & 85.0 & $3 \cdot 3$ & 5. I & 0.6 & 4.5 & I. 5 \\
\hline Alsike in full bloom (Wo) $\ldots$ & 82.0 & $3 \cdot 3$ & 6.3 & 0.6 & 6.0 & 1.8 \\
\hline HAY. & & & & & & \\
\hline Meadow hay, medium (Wa)... & 13.7 & 9.2 & 42.9 & 2.5 & 25.2 & 6.5 \\
\hline $\begin{array}{l}\text { Timothy cut when nearly ripe } \\
(\mathrm{H})\end{array}$ & I4. I & 5.0 & 43.7 & 2.2 & 3I. I & 3.0 \\
\hline Perennial rye grass $(\mathrm{Wo}) . . . .$. & 14.3 & 10.2 & 36. 1 & 2.7 & 30.2 & 6.5 \\
\hline Italian rye grass (Wo) .... & 14.3 & II.2 & 40.6 & 3.2 & 22.9 & 7.8 \\
\hline Clover hay, medium (Wa) $\ldots$ & I6. 3 & 13.6 & 36.2 & 2.6 & 25.0 & 6.3 \\
\hline Lucerne, average (Wo) .......... & 16.0 & 14.4 & 27.9 & 2.5 & 33.0 & 6.2 \\
\hline Alsike (Wo) .... & 16.0 & 15.0 & 32.7 & $3 \cdot 3$ & 27.0 & 6.0 \\
\hline Oat hay cut in milk (H) & 15.0 & $9 \cdot 3$ & 39.0 & 2.3 & 29.2 & 5.2 \\
\hline Barley hay cut in milk $(\mathrm{H}) \ldots$ & I 5.0 & 8.8 & $44 \cdot 9$ & 2.4 & $24 \cdot 7$ & 4.2 \\
\hline STRAW. & & & & & & \\
\hline Oat (Wa)...... & I 4.5 & $4 \cdot 0$ & 37.0 & 2.0 & 36.8 & $5 \cdot 7$ \\
\hline Barley (Wa) ...................... & 14.2 & $3 \cdot 5$ & 39.1 & I. 5 & 36.0 & $5 \cdot 7$ \\
\hline Wheat (Wa) $\quad \ldots \ldots \ldots \ldots \ldots \ldots \ldots$ & 13.6 & $3 \cdot 3$ & 39.4 & 1.3 & 37.1 & $5 \cdot 3$ \\
\hline Rice $($ Wo $)$...................... & I 5.6 & $5 \cdot 7$ & 24.0 & I.8 & 37.6 & $15 \cdot 3$ \\
\hline $\begin{array}{l}\text { GRAINS, ETC. } \\
\text { Oats (Wa) } \ldots \ldots \ldots \ldots \ldots .\end{array}$ & & & & & & \\
\hline Maize (H) & $\begin{array}{l}13.0 \\
10.6\end{array}$ & II.3 & $57 \cdot 3$ & 5.4 & 10.0 & 3.0 \\
\hline Maize and cob (II)... & 15.1 & 8.5 & $\begin{array}{l}70.4 \\
64.8\end{array}$ & $\begin{array}{l}3.0 \\
3.5\end{array}$ & $\begin{array}{l}2.2 \\
6.6\end{array}$ & 1.5 \\
\hline Barley (Wa) .......... & $14 \cdot 3$ & 10.6 & 65.5 & $\begin{array}{l}3.3 \\
2.1\end{array}$ & 5.0 & 2.5 \\
\hline Wheat (Wa) & $13 \cdot 4$ & II.7 & 69.3 & 2.0 & I. 8 & 1.8 \\
\hline Wheat bran (Wa) $\ldots \ldots \ldots \ldots \ldots$ & I 3.2 & I4. I & 56.0 & 3.7 & 7.2 & 5.8 \\
\hline 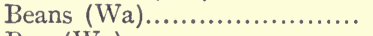 & $14 \cdot 3$ & $25 \cdot 4$ & 48.5 & I. 5 & 7.1 & 3.2 \\
\hline Peas (Wa) & 14.0 & 22.5 & 53.7 & I. 6 & $5 \cdot 4$ & 2.8 \\
\hline Linseed (Wo) .... & 12.3 & 20.5 & I9.6 & 37.0 & 7.2 & 3.4 \\
\hline Linseed cake (Wa)....... & I I.7 & 28.0 & $33 \cdot 2$ & II. 4 & 9.0 & 6.7 \\
\hline
\end{tabular}




\begin{tabular}{|c|c|c|c|c|c|c|}
\hline FOODS. & Water. & $\begin{array}{l}\text { Nitro- } \\
\text { genous } \\
\text { matter. }\end{array}$ & $\begin{array}{c}\text { Soluble } \\
\text { carbo- } \\
\text { hydrates. }\end{array}$ & $\begin{array}{l}\text { Crude } \\
\text { fat. }\end{array}$ & $\begin{array}{l}\text { Woody } \\
\text { fibre. }\end{array}$ & Ash. \\
\hline GraINS-Continued. & & & & & & \\
\hline Rye $(W a) . . . \ldots \ldots \ldots . . . . .$. & I3.4 & II. 5 & 69.5 & I. 7 & I.9 & 2.0 \\
\hline Millet, great (C) $\ldots . . .$. & 12.5 & $9 \cdot 3$ & 72.3 & 2.0 & 2.2 & I. 7 \\
\hline Millet, bulrush (C).............. & II. 3 & 10.4 & 71.5 & $3 \cdot 3$ & 1.5 & 2.0 \\
\hline 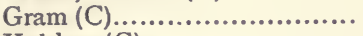 & II. 2 & I9.5 & 53.8 & 4.6 & 7.8 & 3.1 \\
\hline 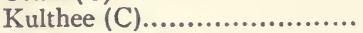 & II.O & 22.5 & 56.0 & I.9 & $5 \cdot 4$ & 3.2 \\
\hline Urud and Moong (C)............. & IO.I & 22.7 & 55.8 & 2.2 & 4.8 & 4.4 \\
\hline Mote (C) $\ldots \ldots \ldots \ldots \ldots \ldots \ldots$ & II.2 & 23.8 & 56.6 & .6 & 4.2 & 3.6 \\
\hline Rice, unhusked (Paddy) (C)... & 14.0 & 6.2 & 68.5 & 1.5 & 6.5 & $3 \cdot 3$ \\
\hline Rice, husked (C)................. & 12.8 & $7 \cdot 3$ & 78.3 & .6 & .4 & .6 \\
\hline Rice meal (Wa) .... & 10. 3 & 12.3 & 47.8 & 12.0 & 8.6 & 9.0 \\
\hline Brewers' grains, dried (Wa) ... & 9.5 & 20.6 & 42.3 & 7.0 & I5.9 & 4.7 \\
\hline Cocoanut meal (Wo)... & II. 8 & 20.0 & 42.0 & 6.2 & 13.4 & 6.6 \\
\hline Soja (or soy) beans (Wo) ....... & 10.0 & $33 \cdot 4$ & 29.2 & I7.6 & 4.8 & 5.0 \\
\hline $\begin{array}{l}\text { ROOTS, ETC. } \\
\text { Carrots (Wa) }\end{array}$ & 87.0 & I. 2 & 9.3 & 0.2 & & \\
\hline 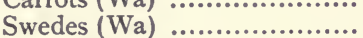 & 89.3 & 1.4 & $\begin{array}{l}9.3 \\
7.2\end{array}$ & 0.2 & $\begin{array}{l}1.3 \\
1.1\end{array}$ & $\begin{array}{l}1.0 \\
0.8\end{array}$ \\
\hline Turnips (Wa) .................... & 91.5 & I.O & $5 \cdot 7$ & 0.2 & 0.9 & 0.7 \\
\hline Apples (Wo) .................... & 84.8 & 0.4 & I 2.5 & 0.3 & 1.5 & 0.5 \\
\hline Potatoes $($ Wo $) .. . . . . . \ldots \ldots \ldots \ldots . . . .$. & 75.0 & 2.1 & 20.7 & 0.2 & I. I & 0.9 \\
\hline Pumpkins, field $(\mathrm{H})$........... & 90.9 & 1.3 & 5.2 & 0.4 & I.7 & 0.5 \\
\hline $\begin{array}{l}\text { ANIMAL FOOD. } \\
\text { Mares' milk (Wa) ....... }\end{array}$ & 90.8 & 2.0 & 5.6 & 1.2 & - & 0.4 \\
\hline 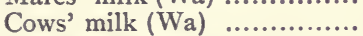 & 87.0 & 3.7 & 4.7 & 3.9 & - & 0.7 \\
\hline Cows' milk, skimmed (Wo) ... & 90.0 & 3.5 & 5.0 & 0.7 & - & 0.8 \\
\hline Cows' colostrum (Wa) .......... & 74.7 & 17.6 & 2.6 & 3.6 & - & 1.5 \\
\hline Hens' eggs (Wo) ................ & 73.6 & 12.6 & 0.6 & I2. I & - & I. I \\
\hline
\end{tabular}

The blades of grass (including corn), clover, vetches, lucerne, etc., contain more nitrogenous matter and less woody fibre than the stalks.

The nitrogenous matter of plants, which, in its composition, closely resembles that of the animal body, may be divided into albuminoids (proteids) and amides. The albuminoids are often called "muscle formers," but would be more correctly termed "formers of nitrogenous tissue"; because their presence in the food is necessary for the construction and repair of every tissue which contains nitrogen. Although amides also contain nitrogen, they are not capable of assisting in the formation of nitrogenous tissue; their office being to produce energy and to manufacture fat. As the respective proportions of albuminoids and amides vary a good deal in different species of plants, the expression "nitrogenous matter" has 
not always the same significance. The following table is taken from Warington's Chemistry of the Farm. We see from it that as a rule the percentage of albuminoids is considerably in excess of that of amides.

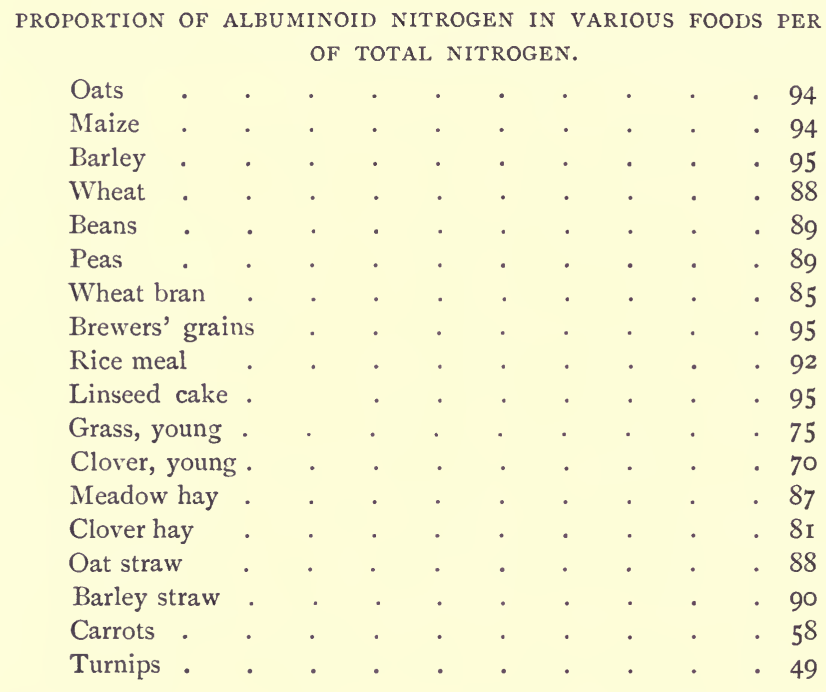

Carbo-hydrates are a group of bodies which, in addition to at least 6 atoms of carbon, contain oxygen and hydrogen in the same proportion as water $\left(\mathrm{H}_{2} \mathrm{O}\right)$. Starch $\left(\mathrm{C}_{6} \mathrm{H}_{10} \mathrm{O}_{5}\right)$, grape sugar $\left(\mathrm{C}_{6} \mathrm{H}_{12} \mathrm{O}_{6}\right)$, and cane sugar $\left(\mathrm{C}_{12} \mathrm{H}_{22} \mathrm{O}_{11}\right)$ are the principal soluble carbo-hydrates in plants. The proportion of starch is far higher than that of sugar in all kinds of ordinary fodder. The substances which are classed together as carbo-hydrates, differ a great deal from each other as regards their feeding value.

"Starch occurs mainly in the form of granules, which differ much in different grains both in size and shape, and, it must be added, in their rate of digestion. Uncooked maize-starch and oat-starch are very quickly turned into sugar by the digestive ferment of the saliva or by the diastase of the 
pancreas; wheat-starch requires a much longer time, and potato-starch is still more obstinate" (Church).

Crude fat is the term applied to all fatty, waxy and resinous substances which exist in plants, and which can be dissolved by ether. Although the fatty and oily compounds in the food are readily absorbed, the waxy and resinous matters appear to be indigestible. As the respective proportions of these constituents vary considerably in different kinds of plants, the feeding value of crude fat is no more fixed than is that of nitrogenous matter or of carbo-hydrates.

The name "fibre" is given to the fibrous and woody material which is contained in plants, and which consists of varying proportions of cellulose $\left(\mathrm{C}_{6} \mathrm{H}_{10} \mathrm{O}_{5}\right)$ and lignin $\mathrm{C}_{18} \mathrm{H}_{20} \mathrm{O}_{8}$ ). Cellulose forms the cell walls and first skeleton of a plant. Lignin, which is also known as vasculose, "is the chief constituent of the vessels which bind the wood-cells and fibres together" (Bloxam). Lignin is harder, denser and more indigestible than cellulose. The fibre of hay and of the straw of cereals (oats, wheat and barley for instance) has a smaller percentage of lignin than that of the straw (stalks) of clover, peas and vetches, and is consequently of higher feeding value. Pure, or nearly pure, cellulose, as we find it in the membrane which forms the walls of the cells of grain, is soft and tender.

The most important mineral matters in plants, from a feeding point of view, are common salt, the phosphates of lime and magnesia, potassium chloride, and salts of iron. The mineral matter of animals is much richer in salts of soda (chiefly as common salt) than is that of vegetables. The vegetable acids in forage consist chiefly of tartaric acid and citric acid, which, with potash and soda, form soluble carbonates, and thus serve to keep the blood, tissues and certain secretions alkaline. The following tables give the respective percentages of the constituents of the mineral matter (ash) of various foods. 


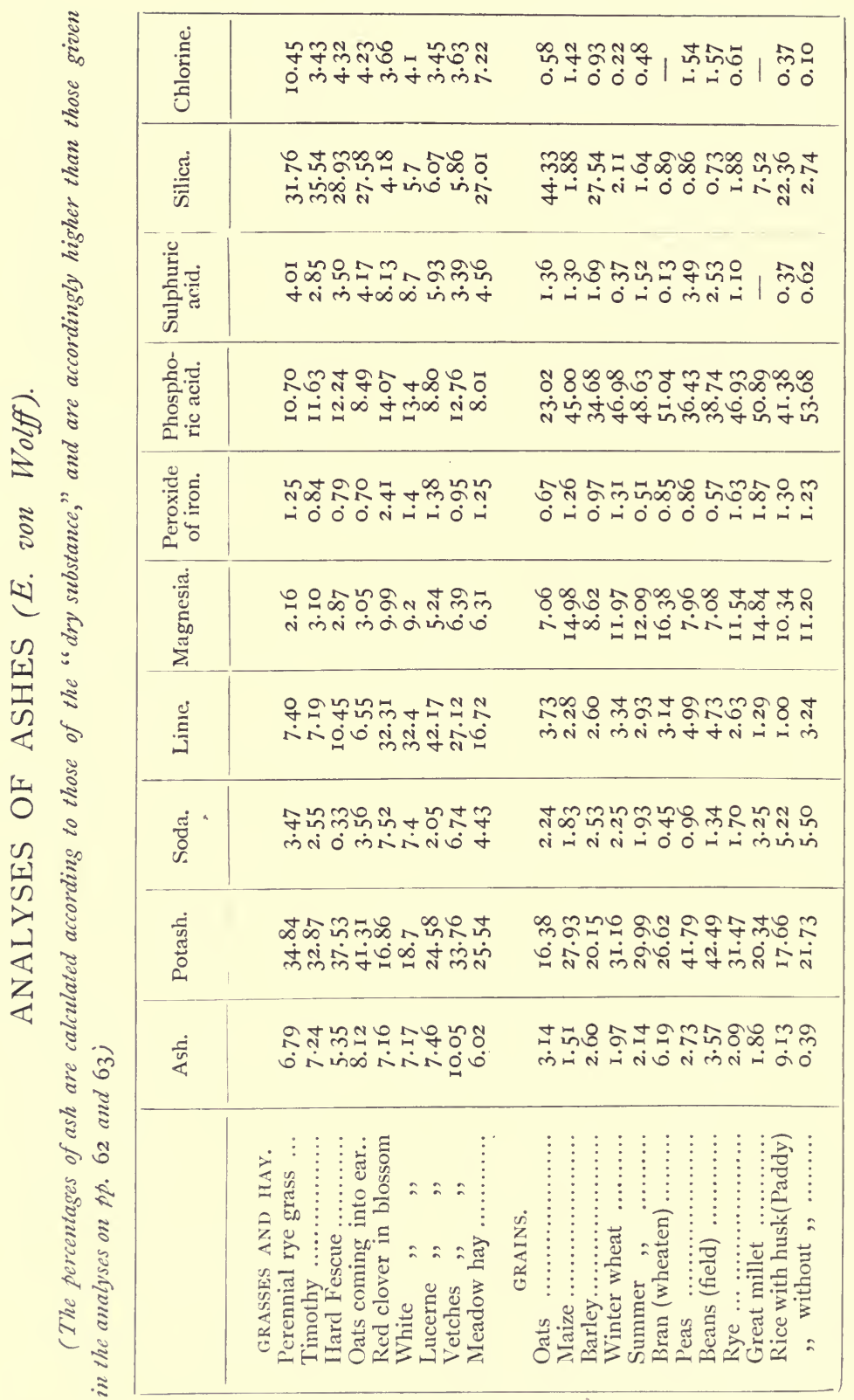


CHEMICAL ANALYSES.

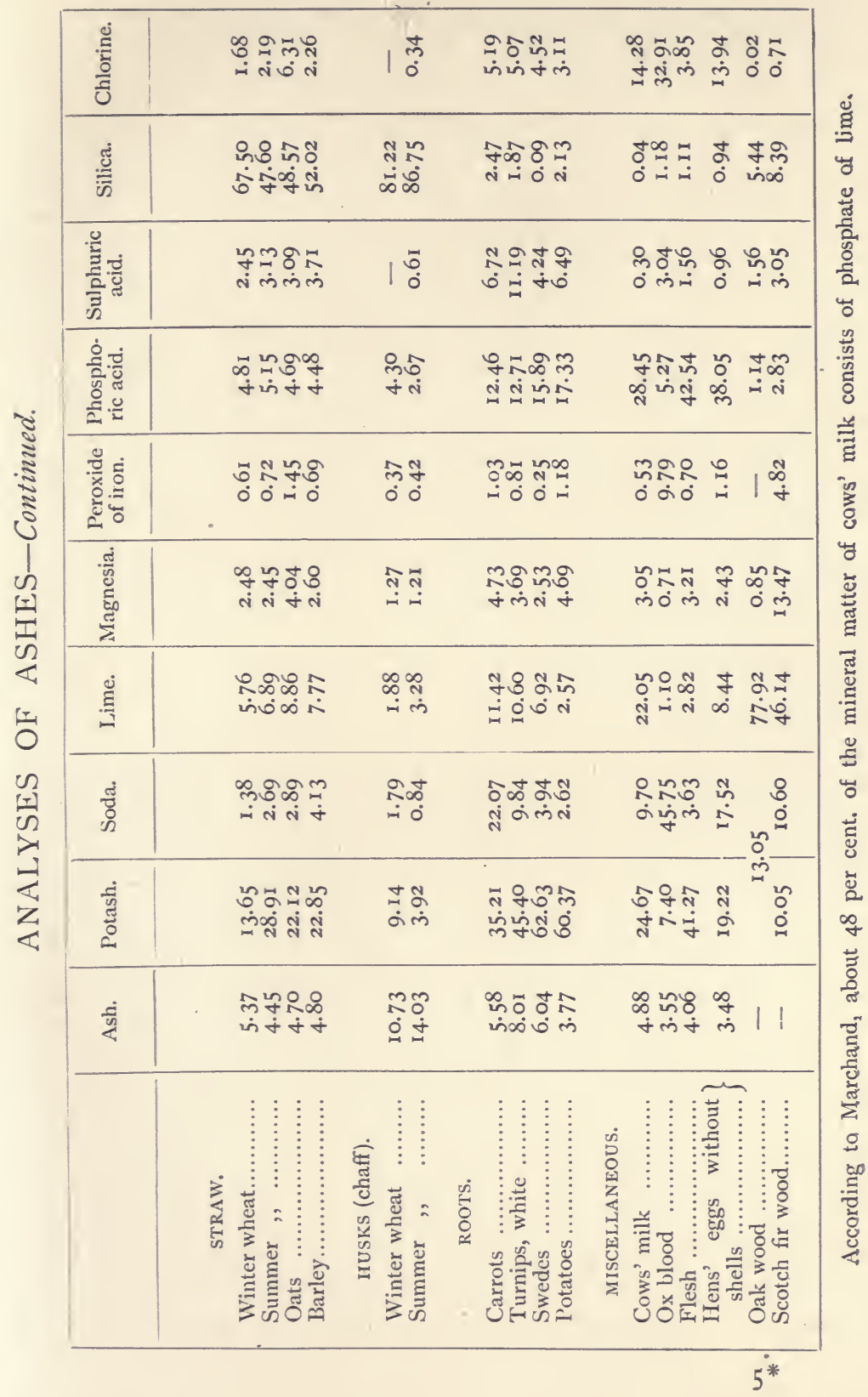


RELIARILITY OF CHEMICAL ANALYSIS AS A GUIDE TO THE FEEDING VALUE OF FOOD.

We can draw only general conclusions from chemical analyses of foods; because (I) the respective feeding values of the constituents of plants, as we have just seen, have not as yet been accurately determined; (2) the percentages of the constituents vary greatly according to circumstances which will be presently considered; (3) neither the percentage nor the presence of ferments is indicated by the analyses at our disposal.

\section{FERMENTS IN GRAIN.}

We learn from the researches of Horace T. Brown (Chemical Society's Transactions, I890, pp. 458-528; and I892, pp. 352-364) that certain grains contain a greater or less amount of an unorganised ferment (enzyme) which, during digestion, has the power to dissolve the walls of the cells of the grain, and thus to expose their contents to the action of the digestive fluids. The membrane which forms the walls of these cells is thin, tender, and is composed of nearly pure cellulose. The enzyme in question has no power to attack starch or the woody and more or less lignified fibre of hay, and does not become fully developed in the grain until the grain has become ripe. True ripening of the grain takes place only after more or less of the original moisture of the grain has been given off. The abundant presence of this enzyme in good oats furnishes us with an explanation of the great rapidity with which the contents of these grains become broken up in the early stages of digestion, and confirms the high estimation in which oats are held as a food for horses; for without this enzyme a considerable portion of the flour of the oats would be unaffected by the gastric and pancreatic juices, and would enter the cæcum undigested. "The animal itself, besides affording a 
favourable temperature, a suitable mixture of fluids, and plenty of mechanical movement, does not contribute to the dissolution of the cell-membrane, which is wholly brought about by the enzyme pre-existent in the grain" (Brown). This writer (Proceedings of the Royal Society, 63, I898, page 3) has found that most of this enzyme exists in the inner layer of the husk (aleurone layer).

This enzyme of grain, like those animal enzymes, ptyalin and pepsin, is a chemical substance, and is different from the ferments produced by bacteria. According to Gamjee, the activity of enzymes is destroyed by exposure to a temperature of $126^{\circ} \mathrm{F}$., which is a fact that probably explains the reason why the feeding value of good oats becomes lessened by the process of kiln-drying or parching. Barley, which either contains very little of this enzyme or is wholly deficient of it, is almost always improved by parching.

Diastase is an unorganised ferment that converts starch into malt-sugar (maltose) and British gum (dextrin), and thus renders it soluble. Diastase is formed only during germination, as in malting.

The reaction, as given by Bloxam, is : ${ }_{3} \mathrm{C}_{6} \mathrm{H}_{10} \mathrm{O}_{5}$ (starch) $+\mathrm{H}_{2} \mathrm{O}=\mathrm{C}_{12} \mathrm{H}_{22} \mathrm{O}_{11}$ (maltose) $+\mathrm{C}_{6} \mathrm{H}_{10} \mathrm{O}_{5}$ (dextrin).

Cerealin, which was discovered by Mège Mouriès, is an enzyme that occurs in bran. Its action is similar to that of diastase, but is much slower.

\section{ORGANS OF DIGESTION.}

The irregularly shaped tube (the alimentary canal) through which the food passes on its way into and out of the horse's body, is formed by the mouth, gullet, stomach, and intestines (small and large intestine), all of which organs are lined by mucous membrane. This membrane also lines the air passages (nostrils, windpipe, and bronchial tubes), bladder, urethra (tube that carries the urine outwards from the 
bladder), ureters (two tubes which convey urine from the kidneys to the bladder), and interior of the eyes and eyelids. It is continuous with the skin, and the skin is continuous with the membrane that secretes the hoof. We may regard the mucous membrane as a modification of the skin, from which it differs with respect to its structure only in its being thinner and softer. The mucous membrane of the stomach and intestines is provided with a great number of minute vessels, called absorbents. The membrane which secretes the hoof may also be looked upon as a modification of the skin. The structure known as skin is composed of a secreting surface (the true skin) and a covering surface (epidermis, page I8), which consists of more or less horny scales secreted by the true skin, and which is more or less impermeable to fluids. The mucous membrane secretes mucus, which is a slimy and semi-fluid substance, as we may see from an inspection of phlegm, or of discharge from the nose. The three surfaces in question possess strong mutual sympathy. Thus, in catarrh for example, the coat loses its polish, and the intestines become irritable; during an attack of indigestion, the condition known as "hidebound " is often present; and laminitis (inflammation of the feet) may arise from superpurgation. On the other hand, a soft, glossy coat is an indication that the organs of breathing and digestion are in good order.

At the beginning of the alimentary canal we have the lips, mouth, and gullet, which, at its entrance into the stomach, is constructed so as to render vomition extremely difficult.

The horse's stomach has an average capacity of about $3 \frac{1}{2}$ gallons, and is provided with a large number of glands which supply it with gastric juice, and which are found only on about one-half of the interior surface of that organ; the other half being merely a continuation of the gullet. Hence the size of the functional stomach is only about half that of the apparent one. 
The small intestine begins at an opening on the right side of the stomach. It is about $72 \mathrm{ft}$. long, and about $I \frac{1}{2} \mathrm{in}$. in diameter. It terminates at the cacum, which is the first portion of the large intestine, and which forms a cul-de-sac of about $3 \mathrm{ft}$. in length and of an average capacity of about $7 \mathrm{x} / 2$ gallons. The large intestine is about $20 \mathrm{ft}$. long, and ends at the anus.

According to Colin, the capacity of the large intestine is about double that of the small one, and their united capacity is more than ten times as great as that of the stomach. In cattle the capacity of the stomach, of which there are four compartments, is about $2 \mathrm{I} / 2$ times greater than that of the intestines.

Under the heading of "organs of digestion" must be placed certain glands that secrete fluids which flow into the alimentary canal, and which are respectively concerned in the digestion of food. The principal glands in question are as follows:-The salivary glands, the most important of which in the horse are the two parotid glands that respectively occupy, on each side, the space where the head is joined to the neck. The office of the salivary glands is to secrete saliva for mastication. The gastric glands secrete gastric juice, which flows into the stomach. The pancreas (sweetbread) secretes pancreatic juice, which is carried out of the gland by a tube that opens into the small intestine close to the stomach. This tube also serves to convey into the small intestine bile, which is secreted by the liver. The intestines are supplied with a large number of small glands (intestinal glands) that secrete a fluid which aids in digestion.

GENERAL VIEW OF DIGESTION, ABSORPTION,

AND ASSIMILATION.

The office of digestion is to dissolve the food, so that it can be absorbed through the mucous membrane of the alimentary canal, and to effect certain chemical changes in its constituents, 
in order that these constituents may be utilised (assimilated) by the system. These changes are brought about chiefly by certain unorganized ferments (p. 68), which are respectively secreted by the digestive glands, and which are characteristic components of the digestive fluids. Digestion commences in the mouth, and does not end until the residue of food quits the body in the form of dung. The action of digestion is not uniform during the progress of the food through the alimentary canal; for it begins slowly, increases steadily, and having reached its effective limit, it gets slower and slower. Owing to the evolutionary influence of the different constituents of food, the alimentary canal of animals is more or less divided into tracts (such as the mouth, stomach, small intestine, cæcum, and remainder of the large intestine), which are respectively concerned in the digestion of special food substances. Hence the form and particular functions of the alimentary canal are dependent on the natural food.

DIGESTIBILITY AND IVHOLESOMENESS OF FOOD.

The digestibility of a food is its capability of being absorbed in the system.

According to Müntz and Grandeau, the respective percentages of digestible material contained in the undermentioned foods is as follow :--

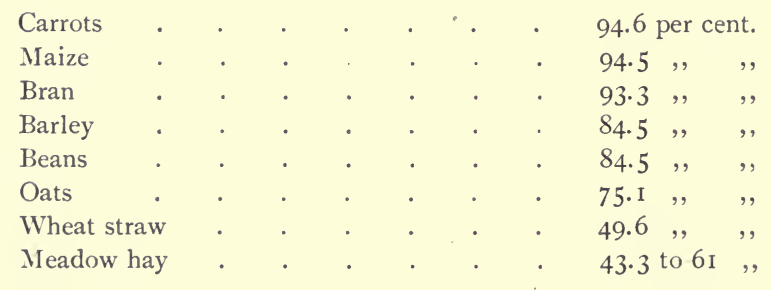

Despite the theoretical correctness of the above table, we know from experience that oats, especially in large quantities, agree with a horse much better than barley or beans, both of which are put down as being more digestible than oats. 
This apparent anomaly is explained by the fact that the wholesomeness of a food for horses is largely dependent on the respective percentages of fibre (p. 65 ) and nitrogenous matter (p. 63) contained in it. Oats are rich in fibre, which, though practically indigestible, greatly aids the digestion of the nutritive part of that grain, and prevents digestive disturbance. Also, oats do not contain, like beans, too high a percentage of nitrogenous matter, which, when consumed in excess, has a poisonous effect on the system (p. 122). Thus we find that when the quantity is not limited, a horse can obtain a larger amount of nutritious material from oats, without his digestion becoming upset, than from either barley or beans. We may therefore see that digestibility and wholesomeness, as applied to foods, are not convertible terms; and that a comparatively indigestible food may be an eminently wholesome one. What a horse, like every other animal, requires, is a wholesome food which contains a sufficiency, but not an excess, of easily digestible nutritive matter, the respective constituents of which are in proportions suitable to his requirements.

As the wholesomeness of a food cannot be exactly measured, we have in estimating it to rely more on practical observation, than on chemical experiment. In this respect, the state of the dung is a valuable guide. In ordinary conditions of health, the dung, without being hard, will be fairly formed, brittle, though moderately damp and free from foul odour and adherent slime, the presence of which will indicate irritation of the intestines. A loose and unformed state of the dung will show either that the mechanical nature of the food is unsuitable (being irritating or too watery), or that the absorption of some of its constituents had produced a purgative effect. During constipation, the dung of a horse becomes hard and dry from its being kept too long in the lower part of the large intestine, and it assumes a consistency 
somewhat resembling that of the dung of goats. Also, from undue retention, the residue of the food which is in the intestines is liable to become decomposed, with the result that the animal's health suffers more or less from the absorption of deleterious products. The bad effect of diarrhœa has already been discussed.

It is interesting to note that the condition of the dung is by no means uniform in all animals. Thus, as compared to horses, dogs are in a constant state of constipation; and horned cattle, in one of diarrhœa.

\section{TAKING FOOD INTO THE MOUTH.}

The first act in the digestion of food is its prehension (seizure), which is accomplished by the lips and afterwards by the front teeth (incisors = cutters). If the grass, hay, or other food offers resistance to its removal on being caught hold of by the lips, the front teeth will help to detach it by their cutting action, and the upper lip, which is gifted with great mobility, a high degree of sensitiveness, and a fair amount of muscular strength, will be capable of more or less encircling it and of exerting traction on it. The knowledge that the upper lip is very sensitive to pain teaches us that an ordinary twitch should be used only in cases in which the infliction of pain is justified by necessity. Also, the employment of this twitch has the great disadvantage, from a pecuniary point of view, that it is liable to depreciate the animal's value by rendering him difficult to be handled about the head, as for instance, in bridling him. When the food has been detached and is held by the lips, the teeth become separated from each other, and the tongue, aided by the lips, conveys the food to the back of the mouth. Colin has shown by experiment, that a horse is unable to take any solid food into his mouth without the aid of his lips. In cattle, the tongue performs the office of the 
prehension of food in a mannèr somewhat similar to that done by the upper lip of a horse.

\section{DRINKING.}

In drinking, the action of the mouth is that of a suction pump, in which the tension of the air in the mouth is reduced by the tongue being drawn back while the lips are kept closed. If this is done while the horse's muzzle is immersed in the fluid and the lips are separated without any air being admitted, the fluid will rush into the mouth and will rise to a height sufficient to render the pressure of the fluid on the air in the mouth equal to that of the atmosphere, and also sufficient for the swallowing muscles to force the fluid into the gullet. In this process, the action of inhaling (drawing in the breath) appears to have little or no effect; for we find that a horse which has an open tracheotomy tube in his windpipe will drink as easily as a sound horse, other conditions being equal. In drinking, a horse naturally keeps his nostrils above the surface of the fluid, as he has to breathe through them; but while his nostrils are unimmersed, the corners of his mouth will also be above the surface of the fluid. Hence, if the lips are separated at their corners, as for instance by the wearing of a curb bit, and especially if the reins are drawn more or less tightly, the animal will be greatly impeded in drinking, even if he is not altogether prevented from swallowing the fluid. A snaffle is less liable to cause interference in this manner than a curb; because it is as a rule put lower down in the mouth, and if jointed, it hangs down by the bending of its joint, and does not draw the lips apart so much as the mouthpiece of a curb would do.

According to Colin, a horse when drinking, takes from .26 pint to .44 pint at each "go-down" (swallow), and drinks at the rate of from 65 to 90 go-downs a minute. The 
quantity of an average go-down would therefore be about $1 / 3$ pint. When thirsty, a horse would drink a gallon of water in about 20 go-downs.

\section{MASTICATION.}

A horse with a "full mouth" has forty teeth, namely, six front teeth in each jaw, and one tush and six back teeth on each side of each jaw (Fig. I). Each tooth is covered with a very hard, white, and comparatively thin layer of enamel, which in the front teeth forms a depression in the middle of the cutting surface of the tooth. Hence, when a front tooth

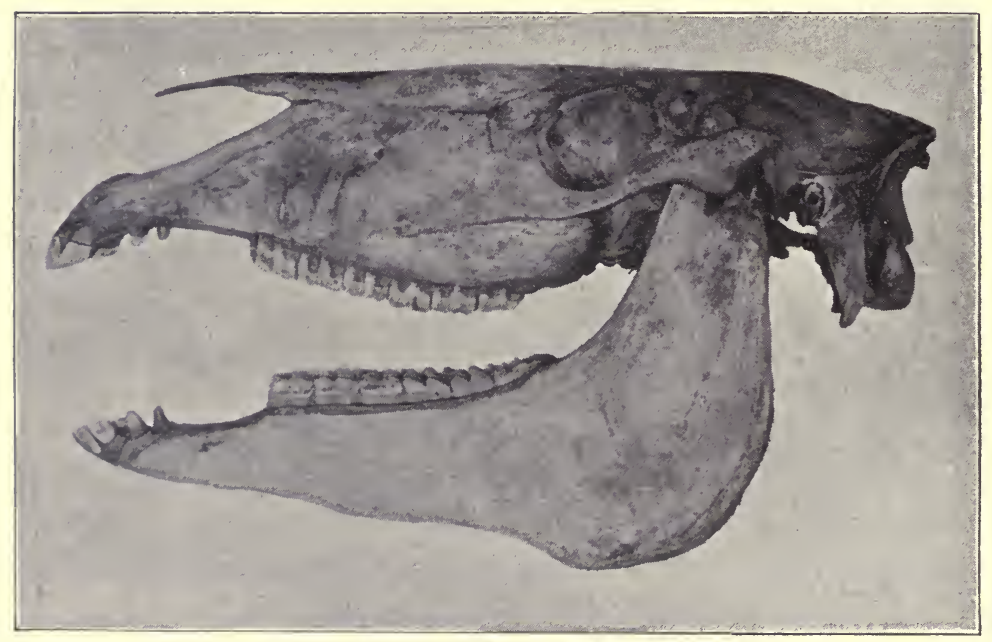

Fig. I. Teeth of Horse.

comes into wear, its table has two irregularly-shaped rings of enamel with soft tooth-substance (dentine) between them. In each back tooth, the layer of enamel is doubled in on each side so as form on the table sharp and hard ridges, which 
project above the soft dentine. The tables of the back teeth slope downwards and outwards, that is to say, their inner edges are higher than their outer edges. The action of the back teeth is that of a mill, in which the sharp surfaces of the

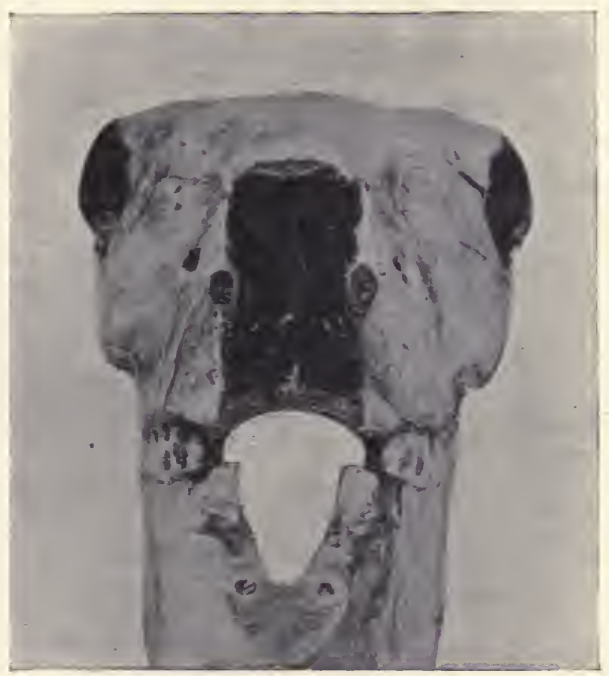

Fig. 2. Transverse Section of Skull of Horse, immediately in front of his back teeth.

lower back teeth on each side of the mouth are worked laterally against those of the upper jaw, and thus the food which is brought between them by the tongue and cheeks, is ground. As the lower jaw is narrower than the upper jaw (Fig. 2), a horse can chew with his back teeth only on one side of his mouth (Fig. 3) at a time, which he often continues to do for even as long as an hour, without changing to the other side. A horse is unable to use his front teeth and his back teeth at the same time; for when he works his lower jaw laterally, the front teeth of the lower jaw become separated from those of the upper jaw (Figs. 4 and 5). 
Each tooth is lodged in a socket in its jawbone, and is developed from its dental pulp, which is provided with blood-vessels, nerves, and secreting cells. Owing to the continued secretion of dentine, the teeth are forced slowly out of their sockets, which movement more or less makes up for the wear entailed on the teeth by mastication. Our own teeth, on the contrary, remain stationary in their sockets after they have attained their full size. The greater amount of wear undergone by the back teeth of a horse is compensated for by the increasing obliquity of the incisors

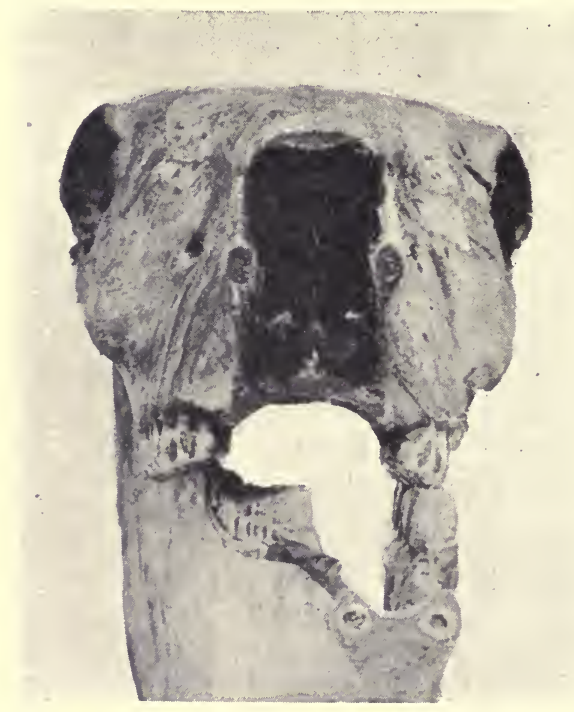

Fig. 3. Transverse Section of Skull of Horse, showing position of back teeth when the animal is chewing on the left side of his motith.

with age. As the teeth wear down in time, the layers of enamel of both the front and back teeth gradually become thinner and weaker, until at last they disappear altogether or fail to fulfil their purpose as cutting projections on the tables 
of the teeth. Hence, mastication becomes less perfect with age, and as the animal grows old, he becomes increasingly liable to indigestion from the faulty action of his teeth.

On an average, a horse takes about 9 minutes to eat $\mathrm{I} \mathbf{l b}$. of oats and about 12 minutes to consume the same weight of hay (Colin).

While food is being chewed, it becomes more or less

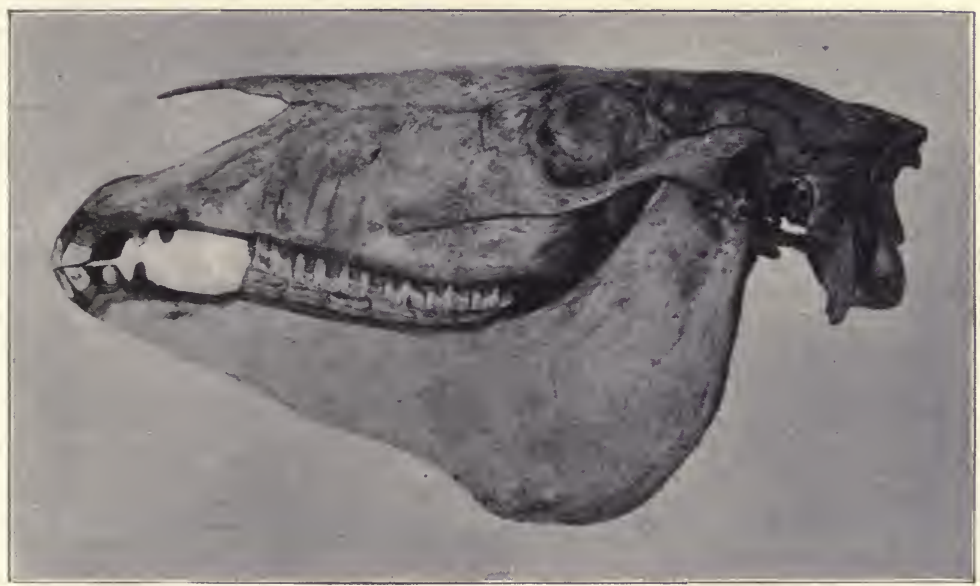

Fig. 4. Jaws of Horse placed evenly together.

mixed with saliva, which flows into the mouth by tubes from the salivary glands (parotid, submaxillary, and sublingual glands), in response to the stimulus caused by the presence of the food, and which helps the animal to swallow. In horses, the chief source of saliva is the parotid glands, which are of greater comparative size in them than in all other animals, except ruminants. The saliva of the parotid glands consists of about 99.2 per cent. of water. Carpenter points out that the size of the parotid glands in animals is proportionate 
to the degree in which the mastication of their food is performed; and that these glands are absent in birds which swallow their food whole. Although dogs secrete saliva abundantly, starch is not a component of their natural food. As the requirements of a horse's digestion demand that he should thoroughly chew his food, we ought to give it to him in

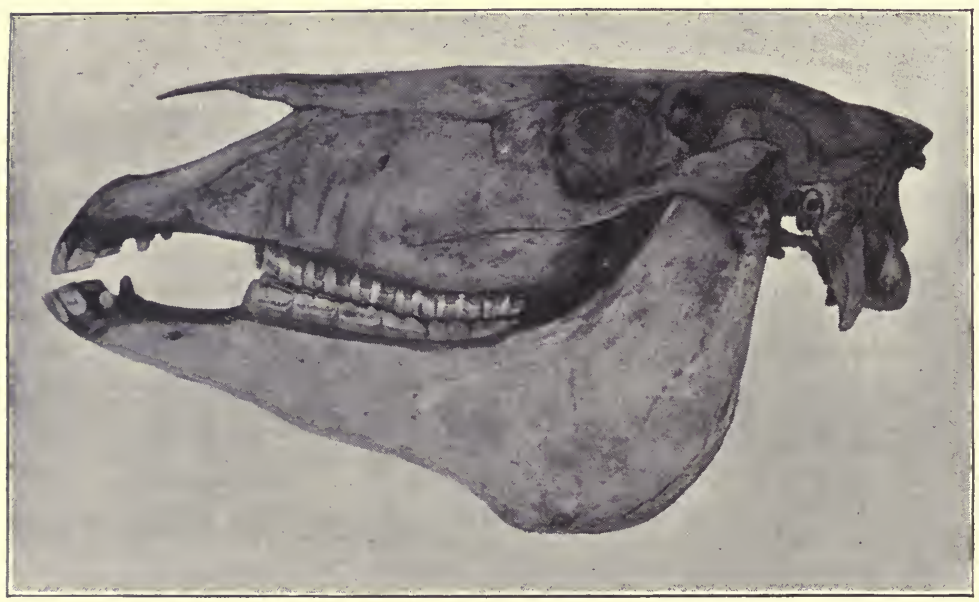

Fig. 5. Lower Jaw moved to the left, as in Fig. 3.

a condition that will induce him to eat slowly. Furthermore, the amount of saliva secreted during mastication is more or less proportionate to the dryness of the fodder; for the dryer it is, the more saliva will a horse require to enable him to swallow it. Lassaigne gives, from experiment, the following results :-

IOO parts of grass require 49 parts of saliva.

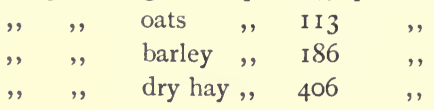


The frothy nature of saliva, caused by the presence of air bubbles in it, aids digestion by rendering the food through which the saliva becomes mixed during mastication, more easily penetrable by the digestive juices, than it would be if air bubbles were absent. The presence of saliva in the food materially aids digestion in the stomach, as we learn from the experiments of Spallanzani and Réaumur, who "found that food enclosed in perforated tubes and introduced into the stomach of an animal was more quickly digested when it had been previously impregnated with saliva, than when it was moistened with water. Dr. Wright also found that if the œsophagus (gullet) of a dog is tied, and food mixed with water alone is placed in the stomach, the food will remain undigested, though the stomach may secrete abundant acid fluid, but if the same fluid is mixed with saliva, and the rest of the experiment similarly performed, the food is readily digested" (Kirkes). I think we may conclude from these observations, that the food of horses should be supplied to them in a more or less dry state, and that the practice of giving soaked food or boiled food is, as a rule, objectionable. If, however, such food is given, as in case of illness, or for a change, it is well to mix it with a suitable quantity (say $\mathrm{I} / 2 \mathrm{oz}$.) of common salt, the presence of which in the mouth excites the flow of saliva.

Saliva, being of an alkaline nature, aids the digestion of fat by forming it into an emulsion, in which the fat is split up into minute particles.

Saliva contains the ferment ptyalin, which has the property of converting starch into sugar, in which form it is absorbed into the body. The action of the ptyalin of the saliva on starch is of too brief duration to have much effect; for it ceases soon after the arrival of the food in the stomach, on account of the presence of acid in the gastric juice. The digestive changes which the food undergoes 
in the mouth therefore appear to be more mechanical than chemical.

\section{DIGESTION IN THE STOMACH.}

It is probable that the presence of saliva, which is an alkaline fluid, is beneficial in checking undue acidity in the stomach. Respecting the action of a cell-membrane dissolving ferment, see page 68 .

The digestion of the nitrogenous matter of the food begins in the stomach and is carried on by the action of pepsin, which is a ferment found in the gastric juice, and which has the property of changing nitrogenous matter into a soluble form (peptone). It also serves to split up vegetable fat into a fine state of division by dissolving the nitrogenous envelopes which enclose the globules of fat. The natural and healthy acidity of gastric juice is chiefly due to the presence of hydrochloric acid, which confers antiseptic properties on gastric juice, as we may see by the immunity with which many races of men eat putrid flesh and decomposing fish. Gastric juice contains about 97:3 per cent. of water, and about .3 per cent. of hydrochloric acid (Schmidt).

The presence of food in the stomach acts as a stimulant to the secretion of gastric juice, which at first flows slowly into that organ, but more quickly later on. - Its secretion is liable to become checked by exercise, by excitement, or by the stomach becoming unduly distended. It is evident from our knowledge of the distribution of blood in the body (p. 7), that stimulation of the muscles and organs of breathing from exercise, or of the brain from excitement, will produce more or less congestion of blood in these parts, and anæmia in other organs, which cannot perform their work efficiently without a copious supply of blood. Undue distension of the stomach or intestines causes anæmia by pressure, as for instance, when the animal consumes large quantities of boiled 
food. Drinking freely of water while digestion is going on in the stomach is liable, by largely diluting the gastric juice, to arrest its action for the time being. The lower the temperature of water that is drunk while digestion is going on in the stomach, the more liable will such water be to check the action of the gastric juice, which is unable to perform its functions at a temperature much below blood heat. When the supply or action of the gastric juice becomes more or less arrested, the food which is in the stomach is apt, in the absence of its natural antiseptic, to become decomposed, with the probable result of indigestion and flatulent colic caused by the evolution of gas. Hence we may conclude that horses should not be worked, watered, or subjected to excitement soon after they have been liberally fed; and that they, as already stated, should not be given large quantities of food which they can readily swallow. The fact of a horse's intestines being of great volume shows that his food should be of a bulky nature. But as his stomach is small and simple in structure; we may assume that the material from which he derives his nourishment should be easy of digestion, and that he should be frequently fed. We know that the stomach of an animal is large and complex in proportion to the amount of preparation its natural food requires in that organ. Thus we find that the stomach of weasels and ferrets, whose natural food (blood) needs but slight modification before being digested, is little more than an enlarged prolongation of the gullet. The stomach of cattle is, on the contrary, very complex, consisting as it does of one true and three preparatory stomachs, and is consequently far better suited for the digestion of coarse and innutritious fodder (such as hay made from grass in seed, and straw) than that of a horse. As the material from which a horse derives his nourishment should be easy of digestion, we are forced to infer that the remainder should be made up of indigestible matter; for it 
would be unreasonable to imagine that a horse could digest all, or even a large part, of the food which his intestines are capable of containing. We may see by referring to pages 96 and to 98 , that this indigestible matter consists chiefly of vegetable fibre, which, although it contributes little or nothing to the direct nourishment of the system, greatly aids the digestion of the nutrient portion of the food.

The conclusion as to the advisability of frequent feeding, is in agreement with the manner a horse eats when at grass, namely, that of consuming small quantities of food at short intervals of time; in fact, feeding more or less continuously. When a horse is fed during frequent intervals between labour, the digestion of comparatively small quantities of food in the stomach is not as a rule followed by digestive disturbance. For instance, although strong exercise immediately after feeding would be dangerous for a horse that has a liberal daily ration divided into only three or four feeds; it produces no bad effect on an ordinary London cab horse, which on every available occasion during his tour of duty has the feeding bag put on his head.

Under ordinary conditions, as soon as a horse's stomach becomes nearly filled while he is eating, food, more or less digested, begins to pass from his stomach into the intestine at the same rate as fresh food enters into his stomach from his mouth and gullet. The food that is then in front, on its way out of the alimentary canal, gets to a greater or less extent pushed out of the stomach by the food behind it. When the animal stops eating, the rate at which the food leaves the stomach, gradually decreases, and even after the horse has been fasting for a considerable time, a certain residue of food will be found in that organ. Hence, the larger the quantity of 'food consumed at one time, other things being equal, the quicker will it pass through the stomach, and the less perfectly will it be digested. During the digestion of food in the 
stomach, the action of the gastric juice increases in activity the longer the food remains under its influence; probably because the gastric juice contained in the stomach during the later periods of digestion, is not so' much diluted with saliva as the gastric juice of the earlier periods. As corn requires to remain for a comparatively long time in the stomach to become properly digested, we should evidently refrain from giving hay to a horse soon after he has eaten his grain. In fact, in giving hay and corn we should adopt the opposite procedure to that usually practised in stables. If our object is to get a horse to eat as much corn (including chop, in the event of its being used) as he can consume, we may give him the corn in the ordinary way, and after he has eaten it, wait for at least an hour before giving him hay. A better plan I have found in such cases, supposing that the animal gets on chop in his grain, is to give a small amount of hay (say, I or 2 lb.) before the corn, and after the corn has been consumed, to give no more hay for an hour or longer. When a horse has a full allowance of hay and a moderate amount of grain (say, $14 \mathrm{lb}$. of the former and Io of the latter), we might with advantage devote, say, two-thirds of the hay to be divided into portions to be given before the feeds of corn, and keep the remaining one-third for night use.

Experiment has shown that the average period of retention of food in the stomach is probably not longer than an hour and a-half.

Under healthy conditions, the opening which forms the exit from the stomach does not permit food to enter the small intestine before the nitrogenous matter is fairly well dissolved. If, however, the passage be effected before that desirable result is obtained, the irritation to the intestine caused by the presence of an excess of unprepared material is apt to give rise to indigestion, the usual symptoms of which will be pain and flatulent colic in aggravated cases, or merely diarrhœea. 
As a rule, the cause of such digestive disturbance is exercise or water given too soon after the horse has had a full feed. Water in such a case is apt to carry the food out of the stomach into the small intestine; because water stays only a very short time in the stomach on its way to the cæcum.

The movements of the muscular coat of the stomach cause the food contained in that organ to become saturated with gastric juice, and to become slowly carried towards the opening from the stomach into the small intestine. The muscular coat of the intestines gives their contents a wormlike motion, which enables them to expel the residue of food onwards.

\section{DIGESTION IN THE INTESTINES.}

The process of digestion is performed much more fully in the intestines than in the stomach. When food leaves the stomach and enters the small intestine, it becomes mixed with bile and pancreatic juice, which flow into the intestine by a common opening. The pancreatic juice of the horse contains, according to Leuret and Lassaigne, about 99. I per cent. of water. Pancreatic juice possesses ferments which respectively dissolve nitrogenous matter and starch, and which split up fat in such a manner that the fat can be readily absorbed. Bunge states that "the pancreas is the digestive gland par excellence."

Halliburton considers that the chief use of bile is to aid the pancreatic juice in the digestion of fat. The results of many experiments (see Colin's Physiologie Comparíe) suggest the conclusion that bile is much more concerned in the absorption of fat than is pancreatic juice. It is doubtful if bile has any antiseptic power; for it cannot prevent even itself from decomposing. When the secretion of bile is deficient in quantity, the intestines during digestion contain a large amount of unabsorbed fat which encloses a portion of the nitrogenous matter of the food and thus 
prevents it from becoming absorbed; the result being that the nitrogenous matter becomes putrid, and consequently imparts a foul smell to the dung (Bunge). Colin estimates that a horse secretes daily about one-sixty-sixth of his weight of bile. This secretion contains from 82 to 91 per cent. of water; various salts, chiefly of soda; fatty matters; and colouring matters.

The liver constantly secretes bile, which in men, cattle, and in the large majority of other mammals, flows into a reservoir (gall bladder) and from thence issues into the small intestine. As horses were found to have no gall bladder, and as they were known to feed more or less continuously when at grass, it was generally inferred that the absence of a gall bladder in a horse was a proof that he should be fed at frequent intervals of time. Although the conclusion was true, the premises of the argument were incorrect; because the possession or non-possession of a gall bladder appears to have no connection with the digestion of food. For instance, among ruminants we find that deer, camels, and llamas have no gall bladder. This reservoir is also absent in ostriches, parrots, guinea fowl, and pigeons (Colin), though present in most other species of birds. Besides, the possession of a gall bladder does not prevent the continued flow of bile into the small intestine, whether the food is or is not passing through that portion of the alimentary canal.

On leaving the small intestine, the food and water become collected in the cæcum, which acts to some extent as a supplementary stomach. In it and in the greater portion of the remainder of the large intestine, the processes of digestion and absorption are continued, until finally the unappropriated residue in the form of dung is expelled. The digestive power of the lower portion of the large intestine is feeble. The intestinal juice has the property of dissolving carbohydrates and nitrogenous matter. In the horse, a portion 
of the woody fibre is broken up in the large intestine by the action of bacteria which are brought into the body along with the food; the result being that the woody fibre which undergoes this change becomes converted into carbonic acid, marsh gas, acetic acid, and butyric acid. Bunge explains that this carbonic acid is absorbed by the intestines and is breathed out by the lungs; but that the marsh gas remains in the intestines until it is passed out in the form of flatus.

As the products of this reaction cannot be utilised by the system, this breaking up of woody fibre by bacteria must not be regarded as digestion.

\section{WATER FOR THE DIGESTIVE JUICES.}

We have seen that for every $2 \mathrm{I} / 2 \mathrm{lb}$. of hay which a horse eats, his salivary glands have to pour into his mouth a gallon of saliva (10 lb.); and for the same weight of oats, more than a quart of saliva. Hence, 6 gallons of saliva would be required for the mastication of a daily ration of $12 \mathrm{lb}$. of hay and I I lb. of oats, without counting the saliva which is continually secreted while the animal is not feeding. There are also large quantities of gastric juice, pancreatic juice, bile, and intestinal juice secreted. Considering the composition of these digestive fluids, we may safely say that the water contained in their daily supply to the alimentary canal, is on an average a good deal more than double the quantity of water drunk by the horse in the twenty-four hours. It is therefore evident, especially when we note the large expenditure of water from the skin, lungs, and kidneys, that a considerable portion of the water contained in the outpoured digestive fluids becomes reabsorbed before it leaves the system. I need hardly explain that all the water in the digestive juices is derived from the blood. This question of the reabsorption of water does not affect the fact that the animal needs his blood 
to be fully supplied with water in order that it may secrete a sufficiency of digestive juices. Consequently we should give a horse as much water as he chooses to drink before feeding him.

\section{ABSORPTION.}

As the absorbents are separated from the contents of the intestines by only a thin membrane, they readily take up water, digested food and dissolved salts, and convey them into the blood after having passed them through the liver and other glands, which produce changes in the food that are necessary for rendering it capable of being utilised by the body. The absorption of digested food begins in the small intestine and is completed in the large one, a certain amount of water and dissolved salts being absorbed in the stomach. The absorbed food may be regarded as that which is taken up by the tissues (assimilated); and that which, being apparently in excess of the requirements of the system, is passed out of it without undergoing change. Thus, egg albumen is often present in the urine of human beings who have recently eaten large quantities of such albumen. Also, common salt is found in the perspiration of horses and men; and when water has been drunk in excess, an increased discharge of urine generally takes place.

\section{NUTRITIVE AND DIGESTIVE FUNCTIONS OF THE} CONSTITUENTS OF FOOD.

Water, whether drunk by the horse or whether it forms a constituent of his food, is evidently necessary for the repair of broken-down tissue, and for maintaining the blood and other fluids of the body in a properly diluted condition, especially when we consider that water forms about three-quarters of the entire weight of the adult horse, and that a large quantity of water is given off by the lungs, skin, and kidneys. The 
presence of an unduly high proportion of water in fodder, injuriously hastens the passage of the food through the stomach and intestines, checks the secretion of saliva, and impedes digestion by diluting the digestive juices, thus hindering their action on the nutritive matter. If the total proportion of water be too small, the dung will probably be passed out too slowly, and the formation and absorption of deleterious matters by the intestines will be promoted. When requirements of work demand that a horse shall eat a large quantity of corn, the consumption of which will fully tax his digestive powers, it is necessary that the corn shall be given in the state in which it can be most easily digested, namely, dry. Hence, if we see fit to increase the proportion of water in the food, we can give "green meat" at a time when it will not interfere with the digestion of the corn, say, an hour before or two hours after feeding on corn.

For practical purposes we may call a food watery when it contains more than 25 per cent. of water (see tables on pp. 62 and 63 ); and dry, when the percentage is equal to or less than 25. A good ordinary working diet will contain about 25 per cent. of water, as we may see from the following calculation:-

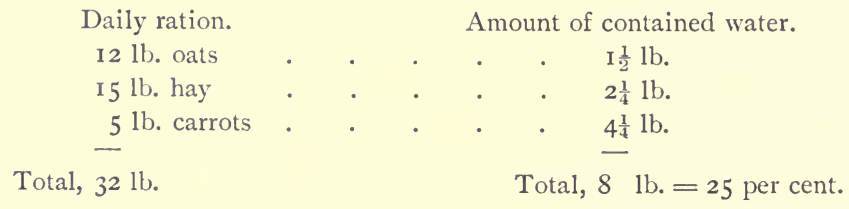

A high diet, the dryness of which should not, I think, be often exceeded, would be :-

Daily ration.

$20 \mathrm{lb}$. oats

Io lb. hay

Total, $33 \mathrm{lb}$.
Amount of contained water.

$\cdot . \cdot . \cdot 1 \mathrm{I}$

$3 \mathrm{lb}$ carrots . . . . $2 \frac{1}{2} \mathrm{lb}$.

Total, $\overline{6} \frac{1}{2} \mathrm{lb} .=20$ per cent. 
If carrots are withheld, a bran mash, which is generally allowed once or twice a week, would add to the water in the food. The addition of water confers laxative properties on the bran, which, when given dry, has not this effect.'

A full diet containing an undue proportion of water would diminish the power of breathing by increasing the volume of the stomach and intestines. We may here note that the interior of the body is divided by the diaphragm (midriff) into two cavities: the thoracic cavity (chest), and the abdominal cavity (abdomen); the former containing the lungs and heart ; and the latter, the stomach, intestines, liver, spleen, bladder, and other organs. The front portion of the stomach and intestines lies against the rear surface of the diaphragm, which is a cone-shaped muscle that has its apex pointing forwards, and its base attached to the spine and to the ends of the ribs. The act of inspiration (taking air into the lungs) is effected by muscles which increase the size of the thoracic cavity. By diminishing the pressure of air in that cavity, these muscles cause air to pass from outside, through the nostrils, windpipe and bronchial tubes, and to enter the aircells of the lungs, which then become inflated. Speaking generally, the muscles in question may be divided into two sets, namely, those which by contracting enlarge the size of the chest by drawing the ribs forward (thoracic breathing), and the diaphragm, which by contracting performs a similar office by pushing the contents of the abdomen in a backward direction (abdominal breathing). Expiration (expulsion of air from the lungs) takes place by the two sets of muscles ceasing to contract and thus allowing the ribs to fall back into their previous position, while the diaphragm and its contents move forward into the chest. As the action of breathing depends on the ability possessed by the chest of increasing its internal capacity during inspiration, it follows that the greater the bulk of the stomach and intestines, the more will the power of 
breathing be restricted by the impediment offered to the contraction of the diaphragm. As the full action of the diaphragm is demanded during health only when the power of breathing is considerably taxed (forced breathing), this question of undue bulk of the stomach and intestines as affecting breathing, is essentially one of work. In pleurisy, the breathing is chiefly abdominal, because any movement of the ribs will cause pain to the inflamed membrane which lines the ribs.

As almost all the nitrogen of the broken-up nitrogenous matters of the body is contained in the urine; we can, by making an analysis of that fluid, find out the disintegrating effect which work has on these substances. Contrary to what we might have expected, such an analysis shows that a horse, under ordinary healthy conditions, excretes as much, or nearly as much, nitrogen along with his urine during rest, as he does when in fairly strong work. The expenditure is increased to some extent during severe and continued labour, and in a marked manner during extreme starvation. Work has a far greater effect in reducing the bodily fat than in breaking up nitrogenous tissue, the larger portion of which consists of muscle (the lean of meat). Besides, no advantage is obtained, from a working point of view, by increasing beyond a narrow limit the quantity of nitrogenous matter in the food. On the other hand, the amount of starch, sugar, and fat which the animal can eat with benefit, is proportionate to the severity of his work. Although horses cannot, like carnivora, digest a comparatively large quantity of fat, fat is a necessary constituent of their food, and cannot be wholly replaced by starch, sugar, or nitrogenous matter without injury to the animal's health. The large percentage of fat in oats and maize undoubtedly enhances the value of these grains as foods for horses.

When animals are deprived of food for a long period, there 
is an abnormally large expenditure of bodily fat, which has to furnish as far as it can, the actual energy required for the work of the body and for the maintenance of internal heat; but the variation in the excretion of nitrogen in the urine is trifling, until the store of fat has been practically exhausted, and then a rapid waste of nitrogenous tissue ensues up to the time of death. It therefore appears that the chief feeding value of nitrogenous matter in the food is to build up tissue ; and that of starch, sugar, and fat, to furnish energy to the body. This conclusion as to the building up of tissue being the principal office of nitrogenous food, is supported by the experiments made by Sanborn and Henry on growing pigs ; for those which were fed on food rich in nitrogen had larger muscles and stronger bones than those fed on food rich in carbo-hydrates, but poor in nitrogen. These deductions are amply borne out by the results of practical experience; for we all know that a horse cannot undergo severe and prolonged exertion successfully, unless he has been fed for some time previously on a highly nitrogenous diet, or, to use a stable expression, has had plenty of corn " put into him." We also know that old horses which have been at grass and without corn for some months, take a long time to regain their former working condition; and that the best way to prevent them, when at grass, from losing muscular strength and staying power, is to feed them on a fair amount of corn. Supposing that a hard-working animal has his muscles fully developed, he will manifestly be in greater need of food which is rich in energy-producing material, than of a diet rich in nitrogen; especially when we take into consideration the comparative permanency of nitrogenous tissue. This statement would, I think, lead us to the conclusion that highly nitrogenous foods, such as beans and peas, are more useful for horses which are low in muscle, whether they are at work or idle, than for hardworked muscular animals. 
Bunge states that "the food must be more abundant in carbo-hydrates in proportion to the work performed by the muscles, and more abundant in fat according to the lowering of the surrounding temperature." From what has already been said, we know that both work and the maintenance of the internal temperature demand the expenditure of energy. The nitrogenous matter of food can be utilised by the system to some extent for supporting the internal temperature and for forming fat, as it contains the necessary carbon and hydrogen to become oxidised. Its fat-forming and heatdeveloping power is, however, much more feeble among vegetable feeders, like the horse, than among the carnivora, whose normal amount of fat and internal temperature can be sustained on a diet of lean meat, which consists practically of nitrogenous matter. Starch and sugar, as we have seen, are capable of forming fat in the system, but not so readily as food-fat, which can become absorbed and deposited in the tissues without having to undergo any chemical modification. Vegetable feeders, like the horse, have far less power of absorbing fat from food than carnivora, which in a state of nature consume little or no starch or sugar.

Professor Ugolino Mosso has shown by experiments he made in the University of Genoa on fasting animals, that sugar is far more efficacious than starch or albumen in raising the internal temperature, when, owing to deprivation of food, it has fallen below its normal standard. This good effect of sugar is particularly well marked in cases of extreme heat depression from long fasting, and is in accordance with the fact that energy is much more readily supplied to the body by sugar than by the other two substances. The amount of sugar given with the object in question, varied from .I to .4 per cent. of the animal's weight, namely, I to $4 \mathrm{lb}$. for a horse weighing $\mathrm{I}, 000 \mathrm{lb}$.

Lawes and Gilbert have proved by experiment, that the 
feeding values of starch and cane sugar are almost identical. Müntz has shown that starch and sugar are almost entirely digested by horses, and that the carbo-hydrates of grain are much more soluble than those of hay, and especially, of straw.

The carbo-hydrates and fat in the food not only build up fat in the tissues and furnish energy in other ways, but they also retard the waste of nitrogenous tissue (muscle, etc.). We can easily understand that with a food poor in carbo-hydrates and fat, the demands of the system may entail increased waste of nitrogenous tissue.

The fact that fat horses can live far longer than thin ones, when both are deprived of all food except water (p. I27), shows that a food rich in fat-formers supplies much more energy than a food rich in muscle-formers.

It is a matter of common knowledge that the fat of pigs and cattle, used for human food, varies greatly in appearance and flavour, according to the food upon which the animals have been respectively fed. The differences in question seem to be principally due to the fact already mentioned, that a certain amount of the food-fat becomes absorbed and deposited in the tissues while undergoing little or no change. The experiments alluded to in the following extract from Henry's Feeds and Feeding, confirm this view : "Lebedeff and Munk fed a dog mutton suet, and later rape oil, for a long time and in large quantities, and found that the fat deposited in the body was more like mutton suet or rape oil in its chemical properties than normal dog fat. Munk showed that neutral fat may be formed in the animal body resulting from the feeding of free fatty acids. He fed a starved dog lean meat and a large quantity of fatty acids prepäred from mutton suet. The animal, which had shrunk 32 per cent. in weight during nineteen days, was fed 3,200 grams of flesh and 2,850 grams of fatty acids in fourteen days, and increased I7 per cent. in weight during this period. When killed 
a well-developed layer of fat was found under the skin, and also large deposits of fat on the internal organs. By the use of the knife, I, IOO grams of fat were separated, which resembled mutton suet, and according to chemical analysis must have contained at least 96 per cent. of neutral mutton suet. It is well known that fatty acids are formed from the fat of the food in the digestive processes through the action of the pancreatic juice, and the above experiment therefore practically proves that the fat stored in the bodies of animals may be derived from the fat of the food. Munk's findings have recently been corroborated by Walker, also in experiments with dogs."

Woody Fibre in passing through the stomach and small intestine suffers but little change, and although it becomes, as we have seen, partly broken up in the large intestine, the process of its chemical alteration cannot be regarded as digestion, for the products of its decomposition are not nutritious; hence it has little or no nutritive value for a horse. Its presence in food is, however, an indispensable aid to digestion, apparently by separating the nutritive particles from each other, so as to allow the digestive fluids to readily permeate through the entire mass. Bunge remarks that "cellulose [fibre] is absolutely essential to animals with a long intestinal tract. If rabbits are fed on a diet containing no cellulose, the onward movement of the intestinal contents ceases, inflammation in the intestines ensues, and the animals rapidly die. But if horn-parings be added to the same food, nutrition is normal. These hornparings are, as Knieriem proved by experiments devoted to that purpose, absolutely undigested, and can therefore only have taken the place of woody fibre in so far as its mechanical properties were concerned." To sum up the matter, we may say that the alimentary canal of a horse is not suited for the digestion of concentrated food; in other words, that unless the nutritive matter of a horse's food is diluted by a more or 
less inert vehicle, of which vegetable fibre is the natural and best form, disturbance of the digestive organs will ensue. The mechanical action of fibre in this respect is generally put down to its bulk-giving properties, on the supposition that a horse is unable to digest a food that is not bulky. We know that absence of concentration is more essential than bulk; for if an animal is put on, say, the starvation and non-bulky diet of 2 quarts of ordinary oats and 2 quarts of chopped hay, he will digest it in a normal manner; although in all probability his digestion would be upset by double that bulk (8 quarts) of oats from which the husk (mostly woody fibre) had been removed. We find that the wholesomeness (p. 72) of different samples of oats varies according to their respective percentages of husk, other conditions being equal, when this grain is given without other food; and that, in such a case, a horse can consume in a healthy manner a moderate quantity of oats which has a fair proportion of husk, but is unable to do so if the husk is absent. Again, maize, which has almost the same composition as oats, except that it contains less fibre and mineral matter, requires for its healthy digestion the addition of more "chop" than do oats. In fact, by adding fibre to maize (for instance, by grinding up the grain and cob together, so as to make the fibre percentage of the mixture about equal to that of oats), we can render maize nearly if not quite as wholesome a food as oats. It is evident that the arrangement by which each kernel of oats is surrounded by a comparatively thick covering rich in fibre, greatly promotes the wholesomeness of that grain. The custom of mixing chopped hay with oats has long been an unconscious recognition of the truth of the principle in question, which principle is also more or less carried out when the animal is allowed hay at feeding time.

From the foregoing observations we come to the important law, that the percentage of fibre in a horse's hay should be 
proportionate to that of the easily digestible nutritious matter of the corn. Highly-fed hunters have so clearly demonstrated the correctness of this principle, by manifesting their appreciation of a feeding material rich in fibre, that "hard hay" and "hunters' hay" have become synonymous terms. As the digestion of hay demands the expenditure of more energy than that of grain, it is better for a working horse to obtain the nutritious portion of his food from the latter than from the former kind of fodder. Hence the larger the ration of corn, the richer in fibre (i.e. the more innutritious) should be the hay or chop. When the supply of corn, and consequently that of easily digestible nutritious matter, is small, the hay given to a working horse should be rich in nourishment and comparatively poor in fibre, as we find with hay which has been made from young, good grass, and which has been well saved.

The amount of fibre, like that of water in food, greatly increases the weight as well as the volume of the contents of the stomach and intestines, as Wolff shows us by the following results of experiments with sheep :-

Fodder.

Contents of stomach and intestines as percentage of live weight.

Chiefly straw . . . . . . . . . 22.3

Hay with a little beans . $\quad . \quad . \quad . \quad . \quad . \quad 15.7$

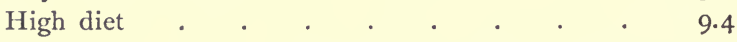

From this we may reasonably infer that the difference between the weight of the contents of the stomach and intestines of a horse fed on food rich in woody fibre, like hay and straw, and that of the same animal when fed principally on corn, might easily amount to 8 per cent. of the entire bodily weight, which difference in the case of a horse weighing $\mathrm{I}, \mathrm{OOO} \mathrm{lb}$. would be $80 \mathrm{lb}$. The woody-fibre method of feeding would therefore force the animal to carry this amount of extra weight without any corresponding gain. In fact, as we have already 
seen, the advantage in muscular strength would be all the other way. Also the work of digesting hay, to take it as an appropriate instance, necessitates, according to Zuntz and Lehmann, the expenditure of II.2 per cent. of the energy produced by the food; and oats, only 2.8 per cent. Furthermore, the large size of the stomach and intestines would greatly interfere with the animal's powers of breathing during severe labour.

The fact that food rich in fibre necessitates for its mastication the secretion of much more saliva, and consequently the drinking of more water than does corn, accounts to a great extent for the marked effect which its consumption has in increasing the weight of the contents of the stomach and intestines.

Among mineral matters, phosphoric acid, potash, soda (mostly as common salt), lime, and iron play the most important part in nutrition. Phosphoric acid, potash, and iron are plentiful in hay and corn, in both of which the percentage of soda is less than the requirements of the system. In the entire body of the higher animals, the quantity of potash is about equal to that of soda. Blood contains much more soda than potash; and bloodless meat, more potash than soda. Lehmann tells us that the mixture of blood and flesh which carnivorous animals consume, contains about three times more potash than soda. On this diet, these animals show no craving for common salt; neither do human beings who live almost exclusively on meat. But persons who live principally on potatoes, which contain a large percentage of potash and little or no soda, eat salt with great relish and find that it is necessary to their health. Horses, whose ordinary mixture of hay and corn contains a comparatively small amount of soda, also crave for salt, and salt added to their food has an obviously good effect on their condition. In the food of plant-eaters (horses, for example), there appears to be an excess of potash, which tends to irritate the mucous mem- 
brane of the alimentary canal. A portion of the common salt in the system is used up in eliminating potash from the body. Thus, as explained by Bunge, if a salt of potash, such as carbonate of potash, meets common salt (chloride of sodium) in solution, a partial exchange will take place by the formation of chloride of potash and carbonate of soda; the chloride of potash being excreted by the kidneys, as it does not enter into the composition of the tissues or fluids of the body.

Common salt stimulates digestion and all the other vital processes of the body. The soda of the body, of which the common salt of the food is the chief supplier, performs many offices in the nourishment and purification of the system. By combining with carbonic acid in the blood, it forms bicarbonate of soda, and thus helps to prevent the blood from becoming overcharged with that hurtful gas. Lehmann points out that an excess of carbonic acid in the blood tends to redissolve the lime salts deposited at the growing ends of bones, or prevents the precipitation of the lime salts. In agreement with this theory, Wachsmuth contends that an accumulation of carbonic acid in the blood is a cause of rickets. As cartilage is much richer in soda than bone, and as young animals have much more cartilage in their bodies than mature ones; they will need more soda in their food, and consequently more common salt. According to Gabriel, bones and teeth respectively contain 8 to $\mathrm{I} 2$ and I to 3 per cent. of soda and potash. They require a large amount of soda to neutralise the acids which might attack them. We all know that the formation of bones and teeth is particularly active in young animals.

The consumption of too much salt causes a large discharge of urine, irritation to the kidneys, and abnormal thirst, with a consequent watery condition of the blood, from which the nutrition of the system suffers. If drinking water be withheld, water 
will be drawn from the tissues, a portion of which will on that account become broken down. These untoward results will occur only when the quantity of salt which has been consumed is very large; for with a plentiful supply of drinking water, the kidneys rapidly eliminate salt from the system.

The amount of soda in soil varies greatly, and consequently the percentage of soda in plants and also in the animal body is of too variable a nature to permit of our making exact calculations for determining the amount of salt which should be added to a horse's food, so as to adjust the proportion which the soda should bear to the potash. We may, however, base an approximate calculation on their proportion in milk, namely, about $2 \mathrm{I} / 2$ parts of potash to I part of soda. Take, for instance, the case of meadow hay, which, according to Warington (Chemistry of the Farm), contains 28.8 oz. of potash and 5.2 I oz. of soda in. every $100 \mathrm{lb}$. Here the proper amount of soda, taking milk as a standard, should be I I.52 oz. ; the deficiency being consequently 6.3 I oz., which is made up of $4.68 \mathrm{oz}$. of sodium and 1.63 oz. of oxygen. To supply the missing $4.68 \mathrm{oz}$. of sodium by means of common salt (sodium chloride), we shall require II.9 oz. (say I 2 oz.) of that mineral. Supposing, therefore, that we give a horse an inclusive daily ration of $30 \mathrm{lb}$. of meadow hay, we ought to add to it about $3 \frac{1}{2} \mathrm{oz}$. of common salt; or at least I oz. for every Iolb. of meadow hay. Church (Food Grains of India) tells us that "the due admixture of food-grains belonging to different classes will secure the necessary mineral ingredients, provided an allowance of at least 230 grains of common salt be added to the daily ration of a man having a body weight of I05 lb." This would be equivalent to about $5 \mathrm{oz}$. for a horse weighing I,000 lb. Church also states that "the amount of salt consumed per head per day in the Bombay Presidency just exceeds $1 / 2$ oz. ; in Sind it is calculated to be a little more than $1 / 4$ oz." I draw attention to these Indian statistics, 
because salt being an excisable article in India, the amount of its consumption can be obtained with a fair degree of accuracy, and as the vast majority of the inhabitants of that country are very poor, they are forced to practise rigid and often unhealthy economy in its use. These comparative considerations will, I think, support my contention that a horse fed exclusively on hay or grass should have a daily supply of not less than $31 / 2$ oz. of common salt. Continuing this line of calculation, we are enabled to construct the following approximate table:-

Nature of fodder.

Oats, maize, and barley

Beans, peas, and gram

Meadow hay.

Red clover hay
Approximate amount of common salt required to be added to each roolb.

Lime is required chiefly for the building up of bones, which process is active in young animals, but is slow in adults, because bone is a comparatively stable tissue. Lime is far more easily absorbed from vegetable food than when given as a mineral addition to the food, as for example, in the form of limewater or chalk. Hence, if the soil that produces grass which is given to young horses is poor in lime, it is well to make up the deficiency through the grass by manuring the ground with bone manure or lime. Soluble phosphate of lime is the form in which an artificial supply of lime is most easily taken up by the system.

As maize is poor in lime and other mineral matters, it is not a suitable food for young horses; although it answers fairly well for adult horses. Oats are much richer in lime than maize, barley, or wheat. Hay, and particularly lucerne hay and clover hay, contain a large percentage of lime.

Deficiency in the mineral matter of food is not an unfrequent 
cause of ill-health or at least want of vigour in horses, which in such a case will evince their craving for the substances of which they are in need, by licking the plaster off walls, eating dirt, and preferring muddy water to clean water to drink.

We learn from the experiments made by Henry on growing pigs, that an addition of bone meal to the food greatly increases the strength of the bones. A similar result, though to a lesser extent, was arrived at by an addition of wood ashes. These experiments lasted from 84 to I 28 days. In II 2 days, two pigs consumed $10 \mathrm{I} / 2 \mathrm{lb}$. of bone meal and $7 \mathrm{I} / 2 \mathrm{lb}$. of salt ; and in the same time, two other pigs consumed $33 \mathrm{lb}$. of hard wood ashes and $8 \mathrm{lb}$. of salt.

Attention may with advantage be directed to the fact to which I have tried to give prominence in the foregoing pages, that the quality of the muscles, tendons, ligaments, bones, fat, and other tissues greatly varies according to the food upon which an animal is fed. Although we all know that this is the case in butcher's meat, some are inclined to think that for working purposes "bone is bone" and "muscle is muscle," whatever has been the food upon which they have been produced.

\section{NUTRITIVE RATIO OF FOOD.}

The "nutritive ratio" of a food is the term used to express the proportion which exists between the nitrogenous matter of the food and the other energy-producing constituents, namely, the starch, sugar, and fat. As fat is calculated to possess 2.3 times the energy-giving properties of sugar and starch, the weight of the fat is multiplied by 2.3. Thus, taking the analysis of oats given on page 62 , we find that the nutritive ratio of that grain is- 
The nutritive ratio of beans would be-

That of maize-

$$
\begin{gathered}
25.4 \text { to } 48.5+\mathrm{I} .5 \times 2.3=5 \mathrm{I} .95 \\
\text { I to } 2 \text { (about). }
\end{gathered}
$$

$$
\begin{gathered}
\text { I0.3 to } 70.4+5 \times 2.3 \\
\text { I to } 7.9 \text { (about). }
\end{gathered}
$$

Experience shows that the nutritive ratio of oats is practically correct for the usual requirements of horses. Hence, in the combination of grains for the food of these animals, it is generally advisable to try to obtain a mixture which has a nutritive ratio somewhat similar to that of oats.

APPETITE AND DIGESTIVE POWER.

Appetite (hunger or craving for food) is the instinct which prompts an animal to eat. As it has become developed in the species under the natural condition of the animal having to find his own food with more or less difficulty; we may conclude that it is a more reliable guide to the selection of suitable food when the horse is in full exercise, than when he is idle. Hence we find, that although in almost all cases it is safe to allow a horse an unlimited supply of oats and hay, with free choice between the two, when he is in very hard work, it is highly dangerous to be equally indulgent when his physical powers are not taxed. We should here take into consideration the nature of the forage; for his food in the open is not presented to him in a form so concentrated, and consequently so liable to upset his digestion, as it is in the stable; and besides, it is very rarely as palatable as thrashed oats, for instance. The general wants of the system and a more or less empty condition of the stomach appear to be the essential stimuli of hunger (appetite), which can be allayed, as has been shown by experiment, by the introduction of food into that organ through an artificial opening. Appetite is also excited by external impressions connected with food, as we may note when the idea of food presents itself to the horse by his sense of smell, taste, 
feeling, seeing, and even hearing, which excites the cavalry trooper to neigh and paw the ground when the trumpet sounds "feed!" In such cases, the stimulus is not confined only to the appetite, but also extends to the entire digestive apparatus ; hence the value of flavour by odour and taste.

In order to avoid excess under the promptings of appetite, we should try to make our horses eat slowly. Carpenter remarks : "To eat when we are hungry, is an evidently natural disposition; but to eat as long as we are hungry, may not always be prudent. Since the feeling of hunger does not depend so much upon the state of fulness or emptiness of the stomach, as upon the condition of the general system, it appears that the ingestion of food cannot at once produce the effect of dissipating it, though it will do so after a short time; so that, if we eat with undue rapidity, we may continue swallowing food long after we have taken as much as will really be required for the wants of the system; and every superfluous particle is not merely useless, but injurious." These observations apply with greater force to horses than to ourselves; for the size of the stomach as compared to that of the intestines is much smaller in them than in us, and besides, they are unable to relieve by vomiting, an overcharged condition of the stomach.

Appetite guides ourselves as well as horses, not only as regards the amount, but also in the selection of food suitable to the requirements of the body. Thus, men who habitually work hard, such as navvies, miners, and sailors, can eat with benefit a quantity of fatty food, from which a person leading a sedentary life would turn with loathing. We here see the good effect of healthy exercise in promoting the power of digestion, and in increasing the appetite, the activity of both of which functions is lowered by severe work, as we may judge from the fact that the appetite of racehorses in training generally becomes capricious when they are kept at "concert pitch" for too long a period. 
The following results were obtained by Grandeau and Leclerc from carefully made experiments on horses :

Comparative amount of food digested.

$\begin{array}{lllllllll}\text { At rest } & . & \cdot & . & . & . & . & . & 1000 \\ \text { Walking exercise } & . & . & . & . & . & . & . & 1032 \\ \text { At work, walking } & . & . & . & . & . & . & . & 1007 \\ \text { Trotting exercise } & . & . & . & . & . & . & . & 976 \\ \text { At work, trotting } & & \cdot & . & . & . & . & . & 973 \\ \text { At work in cab } & . & . & . & . & . & . & . & 959\end{array}$

In ministering to the requirements of the system, we should be careful to act in agreement with the order in which the functions of nutrition stimulate each other. Thus, if the power of taking up nourishment by the body be more or less in abeyance from the effects of fatigue or illness, it would be manifestly injurious to tempt the appetite or to excite the digestion. On the contrary, the only safe procedure in such a case will be to promote the removal of the cause of the functional torpidity, and when that has been accomplished, the healthy stimulation of digestion and appetite by the demands of the tissues will put the animal machine into perfect working order, supposing that the food and the manner of its supply are suitable. To briefly illustrate this point, to which I shall refer more fully later on, I may say that instead of forcing food on a horse which is "off his feed" from overwork, and giving him stimulants, it is much better to content ourselves with allowing him a full supply of drinking water and some green food or carrots, so as to facilitate the removal from his system of the deleterious products that are the cause of his depression. When they have been excreted, his tissues will demand materials for repair, with the result of healthy general stimulation.

The craving for change of food depends, as a rule, on the 
fact that the fodder habitually consumed is not sufficient for the requirements of the system. In this case, the condition of the food-its being too dry, too hard, or too moist-or the proportion or number of its constituents or elements will probably be at fault; for in health, the nearer the food is to perfection, the less will be the desire for change. Thus we find that the craving for vegetable food evinced by a foal increases with age; and that many species of animals live almost exclusively on one particular kind of diet. Although the horse in a state of nature might appear to be a one-food (a solely grass-feeding) animal, grasses differ from each other in their nature and composition. A study of the tables on pages 62 and 63 shows that deficiency of constituents in one food may be supplied by feeding on other foods. As regards the food of the horse, the transition from a state of nature to life under civilised conditions is chiefly one from green food to dry food, and from food poor in nitrogenous matter to one rich in that constituent. The means for remedying any ill effects to health from such a transition are selfevident. It goes almost without saying that, as a rule, the less the desire shown by a horse to change his food, the more suitable will it be to meet his requirements, supposing that he is in strong work.

COMPARATIVE NUTRITIVE VALUES OF DIFFERENT FOODS.

Supposing that a horse has a full supply of water and oxygen, we may regard the nitrogenous matter, carbohydrates, fat, and mineral matter of his food as its nutritive constituents. If when comparing two foods, we find that each of them is richer than the other in different constituents, it will be impossible for us to say which has the higher nutritive value; because these respective constituents have their own special work to perform, and their importance to the body varies according to circumstances, such as those of work, age 
and climate. We cannot therefore express the nutritive value of a food by a formula; but must be content to estimate it by general considerations.

CAUSES AFFECTING THE NUTRITIVE VALUE OF VEGETABLE FOOD.

I. Age.-With age, the percentage of nitrogenous matter in plants decreases, and that of woody fibre increases. We cannot, however, assume that the nitrogenous matter in young plants is always as valuable as that in older ones. Dr. Voelcker points out that unripe roots are poorer in sugar than mature roots, and that they contain hurtful organic acids (notably oxalic acid), and imperfectly elaborated nitrogenous matter, which are the cause of their being unwholesome. Therefore, in choosing the period of growth for economically utilising those plants which our horses consume as a whole (e.g., grass and clover), we should try to select the happy medium between a maximum of nutriment and a minimum of woody fibre, which as a rule will be obtained in the making of hay from the plants in question, by cutting them during the period of flowering and not later than the first appearance of seed. Further maturity will undoubtedly entail loss in the nutritive constituents of the stalk and leaves, and an excess of woody fibre in them. When plants, like oats, in the ordinary way, are grown for their grain, the nutritive value of their other parts is not considered.

2. Conditions of Growth (climate, soil, manure, moisture, etc.). - The respective percentages of the constituents of plants vary greatly according to their conditions of growth. For instance, hay made from grass grown on rich land, highly manured, and well supplied with moisture, will contain a larger percentage of nitrogenous matter than that made from similar grass produced under less stimulating influences. The nitrogenous matter of the former will, however, be less nutritive as 
a rule than that of the latter; for the more time is allowed for development, the more complete will be the changes that are necessary to make the constituents of the plant digestible, and to develop those vegetable principles which give flavour to the fodder. It appears that the percentage of fibre is proportionate to the luxuriance of growth. It is a fact of every-day knowledge that fruit which has become ripe in the open air, is more wholesome and better flavoured than similar fruit which has been forced. In the growth of tea we have an admirable instance of the good influence of time in the production of agreeable flavour and in reducing the amount of deleterious constituents. Thus we find in the case of Indian tea, that the slowly growing hill leaves of Kangra Valley, Kooloo and Darjeeling are far superior in aroma to the luxuriant lowcountry leaves of Assam, and that they possess a smaller percentage of compounds which, like tannin, have a hurtful effect on the digestive organs.

The necessity of a full supply of solar heat in the production of fodder for horses, is well shown by the fact that doob grass (creeping dog's-tooth grass ; cynodon dactylon), which is the best Indian grass, is grown on dry and poor sandy soil, over which it usually spreads more or less as a creeper. When, on the contrary, it is well watered, it springs up luxuriantly like other grasses, but is not as nutritious as when its growth has been retarded by lack of moisture. The foregoing observations and the knowledge that the digestive organs of the horse are not fitted for the reception of large quantities of coarse fodder, point to the conclusion that grass grown in the shade, or under the influence of stimulating manures, is not a good food for horses. The presence of lime in grass lands, whether naturally or by the addition of bone manure or lime, is an advantage, especially in the rearing of young stock; for the proportion of lime in grass grown on such land is much higher 
than that in grass produced on soil poor in lime. Soil, climate and manure are such important factors in the production of fodder, that inferior varieties of grass, which are well nourished without being coarse, are superior as a food for horses to the best varieties that are starved or luxuriant.

Harvesting.-The mere drying of grass which is necessary to render the resulting hay capable of being stored, in no way affects the digestibility of the hay; but the carrying out of this process may be accompanied by changes which give rise to more or less nutritive loss, and which should consequently be kept in check as much as possible during harvesting.

The action of wet on grass and straw which have been cut, is to more or less dissolve out the soluble nutritive constituents, and to render the nitrogenous matter less digestible. "The amount of depreciation which hay undergoes in a rainy harvest is proved by the fact that 20 per cent. by weight of its dry substance is lost by simply soaking in cold water. Stöckhardt examined two kinds of hay, both taken from the same meadow and mown at the same time. One sample had been dried in three days and was housed in its best condition; the other had been left lying in the fields in alternately wet and dry weather for thirteen days before it could be gathered in. Analysis proved that the hay which had been left in the rain had lost I 2.5 per cent. by weight of the total dry substance, representing at least a quarter of its original nutritive value, since the loss consisted entirely of the more easily soluble, and therefore especially valuable nutrients (2.I parts of albuminoids and I0.4 of non-nitrogenous nutrients and mineral salts). After chemical examination in two instances, Marcker calculated the loss of meadow hay through prolonged and heavy rain at I8.4 and 17.6 per cent. of the dry substance. The preparation of clover hay in unfavourable weather is a frequent source of deterioration, for this fodder suffers from rain even more than 
meadow hay, as from 25 to 40 per cent. of its dry substance can be dissolved in cold water" (Farm Foods).

Growing plants possess a waxy varnish which acts as a protective covering against damp. When the plant dies on being cut, the varnish, if exposed to the action of moisture, soon becomes dissolved, and then washed away. The bruising and rough handling of hay in making and storing is a cause of nutrient loss: for such treatment exposes the softer and more porous inner structure of the plant to the hurtful action of fermentative germs aided by moisture; and inflicts further damage by breaking off a more or less considerable portion of the leaves and other soft parts, which, as we have seen, are far richer in nitrogenous matter than the stalks. Any "heating" (fermentation) which cut fodder may undergo is accompanied by loss of nutritive material. Some of the starch becomes turned into sugar, then into alcohol, if the fermentation is continued, and finally into water and carbonic acid, which escape into the atmosphere in the respective forms of vapour and gas. By this loss, the percentage of fibre in the hay becomes increased. In all cases, any musty smell from either hay or corn will show that the fodder, having become attacked by hurtful bacteria, is more or less unfit for consumption.

As a rule, the more hay is heated in the rick, the browner will it become. Also, before being stacked, it is liable to lose its original green colour from the action of wet on it after it has been cut. Owing to the increase of sugar and possibly to the formation of certain fragrant principles which improve the taste of the hay, we find that horses sometimes prefer brown hay to well-saved green hay, although the former is manifestly of inferior feeding value to the latter; supposing, of course, that the two samples of hay have been made from similar grass. As we have already seen (p. 96 et seq.), the increase in the percentage of fibre in hay, owing to the loss of nutritive constituents, may be no dis- 
advantage to the horse, supposing that this loss is fully made up by corn. Although, when economy has to be studied, all nutritive loss should be guarded against, I am inclined to think that horses managed on a liberal scale might with advantage have their appetites humoured in this respect, especially when they are hard worked. The change from green to slightly brown hay should of course be made only in the event of the horse preferring the latter to the former. It is probable that with even the best saved hay a certain amount of fermentation, which may be so slight as to cause hardly any appreciable change in the colour of the hay, occurs in all cases when hay has been stacked for some time, and that without it the hay would be wanting in aroma. The conversion of new hay into old hay, appears, therefore, to consist of the further drying of the hay and of the development of flavour ; and in ordinary circumstances it may be considered to be complete by the end of January. Hay, even when stored in the most careful manner, suffers continued nutritive loss from slow chemical changes going on in it, and from the breaking off of its leaves; and as its fragrant principles are volatile, it becomes less sapid after they have become fully developed. My experience leads me to believe that "new" hay, even in February, is superior to that which is a year older, other conditions being equal.

Deprivation of water is a well marked advantage gained by corn from keeping. It is evident that the dryer the grain, the more readily will the digestive juices penetrate it, and consequently the more easy of digestion it will be. The fact that properly stored corn has been known to retain its vitality for many years, is a proof that it suffers little or no deterioration from careful keeping. Corn which has been stored, even under the most favourable conditions, appears to undergo a certain amount of fermentation, if we may judge by its change of smell, and by the increase of dust in it. Hurtful fermenta- 
tion injuriously affects the feeding value of the grain, and may be recognised by the musty smell it imparts to the corn and to the great increase of dust, owing to its action on the surface of the husks. To prevent such fermentation taking place, the corn should be kept dry and well ventilated. A year and a half will generally be sufficient for the thorough drying of corn.

There are various forms of fermentation which are respectively produced by special bacteria. As moisture favours the growth and development of these minute forms of vegetable life; the dryer hay and corn are kept, the less chance will they have of being injuriously affected by fermentation.

\section{STOWAGE OF FORAGE.}

As damp is the great thing to be avoided in the keeping of hay and corn, they are best stowed in a loft and not on the ground floor. The loft should of course be dry and well ventilated, and if over a stable, it should be carefully protected from foul emanations which might arise from below. The corn is best kept, particularly if it has not been very well saved, when it is spread out in a layer on the floor, and turned over with a shovel at suitable intervals of time, in order to prevent it from heating. Naturally, this precaution need not be observed when the expenditure is rapid compared to the frequency with which the supply is replenished. As hay, like corn, keeps best in the original stack, provided the stack is efficiently sheltered from inclement weather, by for instance a good thatched roof; it will generally be advisable for an owner in the country to get a load freshly cut from the stack, as he may require it. If he buys his forage from a local corn-dealer, he can get it as he wants it, without having to make any special arrangements about the stowage. A man who grows his own oats, had best keep them in the stack, until he wants to thrash them. 


\section{CLEANING OF FOOD.}

The cleaning of corn is a point of stable management to which special attention should be paid; because foreign substances in the food are apt to give rise not only to ordinary digestive disturbances, but also to the formation in the intestines, of calculi and concretions, which are very often fatal to their bearer. "Experience amply proves that the presence in the horse's food, of indigestible particles, especially if they be of an irritating nature, is a fertile cause of calculus. The frequency of this complaint in the stables of many large firms has been greatly diminished by the adoption of means for the removal of such possible nuclei. One of the best preventives is the use of an automatic separator provided with magnets, which attract and thus remove all particles of iron and steel from the corn passed over them. In small stables, the careful use of a sieve is imperative. Rogerson has pointed out that in foreign corn, among other sources of danger, are to be found numbers of nails and heads of nails which are employed to tack down the canvas that lines the holds of vessels which carry the corn in bulk. . . . Hunting mentions that the indiarubber ring of a mineral water bottle formed the nucleus of a calculus which he examined on one occasion. . . . There is some evidence to show that forage which contains a quantity of the hairs and husks of oats, or meal dust, is liable to give rise to intestinal concretions, which are hardly ever found among animals whose food is carefully looked after" (Veterinary Notes for Horse-Owners). See page I 58.

\section{PREPARATION OF FOOD.}

Although boiling and steaming vegetable food tend, like the action of the digestive juices, to render it soluble; they bring about its more or less complete saturation with water, which is 
such a serious disadvantage that the application of these processes to the preparation of the food of horses should, as a rule, be restricted to the corn of sick horses or to that of animals which need a change of diet.

Steaming is manifestly less objectionable than boiling. Either of these processes might be used with certain very hard grains, such as kulthee (p. I70); but even in their case, the necessity of employing moist heat does not appear to be conclusively proved. The presence in oats of a cellulose dissolving ferment (p. 68), shows that the application of a temperature higher than $126^{\circ} \mathrm{F}$. impairs the feeding value of sound oats; although heat, as in kiln-drying, might improve the quality of musty oats by killing the mould germs. I have found when feeding horses on barley in India, that parching improves that grain as a food for these animals. By the process of drying, it enables the digestive fluids to more easily penetrate the grain. The application of artificial dry heat, as in parching and baking, acts to a certain extent like the natural process of ripening, in forming sugar. A good instance of this is afforded by the sweetening effect produced on sour apples by baking.

My experience in countries where the soaking in water of grain given as food for horses is generally adopted, has convinced me that this practice is hurtful to digestion; because it not only saturates the grain with water, but also facilitates the swallowing of the food before the grain has been fully masticated. Gram in India and maize in South Africa are the chief grains that are soaked in water before being given to horses. Both are best prepared by being broken and by being given $d r y$ with bran, chop, or, in the case of maize, with the cob cut up. Bruising is specially applicable to oats, as it increases the difficulty of swallowing this grain without thorough mastication, and by breaking its husk it exposes the interior of the grain to the full 
action of the digestive juices. Owing to the smoothness of the surface of almost all the grains given to horses, they can be much more easily swallowed without being properly masticated, when given whole, than when bruised; hence the advisability of this process. If the horse was in a state of nature, the covering of the grain would oblige him to chew the ear, cob, or pod before he could swallow its contents. There can be no question as to the advantage of bruising oats and other grain for old horses, and for those whose chewing powers are impaired. Colin, however, maintains that in ordinary cases the bruising of corn does not improve the digestibility of grain. Nevertheless we find that in the experiments from which he drew his conclusions, the period of mastication was $4 \frac{1}{2}$ per cent. longer, and the amount of saliva secreted was I7 per cent. greater with bruised oats than with whole oats. I have found, especially in training racehorses, that horses do better on the former than on the latter food. I feel strengthened in this conclusion by the fact that when such animals are fed on bruised oats, less husk is found in their dung than when they are given whole oats. Leaving oats out of the question, there is no doubt that the crushing or coarse grinding of many kinds of grain-maize and barley, for instancegreatly improves their digestibility and wholesomeness.

Muintz (Recherches sur la Digestion des Fourrages) has proved by experiment, that when uncrushed oats are given by themselves, a certain percentage is passed out in an unchanged condition along with the dung; and that this loss of nutritious material can be almost entirely obviated by bruising. He also found that this loss, in the case of unbruised oats, can be prevented to a great extent by mixing the oats with other forage, such as chop or bran. $\mathrm{He}$ observed that the digestibility of maize and beans was not injuriously affected, like oats, by the fact of their being given 
alone; probably because their husk is not so resistant as that of oats.

The breaking or grinding of grain should be strictly limited to that which is sufficient to nullify the protective action of the husk; for the smaller the particles of the broken corn, the less will horses relish it, and probably the less saliva will be secreted.

With respect to the cutting $u p$ of hay and straw used for food, we know that chop mixed with corn increases the wholesomeness of the grain, and is economical in checking waste. When hay is given in a quantity that cannot be usually eaten "at one go," it appears best to give it in the form of long hay, which a horse will not contaminate to nearly the same extent by breathing and slavering on it, as he would do with cut hay. Besides, the nature of long hay will make him take more time in mastication, than he would be forced to spend with chopped hay. We cannot, however, say that long hay is a natural food for horses; because hay is an artificial preparation of grass, and horses in a state of nature would rarely get grass as long as ordinary hay.

From practical experience in the feeding of horses on straw chop, cut in the ordinary way, and on straw, broken and bruised in the Eastern fashion (p. I 54), I feel certain that a machine which would be capable of breaking and bruising straw in a manner similar to the latter method, would be a very useful addition to our stable appliances; for its employment would greatly enhance the value of the resulting chop, as a vehicle for the corn. I trust that some capable manu. facturer of stable machinery will take this hint.

FOOD IN RELATION TO WORK.

In order to obtain an adequate supply of material for furnishing energy and for repairing bodily waste, the food must be sufficient in quantity and composition. 
The measure of a horse's appetite is by weight, rather than by bulk. As the feeding value of corn is more than double that of hay, we can, by substituting corn for a portion of the hay, increase the amount of nutrition in the food, without exceeding the limit of appetite. Thus, a daily ration of I9 lbs. of corn and $12 \mathrm{lbs}$. of hay (total $=3 \mathrm{I} \mathrm{lbs}$.) would be theoretically equivalent to at least one of $50 \mathrm{lbs}$. of hay, which would be a quantity far exceeding the eating capacity of an ordinary horse. The consumption of hay takes more time than that of corn (p. 79); it entails a greater loss of energy in chewing and digesting it (p. 99); and causes a horse to drink more water (p. 99), and consequently impedes his breathing powers to a greater extent, by increasing the weight and size of the contents of his stomach and intestines. Hence the necessity of corn for working horses.

As regards the composition of food, we find that the harder the work, the more starch and fat does a horse need, and that little or no increase is required in nitrogenous matter. Consequently, maize is an admirable food for hard-working adult horses; although, as we have seen, it is a poor one for growing animals.

FOOD FOR YOUNG HORSES.

The great difference between the feeding requirements of a young animal and those of an adult, is that the former needs more materials for development than the latter, and that the grown-up animal wants a larger supply of energy in his food, on account of his labour being more severe as a rule. Hence a foal will require a larger percentage of albumen and of boneforming substances than an older horse. This conclusion is supported by the nature of the respective composition of colostrum, milk, and pasture grass. In determining their nutritive ratios, we must take into consideration that about 25 per cent. of the nitrogenous matter of grass consists of 
amides (p. 63), which must be reckoned along with the carbo-hydrates.

As the proportion which the fat bears to the carbo-hydrates in milk is far higher than that in hay and corn, which we may regard as the typical food for mature horses; an addition of fat to the fodder given to young animals is generally advisable, and may be made by means of linseed (p. I62).

The principal materials for development are albumen and lime; the former being needed for all the tissues; the latter, chiefly for bone, the composition of which is as follows :

COMPOSITION OF BONE (Bloxam).

\begin{tabular}{rrrr} 
Fat & $\cdot$ & $\cdot$ & 5.4 \\
Nitrogenous matter & $\cdot$ & $\cdot$ & 28.6 \\
Calcium phosphate & $\cdot$ & $\cdot$ & 56.5 \\
, fluoride . & $\cdot$ & $\cdot$ & 1.2 \\
, carbonate & $\cdot$ & $\cdot$ & 7.3 \\
Magnesium phosphate & $\cdot$ & $\cdot$ & 1.0 \\
\hline & & &
\end{tabular}

Corn is particularly rich in easily digestible albumen; and grass, in phosphate of lime. Respecting the development of bone, Wolff points out, that $\mathrm{I}, 000 \mathrm{lb}$. of oats contain :

6 lb. 13 oz. phosphoric acid

I lb. lime ;

and that $\mathrm{I}, 000 \mathrm{lb}$. of hay contains :

$4 \mathrm{lb}$. phosphoric acid

9 lb. 13 oz. lime.

We may therefore conclude that the more we feed young animals on corn within healthy limits, the stronger will be their muscles and other tissues, but their bones will be wanting in size. This conclusion is strengthened by the fact that the great majority of thoroughbreds which are reared for racing, and which are largely fed on corn, are very light in bone, at least from a hunting man's point of view. When, 
however, thoroughbreds are raised almost entirely on grass, as we often see in Australasia, the bone below the knees and hocks would as a rule satisfy the majority of Leicestershire middle weights. Such bony development would not be desirable in high class racehorses; because large bones and great speed are not compatible, as I have tried to show in Points of the Horse. On the other hand, bone of fairly good size is indispensable for weight-carrying purposes. Some superficial observers think that thoroughbred blood is not capable of producing bone sufficiently large for hunting and cavalry requirements; but we should remember that the physical peculiarities of our racehorses are not due to any racial difference between them and Shire horses, for instance; but to the process of selection and feeding to which they have been subjected during hundreds of years. Any attempt to obtain "bone" in riding horses by the admixture of common blood, is open to the very serious objection, that even its success would be counterbalanced or more than counterbalanced by the introduction of undesirable points of conformation, such as faulty shape of the legs, and heavy shoulders. In a well-built thoroughbred, we have every desirable point in a riding horse, except a sufficiency of bone, which could be obtained by selection and feeding through several generations. If the process of establishing a race of thoroughbreds with sufficient bone for weight carrying hunters and troopers would be too slow for private enterprise, it is eminently worthy of the attention of the State. This suggestion is of course made with reference to military and hunting requirements, and not to those of racing.

Grass to produce compact and well developed bone, requires to be grown on dry land rich in lime. "A good sound limestone soil always produces bone" (Pallin). The soil of Norfolk is dry and rich in lime. "You rarely see bandy-legged children in Norfolk, and the bones of Norfolk-bred horses are 
very hard and serviceable" (Sapwell). Lucerne is an excellent food for young horses; for it contains a large percentage of lime. Naturally, it will not thrive unless its roots can obtain a plentiful supply of lime.

The foregoing remarks specially apply to the feeding of young saddle horses and young horses of general utility, in both of which classes bone is the chief requirement. As soil which confers compact bone is not suitable for the production of great height and immense bodily weight, both of which are essential conditions in high-priced Shires; these massive giants cannot be raised on the dry limestone districts of Ireland, or in Norfolk. The Fens suit them better.

\section{ILL EFFECTS OF TOO MUCH FOOD.}

The principal ill effects produced by an excess of food may be classed according to the composition of the offending article of fodder, as follows :

I. Too high a percentage of water, as in the case of an unduly large consumption of rank grass or roots, gives rise to a laxative state of the bowels, which does not allow sufficient time for digestion and absorption to be carried on efficiently, and weakens the system by throwing an excessive amount of work on the alimentary canal in passing the food onwards. We have seen that it diminishes the power of breathing by increasing the volume of the stomach and intestines, and in extreme cases, as we find when horses are fed on boiled turnips, the distension produced by an easily swallowed and very bulky food, sets up serious digestive disturbances, among which we may number colic brought on by impairment of the strength of the muscular coat of the stomach and intestines.

2. An excess of fibre, like that of water, injuriously increases the weight of the contents of the stomach and intestines 
(p. 98); and also has a constipating effect, as we may see when an animal is fed almost exclusively on straw.

3. An excess of starch and fat tends to produce an obese condition in horses which are not sufficiently worked. When the labour is severe, there is no danger of a horse eating too much food of this kind. Obesity in idle horses is apt to set up fatty infiltration of the tissues and conseqent weakening of the system, and possibly fatty degeneration. Linseed is the only ordinary horse food which contains a proportion of fat high enough to render it a laxative, if given in large quantities.

4. The bad results of an excess of nitrogenous matter, although less hurtful to a busy horse than to an idle one, cannot be entirely counteracted by work, however severe or prolonged the labour may be. Its so-called "heating " effects appear to be chiefly due to (I) the presence in the system of an abnormally large quantity of waste nitrogenous products which produce a poisonous action on the body; and (2) the presence of an excess of sulphuric acid, which is formed, as Bunge tells us, from the sulphur contained in the nitrogenous débris and which is capable of acting in a destructive manner on the tissues. If the system contains a good supply of soda, potash, and lime, the sulphuric acid will become neutralised on uniting with these bases, which are found far more plentifully in hay, clover, lucerne, and bran, than in corn. Common salt is not capable of neutralising sulphuric acid, and consequently an addition of it to the food will not prevent corn from having a "heating" influence.

In the equine disease which is known to stablemen as "weed" or "Monday morning disease" (lymphangitis), we have an admirable instance of the hurtful effects of too much nitrogenous food, combined with too little exercise; for the malady in question is practically confined to highly fed horses 
which are put to work after having been kept for some time in a state of idleness, during which period their systems become overloaded with nitrogen. Strong work given to them while they are in this state, has the effect of causing the formation, by chemical decomposition, of an amount of poisonous products which the excretory organs cannot always remove with sufficient quickness to avoid disturbance of health. It is a suggestive fact that lymphangitis sometimes appears in horses that are in a starving condition. We have seen (p. 93) that when animals are in this state, there is a rapid breaking up of nitrogenous tissue, after the supply of fat in the system has become exhausted.

In considering the treatment for a heated condition of the system brought on by an excess of nitrogenous food, we should evidently seek for an agent which will neutralise sulphuric acid and promptly remove it from the body. Although we cannot definitely lay a portion of the blame on the presence of an excess of uric acid in the blood, the experience of human medicine tells us that when illness is accompanied by a large percentage of this acid, great relief is generally obtained by medicines which, like salicylate of soda, form soluble compounds with uric acid. If it is not convenient to use salicylate of soda, we have a cheap and fairly good substitute in bicarbonate of soda, which also acts well in helping to eliminate from the body the excess of potash obtained from the food.

The good influence of work in counteracting the evil effects of an excess of nutritious food, appears to be due chiefly to the increased supply of oxygen conveyed by the blood from the lungs to the tissues.

COMBINING FOODS ACCORDING TO A STANDARD.

It often happens that a horse-owner in a foreign country, can obtain for his animals two or more grains, none of which 
are of suitable composition; although a combination made from them might give the desired result. For instance, we might wish (as I have done, when stationed in Eastern Assam) to combine unhusked rice (paddy) and gram, so that the mixture might contain the same percentage of nitrogenous matter as oats, which we may accept as the best grain for all ordinary requirements. To do this, we can look up the table of analyses on pages 62 and 63 , and will then find the following figures.

Percentage of nitrogenous matter in paddy $=6.2$

$$
\begin{aligned}
& \text {, }, \quad, \quad, \quad, \text {, gram }=19.5 \\
& \text {, , , , , , , , oats }=\text { II.3 } \\
& \text { Let } \mathrm{x}=\text { percentage of paddy in mixture, } \\
& \text { and } 100-x=,, \quad \text {, gram, , } \\
& \text { Then, } \frac{6.3 x}{100}+\frac{19.5(100-x)}{100}=11.3 \\
& x=62 \text { (about). }
\end{aligned}
$$

Therefore the required mixture should contain about 62 per cent. of paddy, and 38 per cent. of gram.

Again, suppose we wanted from maize and beans to get a mixture having 12 per cent. of nitrogenous matter, we might proceed as follows :

Percentage of nitrogenous matter in maize $=\mathrm{IO} 0.3$

$$
\text { , " , , , , beans }=25.4
$$

Let $\mathrm{x}=$ percentage of maize in the mixture.

$$
\begin{gathered}
\frac{10.3 \mathrm{x}}{100}+\frac{25.4(100-x)}{100}=12 \\
x=88.7
\end{gathered}
$$

Therefore the mixture would contain I part of beans to about 8 parts of maize.

For reasons already stated (p. 68), these calculations are only approximately correct; although their limits of error are not sufficiently great to materially affect practical results.

Maize and linseed will be the most suitable constituents for increasing the respective proportions of starch and fat in a 
mixture of food. Both hay and straw furnish a liberal supply of fibre and ash.

\section{MAXIMUM AMOUNT OF NITROGENOUS MATTER IN FOOD.}

The foregoing considerations suggest the question: what is the maximum amount of nitrogenous matter which a hardworking horse can eat daily without injury to his health? From practical experience in India of feeding horses on gram (pp. 169 and I70), which is a highly nitrogenous food, I know that not more than $\mathrm{Io} \mathrm{lb}$. of this grain can be consumed daily by an ordinary saddle horse without its upsetting his digestion and "heating" his system. In ro lb. of gram there are about $2 \mathrm{lb}$. of nitrogenous matter, which we may take as a maximum for average sized animals. That quantity would be found in about $18 \mathrm{lb}$. of oats, $20 \mathrm{lb}$. of maize, or $7 \mathrm{x} / 2 \mathrm{lb}$. of beans. This maximum might be slightly increased in exceptional cases. In the East, highly nitrogenous foods, like gram, are used by sensible people as an exclusive grain food, only when they are unable to obtain more suitable grain, such as oats or maize. An addition of bran, owing to the comparatively large percentage of mineral matter it contains, will be desirable when highly nitrogenous grain is given to a horse in considerable quantities. In such cases, a particularly liberal supply of hay or grass should be allowed; because these articles of fodder contain a large proportion of ash.

\section{HUNGER AND THIRST.}

We may define hunger as appetite (p. I04) in excess.

Thirst is the desire to drink, caused by functional necessity, and accumulation, in the body, of decomposition products which require water for their removal. Colin tells us that if a horse is thirsty while he is eating, he will chew his food slowly and the flow of saliva will be languid. He will soon 
stop feeding, will become restless, will look about him, and will often neigh for water. If he is outside, he will make strenuous efforts to get water. We all know how a thirsty horse plunges his muzzle into water, and how he will try to resist any attempt made by his ignorant or cruel master or groom to prevent him from satisfying his longing for that fluid. If his thirst continues to remain unappeased, his uneasiness will increase, his mouth will become dry from want of saliva, his tongue hot, his blood thick, fever will set in, digestion will become checked, and constipation will ensue from the dry and balled condition of the food in the intestines. We may take for granted that severe thirst is a very painful feeling in horses, and that it can cause much more distress than hunger.

When a horse suffers from hunger alone, or from hunger and thirst, he at first becomes excited and ravenous ; but later on, he becomes affected with increasing depression, which soon deprives him of all desire for food, even if it is offered to him ; and his temperature becomes lower and lower. The torpor appears to be largely due to the great increase, in his system, of poisonous products, caused by the breaking up of nitrogenous tissue, after the other sources of heat production have become more or less exhausted. The fall in temperature naturally results from the small supply of energy available in the body.

Death seems to be produced principally by an insufficient supply of energy; by disintegration of the tissues; and by poisonous effects of an excess of nitrogenous waste. Towards the end, the horse remains lying on his side, and death is preceded by cold sweats and a few brief convulsions (Colin).

Ability to bear abstinence from food depends mostly on age; percentage of fat in the system; and general health. As the needs of the system are more pressing, and the process of waste is more active in young horses than in mature ones; 
they are of course less able to endure privation of food and water. The advantage of age naturally decreases as the animal's health becomes enfeebled with the weight of years. Colin states that when horses are deprived of all food except water, thin ones will live on an average only from five to ten days; and fat ones, from three to five weeks. Twelve or thirteen days appear to be the maximum length of time which a horse can live, when he is deprived of both food and water.

We have seen (p. 94) that sugar dissolved in water is the best means for resuscitating a horse which is dying from nunger. In making this attempt, or in trying to save a horse which is dying from thirst, the food or drink should be given in small quantities at a time, and at intervals appropriate to the enfeebled condition of the animal's digestive organs. The same principles, including the use of sugar, should be carried out with human beings placed in similar circumstances. 


\section{CHAPTER IV.}

\section{THEORY AND PRACTICE OF WATERING HORSES.}

Objects of Drinking Water--Destination of Water drunk by Horses-Conditions which Drinking Water should fulfil-Quantity of Drinking Water required daily by Horses-Number of Times a Horse requires to drink daily-Change of Water-Summary of Rules for watering Horses.

\section{OBJECTS OF DRINKING WATER.}

I. To aid in the nourishment of the system.-The importance of this duty is shown by the fact that water is the largest constituent of the body, and that its stay in the system is particularly brief, as we may see by the great quantity of it which is expelled by the lungs, skin, kidneys, and other excretory organs. The nutrition of the body is performed by fluids (saliva, gastric juice, bile, blood, etc.) which cannot act efficiently unless their usual proportion of water is maintained. Boussingault has proved by experiment that lime (chiefly in the form of carbonate of lime) in water drunk by animals, assists in the formation of bone and in supplying lime to other tissues.

2. To keep down any abnormal rise of bodily temperature, which is accomplished by evaporation (p. 12), and also by the loss of heat which the system experiences by warming cold water that has been drunk. This cooling effect by conduction has been demonstrated by H. L. Russell and V. R. Bassett (Annual Report of the Agricultural Experiment Station of the 
University of Wisconsin, 1899), who have shown by experiment that horned cattle suffer a loss of temperature of from $\mathrm{I} 12^{\circ} \mathrm{F}$. to $3^{\circ} \mathrm{F}$. by drinking ordinary cold water when they are at rest; but only one of less than $1 / 2^{\circ} \mathrm{F}$. by drinking water which has been raised to $\mathrm{IOI}^{\circ} \mathrm{F}$. (the approximate temperature of their bodies). In this case, the fall in temperature of somewhat less than $1 / 2^{\circ} \mathrm{F}$. may be attributed to the effect of increased evaporation. It appears that up to the present, no experiments have been made to show the cooling action by evaporation which water recently drunk, has on the system, when the bodily temperature has been considerably raised by exercise. We may, however, conclude from experience, that in such cases, the ingestion of water is a strong stimulus to evaporation.

3. To assuage thirst, which, apart from artificial stimulation (for instance, by an excess of salt in the food), is as a rule proportionate in intensity to the need the system has for water.

4. To aid in excretion.-The blood requires water as much for removing waste and injurious products out of the body, as for nutrition. Among these deleterious substances we have nitrogenous compounds which give rise to the feeling of fatigue ( $p .56$ ); and, if retained too long in the system, to nervous depression and to rheumatic affections. As they are sparingly soluble in water, their due removal demands a free supply and a free excretion of water. I am inclined to think that continued restriction in the quantity of the drinking water, is a not uncommon cause in horses, of obscure cases of lameness which are usually thought to be joint rheumatism or navicular disease. The presence of water in the body stimulates change of tissue and aids in the removal of carbonic acid. Hence it is specially necessary during hard work:

Water also plays an important part in excretion by mechanically aiding the intestines to get rid of the residue of food 
which is in them, before such residue, in the more or less perfect form of dung, decomposes, or before its presence can interfere with digestion. The water which is drunk by a horse naturally helps the water which is contained in the food to perform this office.

\section{DESTINATION OF IVATER DRUNK BY HORSES.}

When water is drunk by a horse in the usual way, it passes through the gullet, stomach, and small intestine, which is able to absorb fluids, and the remainder flows into the cæcum. This transit from mouth to cæcum is rapidly effected, and consequently with little loss of water. The stomach of the horse, according to Colin, has hardly any absorbent power. The cæcum, the walls of which can freely absorb water, is constructed in such a manner that it can hold a considerable quantity of fluid; the excess being passed out along with the food, into the lower portion of the large intestine. As the absorbents take up water only to the extent required by the body, the cæcum acts as a water reservoir to the system. It appears that the fact of the horse possessing this water reservoir prompts him, when he is thirsty and when he has the opportunity, to take a copious drink, so as not only to supply his present need, but also to lay up a store for the requirements of the next few hours. We also find that, unlike the majority of human beings, he does not as a rule drink frequently during the twenty-four hours, supposing that he has free access to water. We may therefore conclude that it is in harmony with a horse's nature for him, under ordinary conditions, to drink copiously when he is thirsty, so as to fill his cæcum. To restrict him to small and frequent drinks, would be as irrational as it would be to apply the same method to the feeding of dogs, whose health is best maintained when their comparatively large stomach receives food only once or twice a day. When the water in a horse's system suffers from 
a rapid and continuous drain, as for instance, during long and severe work, the intervals between watering ought to be proportionately decreased.

Absorbed water is excreted chiefly by the skin, kidneys, lungs, and in the recently delivered mare, by the udder. Unabsorbed water is passed out with the dung.

\section{CONDITIONS. WHICH DRINKING IVATER SHOULD FULFIL.}

\section{It should be free from injurious matter and hurtful} organisms.-Among these we find decomposing organic (vegetable and animal) matter, which is often derived from sewage; and infective microbes, which play a large part in the spread of disease in the tropics, and a smaller though not an insignificant one in temperate climates. Organic matter in drinking water is of far less consequence of itself than the fact that it renders water a favourable medium for the cultivation of disease germs ; pure water being altogether unsuitable for that purpose. We should not accept the presence of fish in water as an unquestionable proof of its practical purity; because many species of coarse fish are able to thrive in water which is unfit for horses to drink. In India and other hot countries, stagnant water often contains large numbers of thread-like worms (filarice), which produce various forms of disease among horses. Neumann gives in his book on the parasites of domestic animals (which has been translated by Fleming) a full account of the serious effects on horses caused by leeches entering their mouths while the horses are in the act of drinking. The leeches (chiefly the Hamopis sanguisuga) which make this attack are generally young ones which usually inhabit running water, and are seldom longer than $\frac{1}{50}$ th of an inch. The streams and springs of Algeria are greatly infested by them.

2. It should be sufficiently aerated.-When water is freely exposed to the air, as in the case of rain, or when water 
is poured backwards and forwards from one vessel into another, it will absorb a certain proportion of the gases which are in the atmosphere. Thus, a gallon of freshly fallen rain water will generally contain about 4 cubic inches of nitrogen, 2 cubic inches of oxygen, and I cubic inch of carbonic acid gas (Bloxam). We here see that oxygen is more soluble than nitrogen in water; because air contains about four volumes of nitrogen to only one of oxygen. The absorbent power of water for gases diminishes in proportion as its temperature is raised, as we may prove by bringing into a warm room a glass jug full of fresh rain water, in which case bubbles of gas which have separated themselves from the water, will be seen to quickly form on the inside of the jug. When stagnant rain water is exposed to the rays of the sun, it will, on becoming heated, lose a certain percentage of its dissolved gases, and will be far less capable of recovering this loss than running water, on account of the comparatively small surface it presents to the atmosphere. Hence we find that rapidly running shallow streams, especially if their course is a good deal broken up by inequalities in their bed, are more highly aerated than stagnant collections of rain water. Under the ordinary pressure of the atmosphere, one volume of water will dissolve about one volume of carbonic acid gas. With a pressure equal to that of two atmospheres, it will dissolve two volumes; with a pressure of three atmospheres, three volumes; and so on. Spring water, when below the surface of the ground, often becomes charged with carbonic acid gas under pressure. When this pressure is removed by the water rising to the surface, the extra carbonic acid escapes with more or less effervescence. This gas imparts to the water a bright appearance and pleasant taste, which are in marked contrast with the dull look and insipid flavour of soft water. The gases contained in naturally aerated water promote 
digestion by, among other ways, assisting the digestive juices to permeate through the food that is in the alimentary canal. The fact that this water is universally found by mankind to be pleasanter to drink than water poor in gases, is a strong proof that it is the more healthy beverage of the two. Although from want of exact knowledge we cannot unreservedly extend this conclusion to horses, the probabilities are all in favour of its being equally true in their case.

The foregoing considerations suggest the sound practical rule that it is better to give a horse fresh water, than water which has been allowed to stand for some time after it has been drawn, and that it should not be artificially warmed. If a particular sample of water happened to hold a large quantity of suspended matter, as might occur on rare occasions, it might be necessary to let the solid particles settle down as sediment, before giving the water to a horse to drink.

The presence of carbonic acid gas in water increases the solubility of carbonate of lime and may thus assist in nutrition.

3. It ought not to contain an excess of mineral matter, which excess may be defined as a greater quantity than $4 \frac{1}{2}$ grains to a pint of water. The Thames water which is supplied to London contains about $23 / 4$ grains to the pint. The principal mineral substances held in solution by river and spring water are carbonates of lime, soda, and magnesia; sulphates of soda, potash, lime, and magnesia; nitrates of potash, soda, and magnesia; chlorides of sodium and lime; and peroxide of iron. The chief mineral matters held in suspension are clay and sand.

Drinking water may be broadly classed as soft water, and hard water, which is the term commonly applied to water in which it is difficult to make a lather with soap. Hardness of water is caused by a comparatively large percentage of mineral matter being held in solution in that fluid, and may be divided 
into temporary hardness and permanent hardness. Temporary hardness is due to the presence of carbonate of lime and to a lesser cxtent to that of magnesium carbonate, both of which are soluble in water containing carbonic acid. Hence, when temporary hard water is boiled, the carbonic acid is driven off and the hardness disappears by reason of the precipitation of the carbonate or carbonates, as the case may be. Permanent hardness is caused by salts which are not precipitated by boiling. The best example of soft water is distilled water, and, after that, rain water and river water. Spring water and well water are generally hard. Mr. Thomas Hawkesly, the engineer, points out that at least 80 per cent. of the surface of the globe yields hard water. Letheby considers that moderately hard water is best for the drinking, purposes of human beings. My experience leads me to form the same opinion of hard water for horses, provided that the hardness is temporary. "The presence of dissolved solid matter in the water also influences its taste, preference being generally expressed for those waters which are not exceedingly poor in such solids" (Bloxam). Besides, carbonic acid gas is always an agreeable addition to drinking water, and as carbonate of lime is readily soluble in water containing that gas, it can hardly fail to be present in natural water in which that gas is dissolved. All natural water which is palatable to human beings, and most probably to horses, is hard. The preference sometimes evinced by horses for muddy water is, I think, due as a rule to deficiency of mineral matter in the food of these animals, and if that be the case, it cannot be reasonably urged as an argument in favour of the employment of such water for the drinking purposes of horses which are kept under healthy conditions of food. The deficiency in question is usually that of common salt. When water is brought by leaden pipes, there is less danger of lead poisoning with water which con- 
tains carbonate of lime in solution, than with soft water; because the oxide of lead which is formed by the action of the oxygen in the water, is practically insoluble in water that contains a fair quantity of carbonate of lime (Bloxam).

Apparently, the only natural mineral impurities of water that are desirable within narrow limits are carbonate of lime (chalk) and common salt, the nutritive rôles of which have been already discussed. The great objection to an excess of mineral substances in drinking water is that they have a hurtful effect on the stomach and intestines, either by their astringent or by their laxative properties. "Hard water undoubtedly produces a derangement of the intestinal canal, and sympathetically of the skin; the harsh staring coat of horses receiving hard water rapidly disappears when a softer water is supplied. The amount of hardness in water which will produce this derangement of the intestinal canal has not been accurately determined, but from eight to ten grains of lime per gallon has, in many cases, been found injurious" (Fred. Smith). I have never known a case of illness in a horse being caused by the drinking of ordinary hard water ; although every horse I have ever owned or trained was watered almost exclusively on hard water. They were not watered thus, because I was prejudiced one way or the other ; but because hard water is the usual drinking water for man and stabled beast, and what is good enough for the master is generally considered to be good enough for the horse. I am here, of course, speaking of ordinary spring or well water, and not of mineral waters, which are "spring waters containing so large a quantity of some ingredient as to have a decided medicinal action" (Bloxam).

The production of a tendency to the formation of calculi (stones in the intestines, bladder, and elsewhere) has often been put down to the drinking of hard water by horses, although statistics are wanting to support the allegation. For instance, Fred. Smith states that "cystic calculi among animals, 
particularly sheep, have been attributed to the excessive hardness of the water. Calculus disease is more common in the limestone districts than any other." On the other hand, we have the well-known fact that limestone districts are more suitable for the breeding and rearing of good horses, than districts which are poor in lime. The basis of limestone is of course carbonate of lime.

4. It should be free from any odour or unpleasant taste.-Any smell which natural water may possess will generally be caused by the presence of decomposing organic matter. As a rough test, we may " pour half-a-pint of the water into a wide-mouthed bottle or decanter, close it with the stopper or with the palm of the hand, and shake it violently up and down. If an offensive odour is then perceived, the water is probably contaminated by sewage gas, and possibly with other constituents from the same source" (Bloxam). Horses have a very acute sense of smell, and consequently they will often refuse to drink water which has been boiled, on account of its having been smoked, even when the smell thus imparted is extremely faint. Rain-water which comes off the roof of a house often contains particles of soot, and in such a case might be distasteful to a horse.

Although, as we have seen, a small percentage of mineral matter improves the taste of water; an excess-particularly of common salt, iron, sulphate of lime, and salts of magnesium and potassium-will render it disagreeable for drinking purposes. The sweetish taste communicated to water by clay appears to be in no way unpleasant to horses, which is a fact we can readily understand from our knowledge that grass is often a good deal impregnated with clay. The presence of decomposing organic matter gives a mawkish taste to water.

5. It should be free from any unusual colour or lustre.A green or yellow colour, or an opalescent or slimy lustre, 
shows that the water contains a percentage of organic or mineral impurities which render it unfit for drinking. A slightly muddy shade from the presence of clay is no great objection; because clay consumed in small quantities by a horse does not injuriously affect his health.

6. It should not be artificially warmed.-When a horse is hot and tired from severe work and his temperature is consequently raised ( $\mathrm{p} .52)$, the best thing we can do is to give him a drink of cold water, which will have a more cooling effect on him than warmer water (p. 129), and his thirst, which is prompted by the requirements of his system, will be satisfied with a smaller quantity of it-a fact that will be a direct gain, if work has to be resumed. An experience of two winters in Northern Russia has shown me that the coldest water even in the coldest weather, is neither distasteful nor hurtful to horses. In that country, during winter, all the common horses, such as cab and cart animals, are habitually given icy-cold water, and no attempt is ever made to warm it for them. These horses, which lead a very rough life in every way, except that they are well fed, and get as much cold water as they choose to drink, keep in excellent health; although the Russian and foreign horses which are pampered in the stables of Russian gentlemen suffer a great deal from disease. The cab horses of St. Petersburg, even in the middle of the terribly cold winter, maintain remarkably good condition. London cab horses, as we know, lead a very laborious life; their drinking water is never warmed for them, and yet their organs of digestion keep healthy. Throughout my long life, which has been spent among horses in all kinds of climates, and in many different parts of the world, I have never known, heard, or read of a case of injury to a horse caused by the fact of the water he drank being cold. On the other hand, I have seen scores of cases of horses refusing to drink, because the water offered to them had been arti- 
ficially warmed. The employment of any means that prevents a horse from quenching his thirst, or at least renders water more or less distasteful to him, can hardly fail to be prejudicial to his health-to say nothing of the cruelty. A practice which can fulfil no good end, and which is liable to do harm, should not receive our encouragement.

QUANTITY OF DRINKING WATER REQUIRED DAILY BY HORSES.

Some animals, such as sheep, goats, rabbits, and hares, will drink little or no water while subsisting on green food, because they perspire only to a slight degree (Colin). The skin of horses, on the contrary, is very active, and therefore they need a comparatively large supply of water. The necessary quantity is, however, subject to wide variations, which are influenced chiefly by the nature of the forage and the activity of the skin, lungs, and kidneys. The fact that grass contains about 80 per cent. of water, and the ordinary food of stabled horses only about 25 per cent., is sufficient to show the effect of diet on the amount of water which is needed. The respective influences of work, climate, clothing, temperature of the stable, and state of the coat, are too well known to need discussion. When a horse is suffering from fever, or from having consumed too much salt or other thirst-producing substance, he will require an unusually large quantity of drinking water to aid in removing the irritating material from his body.

The daily quantity of water which a horse will drink may be estimated at from 4 to Io gallons. In hot climates a horse which is doing no work, as on board ship, will drink 5 or 6 gallons. Under similar circumstances during cold weather, he will drink about 4 gallons.

From an experiment which Fred. Smith carried out on ten horses in India during the month of February, he found that 
the average was about $8 \pi / 2$ gallons, which the animals divided as follows for themselves :-

\begin{tabular}{|c|c|c|c|c|c|c|c|}
\hline Morning . & - & . & - & - & - & $1.9 g$ & allons. \\
\hline Midday . & - & . & • & - & . & 3.4 & , \\
\hline Evening & . & . & - & • & - & 3.15 & , \\
\hline & & • & & & & 8.45 & ", \\
\hline
\end{tabular}

During hot weather, the average would probably have been about 10 gallons.

Horses which have to perform long and severe work, particularly when the weather is hot, might require more than twice the quantity they would usually drink.

NUMBER OF TIMES A HORSE REQUIRES TO DRINK DAILY.

The small size of a horse's stomach points to the conclusion, which experience verifies, that a horse should be frequently fed. On the other hand, the large volume of his cæcum shows, as we have already seen, that although he requires a liberal supply of water, he does not need to drink nearly as often as he requires to eat, supposing, of course, that he is kept under ordinary conditions. For want of sufficient opportunities for making observations, I am unable to say positively how often horses require water daily, when they are in a state of nature; but am inclined to think that in such a case they would suffer no great hardship if they were watered only once a day, although watering them twice a day or allowing them free access to water would no doubt be the safer plan; for even if they did not drink as often as one expected, there would be no harm in offering water to them. I have found that ordinary hacks and horses in training for racing and steeplechasing often will not drink more frequently than twice a day, provided that at each time of watering they are given as much as they desire to have. I have known some of these horses make a habit of drinking only once a day. Young animals 
and brood mares, especially mares with a foal at foot, would require to drink oftener than others. Under severe conditions of work and atmospheric heat, it might be necessary for a horse to drink several times a day.

\section{CHANGE OF WATER.}

Change of water is sometimes cited as a cause of indisposition in horses. The cases are generally those of racehorses which are said to have suddenly lost their "form," on account of broaching a new tap of drinking water at stables away from their home. Although I have travelled thousands of miles, from one country to another with horses, I have never met with the slightest difference in the health of these animals from change of water; provided, of course, that the water was good of its kind. To verify the accusation in question, one would have to eliminate all suspicion from the hay, corn, and sanitary conditions of the new abode. Until such a test has been made, the burden of proof rests on those who assert the affirmative. It is possible that horses which have been long accustomed to hard water might not at first freely drink soft water; and vice versâ.

\section{SUMMARY OF RULES FOR WATERING HORSES.}

I. Drinking water for horses should not be artificially warmed, especially if the animal is at work (p. 137).

2. It should be given to a horse as fresh as possible (p. I33).

3. The best general rule for watering horses in the stable is to have a constant supply of it in their box or stall, in which case the ideal arrangement would be, to have a continued flow of water to pass through the water receptacle. If this plan could not be carried out, the water should be changed at least thrice a day. In adopting this constant supply method, we should bear in mind that water left in a stable, even for a few hours, becomes flat, and during that time absorbs ammonia 
and other noxious impurities from the more or less tainted air.

If it is not practicable to keep a constant supply of water in reach of a horse when he is in his stable, he should at least be given as much water as he will drink, before each feed, and immediately after his return from work.

As water is the natural drink for horses, it possesses no properties that would induce these animals, under natural and usual conditions, to take more water than the quantity demanded for the requirements of the system. Although we find that many human beings are inclined to drink more beer, wine, tea, and other artificial beverages than is good for their health; we meet with few, if any, cases of persons who habitually drink more water than is good for them. We may therefore accept the fact that a horse's appetite, in the form of thirst, is the best general means for regulating the quantity of water he should drink.

Owing to the ignorance and laziness of grooms, and the ignorance and apathy of owners, the large majority of horses in England which are kept in private stables, suffer greatly from thirst. Omnibus, tramway, railway and city corporation horses are generally better off in this respect; because they are as a rule under veterinary superintendance.

4. Special precautions should be observed in watering a thirsty horse which has been recently fed; because, as we have already seen, watering horses after feeding, instead of before feeding, is a prolific cause of colic. Supposing that a horse had as much water as he wanted to drink, say, an hour before feeding; it would be extremely unlikely that as soon as he had cleared out his manger, he would be thirsty enough to take sufficient water to do himself any harm. My experience is, that if a horse has not been allowed to fully satisfy his thirst a short time before being fed, it is dangerous to give him free access to water for at least two hours after he has finished his 
feed. If we found, after a horse had eaten his corn, that by a mistake or through ignorance he had not been watered for a considerable time before getting it, the safest plan would be to give him, say, from half a gallon to a gallon of water every halfhour, until his thirst was assuaged. The longer the period after feeding, the larger would be the quantity of water which could be given with safety. Feeding a thirsty horse, and at the same time withholding water from him, is a practice altogether opposed to the conditions which promote digestion. In speaking of feeding, I refer particularly to feeding with corn, the digestion of which is more liable to become upset by subsequent watering, than that of grass or hay.

5. It is injudicious to give a horse as much water as he can drink, shortly (say, within an hour) before taking him out of the stable to be worked; supposing that he had been deprived of water for several hours previously.-In such a case, the presence of a large quantity of unabsorbed water in the horse's alimentary canal would be liable, under the influence of subsequent exercise, to set up temporary diarrhœa. I have often known this to occur with horses which had been watered shortly before being taken out in the early morning; but have observed no such tendency when the interval between the watering and the beginning of the work has been extended to over an hour. Some horses which we might class as "washy," are very susceptible to the influence of water in thus bringing on diarrhœa. This tendency to looseness of the bowels is aggravated by excitement, fast work, the presence of undigested food in the alimentary canal, and a large quantity of corn in the daily ration; and can easily be obviated by keeping a constant supply of water in the box or stall, or by frequent watering.

It is instructive to note that horses which drink water when they are warm from exercise, seldom if ever "scour" on being again put to work. Their immunity is evidently 
due to the fact that while their blood is in a rapid state of circulation, owing to recent exercise, the water they drink, is quickly absorbed out of the intestine, and into the fluids and tissues of the system.

6. A horse should not be watered shortly before work which, like racing, would try his breathing powers to the utmost.Considering the fact that a horse which has an unlimited supply of water will under ordinary circumstances drink only two or three times a day, and that he drinks, not only to meet existing requirements, but also to lay up a store for use during the next few hours; I think that before running a race a horse should have no water to drink for, say, three or four hours. It is evident that a considerable quantity of water in the cæcum will more or less interfere with the action of the diaphragm during forced breathing, and its weight will have a retarding influence. On the other hand, depriving a horse of water for such a long period as will make him decidedly thirsty, cannot fail to injuriously affect his lungs, heart, muscles, and other organs, by depriving the system of its due supply of water. This practice of stinting a horse of water, so that he might maintain the highest possible rate of speed for a few minutes (say, 62 seconds for 5 furlongs, or 10 minutes for the Grand National) would of course be injurious if applied to ordinary horses, such as trappers and hunters.

7. A horse should be frequently watered during long-continued work, especially if it be severe and the weather hot; and he should be watered immediately after hard work, whether it be long or short.-I have had ample opportunities of seeing the good results from the practice observed by the St. Petersburg cab drivers, of frequently watering their horses in the middle of their journeys at the numerous public watering troughs in that city, especially when the animals were hot and tired, no matter how intense the cold might be. During winter, the attendant at the respective troughs is almost 
constantly employed in breaking the ice, so that the water supply may not be stopped. In India, tonga (a kind of curricle) and ecka (a small, two-wheeled trap) ponies, which average about $13 \mathrm{~h}$. I in. in height, frequently travel 50 or 60 miles in a day over unmetalled roads during the hottest weather, when the noontide heat often exceeds $I I O^{\circ} \mathrm{F}$. in the shade. Such performances can be accomplished only by watering the ponies about every hour; the system pursued being to give them at each bait I to $2 \mathrm{lb}$. of barley meal or Indian corn meal in a couple of quarts of water. Persons who have had to ride long distances in hot countries are aware of the advisability, during a journey, of allowing their mounts to drink frequently from any good water near which they may pass, even when the horse is bathed in perspiration. I have always found out hunting, especially on a long day, that my mount received great benefit from being allowed to drink, when he was thirsty, at any convenient watering place. We should remember that the longer a horse has been without food, the less likely is water to do him harm.

During many years, when I was training horses in India, I had the best results from giving them half a bucket of water immediately after their gallops; and as much water as they cared to drink, as soon as they returned to their stable. This plan of watering immediately after a training gallop or race, which I was the first to put into practice and write about in India, is now generally adopted by persons who train horses in that country. The very time above all others at which a horse requires a liberal drink of water, is when he is heated an 1 exhausted by hard work; for not only is the body then in the greatest need of water, but the danger of chill from drinking it is less than when the horse has become cool, because the circulation of the absorbent blood-vessels is more active. If the animal be allowed to cool down without getting water, his blood will recover its fluidity at the expense of the tissues. It 
is therefore reasonable to suppose that useless waste of tissueof which water forms a large component part-and consequent loss of strength will be incurred by keeping a horse in a state of thirst. Experience proves, both in our own persons and in that of horses, that water taken when a man or animal is hot and tired from hard work diminishes to a great extent, or altogether obviates, any subsequent exhaustion, which in all cases has an injurious effect on the system.

8. Regularity should be observed in the watering of horses which have not free access to water. - The remarks already made on the recessity of regularity in feeding apply equally well to regularity in watering. 


\section{CHAPTER V. \\ VARIETIES OF FOOD.}

Oats-Maize-Barley-Dried Brewers' Grains-Wheat-Bran-Linseed-Beans and Peas-Millet-Rice-Rice Meal-Rye-Cocoanut Meal-PotatoesRoots, Fruit, Gourds, and Sugarcane-Indian Pulses-Cows' Milk-Grass; Hay and Straw-Lucerne-Bamboo Leaves-Condiments, etc.

OATS.

Description. - Oats are divided according to their colour, into white oats, tawny or grey oats, and black oats. The shape and weight of oats vary more than those of any other kind of feeding grain, chiefly on account of the nature of the husk, which is usually well developed; but in some varieties - it is thin, and there is a kind of oat that has no husk. In some, the kernel is short and plump; in others, long and thin, as we find in oats grown in hot climates. The possession of a beard (awn) naturally makes oats which are thus furnished lie loosely in the measure, and consequently to weigh light. Henry states : "In the southern portion of our country [U.S. of America] a bushel of oats often weighs only twenty pounds." Oats produced in India are generally very light. Oats grow best in temperate and moderately cold climates, and do fairly well even in sub-arctic countries, like those of Northern Europe for instance, provided that the summer is sufficiently long for their development. Good English oats may be said to vary from 37 to $48 \mathrm{lb}$. a bushel.

Comparative value of oats as a food for horses.-In this respect oats are superior to all other kinds of grain, owing to 
their wholesomeness (p. 72), and to the admirable manner in which the necessary nutritive constituents are combined in them. Their high degree of wholesomeness, under favourable circumstances, is due to their possession of a cellulosedissolving ferment, and to the nature of the husk, which is largely composed of fibre. When the husk is masticated, its broken-up particles aid in checking the too rapid passage of the food through the stomach and small intestine; they furnish interstices through which the digestive juices can penetrate; and they help in preventing the alimentary canal from becoming loaded at any particular part with food which, on account of its richness, might be liable to decompose, and to set up more or less serious indisposition. The large proportion of fat contained in oats is of special value from a feeding point of view.

The statements made by various chemists that oats contain a stimulating principle have not been confirmed.

Tests of quality.-Oats should have an agreeable smell, clean appearance, and pleasant taste; should feel dry, hard, and elastic when taken in the hand, and when broken between the teeth; and should be well provided with flour. The fact that they fulfil these conditions will show that they have been well saved, are sufficiently old, possess a due amount of nutriment, and have not suffered from injurious influences, such as damp and mould, as would be evident if they were musty in smell and dull in colour. The presence of much dust in oats proves that they have been badly saved, and that their quality has undergone deterioration. A shrivelled-up condition is also a sign of inferiority. With a plump variety of oats, if the grains feel heavy in the hand, rattle more or less like shot when poured out, rebound when they fall on wood or other hard object, and show no tendency to stick together, our good opinion of their nutritive value and sound condition will be still further increased. The 
artificial presence of sulphur, which is sometimes used for bleaching damaged oats in order to improve their colour, may be detected by the smell given off by the oats when they are rubbed briskly between the hands. "Oats which have been kiln-dried, even if not bleached, shrink unduly from the points of the husks, and so can very readily be detected, and they also have a brown appearance at the points" (Fisher). The plumper, more rounded, and heavier oats are, the higher will be their market value. Thinness of husk will also enhance the price as a rule. The cost of white oats, probably on account of their cleaner and more pleasing appearance, is higher than that of either black or tawny oats. Old oats are sold at about 15 per cent. more than new oats. The term "old" is applied to oats as soon as the next crop begins to be thrashed.

Practical experience is the only certain means for teaching us how to distinguish old oats from new ones; the differences between the two being due to drying and fermentation. The slight fermentation undergone by even the best old oats removes from the husk a good deal of the gloss which characterises sound new oats. During this fermentation, a certain amount of dust is formed, which would probably be got rid of by the corn-dealer before showing a sample. The difference of smell is well marked; and also that of dryness, which we may test by placing a hand into a heap of the grain, and by chewing a few of the kernels. The best way of making sure that the oats we buy are old, is to purchase our yearly supply a little before the oat harvest is cut.

The feeding value of a given weight of oats varies according as the weight of the kernel exceeds that of the husk, other things being equal. This statement is self-evident, when we consider that the husk is almost entirely composed of crude fibre, which we have seen has little or no nourishing properties. In fact, the husk has about the same feeding value as straw. 
Generally speaking, the heavier the oats, the larger will be the percentage of flour (kernel), and consequently the more will they be worth. This rule is liable to many exceptions; for, as we have seen, the density, thickness and form of the husk of oats are by no means uniform. Accordingly, we may not unfrequently find that a sample of heavy oats contains a smaller percentage of flour than one of light oats, and is consequently of inferior feeding value; weight for weight. Experiments made by Hickman gave the following results :-

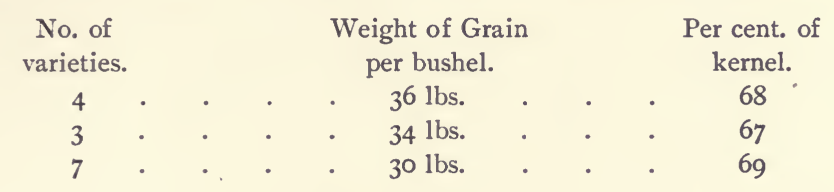

We should here bear in mind that although light oats might show a higher percentage of flour than heavy oats, it does not follow that a bushel of the former would necessarily contain more flour than a bushel of the latter. For instance, if we took a bushel of the $30 \mathrm{lb}$. oats of the foregoing table and the same quantity of the $36 \mathrm{lb}$. oats, we would find that the weight of the flour of the former comes to $20 \mathrm{lb}$. I I oz., and that of the latter to $24 \mathrm{lb} .7 \mathrm{x} / 2 \mathrm{oz}$. In selling by weight the advantage would, however, be with the $30 \mathrm{lb}$. per bushel oats, in, of course, the proportion of 69 to 68 .

If we can increase as we wish the quantity of oats given to a horse, we shall find, as a rule, that no feeding advantage is obtained by using oats that are heavier than, say, $40 \mathrm{lb}$. (or perhaps even $38 \mathrm{lb}$.) a bushel; for in almost all such cases the animal will desire to supplement the oats with hay or straw, both of which are less palatable to a hungry horse than oats; although, after his appetite for nutriment has been more or less allayed, his need for fibre will make him leave the corn in order to seek for hay or straw. I am indebted to 
Mr. John Hubert Moore, the famous owner and trainer of steeplechase horses, for drawing my attention to the fact that when horses are given as much corn as they can eat, oats of moderate weight are quite as good as the heaviest samples. Owing to the general belief among stablemen that the weight per bushel of oats is a correct measure of their nutritive worth, heavy oats as a rule command a fictitiously high price as compared to the cost of lighter samples.

The feeding value of black and tawny oats appears to be as great as that of white oats, other things being equal. New oats are apt to act as a laxative, and to produce a debilitating effect on horses, probably on account of their comparative indigestibility. I do not think that English oats are at their best before they are at least a year old. Oats grown and kept in hot countries need not be stored so long as English oats; for they lose their moisture quicker. Oats are best preserved in an unthrashed condition (in the stack).

Measuring and weighing.-In the United Kingdom oats are usually measured as follows :-

$$
\begin{aligned}
\text { I6 quarterns (4 gallons) } & =\mathrm{I} \text { bushel. } \\
4 \text { bushels } & =\mathrm{I} \text { sack. } \\
2 \text { sacks } & =\mathrm{I} \text { quarter. }
\end{aligned}
$$

In Cheshire, a bushel is generally called a "measure." Quartern and quart are synonymous terms.

Oats are sold by weight or by measure (so much a bushel). As the difference between the market value of heavy oats and light oats is greater than the difference between their respective weights per bushel; it follows that if a buyer pays the market price of heavy oats, he will not get proper value for his money, if he is given a lighter sample made up to the weight of the heavy oats. For instance, if instead of getting a quarter of oats worth $25 \mathrm{~s}$. and weighing $360 \mathrm{lb}$ : (45 lb. per bushel), he were to receive $360 \mathrm{lb}$. of oats which were worth 20 . 
a quarter and which weighed $40 \mathrm{lb}$. a bushel, he would be paying $25 \mathrm{~s}$. for a quarter and one-eighth. of the $20 \mathrm{~s}$. oats, the quarter and one-eighth of which would be worth only $£$ I 2s. 6d. The inconvenience of measuring each bushel of oats, and the manner in which the result is affected by the method of filling, have caused in many places the adoption of the plan of selling oats by weight (at so many pounds a quarter), after agreement as to their value. I am of course here considering the market value and not the feeding value of light and heavy oats respectively.

The ordinary method for finding the weight per bushel of a sample of oats is to fill a bushel measure with the oats, remove the oats that are above the top of the measure by means of a flat board or other convenient appliance, and weigh the oats contained in the measure. As the quantity of oats that can be got into a measure will vary a good deal according to the manner in which the measure has been filled; it is necessary that a uniform procedure be adopted in this process. The rule is that the filling should be done in an ordinary manner, and with as little tendency as possible to make the oats weigh heavy. If the oats are in a heap, we may push the mouth of the measure into the oats, turn the measure over, and skim off the superfluous oats from the top without shaking the measure, striking it, or pressing the oats down. Or we may gently pour out the oats into the measure from a sack, the mouth of which should be kept fully opened out while this is being done.

\section{MAIZE.}

During late years, maize has steadily increased in favour among English and Continental owners as a food for horses, in which respect it certainly comes next to oats as regards value. Formerly it was held in low repute in Europe, and the results of experiments conducted on a large scale in France and 
Austria appeared to prove, that although horses like maize, digest it, and on it get fat and acquire glossy coats, they show a marked deficiency in vigour, speed, and stamina, as compared to animals fed on oats. Also, Professor Bruchmüller, who conducted a six months' trial of feeding 5,200 horses partly on maize, came to the conclusion that it can be used to advantage only with horses which are not required to move out of a walk. Against this we have the fact that in South Africa the mail coach horses, which have to do ten to twelve mile stages over bad ground at a sharp trot or gallop, go through their work well, and keep in good condition on nothing but maize (about I 8 lbs.) and oat chop or straw chop (about 5 lbs.) with an occasional feed of grass on the veldt. As I have often sat behind them, I can vouch for the good effect maize has on their mettle. "The great Paris Omnibus Company has tried replacing half the oats usually provided for the horses by crushed maize (including the cobs) with most excellent results. The cobs provide the cellulose lacking in the maize, and the two together are equivalent in composition and feeding value to oats. The New York Omnibus Company give each of their horses I4 lbs. of maize a day; while the Berlin Tramways Company supplement 3 lbs. of oats with 15 lbs. of maize per horse per day, with most satisfactory results. Maize has proved an excellent food for horses doing hard and regular work at a moderate pace, but is less suited for hunters or light hacks" (Farm Foods). The writer of the above extract (E. von Wolff) is not quite correct in saying that the grain and cob of maize, when combined, are equal in composition to oats; because oats are richer than this mixture is in mineral matter and fat. Passing over this slight exaggeration, we have the fact that the London Road Car Company's horses, which show better condition than the horses of any other Metropolitan omnibus company, are fed almost entirely on maize and hay, as we shall see later on. At present, in 
England and on the Continent, hundreds of thousands of horses which are fed principally on maize, are worked in 'busses, trams, vans and heavy carts, and leave nothing to be desired as to the manner in which they perform their labour. The merits of maize have long been recognised in America, from which country we have adopted it as a food for man and beast.

The contradictory nature of the foregoing results may, I think, be explained by the fact that the feeding value of maize is greatly affected by the manner in which this grain is presented to the horse to eat. Its undue hardness and its deficiency in woody fibre are the two weak points about maize which should be specially provided for, and which can be best avoided by grinding the grain and the cob together (see preceding paragraph). Henry tells us that "about one-fifth the weight of well-dried corn of the better varieties consists of cob." When the cob cannot be utilised along with the grain, the maize should be crushed or coarsely ground, and mixed with bran or chop. "Corn meal alone is a sodden substance in the animal's stomach, and should be diluted or extended with something of light character. Bran serves well for this purpose, because of its lightness and cooling effect, as well as the protein (nitrogenous matter) and mineral matter it furnishes" (Henry). As South African chaff consists of bruised and broken-up straw, it forms an admirable vehicle for maize, the particles of which it keeps separate, and by its softness it allows the animal to thoroughly masticate them, whether the grain be broken or whole. Under ordinary conditions, if maize be given whole, it is apt by its hardness to make the horse's mouth sore, and when his mouth is in that state he is inclined to swallow the grain without chewing it, in which case it will be liable to give rise to digestive disturbance.

While fully granting the value of maize as a food for ordinary working horses, I think we would do well to restrict 
it to their use. The experience of owners and trainers in America and South Africa, in both of which countries maize is largely employed in the feeding of common horses, is that oats are much the better grain of the two for racehorses, match trotters, and animals of the hunter class. As I have already pointed out, it is unsuitable to young horses, owing to its poverty in mineral matter.

\section{BARLEY.}

A long experience of feeding horses on barley in India leads me to conclude, that when properly employed, it answers its purpose fairly well, and that it is not much inferior to maize as a food; provided that it is used only in comparatively small quantities. Being poor in woody fibre and hard, it should, before being given to horses, be broken and mixed with a material which is rich in woody fibre, such as chopped hay or chopped straw. It is the only grain that is generally used for horses in Syria, Egypt, Arabia, Persia, Algeria, and other Eastern countries, where Io lb. is regarded as an ample daily ration. In these places, it is usually mixed with barley straw or wheaten straw which has been broken into small pieces and thoroughly bruised by the native threshing machine (Arabic, Noraj). This form of chaff or chop is called tibben in Arabic. The softness of tibben and of the chaff employed in South Africa with maize, is undoubtedly the chief cause of the good results obtained with barley and maize in these respective countries. It is instructive to know that a mixture of barley and tibben keeps Eastern horses in excellent condition without any other kind of forage. Chopped hay or chopped straw, owing to its greater hardness, is by no means such a good vehicle for barley as tibben. The only valid objection which can be advanced against the use of barley, and which can be more or less obviated by mixing it with bran or suitable chaff, is that it is liable to cause the 
horse's dung to become loose and to acquire a bad smell. Owing to this effect, which increases in proportion to the amount of barley consumed, ro lb. may be taken as a healthy maximum daily allowance of this grain. Parching appears to increase the digestibility of barley, but I am unable to explain its action in this respect.

Steamed or boiled barley, when given to a moderate extent, is an excellent adjunct to the food of some delicate horses, even when they are put to hard work. It also forms a useful change for animals that are out of condition.

"Barley often commands a low price because the grains have been tarnished during harvest by rainfall or foggy weather. Such grain has lost little or none of its nutrients, though for the brewer its value may have been much diminished. The wise stockman will use such barley for food rather than force it on the market at the low price which it commands. Light-coloured, bright barley makes beer of better colour than dark, weather-stained grains" (Henry).

Although barley, owing to its laxative effect when given in large quantities, is by itself unsuitable to horses doing hard work; it can often be economically used with other food for these animals. Mr. John Malcolm, F.R.C.V.S. (Journal of Comparative Pathology and Therapeutics), gives the following very interesting account of an exhaustive and valuable experiment on the feeding value of barley for cart horses. His conclusions are indisputable.

"A section of the Birmingham Corporation stud, consisting of 120 cart horses, was selected for the experiment. These horses were all of the same class and all doing the same kind of work, and as nearly as possible the same amount of work. They were divided into two lots of sixty each, and all were weighed. One lot was fed on oats, maize, beans, and hay, and the other lot on barley, maize, beans, and hay, the daily allowance for each horse being as follows :- 
BARI.EY-FED HORSES.

\begin{tabular}{|c|c|}
\hline Hay. & \\
\hline Beans & \\
\hline Maize & \\
\hline Barley & \\
\hline
\end{tabular}

OAT-FED HORSES.

\begin{tabular}{|c|c|c|}
\hline Hay & & \\
\hline Beans & & \\
\hline Maize & & \\
\hline Oats . & & \\
\hline
\end{tabular}

"This experiment was commenced on Ist October. In a report on the subject dated 2 ist November, it is recorded that, although still too soon to report with any authority on the point, yet so far as could then be seen, the horses on barley were doing quite as well as those on oats. The daily allowance was continued to each lot without change till 3 Ist January, I895, when all the horses were re-weighed. The result of the weighing showed that the barley-fed horses had decreased in weight an average of $28 \mathrm{lbs}$. each, whereas the oat-fed horses had only decreased i 8 lbs. each. It will be remembered that the winter I894-I895 was severe, and I may state that the general reduction in weight was attributed to the severe character of the weather and the consequent heavy work of the horses. It was decided to continue the experiment until 3ist March, but owing to the general loss of weight it was resolved to increase the daily rations in each case by the addition of $\mathrm{I} \mathrm{lb}$. beans and I lb. hay. This was done, and the horses continued to receive this increased allowance till 30th March, I895, when they were again reweighed. The result was somewhat curious, and not in accordance with the previous weighing. The oat-fed horses had only recovered $3 \mathrm{lbs}$. of the previous loss, whereas the barley-fed horses had recovered I4 lbs. of the previous loss. Thus, the nett result was that on 30th March, I895, the 60 barley-fed horses were on an average 14 lbs. lighter than on Ist October, I 894, while the oat-fed horses were I 5 lbs. lighter. It will therefore be seen that in a stud of 120 horses, all of the same class and doing the same kind of work, 60 of which received 8 lbs. barley daily, and 608 lbs. oats, but whose 
food was otherwise precisely the same, no appreciable difference, so far as weight was concerned, could be detected between the lots after an experiment extending over six months and including severe winter weather. As with the weight, so with the general condition and staying powers of the horses, no recognisable difference could be discovered between the lots. The health likewise of the one lot was equal to that of the other, nor could we perceive any difference in their skins or coats. The sole perceptible difference between the two lots was in the character of the fæces. The fæcal pellets from the barley-fed horses were not so uniform in shape nor so firm in consistence as from the oat-fed horses, but no real detriment of any kind could be recognised in connection with this, and it was particularly observed that the horses on barley were as free from colic as those on oats.

"The general conclusion arrived at was that so long as good sound corn is given it is immaterial in feeding cart horses whether barley or oats are the grain used, the chief point being their relative market values. As a result of this conclusion, and owing to the cheaper relative value of barley, the whole stud of 400 horses were put on barley in place of oats on Ist April, I895, and continued to be fed in this way until Ist April, I896, and the general results were never more satisfactory than during that time.

"In feeding my own horse I candidly confess I prefer oats to any other grain, partly because the fæces are less offensive than with any other corn, but while this point may counterbalance the economic one in horses kept for pleasure or personal use, it is not generally allowed, and it should not be allowed, to influence the procedure in connection with a working stud of cart horses, where the preponderating condition is efficiency with economy.

"Whenever economy makes it expedient to use barley in place of oats, care should be taken to supply clean barley. 
Much of the barley imported contains a large percentage of dirt, and it is manifestly absurd to expect the same result from feeding with an equal weight of barley mixed with dirt as with clean oats. In one marked case in connection with a large stud in which barley has recently been condemned as horse food, the real mistake, I believe, was in giving dirty barley, and the condemnation should have been confined to the dirt, and not extended to the barley."

My readers will consult with advantage Mr. Shaw's remarks on barley, page I80.

\section{DRIED BREWERS' GRAINS.}

"Sattig reports using dried brewers' grains and finding them a cheap winter feed for horses, the energy and general condition of the animals being pronounced as good as though they were maintained on oats. Trials in feeding the dried grains to street-car horses by the New Jersey Station gave satisfactory results, with the cost of the ration reduced several cents per day" (Henry). The ration in question was as follows :- Hay, 6 lb.; bran, 2 lb. ; maize, 4 lb. ; dried brewers' grains, $8 \mathrm{lb}$. We also learn from Henry's Feeds and Feeding, that the following low-priced ration has given good results in America with cart horses weighing from I, IOO to I,200 lb. : Hay, 8 lb., maize meal, 6 I $/ 2$ lb., and dried brewers' grains, $6 \mathrm{x} / 2 \mathrm{lb}$.

In brewing, the starch which has been converted into soluble compounds by the process of malting and the sugar that is present in the grains are utilised for the manufacture of beer, while the nitrogenous matters remain unchanged. Consequently, these grains are rich in nitrogen. They also contain a large amount of phosphates, but are poor in potash, which deficiency is no drawback to their feeding value; because the percentage of potash in hay and other kinds of forage is in excess of the requirements of the horse. "While brewers" 
grains dried by any open air process may be subject to criticism, the charge cannot stand for grains which are dried rapidly in partial vacuum" (Henry).

Owing to its high percentage of starch, maize would be a 'very 'useful addition to dried brewers' grains, which are particularly rich in nitrogen.

\section{WHEAT.}

A grain of wheat consists of cells, each of which has a thin cellulose wall. Some of these cells contain starch; and others gluten, which is a kind of albumen. They are collectively surrounded by a layer (the "aleurone layer") which is rich in nitrogen and which is covered by three other layers that form the husk. The three outer layers have nearly the same composition as straw. All four layers are contained in bran, with which are mixed particles of flour. The fact of gluten being sticky and tenacious renders wheat a dangerous food for horses, especially when given in large quantities; for it is apt to form a pasty mass which the digestive juices will have great difficulty in penetrating. This disadvantage may be more or less overcome by coarsely grinding the wheat and mixing with it a suitable quantity of bran. A safe proportion would be $2 \mathrm{lb}$. of wheat to $\mathrm{I} \mathrm{lb}$. of bran. In the absence of bran, which appears to be the best vehicle for wheat, we might give chop. In South Africa I have seen wheat given even whole, without producing any ill effects, three times a day in quantities of $2 \mathrm{I} / 2 \mathrm{lb}$. each time, and mixed with chaff. Wheat should be at least a year old before feeding horses on it.

The bad reputation which wheat has in England as a producer of colic and laminitis, is chiefly due to ignorance of the proper way to prepare it for a horse to eat.

A couple of pounds of boiled wheat, in which a little salt has been mixed, form an agreeable repast for a horse at night when soft food is required. 
BRAN.

Bran, except in the form of bran mash, is used for horses in England, almost exclusively as an adjunct to other foods. Müntz (Annales de l'Institut National Agronomique) has shown that it is highly digestible (p. 72), even in daily quantities of $16 \mathrm{I} / 2 \mathrm{lb}$. Its admixture in a dry state, with grains which, like barley and gram, give rise to a foul condition of the dung and more or less diarrhœa, helps to correct this form of digestive disturbance, and consequently improves their wholesomeness (p. 72). At the suggestion of Veterinary Colonel Anderson, late Inspecting Veterinary Surgeon of the Bombay Army, I frequently adopted in India the practice of feeding horses which were doing light work, on dry bran in daily quantities up to I2 lb., and found it a sustaining and very wholesome food. In countries like India, where the separation of the bran is effected in a primitive manner, the bran retains a considerable portion of flour. Owing to the highly economical method of milling in this country, English bran consists almost entirely of the four layers of husk, with a minimum of adhering flour. Dry bran by itself has an excellent effect on horses whose digestive organs have been upset by food of too stimulating a nature. Bran merits a more extended trial as a food for horses than it has received.

Given as an adjunct to grain, it serves the valuable purposes of obliging the animal to chew his food thoroughly, of diluting concentrated food (like wheat) and thus allowing the digestive juices to readily penetrate through it, and probably, of acting like fibre in preventing corn from passing through the alimentary canal too rapidly. Also, its inner layer possesses a ferment which aids in digestion (p. 69). Being rich in mineral matter, it is specially useful as a food for building up the bony structure of young animals; and for the same reason, it is a particularly valuable addition to the diet of horses which are 
fed on a large amount of grain, especially when the grain is highly nitrogenous (p. 122). In such cases, bran should of course be given dry. I would advise that more or less bran (say from 2 to $4 \mathrm{lb}$.) be given with the food of all kinds of horses. In the form of mash, bran is a laxative, owing to the presence of the contained water.

It appears from the experiments of Shepperd in America (see Feeds and Feeding) that a mixture of equal quantities by weight of bran and "shorts" has about the same feeding value as oats for hard-working horses. According to Henry, shorts are simply re-ground bran. What are known as "sharps" and "middlings" in England, are the finely-ground intermediate product between flour and bran. They are of higher nutritive value than bran.

As bran is very absorbent of moisture and gases, it suffers rapid deterioration in quality, and should consequently be used only in a fresh state.

It is a pretty general custom to give a bran mash every Saturday night, or oftener as the case may demand. A horse which from want of habit shows a reluctance to eat a bran mash, may be got to do so by mixing a little corn through it. Instead of a simple bran mash, one to which linseed has been added, in the manner described on the next page, is usually preferable for horses that are out of condition.

We may make a bran mash as follows: After scalding a stable bucket with boiling water, put into it about $3 \mathrm{lbs}$. of bran with an ounce of salt, and pour in as much boiling water as the bran will take up, the weight of which will be about equal to that of the bran, calculating a gallon of water to weigh Io lbs. After the bran has been well stirred up with a stick, it should be covered over so as to keep in the steam, and should be left to stand for a quarter of an hour or twenty minutes before being used. A regular supply of carrots or green food is much better for horses than bran mashes. 


\section{LINSEED.}

This grain, which is the seed of the flax plant, contains 37 per cent. of fat and oil, and consequently is useful for fattening horses that are low in flesh. It improves the state of the coat in a marked manner, and has a soothing effect in diseased conditions of the urinary organs and organs of breathing. A linseed and bran mash is the usual way in which it is given and can be made as follows :-Boil I $\mathrm{lb}$. or $\mathrm{I} / 2 \mathrm{lb}$. of linseed slowly for two or three hours until the grains become soft, allowing only just sufficient water, when the linseed has been cooked, to soak up a couple of pounds of bran, which is then mixed in and the whole covered up in the manner employed for making a bran mash. The thicker the mash, the more inclined will a horse be to eat it.

Instead of giving a linseed and bran mash, it is, as a rule, a better, and certainly an easier, plan to give linseed in the form of linseed meal, I lb. of which may be added daily to the other grain. The grinding of the linseed will be facilitated by mixing it, before putting it into the mill, with, say, double the weight of maize. One part of this mixture with one part of bran and four parts of bruised oats, will make an admirable food for horses. We may for a time replace the drinking water by linseed tea, which may be made by boiling $\mathrm{I} / 2 \mathrm{lb}$. of linseed in two gallons of water for a couple of hours, and then straining off the fluid and letting it cool. I do not think that linseed oil (say a quarter of a pint) mixed through the daily corn, has as good an effect as the meal.

The outer covering of the grains of linseed contains a large quantity of mucilage (the gum of seeds and roots), which swells up when linseed is boiled in water, and to a much less extent when it is merely soaked in cold water. The mucilage gives the water in which it is present, more or less the character 
of a solution of gum, and serves to form an emulsion with the oil which is in the seeds.

Indian Linseed sometimes contains a comparatively large proportion of mustard seed, which is small, round, light yellow in colour, and has a characteristically warm taste when chewed. It should be carefully separated from the linseed; because, if consumed by a horse, it may have an irritating effect on his digestive and urinary organs. We may also find hempseed and rape in linseed. The former is an oval and somewhat flattened seed, about half the size of a grain of wheat, and is of a light brown colour. The latter is a dark seed of about the same size and shape as mustard seed. The consumption to a moderate extent of rape and hemp seed causes no ill effect on horses.

From 2 to $4 \mathrm{lb}$. of linseed cake makes a good addition to the food of young horses, or those which are out of condition.

\section{BEANS AND PEAS.}

Müntz has shown by exact experiments that beans are very digestible, even when given in daily quantities of $14 \mathrm{lb}$. Such a conclusion, though chemically correct, may be practically misleading; because the consumption of so much nitrogenous matter as that contained in a stone of beans, would certainly be injurious to the animal's health (p. 125). Experience teaches us that oats contain a sufficiently high percentage of nitrogen. Therefore, taking $\mathrm{I} 8 \mathrm{lb}$. of oats as an ample daily ration for all ordinary requirements of a horse; we find that the nitrogenous matter in it is about equal to that in $7 \mathrm{x} / 2 \mathrm{lb}$. of beans, which may consequently be regarded as a maximum daily allowance. As beans are comparatively poor in starch and other carbo-hydrates ; $7 \mathrm{x} / 2 \mathrm{lb}$. of it would be insufficient for purposes of work. We may consequently conclude that beans are useful only as an adjunct to grain rich in starch, as for instance, maize. It is probably advisable not to give more than $5 \mathrm{lb}$. of beans a day to horses. A slightly larger quantity 
of peas might be allowed; for they contain more starch and less nitrogen than beans.

In this country, beans should not be used before they are a year old, so that they may be thoroughly dry, in order to allow the digestive juices to soak into them. To facilitate this object, these grains should be given in a crushed state and mixed with a suitable vehicle, such as bran or chop. White peas are generally supposed to be superior to beans as a food for horses.

See Mr. E. D. Miller's remarks on beans, page 389 .

\section{MILLET.}

These seeds are largely grown in India, South Africa, Northern Africa, and America. In Bengal, great millet or guinea corn (Sorglum vulgare) is known as juwar; in Madras, as cholum; and in South Africa and America, as "Kaffir corn." Bulrush, or spiked, millet (Pennisetum typoideum, Rich.) is largely grown in India, where it is called bajra. Although I have seen sorghum seed used as food for horses with fair results in South Africa and India, I have had but little experience of it, and can only say that, like maize and barley, it is best given dry, broken, and mixed with bran or chop. "The seed of Kaffir corn weighs from fifty-six to sixty pounds to the bushel. Since this grain is used by millions of human beings for food, we can readily believe it valuable for feeding farm stock. Enthusiasts declare it fully equal to Indian corn for stock feeding, but this statement seems overdrawn. Probably Kaffir corn ranks a little below barley in feeding value" (Henry).

Stewart (Feeding Animals) states that millet "is found, when well ground (and it cannot properly be fed without grinding), to be one of the best rations for horses, being particularly adapted to the development of muscular strength." The stalks of both great millet and bulrush millet are a fair 
substitute for grass and hay as a food, and for straw as a bedding.

Bulletin 93, March, 1900, of the Kansas Agricultural College, states that Kaffir corn is stored best in the heads, hung up separately, or loosely piled and kept dry and well aired. If the grain is stored in bins, it is liable to heat badly in damp weather. "We have fed Kaffir corn meal to horses doing heavy farm work, and have found it to be a good feed. We feed the same weight of the Kaffir corn as we would of maize. Kaffir corn is generally fed to work horses on Kansas farms, when raised in large quantities. Some farmers grind it, some feed the thrashed grain, and others feed it in the head. Feeding in the head saves all expenses of preparation, and the stems of the head being eaten with the grain seem to be of value. To young horses and those not working, Kaffir corn may be fed just as it is harvested-stalk and heads-and makes a good feed. We have usually fed Kaffir corn ground to cows, calves, and horses, but have not made sufficient trials to determine whether grinding is best for these animals or not. For mature cattle and horses we know that feeding it in the head is a satisfactory method. We have tried grinding the heads without thrashing. They grind easily in a power Bowsher iron grinding mill. The resulting meal is a good feed for animals who need roughness, and the expense of thrashing is saved."

The writers of this Bulletin point out that stock quickly tire of Kaffir corn, when it is given by itself; but that this distaste can be obviated by combining this millet with a food rich in nitrogenous matter, such as beans, bran or linseed meal. They also state that this lack of nitrogen and excess of starch render Kaffir corn a very constipating food, and that it induces an unhealthy condition, which can be easily removed by an addition of lucerne hay or soy beans, both of which are rich in nitrogen. 
To obtain a percentage of nitrogenous matter equal to that of oats, in a mixture of Kaffir corn and one of the following grains, we would have to take, respectively, $121 / 2$ per cent. of beans, 18 of linseed, 20 of gram, and $81 / 2$ of soy beans.

The subject of great millet as an article of forage, is of special interest to horse owners in India, South Africa, the United States and other countries where the grain is grown.

RICE.

In some parts of India, especially in Eastern Bengal, unhusked rice, which is commonly called paddy (Hind., Dhan), is often given to horses after it has been kept for a year. In a raw and unbroken state it forms a fairly good food, which is much improved by being mixed with gram and bran, in the proportion of, say one of bran, two of gram, and four of rice. Rice being poor in nitrogenous matter, is improved by an addition of gram. Rice from which the husk has been removed is unsuitable for horses, owing to its poverty in fibre and mineral matter.

Rice-water (Hind., Kanjee) is useful in cases of undue looseness of the bowels. It may be prepared by boiling a pound of rice in two gallons of water for a couple of hours. If time be of consequence, and boiled rice be at hand, a sufficient quantity may be taken and well mashed between the fingers in warm water, the whole being brought to the boil, and then allowed to cool.

RICE MEAL.

Rice meal is the covering (or bran) of the grains of rice which is removed during the preparation of rice for table purposes. Its analysis shows that it is particularly rich in fat and mineral matters, both of which are valuable food constituents, especially for young horses. It has practically the 
same nutritive ratio (I to 6.I) as oats (p. I03), with three times more mineral matter, but a little less fibre, which can be amply supplied by hay or straw. I have no experience of rice meal in the feeding of horses. Mr. W. F. Shaw informs me that " in an agricultural district where oats command a good price, the more enlightened farmers sell their oats, and feed their farm horses on rice meal with chopped hay in a slightly damped state. These horses keep most excellent condition on the rice meal with a very small percentage of oats, and do not suffer from colic or other abdominal disorders, more frequently than the other farm horses of the same district which are fed exclusively on oats." These remarks from an experienced veterinary surgeon confirm the good opinion of rice meal which a study of its analysis would suggest.

RYE.

Horses are fed on rye (Secale cereale) to some extent in Northern Europe; but even in Russia, where it forms the staple food of the peasants, it is considered to be much inferior to oats as an article of fodder. It is, I believe, generally given in a coarsely ground state, moistened with water, and mixed with chop. I have often heard that it is not safe to give more than $5 \mathrm{lb}$. of rye daily to a horse.

\section{COCOANUT MEAL.}

According to experiments made in the French army, cocoanut meal proves an efficient substitute for oats. It is the residue in the manufacture of cocoanut oil, and has nearly the same composition as dried brewers' grains.

\section{POTATOES.}

Raw potatoes given to horses are very apt to disagree with them. In fact, many experienced veterinary surgeons are of opinion that they have a poisonous effect on these animals. 
Steamed potatoes mashed up and mixed with chop are probably the least objectionable form in which these tubers can be given. Even then, like other kinds of boiled food, they cause undue distension of the stomach and intestines of horses fed on them for a long period. The nutritive value of hay has been estimated at about three times that of potatoes.

\section{ROOTS, FRUIT, GOURDS, AND SUGAR-CANE.}

The chief articles which come under this heading, and which can be given to a horse with advantage, are carrots, parsnips, swedes, pumpkins, apples, pears, plums, and other sweet and succulent fruit. Although such roots and fruit can furnish but little energy to their consumer, they have a good effect on the system, possibly on account of their being richer in soda and poorer in potash than the other forms of fodder which horses consume. Hence, although roots and fruit cannot replace the hay and corn necessary for working horses, they are a very useful addition to equine diet. To avoid purging the horse, and unduly distending his stomach, we may accept Io lb. as a maximum quantity of such food. Carrots are the only kind I have used to such a large extent, although I have employed all the others as dainties for horses. Parsnips are supposed to be the next best roots to carrots, about the merits of which I can fully endorse what Stewart said about them in the following extract from his Stable Economy: "Carrots also improve the state of the skin. They form a good substitute for grass, and an excellent alterative for horses out of condition. To sick and idle horses they render corn unnecessary. They are beneficial in all chronic diseases of the organs of breathing, and have a marked influence upon chronic cough and broken wind. They are serviceable in diseases of the skin. In combination with oats, they restore a worn-out horse much sooner than oats alone." An addition of 5 or $6 \mathrm{lb}$. of carrots to 
the daily food ration of ordinary working horses will almost always be of benefit; and $3 \mathrm{lb}$. a day will not be too much for racehorses, even in the highest state of training. It is safest to give carrots sliced longitudinally, so that they may not stick in the animal's gullet and thus choke him.

Horses greatly relish good, ripe eating apples. I have never found that they have any difficulty in breaking the stones of plums between their teeth. In South Africa pumpkins are often given to horses as "green meat." Horses eat sugar-cane with great relish, and apparently with benefit. If this variety of grass is given in long stalks, a horse is apt, when consuming a piece, to put a forefoot on one end of it, and to squeeze the juice out of the other end, by drawing the stalk between his front teeth, which will tend to become quickly worn down by the resulting friction with the flinty surface of the cane. The possibility of a horse practising this form of cribbing, can be prevented by cutting the canes into short pieces.

As before indicated, I do not think it advisable to give roots, tubers, and similar articles of fodder in a boiled state to horses. In some parts of the East, horses are fed to a considerable extent on dates, which have a comparatively high nutritive value.

\section{INDIAN PULSES.}

Gram (Cicer arietinum), which is called chunna in Hindustanee, is a kind of pea, and is the grain most commonly used for horses in Northern India and the Bombay Presidency; not because it is preferred in those parts to oats, but because oats are more expensive and are more difficult to be obtained. Gram, like other peas, is too rich in nitrogenous matter to serve efficiently as the only grain for horses. In fact, a larger quantity of it than Io lb. daily can rarely be given without its causing offensively-smelling diarrhœa, and a 
" heated" state of the system. Gram is best used in combination with bran, Indian corn, barley, or unhusked rice; or with two or more of these grains. The nature of such combinations will naturally be governed to a large extent by the capabilities of the local market. In almost all cases bran will be readily obtainable. Gram before being used, should be at least seven or eight months old; should be given in a broken and dry state; and should be mixed with a vehicle, such as bran or chop, that will dilute it, and will separate its particles, so that the digestive juices may freely act on them. The process of steeping gram in water is objectionable, because it increases the indigestibility of that grain. With gram as the staple food, we may with great advantage combine it with bran in the proportion of seven parts of the former to five parts of the latter. If oats or Indian corn is available, I would by no means recommend the use of gram, except, as in the case of beans and peas in England, to increase the proportion of nitrogen in the food. For this object we might employ the following combination, in which the bran is a useful addition :-

Oats or Indian Corn .

Io parts

Gram

2 ",

Bran

If a mixture of gram and maize be employed without any other grain, it may require an addition of bran or chop, owing to deficiency in woody fibre. The necessity of this addition is not imperative when gram is used with Indian oats, the percentage of husk in which is very high.

Kulthee (Dolichos biflorus) is used extensively throughout the Madras and Bombay Presidencies as a food for horses. It is always given boiled; because the hardness of its husk is supposed to preclude its employment in a dry state. This conclusion probably requires further corroboration. I am inclined to think, from my experience among native 
grooms on the Madras side, that the idea of the absolute necessity of boiling kulthee in order to render it fit for horses to eat, is greatly strengthened in the minds of these men, by the fact that the water left after boiling this grain forms excellent "stock" for their own "pepper water" (mulligatawny). The experiment of feeding horses with broken, dry kulthee mixed with bran or chop is worthy of trial. If it be desired to boil kulthee, only enough water to cook it should be used, so that, when it is fully done, the fluid which remains over in the pot may be absorbed on cooling. The steam should be allowed to escape, so that the boiled kulthee may be as dry as possible. When properly boiled, the interior of the grains will be dry and floury, like that of good and well-cooked potatoes. Kulthee is nearly similar in composition to peas, and consequently it is of a too highly nitrogenous nature to allow of its being given to horses in large quantities. The daily maximum of kulthee might be put down at ro lb., which is a quantity that would contain far too little starch for a hard-working animal. Consequently, maize or rice (paddy) would form a valuable addition to it. Boiled kulthee, used in small quantities, has often an excellent effect on the general condition and coat.

Urud (Phaseolus mungo var. radiatus) and moong (Phaseolus mungo) are both very like kulthee in composition and qualities, and can be prepared in the same manner.

Mote (Phaseolus aconitifolius) is a grain of the feeding value of which I have no personal knowledge. A friend of mine who has had a long experience among horses in India, tells me that equal quantities of mote and gram, broken and given raw, forms a good food for horses. I would with confidence suggest the daily addition of from 2 to $4 \mathrm{lb}$. of bran to this mixture, which, also, ought to have chop added to it. 
COIVS' MILK.

On comparing the respective analyses of mares' milk and cows' milk, on page 63, we find that to make the latter approximately equal to the former, we should add to each pint of fresh cows' milk about $1 / 2$ pint of water and $1 / 2$ oz. of sugar. If we adopt the following analysis, which is by König, we should add about $3 / 4$ pint of water, and I oz. of sugar.

\begin{tabular}{|c|c|c|c|c|c|c|c|c|c|}
\hline Ia & & $\begin{array}{l}\text { Water. } \\
90.78\end{array}$ & $\begin{array}{l}\text { Nitrogeno } \\
\text { matter. } \\
\text {... } \quad \text { I.99 }\end{array}$ & & $\begin{array}{l}\text { Fat. } \\
\text { I.2 I }\end{array}$ & & $\begin{array}{c}\text { Sugar. } \\
5.67\end{array}$ & & \\
\hline ows' milk & $\ldots$ & 87.17 & .. 3.55 & $\ldots$ & 3.69 & $\ldots$ & 4.88 & $\ldots$ & $0.7 \mathrm{I}$ \\
\hline
\end{tabular}

As the difference between fresh cows' milk and skim milk or separated milk is simply one of fat, these creamless forms of milk are useful additions to the food of horses, especially to that of growing animals. It is evident that they contain nearly all the salts and nitrogenous matter (casein) of fresh milk. As horses appear liable to become infected with tuberculosis from drinking the milk of tubercular cows, great care should be taken that any milk given to them is obtained from healthy cows or has been sterilised. Tubercular milk may be rendered harmless by keeping it for a few minutes at a temperature of at least $185^{\circ} \mathrm{F}$. Tuberculin furnishes us with a valuable, though not always infallible, means of testing cattle for tuberculosis. It appears that not less than 25 per cent. of all the horned cattle in the United Kingdom is affected with this disease.

GRASS, HAY, AND STRAW.

As far as their respective feeding values are concerned, hay may be regarded as grass which has been deprived of a portion of its water and of a varying percentage of nutritive matter, lost during harvesting and storing. Each 
variety of grass thrives best on a certain kind of soil ; hence we find that what is excellent grass on one sort of land is of inferior nutritive worth when grown on another. Also, the nature of the manure greatly influences that of the herbage. It is therefore useless to lay down hard and fast rules as to what are the most suitable grasses under all circumstances for pasture or hay. Figs. 6 to 12 show specimens of some of the best grasses and clovers. The presence of Yorkshire fog, twitch, thistles, docks, sorrel, coltsfoot, sedges, rushes, tussock grass, ragwort, and other useless and injurious grasses and weeds is always undesirable.

Hay is obtained either from permanent (natural) or temporary (artificial) pasture. The cultivation of meadow (permanent pasture) hay is so much neglected, as a rule, that it is generally inferior to temporary pasture hay, for the production of which the experienced seedsman will furnish "prescriptions" that will give crops respectively for from one to eight years (see Sutton's Permanent and Temporary Pastures). Besides, the grasses of permanent pasture usually consist of varieties which do not all flower about the same time, and consequently such pasture would, as a rule, be better suited for grazing than for mowing. Horses which are fed on a large quantity of corn, usually prefer the hard hay made from the first and second cuttings to those of subseqquent ones, which become successively softer in structure. I have nothing to add to the remarks already made on pp. 98 and 108 to II 2 with respect to the quality of hay, except to repeat that it should be dry, fairly green in colour, fragrant in smell, and that the seeds of the contained grasses should not be so ripe as to readily fall out of their ears. As a rule, clover hay becomes more or less brown.

As explained on pp. 97 and 98, hay made from mature grass is more suitable to horses which are fed on a large 
quantity of corn than hay made from younger and more nutritious grass. Animals which have to depend for their sustenance mainly on hay will naturally do best when that article of fodder has a high nutritive value.

Hay tea, which may be prepared by steeping hay in boiling water and then allowing the infusion to cool, contains valuable nutritive material in the form of mineral salts and other soluble substances.

Although, as we have seen, straw has very little nutritive value, it is rich in woody fibre, the presence of a certain proportion of which is a necessary constituent of the food of horses. Hence the larger the ration of corn, the more appropriate will be an addition of straw. Therefore, if a horse has a large daily allowance of corn (say, I8 lb. or more), straw, in the form of chop, will probably suit his digestive organs better than the most nutritious hay. Here we have a point of stable economy which should not be neglected by an intelligent horse-owner. It is an instructive fact that, as a rule, the more corn a horse gets, the more inclined will he be to prefer straw to hay. Hence the so-called vice of eating straw bedding, is often an act of obedience to the stimulus of a healthy appetite. We may here remember, as I have already pointed out, that horses in many Eastern countries are fed only on grain and straw for the greater part of the year, and keep in excellent condition during that time. If a horse be stinted in corn, it would of course be much better to add nutritious hay to his ration than innutritious straw. I have known dangerous attacks of constipation to be caused by giving horses too much straw to eat, and at the same time depriving them of a sufficiency of corn, hay, and other nourishing food. Oat straw is more nutritious than any other kind of straw, especially when it is young.

Chop or chaff is the usual term applied to chopped hay or 


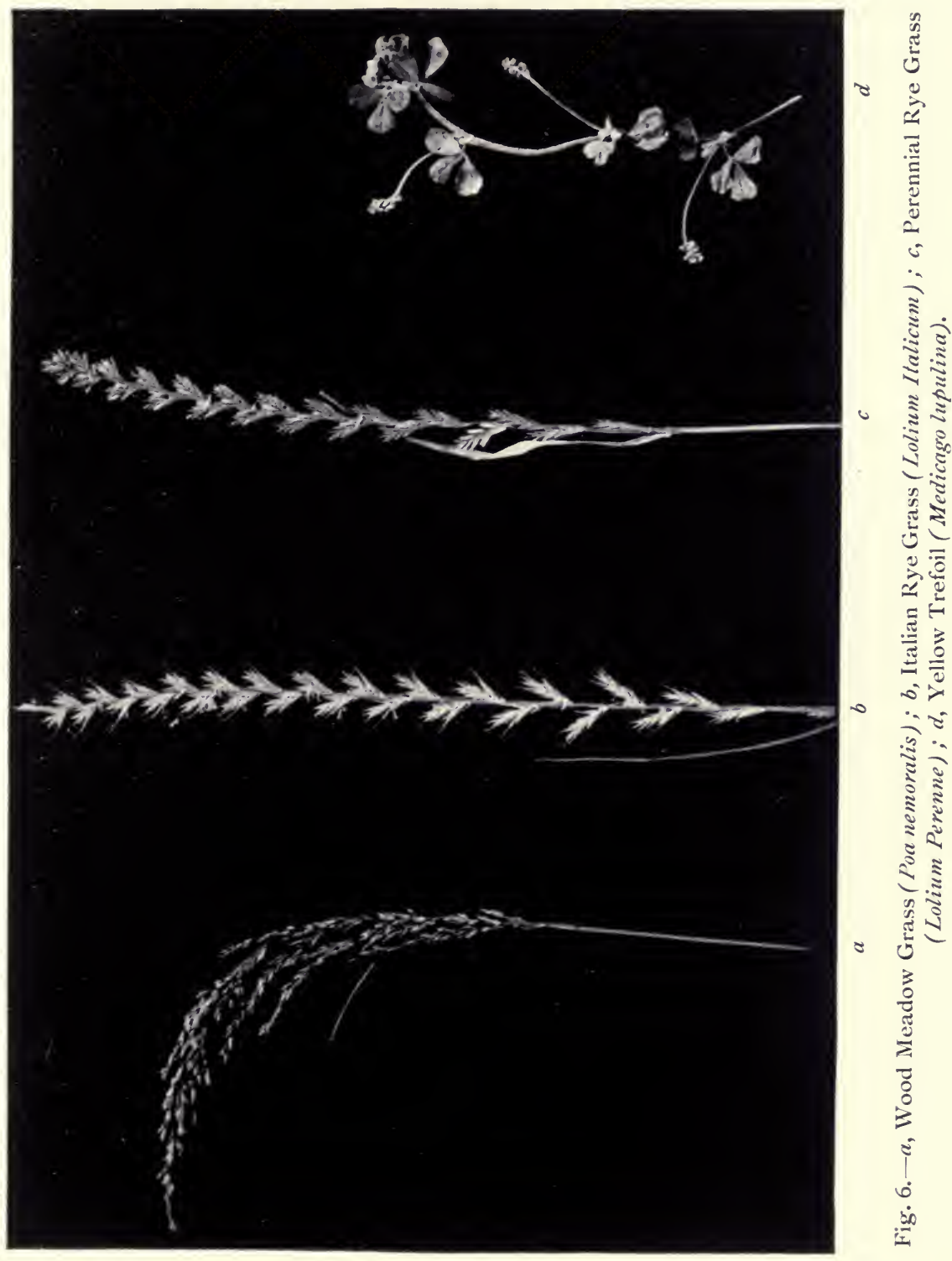



chopped straw which is added to the corn given to horses. An economical and common mixture of chop consists of two parts of hay to one of straw. See Mr. Shaw's remarks on chop, page $18 \mathrm{I}$.

\section{LUCERNE.}

Lucerne, which is known as alfalfa in America, is a very valuable food for horses, both green and as hay. It requires dry ground, a warm aspect (preferably in England, ground sloping to the south), and a permeable subsoil rich in lime, which forms a particularly large percentage of the mineral matter in this plant. As the roots descend to a great depth, the absence of lime in the subsoil cannot be efficiently replaced by lining the ground. Ten or twelve feet is not an unusual length for the roots. Bonnet gives an instance of the main root of a plant of lucerne being sixty feet long.

Unfortunately, the necessary conditions of climate and soil for the successful growth of lucerne, cannot always be obtained in England. This fodder thrives best in climates like France, Italy, Spain and the Argentine Republic. It grows well on suitable soil in India, provided that it is frequently watered during the dry weather. Owing to the great depth the roots penetrate, it can bear drought better than any other plant of its kind. Stebler and Schröter state that " if the district has a heavy rainfall, the plant does not thrive at all. It may, in fact, be assumed that lucerne cannot be successfully grown wherever the annual rainfall exceeds 32 or 36 inches, even though the soil is suitable in other respects. Not only is the rain directly injurious, but weeds are favoured and obtain the upper hand." I venture to think that this remark with respect to the quantity of rain which is detrimental to the growth of lucerne, holds good only with reference to temperate climates; for I have found in tropical countries, that this plant thrives only with a frequent and liberal supply of water. In any case, stagnant water is hurtful to it. 
In the cultivation of lucerne, which is not an unimportant branch of stable economy, we should bear in mind that the young shoots grow perpendicularly upwards from the rhizome (rootstock), and thus leave spaces which are liable to be occupied by grass and weeds that will more or less choke and impoverish the plants. Hence, in the sowing of lucerne, care should be taken to obtain pure seed and clean soil. The best preparatory crop is roots or potatoes which have been well manured. "After harvesting the preparatory crop, the ground is prepared as thoroughly and as deeply as possible. The subsoil-plough may be used, or two ploughs can be passed through the same furrow, the one to turn the surface soil and the other to stir the subsoil. This preparation of the subsoil is essential, if the land is at all firm. Lucerne is usually sown about the end of April or the beginning of May, when there is no danger of late frost, which acts injuriously upon the young plants. Late sowing also has its risks, as the fly which comes in with the warm weather is equally injurious" (Stebler and Schröter). It is well to sow in drills, so as to facilitate weeding; and Sutton tells us that the seed must not be deeply buried. In the event of manure being required, Stebler and Schröter advise the employment of 40 or $60 \mathrm{lb}$. of nitrate of soda on each acre, and point out that a dressing of stable dung is not only a waste of manure, but is actually hurtful, because it greatly favours the growth of weeds. Sutton recommends three cwt. of superphosphate per acre. "Its duration varies from 3 to 20 years and depends upon the nature of the soil and climate. In climates where the soil is warm and deep, fields of lucerne from 12 to 15 years are quite common; some fields are in their twentieth or even their twenty-fifth year and still the plants are good. If the conditions are unfavourable, the plants usually die out within a period of 3 years. Cultivation is only profitable when a ley of 5 or 6 years' duration can be relied upon. At the end of the ley, the land 


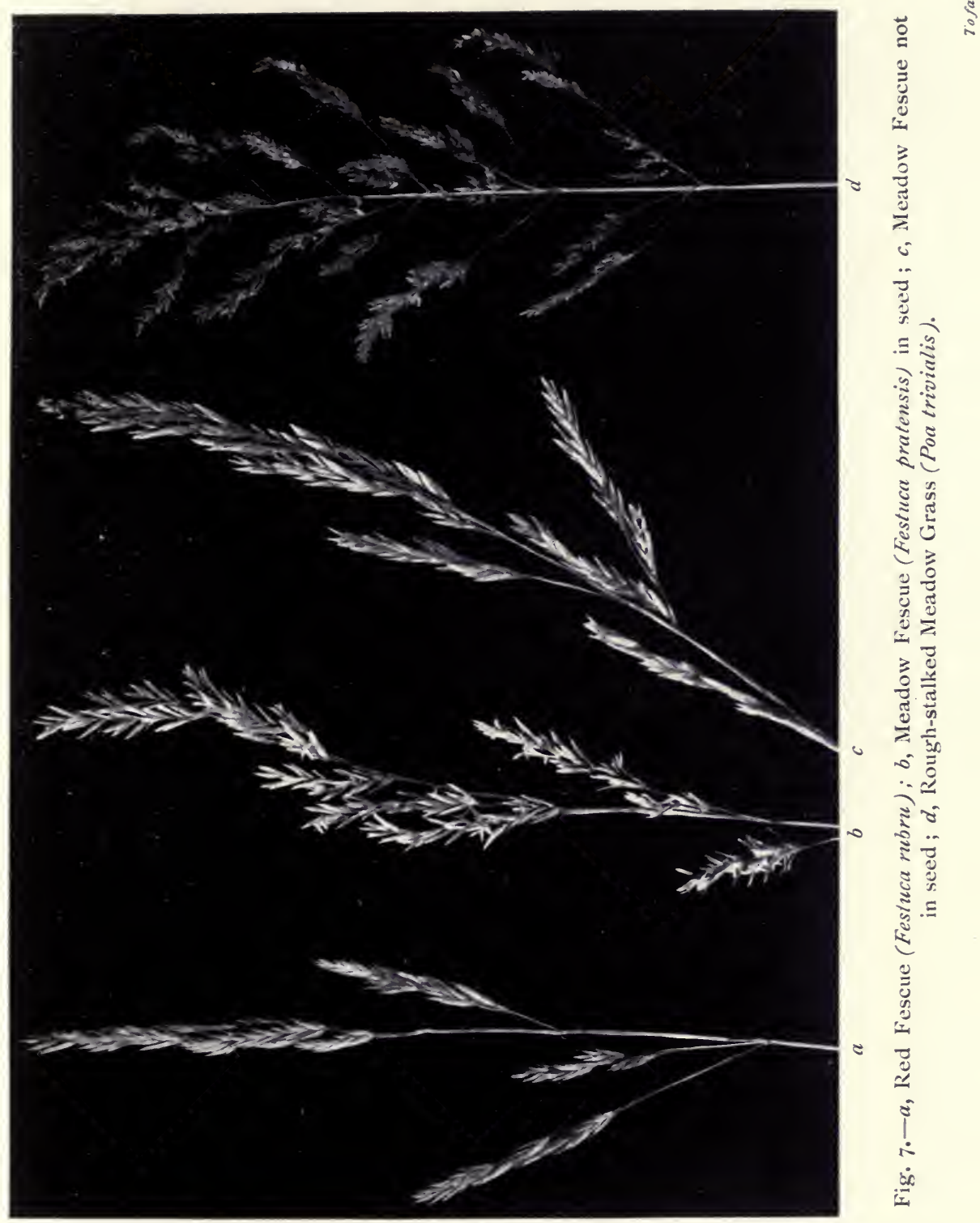



is broken up, and a cereal crop follows. As a general rule, it can recur on the same land only after a period of rest equal in duration to the lucerne ley. This interval of time, however, depends largely upon the nature of the subsoil ; if this is good, the crop may recur sooner" (Stebler and Schröter).

Lucerne can usually be cut four or five times in the year. In fact, whether it is used green or as hay, it ought not to be allowed to flower; for as Wolff points out, it rapidly loses its nutritive properties after that period, by developing fibre. Besides, if cut when in flower, and especially when in seed, the plants become exhausted, and their life shortened. The best way for stable use, is to cut a little every day, according to requirements. It is advisable to dry it in the sun for an hour or more before giving it, so as to render it more digestible and to make the horse chew it better. For working horses, 3 or $4 \mathrm{lb}$. of green lucerne will be a fair daily allowance; and for idle horses, 8 or $9 \mathrm{lb}$.

Exact experiments have shown that hay made from young - lucerne, is of higher feeding value than either pasture hay or clover hay (Farm Foods). Such hay, which is probably the best form of lucerne for feeding purposes, will be more or less of a green colour. As the nutritive matter of cut lucerne is very soluble in water, and as the leaves of dry lucerne are particularly brittle; it is essential when making lucerne into hay, to dry it quickly, and to turn it as little as practicable. Care should be taken to give in a clean state to horses, and to remove from it any adhering fungi, which often attack lucerne.

A plot of lucerne forms a very useful adjunct to a stable.

\section{BAMBOO LEAVES.}

In the hill districts of Eastern Assam and Burma, I have had many opportunities of seeing bamboo leaves used as a complete substitute for ordinary grass and hay in the feeding of horses, without any marked difference in the condition of 
the animals. This giant-grass, if given in too large quantities, is apt to have a laxative effect. Only the tender leaves and young shoots should be employed, because the old leaves are not only unwholesome on account of the large amount of silica (flint) contained in their surface, but from the same cause, they are also apt to inflict severe wounds on the tongue and lips during mastication. "During the Chin-Lushai Expedition in I889-90, the animals with the force got nothing else for nearly eight months. I had three ponies of my own that were worked moderately hard the whole time, and they remained in good condition. The transport mules, which were worked very hard indeed in a very trying climate, did not fall away nearly as much as I expected " (Nunn).

\section{CONDIMENTS, ETC.}

Condiments are agents which stimulate the appetite, but do not supply material that can be utilised in the nourishment of the system. Fortunately for horses, the use of condiments has almost entirely gone out of fashion. Lawes and Gilbert state, with reference to the feeding of sheep, that " in both of the comparative experiments, more food was consumed to produce a given amount of increase with Thorley's Food, than without." The use of tonics and alteratives should be restricted to cases of illness, which should be treated, if possible, only by a veterinary surgeon. 


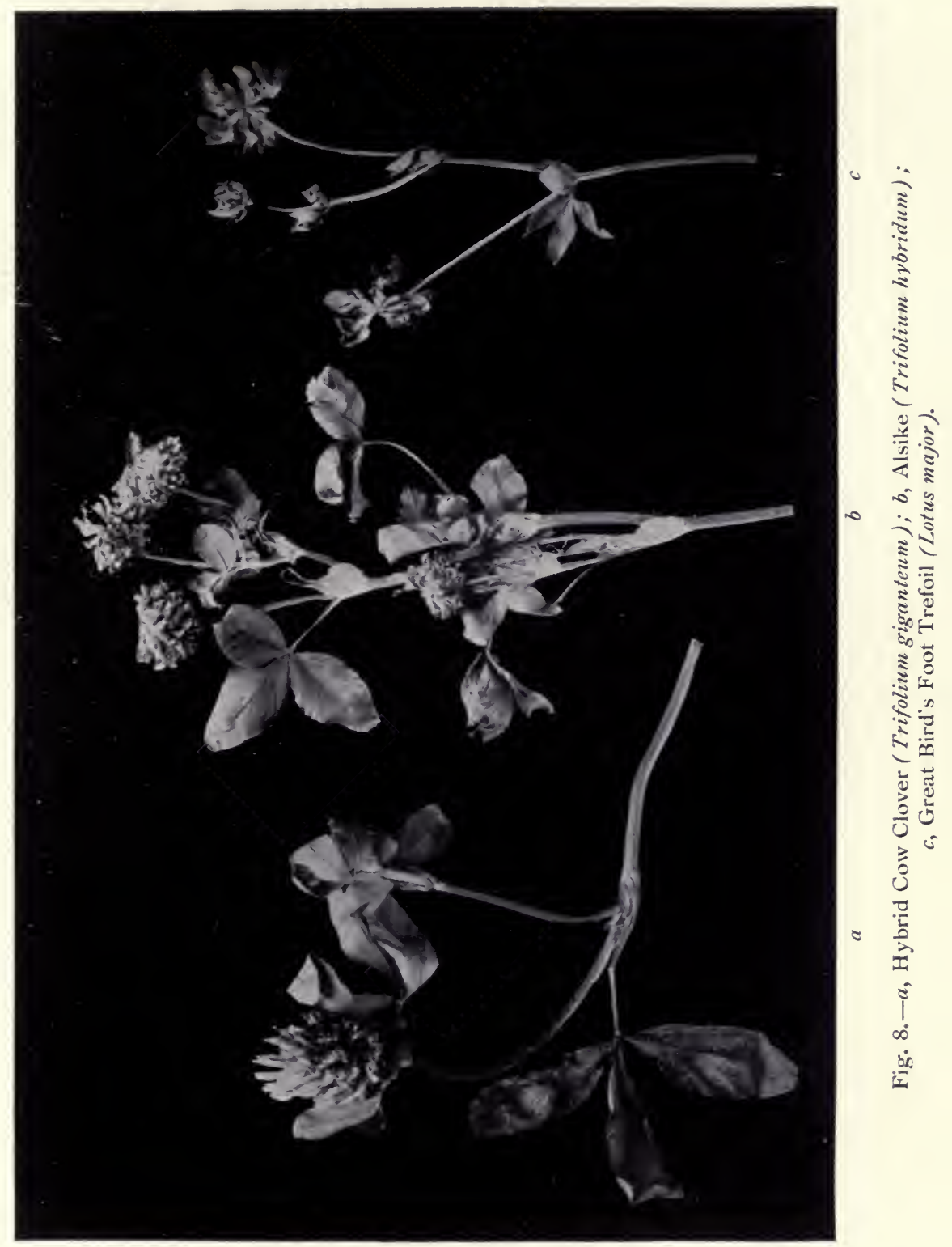


canal; but dry forage which is rich in fibre, such as hay and straw, retard its action. Hence, when horses, presumedly idle ones, are given little or no corn, the remainder or the entire of their ration, as the case may be, should not be exclusively composed of hay or of hay and straw, but should consist more or less of green food, which will keep the alimentary canal in good order, and will aid in preventing the accumulation of injurious materials in the system.

\section{ECONOMY IN THE SELECTION OF FOOD.}

Although oats are the best kind of corn for every class of horse, we may be forced to seek for a substitute from motives of economy. Maize appears to be the only efficient substitute in the case of hard-working horses. Although barley (p. I 54) may be given up to 9 or Io lb. daily, it is not conducive to health if the quantity be much increased beyond that limit. Mr. W. F. Shaw, F.R.C.V.S., who has had great experience in the feeding of tram and cart horses, tells me that "a few years ago, barley, $50 \mathrm{lb}$. to the bushel, could be purchased at I2S. or I3s. a quarter; while oats, $38 \mathrm{lb}$. a quarter, cost I4S. or I5s. Barley was then used to adulterate oats very heavily. In some cases a mixture containing a third of barley was sold as oats to small horseowners. This barley was not even crushed, and yet at that time knackers' yards did not receive more carcases of horses which had died from digestive derangements than at times when oats were cheap. A certain tramway company at that time fed their horses on a daily allowance of $16 \mathrm{lb}$. of crushed barley mixed with chop. The mortality was considerably increased; but even then the company, I am inclined to think, were in pocket, on account of the saving on the corn bill." Mr. Shaw mentions this as an economic fact, but not as an example to be copied.

The principle upon which commercial horses are at present 


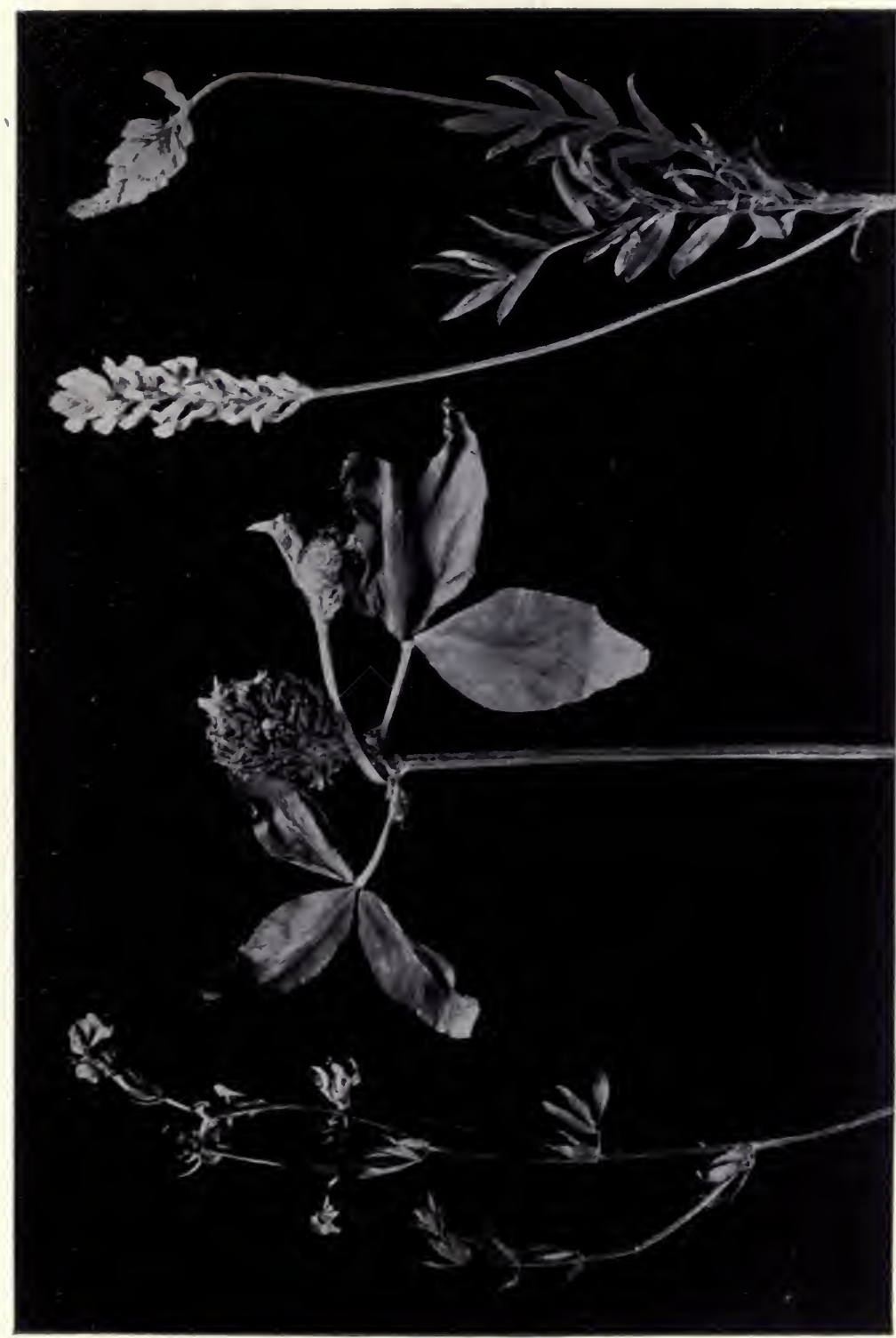

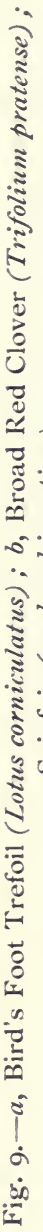



generally fed, is that the grain which is cheapest, weight for weight, is the one that is selected for use. It is usually thought advisable to increase the feeding value of maize by an addition of about a sixth part of peas or beans. Mr. Shaw, however, states that "in feeding cheaply, even for hard work, beans and peas can be left out of the bill of fare. Although I am fully aware that this is contrary to general usage, and opposed perhaps to the teaching of chemistry, I consider that the high price of these grains prohibits their employment, when trying to feed economically. I found from an experience of several years in feeding a large stud of horses which had to be maintained in condition to perform hard and fast work, that these animals accomplished their task and kept their condition in a satisfactory manner without a single pea or bean being given them." Mr. Shaw considers that bran, even in small quantities, is not an economical food.

With respect to the nature of the chop, Mr. Shaw tells me that "in the majority of commercial studs the principal constituent of the chop is meadow hay, which by itself would render the chop too soft for obtaining a uniform distribution of the grain throughout the entire mass of the food. A small quantity, say a third, of oat straw placed in the cutter, will enable the hay to be cut shorter, and the resulting chop will be more useful for mixing, and will entail no deteriorating effect on the condition of the horses. Clover, lucerne, and sainfoin are employed for the same purpose to mix with meadow hay. Best clover hay is too expensive for economical feeding, and inferior clover hay, which may. be purchased cheaply, is apt to cause serious digestive disturbance from its unduly hard and woody character.

"Dutch hay, Russian hay, American and Canadian timothy, South American lucerne, and Algerian hay are used in this country, when home-grown meadow hay becomes expensive. If foreign hay, either wholly or in part, is employed, care 
should be exercised in its selection; because serious mortality is often brought about in a stud by the injudicious feeding of such forage, in which case, as a rule, the grain, and not the hay, unjustly gets the blame. A few years ago, great mortality was produced amongst horses in this country by the importation of a large quantity of Algerian hay. As long as the chop is sound, its composition is of little moment, because it is merely the vehicle for facilitating the assimilation of the grain, which is the essential force-producing material.

"During the hay famine which occurred some years since, I witnessed a six months' experiment of giving chop, consisting entirely of straw, to a hundred horses in a large working stud, the remainder being supplied with hay chop, in which there was a small percentage of straw, but no change was made in the grain. During the allotted six months, the hundred experimental horses performed their work quite as well as the hay-fed animals, and at the end of this period were in equally good condition.

"With horses that are inclined to waste their food by throwing it out of the manger, there is economy, without injurious results, in damping the food."

\section{SCALES OF DIET.}

In all cases I assume that the horse gets at least $3 \mathrm{x} / 2 \mathrm{oz}$. of salt (p. IOI) daily in his food, or that he has a lump of rock salt constantly in his manger.

I. Idle Horses. - The experiments of Grandeau and Leclerc show that an average horse, when in a state of idleness, can maintain his weight on $17 \mathrm{I} / 2 \mathrm{lb}$. of hay, or on $5 \mathrm{lb}$. of oats and $5 \mathrm{lb}$. of hay. We all know that an ordinary horse turned out to grass can keep in health on simply the natural herbage of the field; but on such a ration his muscular powers will gradually decrease down to his grazing requirements. Hence, if we want him to maintain his strength, as 


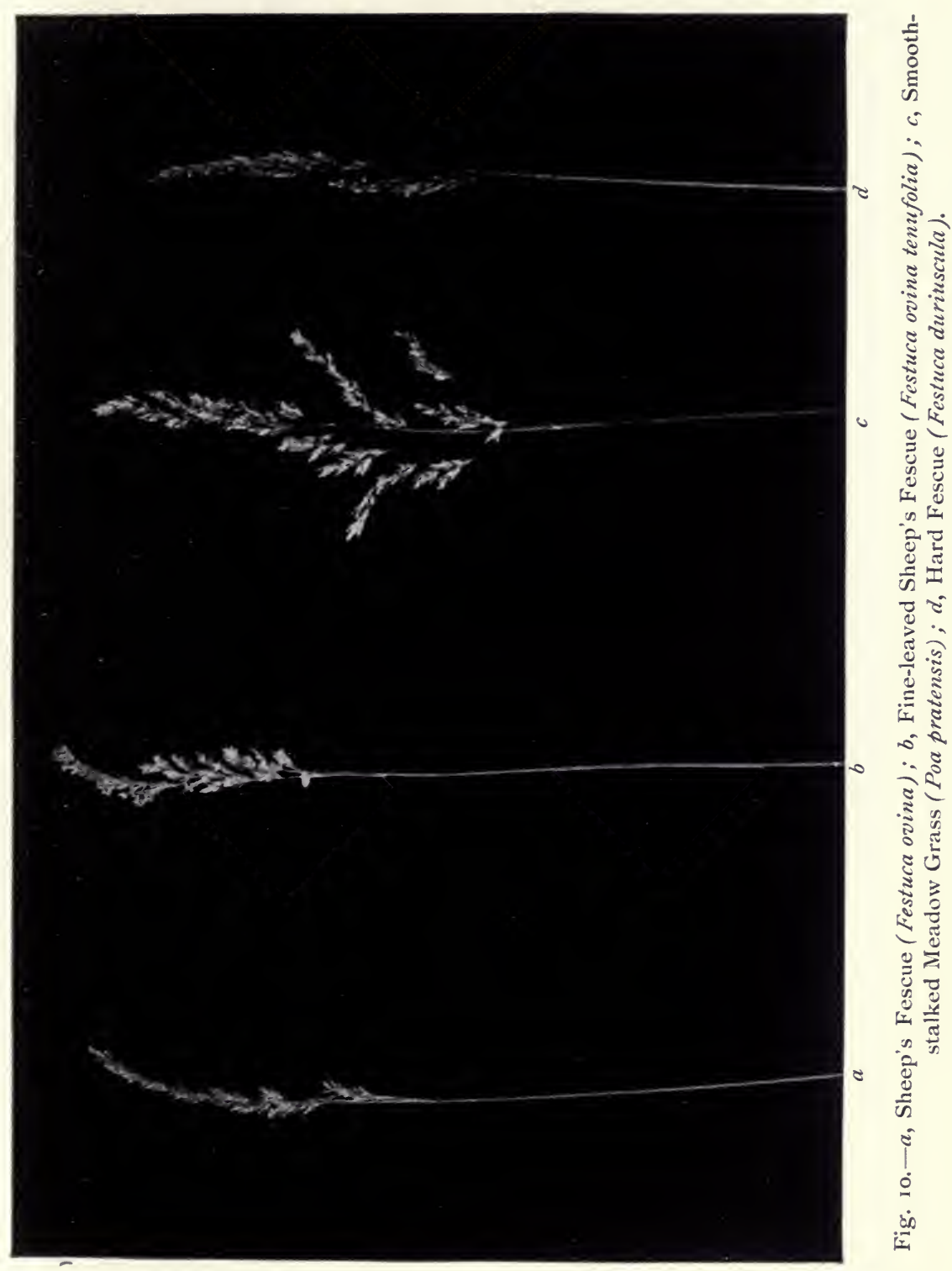



in the case of a hunter turned out in summer, or a polo pony at grass during winter, we should supplement his open-air food with a moderate quantity of corn, say, about $5 \mathrm{lb}$. This addition will have no "heating" effect; because the extra nourishment received into the system will become "worked off" by the increased exercise which the animal will take in response to the stimulating action of the corn. This voluntary exercise, supposing the animal to be sound, will be of great benefit in keeping up his condition, which once lost, takes a long time to regain. A horse cannot maintain life on straw as his only food.

Healthy horses which take no exercise, such as those on board ship, may get either of the following rations, according as carrots can or cannot be obtained :-

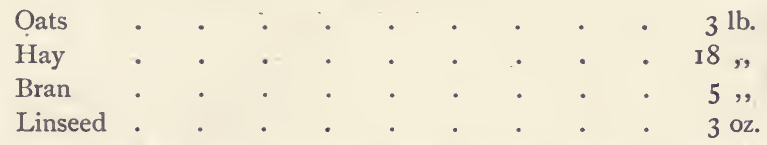

The linseed may be given as a mash or as linseed tea from time to time, or as meal.

Or,

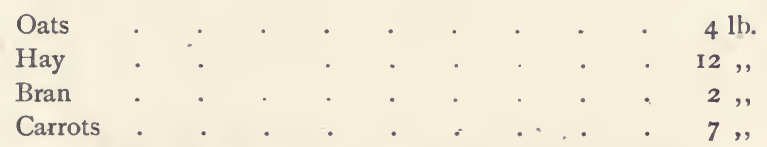

With this ration there is no need to give a mash.

2. Horses in Light Work.-

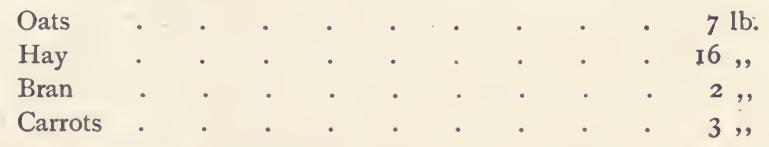

3. Horses in Moderate Work.-As examples under this heading we may take cavalry horses during peace time :-

ENGLISH CAVALRY HORSES.

Oats

Hay

Io lb.

- The hay might with advantage be increased to 15 or $16 \mathrm{lb}$. 
GERMAN CAVALRY HORSES.

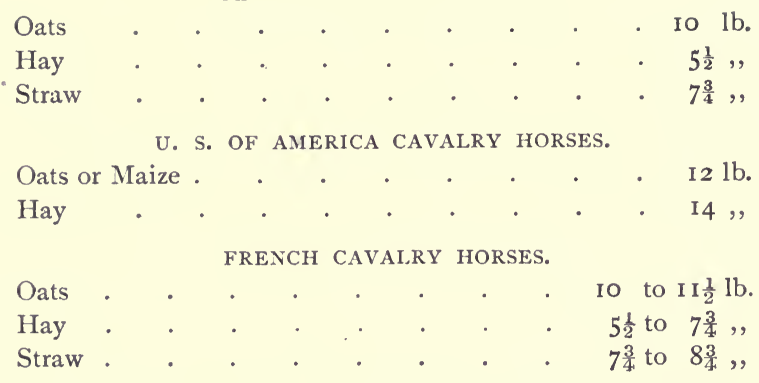

4. Horses in Full Work.-Hunters and light harness horses might get on an average $\mathrm{i} 4 \mathrm{lb}$. of oats, $\mathrm{I} 2 \mathrm{lb}$. of hay, $3 \mathrm{lb}$. of carrots, and $2 \mathrm{lb}$. of bran. If the work is extra hard, an addition up to $4 \mathrm{lb}$. to the allowance of oats need not usually be exceeded. With an increase in the quantity of corn, there should be a corresponding diminution in that of hay. Racehorses in full training and others, like London cab horses, which have to do as much labour as can be extracted out of them, should get as much corn as they can eat, the maximum quantity of which may be put down at about $22 \mathrm{lb}$. As the height of polo ponies is $\mathrm{I} 4 \mathrm{~h} .2 \mathrm{in}$. and under, they will eat about three-quarters as much as hunters; say, IO or I2 lb. of corn a day.

We should bear in mind the law which experience and theory teach us, that the more continuous the work, the more corn will a horse require.

As illustrative feeds for cart, 'bus, tram, boat, and van horses, which have to be regarded, as a rule, from an economic point of view, we may take the following scales of food :LONDON ROAD CAR COMPANY'S HORSES.

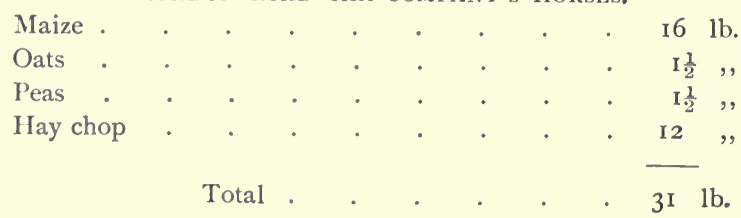




$$
\text { Sidition. }
$$

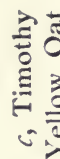

$\ddot{i}$

$\because$.

$\approx 2$

帘

a

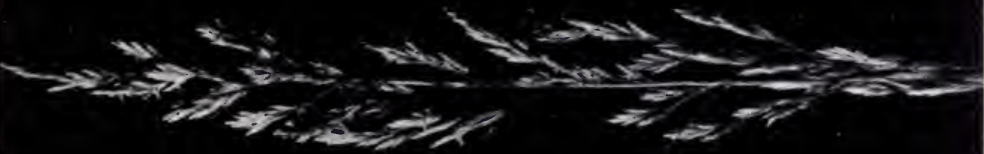

$$
x^{-\frac{1}{3}}
$$

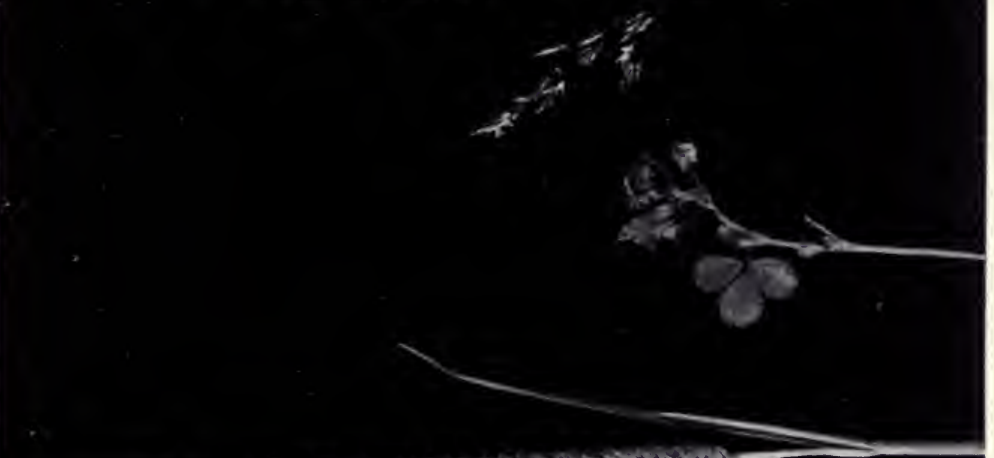

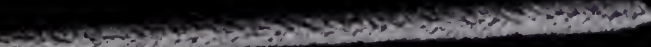

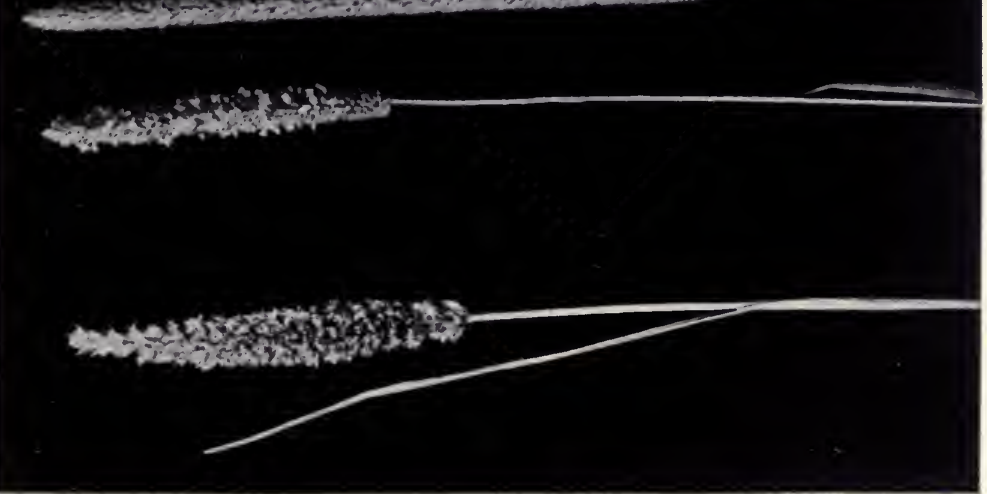

ริ

ปั ธूँ $\nabla$ 记 茂 

The good condition of these animals, and the large amount of hard work which they go through daily, prove that the above economical though liberal ration serves its purpose in a manner that leaves nothing to be desired. The former daily ration for the horses of this company was :-

$$
\begin{aligned}
& \text { Maize • • • • . • • • . II lb. } \\
& \text { Oats . . . . . . . . . } 5 \text { " } \\
& \text { Peas or beans . . . . . . . . } 3 \text {, } \\
& \text { Hay chop . . ‘ . . . . . } 12 \text {," } \\
& \text { Total . . . . . } 3 \mathrm{rlb} \text {. }
\end{aligned}
$$

The average cost of this food was about 9s. a week.

A heavy cart horse or powerful omnibus animal in full work will generally require about $19 \mathrm{lb}$. of corn a day. An ordinary tramway or light omnibus horse should not have less than $15 \mathrm{lb}$. One tramway company gives the following ration with good results :-

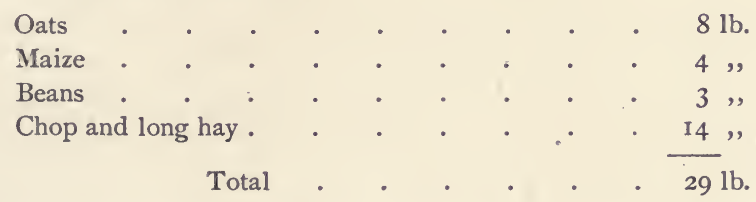

This ration would on an average cost fully IOs. a week, owing to the large proportion of oats and beans in it.

A full-sized Shire, Clydesdale, or Suffolk cart horse doing ordinary work in town or country would need not less than I6 lb. of corn, to be made up with hay or hay and straw to at least $30 \mathrm{lb}$. of fodder. For really hard work, the daily amount of corn should be increased to 19 or $20 \mathrm{lb}$. A moderately-sized farm animal in hard work might be content with $14 \mathrm{lb}$. of grain and $\mathrm{I} 3$ or $14 \mathrm{lb}$. of hay.

\section{REGULARITY IN FEEDING.}

The good effect which regularity of feeding has on the health of horses is apparently due to the fact that the re- 
spective functions of nutrition and excretion readily accommodate themselves to routine, the influence of which on the mind is made manifest by the formation of a habit. We know from our personal experience that expectation of food stimulates appetite, and that disappointment at not obtaining it at a particular time has the opposite effect. In both these cases, the influence of the mental impression in all probability is not confined to the appetite, but also extends to digestion. We also find that regularity in going to stool is a valuable preventive to constipation; and that "soliciting nature" has often a good effect when we are suffering from that form of indisposition. The tendency which the excitement of hearing the music cf the hounds or seeing a racecourse has to make, respectively, a hunter or a racehorse dung more or less loosely, is a good instance of the strong influence which the equine mind has on the equine body.

\section{ADVISABILITY OF NOT GIVING A HORSE MORE FOOD THAN HE CAN CONSUME AT ONE TIME.}

An important point in the routine of feeding is that a horse should not be given at one time more corn, mash, roots, or chop than he will consume "then and there." If he leaves some of the food, we should have it at once removed, and the manger cleaned out. I venture to base the reasonableness of this limitation of food, on the fact that the unconsumed remainder will be rendered more or less distasteful to the animal for a future meal, by his having breathed and slavered over it, and that if it is kept before him, it will be apt to put him "off his feed." Food which is left in this manner soon begins to decompose, as we can find out by the sour smell given off by it. We must here bear in mind that the horse is a delicate feeder, which, in a state of nature, continually changes the spot from which he selects his food; and that the fresher it is, the more will he relish it. I have often 


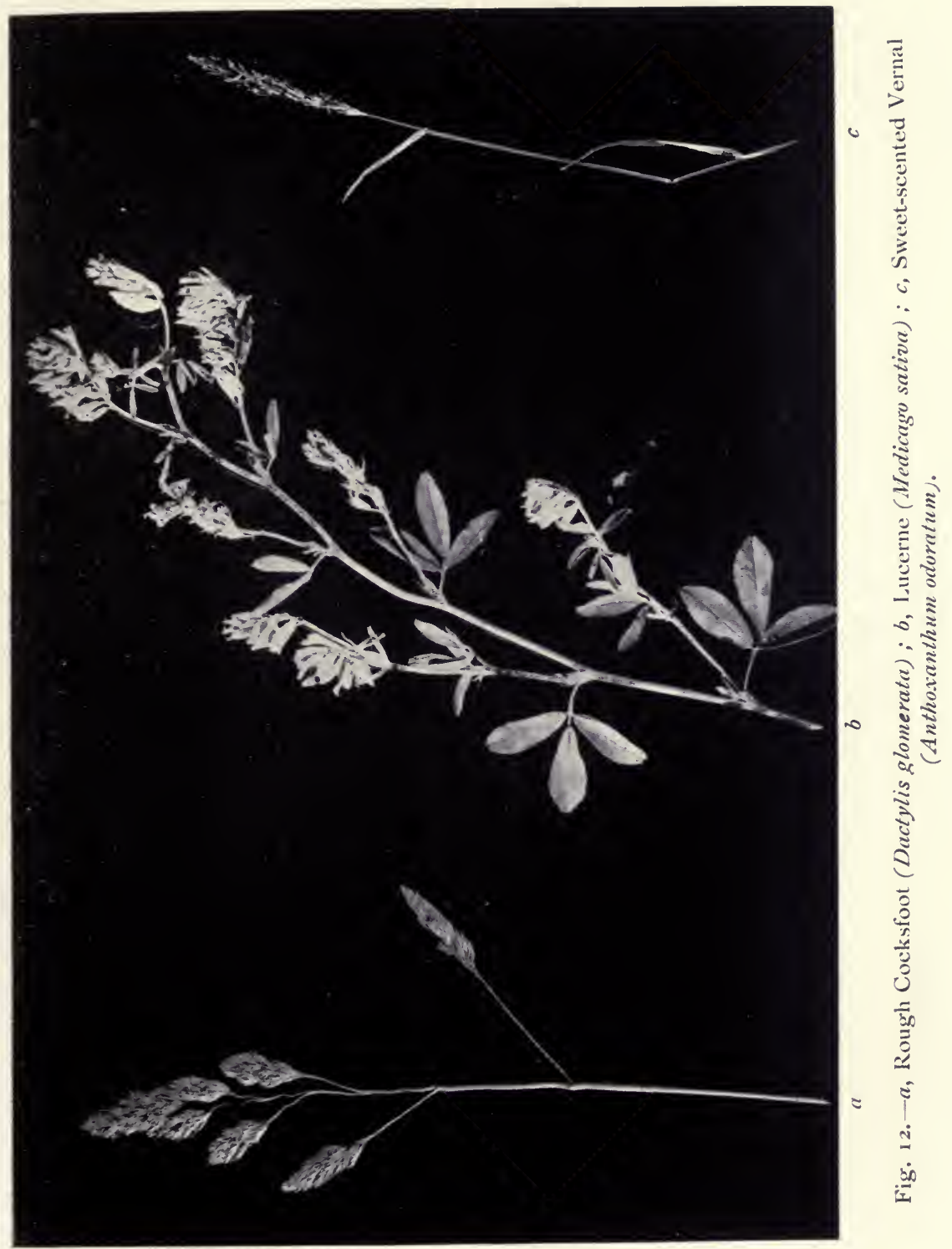



observed that a horse which would fail to consume during the night a large and last feed of corn given to him at six or seven in the evening, would eat up every grain if the same quantity of corn was divided into two halves, one to be given at six or seven; the other, at ten or eleven. When hay is given after the last feed at night, or at times when the animal is supposed to consume it at his leisure, it is best for it to be long hay; because, when it is in this form, the horse will be inclined to pull out the chosen mouthful and separate it from the remainder of the hay, which will then run but little risk of becoming tainted by the horse's breath and saliva. Taking into consideration the inevitable ennui which a horse must suffer from the more or less solitary confinement he undergoes in a stable, we ought, I think, to allow him the innocent distraction of selecting and picking out the stalks of hay, when rigid economy of fodder is not a matter of supreme importance. In any case, long hay might be given after the last feed at night.

\section{DAILY DISTRIBUTION OF FOOD.}

A working horse, as we have already seen, should be frequently fed. While observing the rule that a horse should not get more corn than he can finish straight away, we should bear in mind that the sooner work follows the consumption of food, the more apt will it be to cause indigestion. Hence, the quantity given to a horse at one time should, to some extent, be proportionate to the length of the period of idleness which is to follow the meal.

In the giving of hay (under which term we may include straw and other substitutes), we may give some before feeding, mix chop through the corn, or give hay at the same time as the corn, but not mixed with the grain, so as to allow the horse to go to one or the other as he chooses. The usual plan of giving hay after feeding is objectionable in the case 
of an animal which does not get sufficient corn to satisfy his appetite; because the quantity of hay which he will consume, in order to fill up the vacant space in his interior, will interfere to a greater or less extent with the digestion of the corn in the stomach. Precautions against such an occurrence are hardly needed in the case of a horse which has as much, or nearly as much, grain as he cares to eat; because he is not likely to overfill himself with hay, after having just consumed a good allowance of the more palatable part of his food. As a rule it is best to mix the hay through the corn in the form of chop. When this cannot be done, some hay should be given before feeding, and also while the animal is eating his grain. In determining the daily amount of chop or of the hay which is to be given before feeding, we may safely take as a maximum the average amount of hay which a horse having an unlimited supply of corn would eat. Putting this quantity of hay at $7 \mathrm{lb}$. for a light horse, and at Io $\mathrm{lb}$. for a heavy animal, we may estimate the ordinary weight of chop at respectively $5 \mathrm{lb}$. and $7 \mathrm{I} / 2 \mathrm{lb}$. - say $\mathrm{I} \mathrm{lb}$. and $\mathrm{I} / 2 \mathrm{lb}$. for each of the five daily feeds, the remainder being given last thing at night.

\section{HOURS OF FEEDING.}

The food of a working horse, as we have already seen, should be divided into several portions (at least five) during the twenty-four hours. This rule of frequency of feeding can generally be observed during the day. Although it cannot be usually carried out at night, there is no excuse, except that of laziness or over-work on the part of the groom, for not giving the last feed at ten or eleven at night, and the first one at six o'clock in the morning, or somewhat earlier. This interval of from six to eight hours, which is certainly a long one from a horse's point of view, can best be filled up by a supply of long hay, the use of which might be considered too 
wasteful for a horse managed on strictly economical principles. An objection to feeding as late as here suggested, on the plea that it would unduly interfere with the repose of the animal, is not, I think, valid; because a horse habitually sleeps for such short intervals at a time, especially during the first half of the night, and is such a light sleeper, that the arrangement in question, while greatly aiding in the nutrition of the system, would not disturb his rest to any appreciable extent. During the night when at grass, a horse usually employs his intervals of wakefulness in seeking food. A careful observer tells me that from one to four in the morning is the portion of the night which horses devote specially to sleeping. My experience as to the manner in which horses sleep has been gained chiefly when on long sea voyages with horses; when visiting the lines at night on duty as a subaltern in a field battery; and when looking at horses in paddocks at night. The great utility of a late feed at night in the case of hardworked horses was suggested to me many years ago, when I was training racehorses in India, by Mr. R. Kelly Maitland, who was well known in that country and subsequently in Australia as a successful owner and trainer. I have found this late feed plan to be as beneficial to hunters, trappers and ponies as it is with thoroughbreds, and that it is specially applicable to delicate feeders. A not uncommon arrangement, which is the outcome of ignorance and sloth, is to have an interval of about fifteen hours between the last feed on one day and the first feed on the following morning (say from 6 p.m. to 9 a.m.), in which case the three, four, or five feeds given during the twenty-four hours would be crowded into nine hours! It is evident that frequency of feeding does not imply increase in the daily ration.

Assuming the time for the first feed as not later than six o'clock in the morning, we may have to give it earlier or decrease its quantity according to the time of the subsequent 
work; because exercising a horse sooner than two hours, or putting him to fast or severe work sooner than three hours, after he has had a full feed, would be apt to interfere with his digestion, as we may generally see by his dung becoming unusually loose. Colic from this cause will not often occur. If work has to be early, and if the proper interval between it and the giving of a full feed cannot be observed, we should content ourselves by giving only half a feed, or even less ; for food that causes digestive derangement does a horse injury, and should consequently be withheld.

Having fixed the times for the first and last feeds, we should divide the interval as evenly as circumstances will allow. Taking the racehorse as the one animal above all others to which exact methods of work and feeding can be applied, we may suppose that he is fed at 6 a.m., I I a.m., 2.30 p.m., 6.30 p.m. and at I0.30 p.m. or I I p.m. Exigencies of work prevent an exact division of the time, as we shall see later on. Not much difference need be made between the routine of feeding during summer and that during winter.

The hours of feeding a hunter which is being brought into. condition, or which is kept in exercise on off days during the season, may be the same as that for a racehorse, under which term I may, for purposes of feeding, include chasers, hurdle racers, and match trotters. The order of feeding will naturally have to be altered when the hunter goes out with the hounds. Supposing that the meet is at eleven o'clock, and that he will be ridden or led out to it by the second horseman at a quiet walk of two hours' duration; we might with advantage give him his first feed at five o'clock and his second one at eight, so that he may be ready to start at nine. We may take for granted that the galloping and jumping will not begin before noon. If the animal has to go to the meet at a trot, he will cover the distance in about half the time he would do at a walk, and consequently the 
hour for the second feed need not be much earlier than before. As horses vary greatly with respect to their powers of digestion, we can lay down no hard and fast rule in this case.

As soon as a hunter has done his work in the field, he should be watered and fed with as little delay as practicable. As a rule, his shortest turn of service will be when he is relieved from active duty at the change of horses, say, at halfpast one or two. If he cannot then get home in about an hour and a half's walking and quiet jogging, he should, if possible, be watered and have a small feed at any convenient inn or other place of bait. As we have already seen, he should be watered in any case.

When a horse, like a 'bus or tram animal, has a fixed task to do, the interval between it and the feed immediately preceding it should not be less than two hours.

Animals that have to work more or less continuously, either by day or night, will obtain the greatest benefit from the London cabman's practice of putting on the nosebag during the intervals between the spells of labour. Canal-boat horses are often fed out of their nosebag or sheet-iron pail while they are towing their load.

I trust that the illustrations I have given will be sufficient to explain the principles which should be followed in fixing the hours of feeding working horses. The circumstances of the case will suggest any alterations that may be necessary. 


\title{
CHAPTER VII.
}

\author{
STABLES.
}

Necessity of Stables-Site and Aspect of Stables-Drainage-Temperature of Stables-Ventilation - Cubic Contents of Stables-Lighting of StablesFloors for Stables-Outer Walls of Stables-Inner Walls and Divisions-Roof -Doors-Windows-Passages-Comparative Merits of Loose Boxes and Stalls - Size of Boxes and Stalls-Construction and Fitting of Stalls-Construction and Fitting of Loose Boxes-Sick Box-Feeding Room-Saddle and Harness Room-Cleaning and Brush Room-Drying Room-Coach House-Wash Box-Forge-Stable Yard-Riding School-Iitter Shed-Weighing Machine - Stable Utensils-Plans for Stables-Necessity for Drying New StablesDisinfection of Stables.

\section{NECESSITY OF STABLES.}

THE exigencies of hard work and the demands of fashion require the coat to be kept clean and short (by grooming and clipping); and the extra work which civilised conditions entail, makes the covering afforded by the skin and hair, lighter than it would be, if the animal was at liberty in the open. Hence, working horses have to be stabled, because the necessary protection by clothing and the requirements of cleanliness would be unattainable if the animals were allowed to lie out. From the remarks previously made on the ability of horses to bear cold, it is evident that we should regard a stable in this country as a useful, but by no means an indispensable means of protection, which should interfere as little as possible with the natural conditions that are conducive to the health and comfort of horses.

When a horse is taken into a stable from grass, he is to a great extent deprived, while in the building, of the means of 
keeping himself warm by moving about; and by grooming and clipping he loses a large amount of the protection afforded by his coat and by the dandruff in it. To compensate him for these losses, he is better sheltered from inclement weather and from changes of temperature; he has, as a rule, a more comfortable bed; is usually provided with clothing according to the season; and is generally better fed. Even with the best directed attempts at obtaining perfection in drainage and ventilation, it is practically impossible to have the air in the stable as pure as that outside. To counterbalance this disadvantage, we can usually keep the box or stall drier than the surface of a field or paddock.

\section{SITE AND ASPECT OF STABLES.}

Dryness being, as we have seen, a condition fayourable to the health of horses, the site chosen for stables should be as free as possible from moisture, and should be well drained. Soil which is naturally damp, or which, like clay, retains rain or other water for a comparatively long period on or near its surface, should of course be avoided. The best soil upon which to erect stables, provided the drainage is perfect, is one of deep gravel or deep sand, free from organic matter. Soils made, as we sometimes find in towns, from various kinds of refuse, are often very unhealthy.

As horses require a constant supply of pure air, the position of their stables should be in no way confined. At the same time, as the animals are liable to suffer from the effects of chill, the ground for their abodes should not be too exposed to winds. In confirmation of this expression of opinion, we have the fact that in some parts of India, paralysis of the loins from chill is not uncommon among horses which are exposed to cold winds at night coming after great heat during the day; and that the occurrence of this paralysis has been stopped by the construction of a wall which was capable of sheltering the 
animals from the chilly night breeze. Although this form of paralysis is very rare in England, the knowledge of its cause and means of prevention furnishes us with a lesson which can be usefully applied even in this country.

As sunlight promotes the health of horses, the south or south-west is, as a rule, the best aspect for stables.

We may assume from the foregoing remarks that an ideal site for stables would be on the side of a hill sloping downwards to the south or south-west, and on gravel or sand.

The presence of trees, shrubs, or underwood near a stable might in many cases be objected to with reason, on account of the obstruction it offers to the free circulation of air ; but no exception in this respect should, I think, be taken to fir trees. Their trunks offer but little impediment to the due circulation of air; their lofty foliage breaks the strength of high winds, and the volatile oils which escape from them, and which perfume the surrounding atmosphere, have probably a good sanitary influence on the horses stabled in their vicinity.

\section{DRAINAGE.}

The drainage of a stable may be defined as the removal by gravitation of fluid which is on or near the surface of the stable.

Drainage may be carried out in two ways, namely, more or less horizontally, which is the only efficient method for the removal of fluid containing animal and vegetable matter, and more or less vertically, as we see when rain falls on sandy ground. In both cases, the removal should be distant as well as complete. The depth of the surface water, which as a rule is shown with a fair amount of accuracy by the distance the surface of adjacent wells is from the surface of the ground, is a reliable measure of the efficiency of the vertical drainage, which, as I have just indicated, is applicable to the removal of only comparatively pure water. In order to keep 
the ground of the interior and immediate vicinity of a stable in a dry condition, its surface should as far as possible be waterproof, and its drainage should be of the horizontal kind, for which a difference of level is required. Hence, it is advisable to have the floor of the stable raised, say, 6 to 9 inches above the surface of the ground surrounding it.

When drains outside the stable are required, care should be taken that while they efficiently serve their purpose, no effluvium from them will have any chance of contaminating the air breathed by the horses.

The question of subsoil (covered) drains which open inside the stable is chiefly one of labour. With an exception to which I shall presently allude, they are objectionable; because they tend to render the place unsanitary by the foul gas and damp emitted from them, and because they necessitate a slope being given to the surface upon which the horses stand. A common form of drainage which combines both these disadvantages, is one in which a drain runs down the centre of a line of stalls, into which it opens by means of grates ; the floors of the different compartments being made to slope towards their respective grates. Owing to the presence of the horses' litter, especially if peat moss, tan, or sawdust be used, this drain is liable to become blocked up, and when in that condition is more apt than ever to give off unhealthy stenches and vapour. Besides, as the urine will then be unable to escape by means of the drain, it will probably accumulate under the horses. The objection as to contamination of air and flooring by this system of drainage can be more or less removed, if there be a free supply of water, by having, instead of grates, the openings of these drains provided with blocks of stone or other convenient material, so as to keep them hermetically closed, except when it is required to sluice out the drain, on which occasions the blocks can be taken up and afterwards replaced. 
There is no actual need of any form of drainage inside the building; for all the urine, dung, etc., can be removed along with the soiled portions of the bedding, as is done in racing and other stables-that of the London Road Car Omnibus Company for instance. The use of peat moss as bedding will greatly facilitate the work of keeping the place clean. Under this system, which is the one I prefer for every kind of horse, the flooring of the stalls and boxes can be made level.

There can be no objection to a small open drain placed along the rear of a line of stalls, so as to carry away fluid. A slope of $\mathrm{I}$ in. in $5 \mathrm{ft}$. will suffice for this drain, and a similar slope given to the floors of the stalls will enable them to drain into it. If the stalls thus drained are numerous, and are on the same level, the lower end of the drain will be of a considerable depth, and it may consequently be necessary to provide a portion of it with a covering, so as to enable the horses to go in and out of the stalls without catching their feet in the drain. This covering should be removable for purposes of cleanliness. Drains on this plan are made by manufacturers of stable fittings.

A receptacle for urine in the form of an iron bucket, earthenware pot, or other similar contrivance, placed under a grating in the centre of a box or stall, so as to serve as a substitute for a drain, is such a dirty and unsanitary arrangement, that it should not be allowed in any stable.

Any decided slope-say, more than I in 50-given to the floor of a stall for purposes of drainage is objectionable; because a horse needs for the comfort and health of his feet and legs a more or less level bearing on which to stand. A slope of $\mathrm{I}$ in. in $5 \mathrm{ft}$. will be a fair compromise between comfort to the horse and efficiency of drainage. There is less objection to a slope being given to the floor of a loose-box than to that of a stall; for in a box the animal can readily change his position, supposing that he is not tied up; but in a stall he 
can do so only to a small extent. When the ground upon which a horse stands, rises towards the front, the proportion of weight placed on the hind feet will be greater than if the ground was level; because, in the former case, a perpendicular drawn through the centre of gravity of the animal will be nearer the point of contact of the hind feet with the ground, than in the latter. Supposing -in order to further demonstrate this fact-that the upward slope was so great that this perpendicular passed through the said point of contact; the whole of the weight would be borne by the hind legs, and none by the fore ones. Some erroneously think that when a horse stands on ground which rises to the front, more strain is put on the flexor tendons (back sinews) of the fore legs, than when the horse stands level; because, in the former case, the toes of the fore feet are higher than in the latter. Such persons, however, ignore the fact that the weight borne by the fore feet, and consequently, the strain on the flexor tendons of the fore legs, varies in inverse proportion to the upward inclination of the ground. These conditions are of course reversed when the ground slopes downwards to the front.

Mayhew (Illustrated Horse Management) advocates the use, in stalls, of floors which slope downwards to the front; because, so he says, horses stand with more ease to themselves on ground which slopes in that direction, than on level ground or on ground which slopes to the rear. I have not been able to verify this statement.

\section{TEMPERATURE OF STABLES.}

Experience proves that the health of stabled horses, other conditions being equal, varies according to the purity of the air in the building, which, under ordinary circumstances in cold and moderate climates, varies inversely as the difference between the temperature of the air of the stable and that of the air outside; for this difference will be chiefly due to the 
heat given off by decomposing urine and dung, and by noxious exhalations from the lungs and skin of the animals. Besides, the warmer the stable, especially when the floor is kept in a wet condition, the damper and consequently the more unhealthy will be its atmosphere. Heat directly promotes the contamination of the air of a stable, by encouraging the volatilisation of ammonia and ammonium carbonate. Damp and heat combined, exert a very favourable influence on the cultivation of disease germs. In hot damp stables, contagious pleuro-pneumonia is often a resident; the microbes of influenza and other diseases find a favourable breeding ground; and ophthalmia, with the frequent result of cataract, is common, from the constant irritation to the eyes caused by the presence of ammonia in the air. Veterinary surgeons have often observed that during outbreaks of influenza (pink-eye), the disease is rarer and less severe in stables which have waterproof floors, than in those the flooring of which soaks up moisture, and then, under the influence of heat, continues to distribute it in the form of vapour throughout the building. Also, the substitution of waterproof floors for absorbent floors has frequently proved to be a valuable safeguard against disease in the stables. "Formerly in the French army the mortality among the horses was enormous. Rossignol states that previous to 1836 the mortality of the French cavalry horses varied from I80 to 197 per I,000 per annum. The enlargement of the stables and the increased allowance of air has reduced the loss in the present day to 24.2 per 1,000 . In the English cavalry and in English racing stables the same facts are well known. The annual mortality of cavalry horses, which was formerly great, is now (1895) reduced to 23.7 per I,Ooo" (Notter and Firth).

Experience also teaches us that if horses are protected from draughts and damp, liberally fed, comfortably bedded down, and clothed according to their requirements, they will thrive 
even if the temperature of the stable is as cold as that of a Siberian winter. We should bear in mind that the effect of heat is to lessen the number of respirations; that is to say, it diminishes the action of the lungs. In the influence of residence in high altitudes on cases of phthisis (pulmonary consumption), we have a good instance of the beneficial effect, on the lungs, of a climate which acts as a stimulant to them.

The least objectionable form of artificially warming the inhabitants of a dwelling, is by radiated heat, which, as we have seen, has the property of heating the object upon which it falls, without raising the temperature of the medium through which it passes. Consequently, in a room with an open grate and a brightly burning fire, we may keep warm, even when the air inside the room remains cold. With a system of heating by conduction-as for instance by hot-water pipes or hot air-the persons or animals inside the room become warmed solely by contact with the heated air, which, as we have seen, has a depressing effect on the lungs. The application to stable management of radiated heat acting directly on horses, is of course out of the question in ordinary circumstances.

I have had many opportunities in Russia of comparing the relative healthiness, during very cold weather, of hot stables and of those kept at a natural temperature. In large towns in Russia, the practice throughout the winter is to have stables at a temperature of from $50^{\circ}$ to $65^{\circ} \mathrm{F}$., the difference between the temperature inside and outside being not unfrequently over $80^{\circ} \mathrm{F}$. Consequently, influenza, inflammation of the eyes, and diseases of the organs of breathing, especially roaring among big horses, are common in these abodes. In the Russian cavalry remount depots (cadres), an entirely different course is pursued; for the stables at these places are immensely roomy, very lofty, and are ventilated so freely and kept so clean, that even in the early mornings before the horses are taken out, 
the air inside is free from any suspicion of "closeness." It is instructive to note that the horses kept in them, maintain their health during the extremely cold winter, in the same excellent manner as they do in summer. Some years ago a change was made in the stables of the cadres at Liski on the Don, to the old plan of closing more or less perfectly all inlets and outlets of air; but it was followed by such a marked increase of cases of illness among the horses, that the new system of free ventilation was again put into force and with the happiest results.

In our own cases, we find the advantage, even in winter, of having the air we breathe more or less at the same temperature as that in the open. Even at night, we are far less apt to catch cold, if we make a practice of always keeping one or more of our bedroom windows open, than if we have them all closed ; supposing of course that we have plenty of warm bed clothes. The success of the open air treatment of consumption is a proof of the good sanitary influence of free ventilation. The argument is all the stronger when applied to horses than to us; because they, contrary to the custom observed by human beings, spend a considerable portion of at least the early part of their life in field or paddock without clothing. In the attempt to keep our stables cool, we must not lose sight of the fact that in our climate, a cold draught of air on a stabled horse is very likely to give him a chill, which, as we have seen, is a frequent cause of equine illness. Every experienced horseman knows that draughty stables in England are unhealthy stables.

The great cause of the popularity of hot stables among grooms, is the fact that horses kept in them have a glossier coat while in the stable, than animals which are housed in better ventilated abodes. The difference is all the other way, when the horses are brought into the cold air outside. 


\section{VENTILATION.}

We may define ventilation as the process of removing foul air and substituting for it pure air in a building.

The subject of ventilation is closely connected with that of drainage; for inefficient drainage often entails a bad state of ventilation. Thus, an amount of ventilation which would be amply sufficient if a stable was kept scrupulously clean, might be much below a healthy standard, if the air was exposed to foul emanations from decomposing organic matter. For practical purposes we may take for granted that the ventilation cannot be good, if the drainage is defective.

We have seen that in a climate as cold as that of England, horses should be shielded from draughts in the stable. The question of obtaining free circulation of air in a building, without draughts, brings us to the definition of a draught. Although we cannot determine with exactness when a draught ends and safe ventilation begins, it will suffice for every-day needs if I say that a draught is a current of air which is appreciable to our sense of feeling under ordinary conditions. Hence, to save our horses from chill, and at the same time to give them a full supply of fresh air, we should arrange the ventilation of the stable in such a manner, that the force of in-coming currents of air is broken and distributed, while the entrance and exit of the air is checked as little as possible. The dangers arising from the retention in the atmosphere of the stable, of volatile and floating impurities (products of decomposition, bacteria, etc.), are too well known to need my dwelling on the necessity of their speedy removal by well regulated ventilation. If the source of these deleterious matters is allowed to remain for a considerable time in the stable, it will be impossible by any system of ventilation to keep the air even approximately pure. Our object, however, will be fully attained, if we are able 
to preserve the air inside the building at a standard of purity which will be compatible with the preservation of the health of the stabled animals. Although we have no means for rigidly fixing that standard, which varies according to the requirements of individual horses; we may assume that it is attained for all practical requirements when the air inside the building is free from smell, and gives no sensation of "closeness," or of warmth due to the presence of the horses. Any fears on these points will be further allayed, if we find that the place is roomy and lofty, and has free communication with the outside air.

Normal air contains from 0.02 to 0.06 per cent. of carbonic acid. An excess of this gas causes distress, which is shown by accelerated breathing, and diminution in the number of the beats of the heart. Generally speaking, the breathing of impure air induces diseases of the organs of breathing, diminishes vitality, and favours the attack of infective diseases when special bacteria are present.

"Carbonic acid is not poisonous when taken into the stomach, but acts most injuriously when breathed, by offering an obstacle to the escape of carbonic acid gas, by diffusion, from the blood of the venous circulation in the lungs, and its consequent replacement by the oxygen necessary to arterial blood. Any hindrance to this interchange must impede respiration, and such hindrance would of course be afforded by carbonic acid gas present in the air inhaled, in proportion to its quantity. . . . It may be safely asserted that it is not advisable to breathe for any length of time in air containing more than $\frac{1}{100}$ th (O.I per cent.) of its volume of carbonic acid gas. The air of a room contains too much carbonic acid gas, if half a measured ounce of lime-water become turbid when shaken in a half-pint bottle of the air" (Bloxam).

The following are four ways by which ventilation can be naturally obtained :- 
I. By the direct action of a current of air from outside, entering by the windows or other openings, and thus imparting ' movement to the air inside, which by passing out through various forms of escape, allows fresh air to enter. This method of ventilation is utilised when advantage is taken of the direction of prevailing winds, and on board ship, when wind-sails are employed.

2. By the action of a current of outside air indirectly imparting movement in an outward direction to air inside the building, as we may see when wind blows across an open

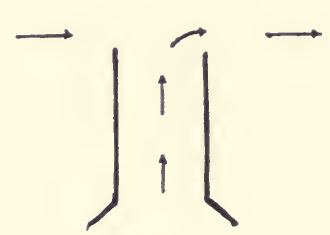

Fig. 13.

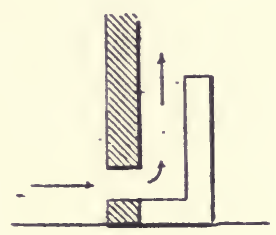

Fig. 14.

window, open door, top of chimney (Fig. I3), or other opening in the stable.

3. By convection, that is to say, by the formation of currents of air inside the building due to the heating of the air from the presence of the animals. This air becomes lighter in proportion to its increase of temperature, and consequently rises. The movement thus imparted to the body of air within the stable, tends to cause a portion of it to escape through convenient openings, and thus facilitates the entrance of fresh air from outside. In this process, we must not lose sight of the fact that the carbonic acid given off by the lungs and to a small extent by the skin, is heavier than air, and therefore has a tendency to become accumulated near the floor. Also, horses breathe downwards; hence the advisability of securing ventilation on or near the floor, as well as higher up.

4. By the diffusion of gases, which is the property one gas 
has of passing into the space occupied by another; supposing that these gases have no mutual chemical action. Consequently, if a stable which was full of foul air, had only one opening (say, a window) in it, and even if the atmosphere both inside and outside was absolutely still, the air in the stable would after a time become comparatively pure; provided of course, that fresh supplies of deleterious gas were not furnished. It is evident that the greater the extent of communication between the stable and the outside air, the more rapidly will diffusion take place.

The foregoing principles of ventilation may be applied in the following ways:-

A. By ventilation on or close to the level of the floor obtained by means of "air bricks," gratings or other narrow openings. These air passages should be small enough to prevent the entrance into the stable of undesirable visitors, such as mice, and are specially applicable to outside walls which are at the head of boxes or stalls, or to doors. In order to prevent a draught coming on the horses from these air passages, we may utilise the principle of the "Tobin tube" (Fig. I4) to give a vertical direction to the current of incoming or outgoing air. We may obtain under a door the same form of ventilation by cutting off, say, an inch from the bottom of the door and attaching a plank to the inside of the door, so as to cover the gap thus made and to allow a space of about an inch between the door and the plank (Fig. I 5). A plan which would be equally efficacious, and which would not disfigure the appearance of the door so much, would be to apply the plank in the same manner, but a little higher up, and instead of cutting away the bottom of the door, to bore one or more rows of holes in the door (Fig. I6). This method of ventilalation is similar to that which was proposed many years ago by Dr. Parkes for ventilating dwelling rooms by ordinary "guillotine" windows. The lower half of the window is 
raised 2 in. or 3 in., a block of wood of the same width as the window is placed in the vacant space, and the lower half of the window is allowed to rest on it so as to give vertical ventilation between the upper and lower halves (Fig. 17).

B. By windows, which should be a little above the heads of

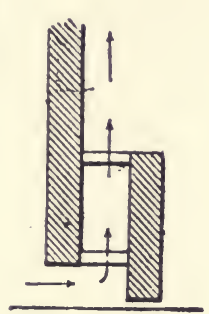

Fig. 15.

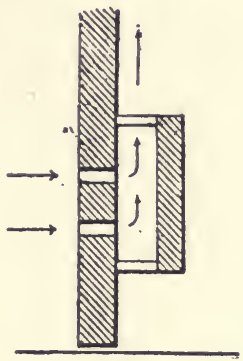

Fig. 16.

the horses, so as to obviate the danger of a draught, and also to prevent the animals reaching them. When the windows are separated from the horses by a passage, they may be placed

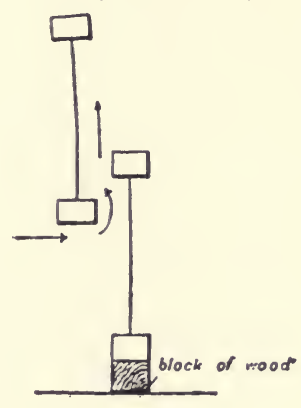

Fig. 17.

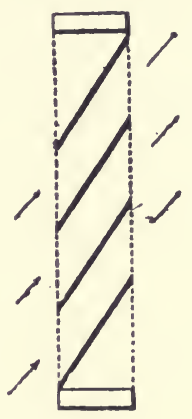

Fig. 18.

lower down. It is well to have these windows constructed so that they may give an upward direction to incoming currents of air, and that while freely admitting air, they will keep out rain and snow. These duties are fully carried out by Sheringham's air inlet, the lower part of which revolves on hinges, 
while the sides are blocked in such a way as to prevent air passing by them. The windows I like best for a stable are those of the louvre pattern, with two or more panes of glass at intervals, say $1 / 2$ in. between them, so that even when these windows are shut they will admit air, and will also give it an upward direction (Fig. I8). They are of course equally useful in giving exit to air leaving the stable. I thoroughly believe in the correctness of Admiral Rous's remark that "The windows of a stable ought never to be shut by night or day. In cold weather, add to the clothing, but never deprive them of the first great source of vitality-fresh air."

C. By roof ventilation, which may be obtained between the roof and walls; at the top of the roof; or by windows in the roof.

D. By ventilating shafts, which may come out on the side of the roof or on the top of the roof. In the market there are various ventilators for these shafts. Ventilating shafts, as a rule, are needed only when there is an upper storey, against the wall of which they may be placed for economy of room.

The requirements of the case will decide the question as to the most suitable methods of ventilation.

Inlets and Outlets for Air.-We are unable by any system of natural ventilation to restrict either the entrance or exit of air to particular openings in a building. Thus, if we have an open door on one side and an open window on the other side, we cannot, without employing artificial means for giving a "lead" to the air, make an invariable inlet of the door, and an invariable outlet of the window; or vice versâ. Although the fact that the wind generally blows in a direction more or less parallel to the surface of the ground, gives rise as a rule to an upward draught in the case of a chimney or vertical ventilating shaft; either of these passages may often serve as an inlet for air, or even as an inlet and an outlet at the same time. It is evident that when this 
double function is in action, there is a certain amount of impediment to movement offered by the influence of the opposing currents of air on each other. Hence we find that the action of a ventilating shaft is improved by separating it into two divisions, each of which can act as an outlet or an inlet, independently of the other (Figs. 19, 20, 21 and 22). In McKinnell's method (Fig. 23), the separation is effected by

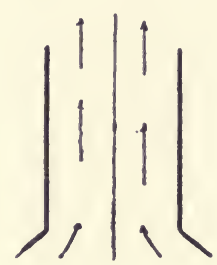

Fig. $x$.

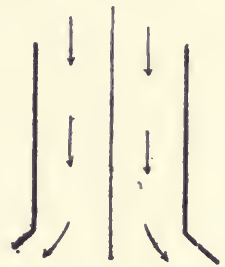

Fig. 20.

using two concentric shafts (one within the other); the inner one being made to project above the outer one, so as to render it an outlet as much as possible.

One of the best examples of an artificial lead to an outlet for air is afforded by an ordinary fire in a room, in which the chimney is maintained as an outlet by the fire causing the

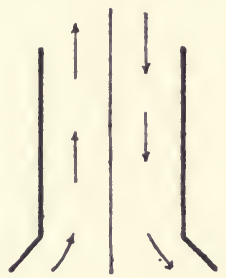

Fig. 2I.

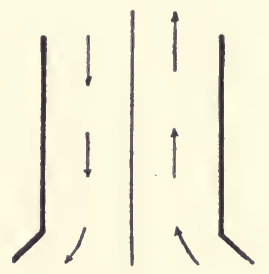

Fig. 22.

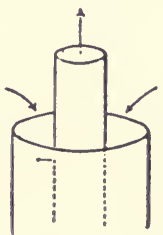

Fig. 23.

production of heated and consequently light gases, which while escaping upwards, are followed by a current of air that takes their place. In this, as in other forms of convection of heat, we find that for the outlet to work well, there must be free admission of air by an inlet; for if we close up all the 
windows and doors and thus prevent as much as possible any air entering the room, the fire will not "draw" properly. Even a chimney with a fire in the grate will not always act as an outlet; for sometimes a downward current of air will be set up by the air outside. The principle of the fire and chimney can occasionally be used in stables to give a lead in an outward direction to the air in ventilating shafts, by placing a lamp or small fireplace in them, with all due precautions. On board ship, when horses are carried on the lower deck or "between decks," it is often necessary to give an artificial lead to the circulation of air by either pumping down fresh air or withdrawing foul air by means of an engine. A similar procedure, by means of a small motor, would be useful in many stables which contain a large number of animals in proportion to their cubic contents, and which are placed in confined positions.

\section{CUBIC CONTENTS OF STABLES.}

A stable should not only be roomy, so as to afford the horses a comfortable abode, but should also be fairly lofty, in order that it may contain a comparatively large volume of air ; because in that case, it will be easier to maintain the purity of the air inside, without the necessity of creating a draught, than it would be if the cubic content of the building were less. It is evident that the smaller the quantity of air in a stable, the quicker will it have to be renewed in order to preserve a healthy standard of purity. Supposing that a stall was $6 \mathrm{ft}$. wide, Io ft. long, and Io ft. high, it would contain 600 cubic feet of space. To this we might add two-thirds more for passages, \&c., and would thus arrive at a total of I,, 00 cubic feet, which would probably be a fair minimum. I do not think that less space than that would afford a healthy place of residence for horses; and even then, every precaution should be taken to obtain free ventilation. If a box consisted 
of a single room or small house with only one door, 1,500 cubic feet (say $12 \mathrm{ft}$. $\times$ I $2 \mathrm{ft}$. $\times$ IOI $/ 2 \mathrm{ft}$.) would be a reasonable average; although the addition of a couple of feet to the height would be an improvement. I do not think that 2,500 cubic feet (say $14 \mathrm{ft}$. $\times 15 \mathrm{ft}$. $\times$ I $2 \mathrm{ft}$.) need be exceeded, even for high-class racehorses. It goes almost without saying, that the more confined the situation, the greater should be the cubic content.

\section{LIGHTING OF STABLES.}

As sunlight has a good effect on horses, we should secure a sunny aspect for the stable and have it well lighted by windows. When the horses are at work, it is a great advantage to be able to open out the stable, so that it may be disinfected by sunlight as well as by fresh air. In our desire for sunlight, we must not obtain it at the cost of raising the temperature of the stable, which we would do by having the roof made more or less of glass. In the case of animals which, like racehorses, do their work in the morning and will want a rest in the middle of the day, it is advisable to have an arrangement for darkening the boxes or stalls, while shutting out the fresh air as little as possible.

I like to have the divisions of the boxes and stalls and the interior of the walls of a light colour, if not actually white, so that there may be but little loss of sunlight. It has been stated that the effect of having a white wall constantly in front of a horse while he was in a stable, would be injurious to his eyes; but I have never known or heard of a horse suffering from that alleged cause. The same may be said of human beings, many of whom live the most of their lives in whitewashed rooms, without their sight being hurt by the supposed glare, which, in almost all cases, would be that of diffused, not direct sunlight. We should also bear in mind that the eyes of a horse, by the possession of corpora nigra 
(the dark-coloured and irregularly-shaped bodies that project more or less over the pupil of the eye), are specially adapted to enable the eyes to bear strong sunlight with impunity. The corpora nigra are portions of the iris, in which the pupil forms an opening.

It is an advantage to have the stable lighted, though dimly, at night, so that in case of alarm or necessity, the owner or groom may be able to see his way about the place, without having to delay in getting a light. We may be quite sure that the presence of the light can in no way disturb the horses; for when these animals are turned out, they get all the sleep they need; although, even on moonless and starless nights, there is as much light, if not more, than there would be in a stable when the gas or lamps were turned low down. Besides, the fact that many horses which kick or are otherwise restless when in a dark stable at night, will remain quiet if the place is somewhat lighted up, seems to show that horses do not like darkness, which in any case is an unnatural condition for them.

Precautions against fire are even more necessary in stables than in ordinary houses. In some luxurious stables each box is furnished with an electric burner.

FLOORS FOR STABLES.

The whole of the ground surface included between the foundations of the outer walls, should be laid down with a material which is thoroughly damp-proof, so as to keep the building dry, and which will afford an immovable bearing for the weight that is to be placed on it. A floor should be durable, waterproof, free from slipperiness, and fairly cheap. It would greatly conduce to the welfare of the horses' feet, if the material of the floor was a bad conductor of heat; but this is a condition which is usually unattainable in conjunction 
with the requirements just mentioned. This drawback may be more or less obviated by keeping the floor of the boxes and stalls covered with bedding. It is an advantage, as far as the lighting up of the stable is concerned, for the floor to be of a light colour. A good kind of waterproof flooring can be made of cement-concrete. I am indebted chiefly to the kindness of the Rugby Portland Cement Company and to that of the Croft Granite and Cement Company for the following details of its construction.

Concrete is a form of artificial stone, and consists, as explained in Potter's Concrete, of an "aggregate" and a "matrix." When the aggregate has to serve as a foundation for a floor of paving bricks, granite sets, or similar material, it may, for convenience or economy, be made of broken-up fire bricks; but when it has to form a part of the floor of a stable, it should consist of hard, tough stones, which should have a rough surface to enable the subsequently applied matrix (cement) to firmly adhere to it. If pebble (kidney) stones be used, they should be broken, and their fractured surfaces placed upwards. In all cases for the purposes under consideration, Portland cement is the best matrix. Cement-concrete may be employed in situ (to use the trade expression), or in slabs. Situ flooring is the cheaper of the two, but is not so resistant to wear as these slabs, especially when they have been stored for a year or more after having been manufactured. In these slabs the aggregate may consist of granite chips, which should be from $1 / 2$ to $1 / 4$ in. in thickness and width. The aggregate should be washed, so as to free it from all adherent earth or other matter which might impair the strength of the concrete. For a situ floor, we may lay down a foundation 4 in. thick of hard stones; the larger ones, which may have a diameter of from 2 to 3 in., being placed at the bottom of the bed and kept apart by smaller stones put between them. We may then pour over this foundation, thin cement (in the 
proportion, say, of a shovelful of cement and a shovelful of clean sharp sand to a bucketful of water), so as to bind the stones together; and work over the whole, cement mortar (consisting of one part of cement and three parts of granite chips of the size just mentioned) to a thickness of $4 \mathrm{in}$. Before wetting the cement and chips, they should be thoroughly mixed together with a shovel, so that the mortar may be of uniform composition. The surface should be worked over with a wooden float, and gutters and notches made as may be required. The application of the mortar should be done in one operation; for if the upper layer be subsequently put on, it might not adhere to the lower one, and would consequently suffer a proportionate loss of strength. Gutters may be conveniently made in the damp surface of the concrete by placing in it metal pipes or metal rods sunk to half their diameter and left until the mortar has become hard. Notches may be cut with any convenient instrument. Only slow-setting cement should be employed, for the quick-setting kind is not so strong. The following is an extract from the pamphlet published by the Rugby Portland Cement Company on "Portland Cement":- " The cement mortar should be used as quickly as possible after it is mixed, for to re-mix or to disturb when partially set, destroys its setting property. No doubt one of the difficulties attending the use of cement mortar is the tendency on the part of the workmen to mix too much at a time and afterwards to re-mix it. Or, secondly, to mix it with too much water. This should be prevented, and in order to secure satisfactory work must be attended to. For cement will not bear working up like lime mortar, the great essential of its success being that it should be gauged, laid in position, and left at rest in as short a time as possible. It should be allowed to dry naturally, artificial heat being injurious." The cost of good Portland cement is about $£ 2$ IOs. a ton, and that of granite chips, exclusive of 
freight, about $6 \mathrm{~s}$. a ton. A square yard of flooring, $4 \mathrm{in}$. thick, would require $108 \mathrm{lb}$. of cement and $324 \mathrm{lb}$. of granite chips.

Excellent cement-concrete slabs, 3 in. thick, are made for stable floors by the Croft Granite and Cement Company. If economy be a matter for consideration and the ground be dry, the ordinary concrete foundation may be replaced by one of 7 or $8 \mathrm{in}$. of well rammed and watered ashes. A convenient size for these slabs is $2 \mathrm{ft}$. square, and they cost at the works $7 \mathrm{~d}$. the square foot, which is equal to $5 \mathrm{~s} .3 \mathrm{~d}$. the square yard. These slabs are grooved, in order to prevent slipping, and they preserve during wear a gritty surface. Owing to the exactness with which they are made, they are far less liable to become shifted when forming a floor than blocks made of stone.

A reliable material for general flooring purposes is hard, grooved blue bricks, which are usually grouted in with liquid Portland cement. They give good results even with heavy omnibus horses, such as those of the London Road Car Company, which use these bricks under their animals. A flooring made from them costs about $7 \mathrm{~s}$. the square yard, including the concrete. For heavy cart horses, the bricks may be placed edge on; that is to say, with a surface of 27 square inches (9 in. $\times 3$ in.), instead of $401 / 2$ square inches ( 9 in. $\times 4 \frac{1}{2}$ in.). In order to give foothold to the horses which have to stand on them, it is well to have paving bricks bevelled, and to have a groove running transversely across them, so as to divide the bearing surface of each brick into two squares. Blue bricks vary a good deal in quality.

An admirable flooring can be made with specially manufactured paving bricks, such as those of Candy and Co., and the "adamantine clinkers" of Towers and Williamson, both of which bricks are buff coloured, extremely durable, 
and are not slippery. They cost about twice as much as the best blue bricks. As they are made more carefully, they can be laid with greater accuracy than ordinary blue bricks. They can be obtained with a longitudinal or transverse groove down their centre, instead of being bevelled at the sides, so as to prevent the fluid, which is to be drained off, from working down between the bricks. We have seen (p. 196) that if the floor of a box or a stall is kept covered with absorbent bedding (such as peat moss or sawdust) while the horse is in the stable, there will be no need for providing means for draining away fluid.

Blocks of granite ("granite sets") laid on a 4 to 6 in. concrete bed, are in common use as a flooring for resisting the wear caused by the massive shoes of heavy cart horses. They are practically indestructible, but have the great disadvantage of being slippery. This objection may be overcome to some extent by grooving them. I have been told that instead of grouting in the sets with cement, it is better to lay them, and then fill up the space between the sets with granite chips, over which hot asphalt should be poured; for asphalt is not so brittle as cement, and urine has less corrosive effect on it. The cost of this flooring with the necessary concrete will be about 95. 6d. a square yard, and it will last ten or twelve years, after which, the sets can be taken up, re-dressed, and used again.

Asphalt is rather slippery for flooring, and does not wear very well. Bricks, blocks of stone," and granite will require a foundation of concrete.

Wood permanently laid down in the form of planks, was largely employed in England many years ago as a flooring for stables, and is at present generally used for the same purpose in Northern Europe. Such a flooring keeps the air of a stable in an unsanitary conditon, chiefly on account 
of the urine escaping through the interstices between the boards, and also by reason of the absorbent nature of wood. In accordance with improved ideas of hygiene, this kind of stable flooring has gone out of favour with us. Blocks of wood laid in a manner somewhat similar to the wood pavement of streets, are sometimes used to pave the forward portion of the stalls of cart horses. They are very durable, and are unobjectionable so long as they are not subjected to the action of moisture. It is a matter of regret that the absorbent and slippery nature of wood precludes its use as a flooring under ordinary circumstances; for being a bad conductor of heat, it forms a far more comfortable surface to lie upon than one made of brick, stone, or cement, especially when there is little or no bedding; and it does not cut up straw bedding nearly as much as the flooring materials just mentioned. Under certain conditions it can be advantageously used as a temporary covering for a waterproof floor in either box or stall. I have seen movable planks used for this purpose in the Straits Settlement, China, Japan, and Durban (Natal). By one arrangement, a shallow, slightly curved, waterproof drain-of a width equal to that of the length of the stall-runs underneath the line of stalls; the planks which form the flooring being made to fit, accurately across the shallow, broad drain, or channel, and to be easily taken up when required. The edges of the planks may be bevelled off a little, so as to allow the urine to drain through the interstices between them, on to the waterproof surface below. The planks are made of the same length as the stalls, and about 3 in. thick and 9 in. broad. The surface under the planks, instead of being hollowed out, may be flat and sloping a little (say, I in 60) to the rear, or may be level. It is evident that when the planks rest on a flat surface, they can be made much thinner (say, half the thickness) than would be required in the event of their having 
to rest on their ends. In any case the planks, when in use should be removed at least once a day during the absence of the horses, washed and dried, and the under surface should be cleaned out. The planks can be tarred over or soaked in asphalt in order to lessen their power of absorbing moisture. This form of floor drains off the urine rapidly, especially if openings be made between the planks at convenient distances and of suitable size. I have found that its employment does not entail more labour in cleaning out than the usual arrangement, and that its only drawback is the necessity for extra space for washing and drying the planks. A somewhat similar plan, except that the floor is formed of a frame of trellis wood-work which rests on a flat waterproof under-surface, is sometimes used for stalls and boxes in England. The trellis work has the advantage of being less slippery than planks. It is almost needless to say that this employment of wood should be restricted to stalls and boxes.

Cobble stones (bowlers, kidney stones, or pebbles), form a cheap flooring; but have the serious disadvantages of giving an uneven bearing to the horses' feet; of being more or less uncomfortable to lie upon; of allowing moisture to soak in between the interstices of the stones; of being difficult to keep clean; and of cutting up straw bedding to a much greater extent than any other kind of flooring material, except perhaps granite blocks. The unevenness of their surface and the difficulty of keeping them clean and dry can be more or less reduced by the use of moss litter or sawdust as a bedding.

In cases where it is impossible to have a properly laid down waterproof floor, a fairly efficient makeshift may be obtained from one of good clay; provided that the cubic content of the stable is on a liberal scale, and that there is free ventilation, so as to carry off the excess of ammonia. The clay 
in the stalls and boxes should be kept covered with sand or peat moss, so as to soak up the urine. All the soiled portions of such a floor, as well as the soiled bedding, should be removed at least twice a day and fresh sand or peat moss laid down. Also, from time to time, the surface of the clay, say, to a depth of a foot or 18 in., should be removed and fresh clay put down. These clay floors are used in India, in the Russian remount depôts, and in many other parts of the world. I have heard that rammed chalk, the tainted surface of which should be removed as may be required, is another makeshift which acts fairly well, especially as it is not slippery.

\section{OUTER WALLS OF STABLES.}

The outer walls of a stable, while serving their purpose as a means of protection to the horses in the building, should be durable; should be as nearly non-porous as possible, so that the walls may not become damp, and may not absorb noxious vapours and disease germs; should not be soluble in water; should not be inflammable; and by their low conducting power of heat or by their thickness should protect the interior from changes of temperature, so that it may remain cool in summer and warm in winter. These conditions are best fulfilled as a rule by thick walls of hard, tough stone. The quality of bricks, which are the next best material, depends on the nature of the brick-earth (brick-clay), from which they are made, and on the manner in which they are manufactured. To obtain the best bricks for this purpose, clay which is free from all injurious impurities, and which contains a small admixture of silica in the form of sand, should be used. The addition of silica is necessary to prevent the clay from cracking on drying. Pure clay consists of hydrated silicate of alumina. As an example of good bricks we may take those of Candy and Co., which 
are made from the granite clay of South Devon, and which have the following composition:-

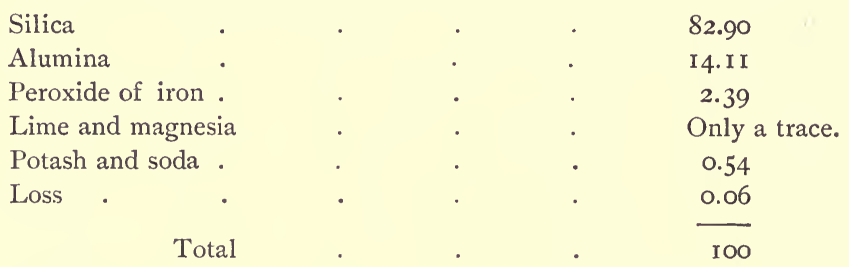

The chief deleterious substances which are found in brickclay are : organic matter (vegetable mould for instance), lime, magnesia, soda, and potash. As organic matter will not stand heat, its presence in the clay of which bricks are made, would evidently spoil them when they are put into the furnace. The more bricks are heated in manufacture, the less porous do they become; hence the best temperature is that which is just short of fusion. If lime, magnesia, potash or soda be present, it will form a silicate which will act as a flux in causing the clay to melt before the required temperature is attained. Another important reason for the desirability of the absence of lime or limestone $\left(\mathrm{CaCO}_{3}\right)$, is that if it be present, a nodule of quicklime $(\mathrm{CaO})$ may be formed in the brick when the clay is heated. The chemical action with limestone would be as follows :-

$$
\mathrm{CaCO}_{3}=\mathrm{CaO}+\mathrm{CO}_{2} \text { (carbonic acid gas). }
$$

If a brick wall which contained one or more nodules of quicklime became damp, the quicklime would be liable to unite with the absorbed water, and the resulting chemical action would probably be sufficiently violent to crack the brick. Here we have the following chemical equation :-

$$
\mathrm{CaO}+\mathrm{H}_{2} \mathrm{O} \text { (water) }=\mathrm{Ca}(\mathrm{OH})_{2} \text { (slaked lime). }
$$

Soda and potash not only form fluxes, but their silicates are to some extent soluble in water, and consequently their presence is objectionable. 
In some districts the brick earth contains clay and sand in proportions which are suited to good brick making, and is practically free from undesirable constituents. "All brick clays contain iron, and the colour of a burnt brick almost entirely depends on the amount of it which is present. Thus, clay containing less than I or I $1 / 2$ per cent. of iron, changes in the kiln to various shades of cream colour and buff, whilst those containing more than 2 per cent. range in colour from yellowish-fawn to dark red. Blue bricks are made from the same clay as the red, by controlling in a peculiar way the supply of air in firing, and by carrying the heat somewhat further. It is asserted by some that the red is changed to the black oxide of iron in the process" (Chambers' Encyclopedia). The dark blue or purple Staffordshire bricks are a well-known example of good "blue bricks." If on breaking a blue brick, we find that the internal surfaces of the fractured parts are of comparatively light colour, we may conclude that the brick is of inferior quality.

Tiles, earthen drainage pipes, and the various varieties of paving bricks are all made in the same way. Although the respective powers of absorption for water of different kinds of bricks and tiles vary within wide limits, no kind of unglazed brick or tile is absolutely waterproof.

The quality of the bricks used, and the amount of exposure (as at the seaside) to damp and rain which the building may have to endure, will naturally have to be taken into consideration in determining the thickness and mode of construction of the walls. The best arrangement for a brick wall is to have it double; the exterior wall being 9 in. thick and the interior wall $4 \frac{1}{2}$ in., with a 2 in. hollow space between them. This is commonly called a "I4 in. wall." An ordinary brick is 9 in. long, $4 \frac{1}{2}$ in. wide, and 3 in. thick. Or an "I I inch wall" may be constructed with the exterior and interior walls each $4 \frac{1}{2}$ in. thick and a 2 in. 
hollow space between them. In both cases, iron ties connect the two walls together. The use of glazed bricks for the interior surface of the walls gives a stable a smart appearance. These bricks can be obtained of any desired colour and glazed on the side, top, or end, so as to meet the exigencies of construction. The lower rows, so as to give the look of a dado, may be of different colour to that of the upper rows; for instance, the former being a dark green or dark red, and the latter a pale green. Glazed bricks cost about five times as much as good ordinary bricks. In the construction of walls, care should be taken that only the best of mortar is used, neglect of which precaution is often shown by the presence of gaping interstices, especially in brick walls. The sand employed in making mortar should be "clean and sharp," that is to say, it should be free from organic matter and should be siliceous (composed of quartz).

Wood is in most respects objectionable. It decays quickly; harbours vermin and parasites; is very absorbent; is liable to catch fire; is apt to shrink and warp; and, when used in a thickness suitable for economic requirements, it fails to keep out heat in summer and cold in winter. The only advantages it possesses over brick and stone are its cheapness; the facility with which it can be adapted to purposes of construction; and the fact that wooden stables can be made portable.

Walls made of good clay and wheaten straw (mud walls) are inexpensive; last a long time, considering their cost ; and give good protection against inclement weather and changes of atmospheric temperature. They are, however, too unsightly for general use, and harbour insects, especially wasps and bees.

INNER WALLS AND DIVISIONS.

For the inner walls and divisions, iron in various forms is to be recommended; for it is non-absorbent, non-inflammable, 
and is stronger, more durable, and occupies less space than any other substance in ordinary use; but is more expensive. Iron divisions, doors, posts, and other fittings can be bought ready made; the only addition required being wood panels for the lower part of the divisions (partitions) of the stalls and boxes. Bricks take up a great deal of room for obtaining sufficient thickness. Wood, on account of its cheapness, is largely used for divisions. An objection to wood as a material for divisions and doors of stalls and boxes, is that horses are as a rule much inclined to gnaw it. This disadvantage can be easily obviated by placing a protective covering (strips of sheet-iron, for instance) over the wood. Elm is one of the woods least open to this objection. Horses are particularly fond of using their teeth on deal.

\section{ROOFS.}

For a roof, thick thatch affords a maximum of protection from both heat and cold; but it is inflammable; needs frequent repairs; and invites the visits of countless birds and rats. I prefer thick flat roofing tiles, especially those which contain a large proportion of iron, to either slates or pantiles; for they give better protection against the weather, and are more durable. Excellent tiles, which are marked "iron," are made at Broseley and Ruabon. A serviceable arrangement is to board the roof with I in. or $\frac{3}{4}$ in. boards, which are then covered with roofing-felt securely nailed down, and finally corrugated iron is put over the felt. This, of course, does not look as well as a tiled or slated roof; but it is cheaper; is durable; and gives good protection against wet, cold, and heat. A simple corrugated iron roof will help to preserve a thatched roof over which it is placed; but by itself it affords very little protection against changes of atmospheric temperature. Great additional protection from outside changes of temperature, especially when the roof i: 
directly over the horses, may be gained by constructing an inner roof of, say, 2 in. boards, at about 12 in. from the outer roof, so as to leave between the two a layer of air that will effectively help to prevent outside alterations of temperature. from being too rapidly felt by the occupants of the building. The best theoretical arrangement for the roof of a stable is one by which the roof directly covers the horses without any interposing ceiling, against the presence of which there can, however, be no practical objection if the ceiling is not less than about Io ft. (or $12 \mathrm{ft}$., if there are several horses) high, and if the stalls and boxes are provided with efficient ventilating shafts, besides good ventilation of the ordinary kind. When a ceiling is present, it is evident that the fact of the roof being made of a material which, like corrugated iron, is a good conductor of heat, is a matter of no consequence as far as the temperature of the stable is concerned; for the overhead floor and the air contained in the room or rooms of the upper storey will give all the protection that is required in this respect.

DOORS.

It is advisable to have the stable door of ample dimensions, say, $6 \mathrm{ft}$. wide and $8 \mathrm{ft}$. high, so as to diminish the chance of an accident occurring by a horse knocking himself against the door post, or rearing up and striking his head against the lintel while he is being led through the doorway. As a rule, the immediate consequences of such an accident are less serious than the resulting vice of being "door shy" (if I may use the expression), which frequently follows an injury thus acquired. This annoying trick may be conquered by methods. described in Illustrated Horse-breaking, supposing, of course, that the animal is given no fresh cause to revert to the practice. of his former vice. It is evidently impossible to completely blot out from the mind of a horse the pleasing recollection 
of having successfully "played up." Hence, although we may by good breaking, followed by proper management, keep a "spoiled" horse under control, we cannot regard him as cured; for he will be always ready to return to his old trick or tricks on very slight provocation.

The door-way of a box should not be less than $4 \mathrm{ft}$. wide. This width may be increased to $6 \mathrm{ft}$. in the case of a box or hovel for a mare with a foal at foot, in which case the door-

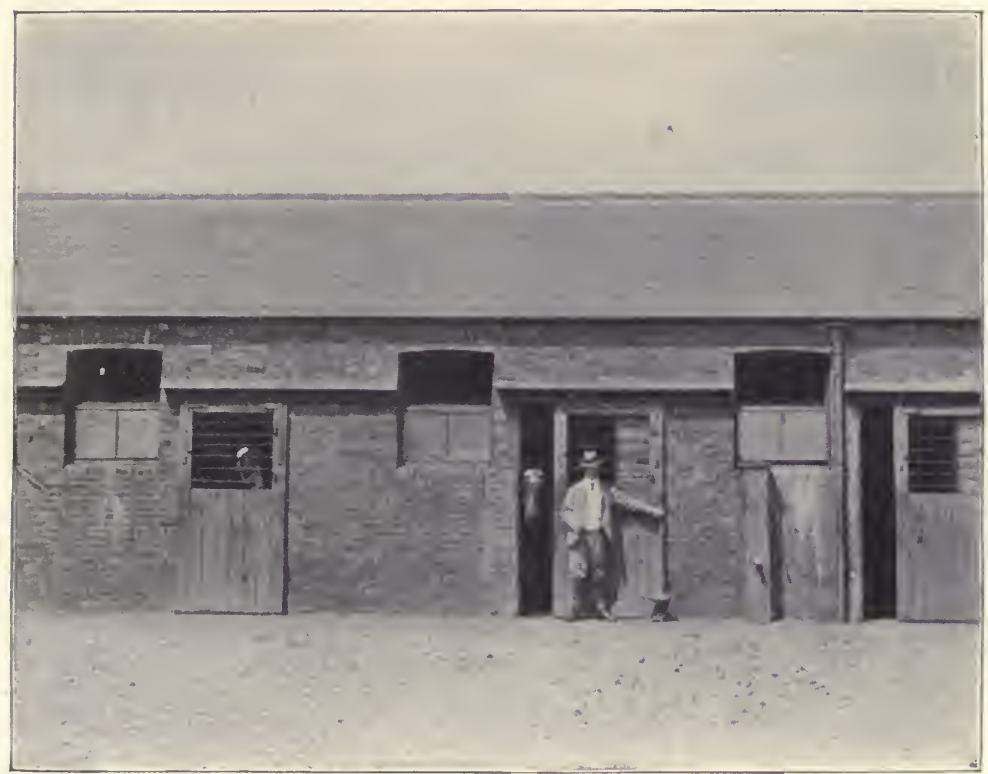

Fig. 24. Stable with Sliding Doors.

post should have a revolving arrangement; for these mares are apt to shove their youngsters up against the door-post when going in or out of the door-way.

A good arrangement for the doors of stables and boxes is for them to slide or traverse on rollers, so that they can be opened or shut by merely pushing them one way or the other (Fig. 24). Even when open, they will then be entirely 
out of the way, and will not be a possible source of injury, as hanging-doors are when open, to a horse passing through or passing by them. All hanging-doors should be made to open outwards; because then, in case of accident or illness, it would be impossible for a horse or other object inside the stable to bar entrance into the building or box; and care should be taken that no projecting points or sharp edges are furnished by the door or its attachments, so that the animal may not hurt himself on them when going through or passing by the door-way. Also, these doors should be made to fold back and to be secured when they are open, so that they may not remain on the swing. In stables, frequent use is made of the half-door principle, which allows the interior of box or stable to be seen, and which aids ventilation, while, at the same time, ingress or egress can be prevented by keeping the lower half-door shut. The upper portion of the door of a box is usually made of open bars, to facilitate ventilation and also to enable the owner or groom to look into the box without opening it.

In a single line of boxes which has no passage inside it, one outside door may serve for every two boxes (as in Fig. 25) in which the doors of each box are made to revolve on the partition between them. If the upper portion of these inner doors be furnished with open bars, the horses will be able to see each other, and thus will have companionship without being able to smell or tease each other.

\section{WINDOWS.}

The windows of a stable should be capable of admitting a plentiful supply of sunlight, and, as we have already seen, should be an effective means of ventilation. They and their appliances for opening and shutting, especially in loose boxes, should be out of the reach of the horses, which, in their hours of idleness, generally like to play with anything they can get hold of. 
MERITS OF LOOSE BOXES AND STALLS. 225

\section{PASSAGES.}

The chief requirement of passages in stables is that they should be sufficiently wide for purpose of separation and for giving horses free and safe admittance and exit.

COMPARATIVE MERITS OF LOOSE BOXES AND STALLS.

The compartments used for the residence of horses in a

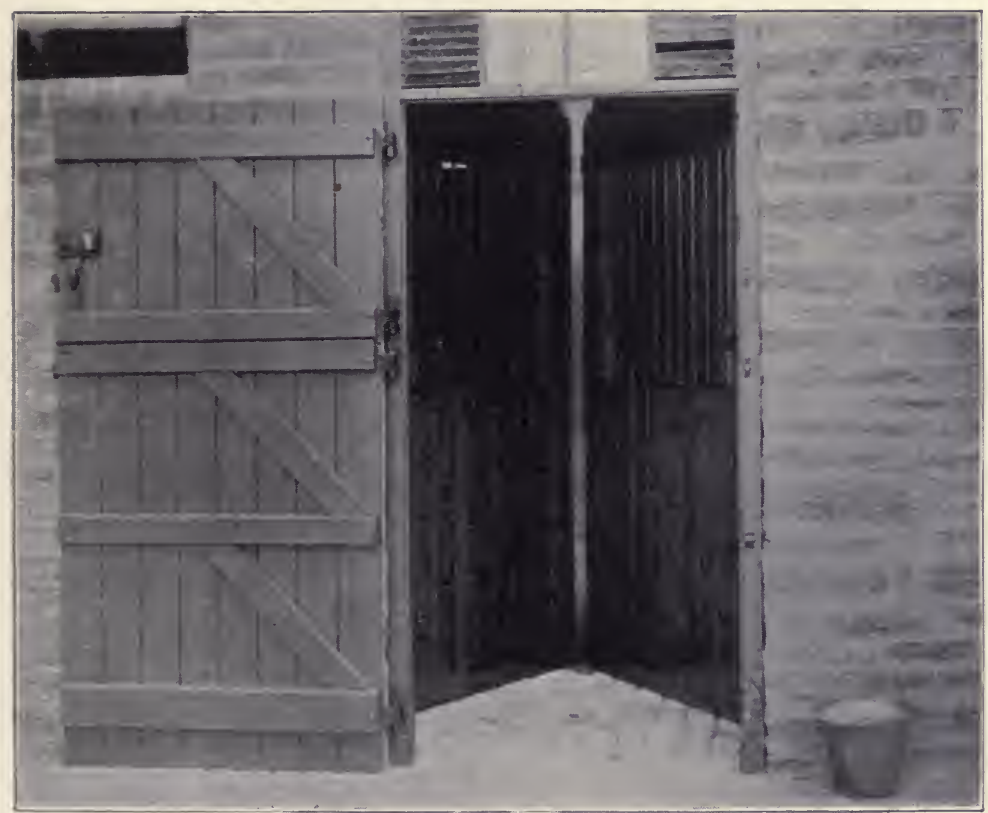

Fig. 25. One Door to Tiwo Loose Boxes.

stable, are either loose boxes or stalls; the presumption being that each animal has a place to itself. In a stall, a horse is constantly tied up; in a loose box, he is supposed to be free, except on special occasions, as for instance, when he is being groomed. 
The chief conditions which regulate the form, size and construction of these compartments are :-

I. Comfort and Safety of the Horses.-In the interests of horses, I strongly advise the use, when practicable, of loose boxes in preference to that of stalls; because the former, owing to the increased liberty they afford, are more comfortable and more healthy for horses than the latter, and are free from the dangers connected with tying-up and leaving open the entrance of the compartment. In a stall, a horse is obliged to accept a constrained position which must be more or less irksome to him, and which renders him liable to "filled legs," thrush, and other ailments, especially of the hind limbs, from want of exercise, and from not being able to change the position of the feet with sufficient facility. The presence of the tying-up chain or rope, whether single or double, is not only a source of discomfort to a horse, especially when he is lying down, and of danger to him by his getting a foreleg over the chain or rope, but it is also an inducement to cribbing. Besides, a horse is apt, particularly when he hangs back in his stall, to inflict injury on his neighbour or neighbours or to get kicked by them, in the event of there being an occupied stall on one or both sides of him, to say nothing of the risk of his kicking a confiding passer-by. Severe accidents from being kicked by a neighbour, and from getting a leg over a tying-up chain or rope, are by no means unfrequent.

Stalls which are separated by swinging bails, have the special disadvantage that horses in them are apt to hurt themselves by getting over the bails, and to injure their neighbours by kicking sideways.

2. Economy of Space.-At first glance we might think that if a stall was big enough for a horse to be tied up in, it would be sufficiently large for him to be left loose in. We must, however, bear in mind that as the side divisions of a box 
which has another box or stall alongside of it, must be high enough to prevent the horse putting his head over them; he will be unable in such circumstances to turn round in as narrow a space as he could do in a stall of similar width, over the side divisions of which he could place his head and a portion of his neck. A horse in a box as narrow as an ordinary stall, might easily hurt himself by trying to turn quickly round. Also, a horse during the night when lying down in a stall, generally utilises a portion of the gangway to stretch himself out, at a time when that passage is not in frequent use. The economy in space is much greater with swinging bail stalls than with ordinary stalls.

3. Economy of Labour.-Even if a loose box, supposing, of course, that the horse was allowed to be loose in it, was only the same size as a stall (instead of being usually about double the size), it would require more labour to keep in order; because a loose horse will disarrange or "mess about" ("morter" as they say in Leicestershire) his bedding, will dirty himself and his clothing more than in a stall, and will give trouble by distributing his dung and urine more or less impartially about his box, instead of depositing them in one place and in a convenient position for removal, as the animal would do, were he tied up. It is evident that swinging bail stalls are easier to clean out than even ordinary ones. The only circumstance that would justify a master in consulting the comfort of his groom in preference to that of his horses, is the fact of the servant having more animals than he can attend to. Although this saving clause might apply to a man who, like a cab proprietor, has to make his livelihood out of his horses, it can have no reference to the owner of "pleasure horses." So great is the disfavour with which the large majority of grooms regard the beneficial practice of giving horses freedom to move about and to assume a comfortable position in which to lie down, that, except in training stables 
almost all the horses which are given in England the supposed luxury of a loose box, are tied up for a considerable portion of the day, and, in many cases, even during the night. This custom is particularly cruel when applied to hard-worked horses, like hunters during the season; for the instinct of the horse prompts him to seek repose in the middle of the day.

4. Economy of Material.-It is self-evident that in the construction of swinging bail stalls, a minimum of material is required, and that boxes demand more material than ordinary stalls.

5. Facilities of Ventilation.-The balance here is somewhat in favour of stalls; for although in the same space they would have more divisions, these partitions would not be so high as those of boxes, and their entrance would be open. Swinging bail stalls evidently offer less obstruction to ventilation than any other kind of compartment.

To sum up, we may say that all valuable horses and all horses kept for pleasure should have boxes ; and that swinging bail stalls should be used only when rigid economy in space and money has to be practised, and when facilities for ventilation are narrowly limited.

\section{SIZE OF BOXES ANI) STALLS.}

A narrow box or stall has the serious disadvantage that a horse is more apt to become "cast" in it than in a larger one. I may explain that a horse usually gets "cast" in the act of rolling, by being prevented from completing the turn over on to the other side by the interposition of some object, such as the wall of the compartment, and at the same time being unable to obtain from the said object a sufficiently effective fixed point (fulcrum), by utilising which he might be able to roll back again to the side from which he started. The fact of the bones (humerus and shoulder-blade) of a horse's fore 
legs above his elbow joints being closely tied down to his sides by muscular attachments, renders his fore legs almost useless for enabling him to recover his position when he is lying on his back. Owing to the presence of a ligament which connects the thigh-bone to the pelvis, the hind legs of a horse have very little lateral play. Also, that portion of a horse's spinal column which lies between the neck and tail is comparatively rigid. Hence, a horse is peculiarly liable to get "cast" in the stable; not only in the manner I have described, but also by the animal's head getting underneath some fixed object, such as the manger, for instance. We should bear in mind that a horse largely utilises his head and neck for enabling him to roll and to get up off the ground, as we may see from the fact that when a horse is on the ground, he cannot rise, if his head is held with the muzzle upwards. We may utilise this fact in keeping a fallen horse down.

An objection which I have heard made against the use of wide stalls, but which I do not consider valid, is that in such a stall a horse might place himself across it, and by looking into the next stall might annoy its occupant. As this could occur only when the sides of the stall permitted a horse to see his neighbour or neighbours, and as it could be easily remedied by blocking up the side divisions near the head of the stall, so as to shut out the view, I do not think that this preventable disadvantage should be held to outweigh the increased comfort in moving about and in lying down, which would be obtained by extra width.

Experience tells us that a loose box, even for a horse in training for the Derby, need not be larger than $12 \mathrm{ft}$. by $16 \mathrm{ft}$. A fair ordinary size is $10 \mathrm{ft}$. by $12 \mathrm{ft}$. ; and one of $9 \mathrm{ft}$. by $10 \mathrm{ft}$. may be taken as a minimum. A good size for a stall is $6 \mathrm{ft}$. by I I ft. ; although an extra foot in length might be added with advantage. In Newmarket racing stables, the 
width for stalls is generally $6 \mathrm{I} / 2 \mathrm{ft}$. Ponies 14 hands and under can do with stalls $5 \mathrm{ft}$. by ro $\mathrm{ft}$.

\section{CONSTRUCTION AND FITTING OF STALLS.}

Divisions of stalls (and boxes) are made with the following objects: I. To keep the animal within certain limits of space; for instance, those necessary for the economical employment of bedding. 2. To prevent him from kicking or otherwise injuring a neighbour on either side of him. 3. To prevent him from smelling and sometimes from seeing his neighbour or neighbours. While carrying out these objects we should be careful to interfere with ventilation as little as possible. The first mentioned condition is the only one which has to be fulfilled in all cases. The second is not provided for, or only in exceptional cases (as with a kicker for example), in military and other stables where swinging bails are used. The third condition may often be dispensed with. The divisions may be made I I ft. long, $7 \mathrm{ft}$. high at the head of the stall, $4 \mathrm{ft} .9 \mathrm{in}$. high at the foot, and solid for a height of $3 \mathrm{ft} .6$ in., in order to aid in saving the animal, if he happens to kick against the divisions, from injuring himself, which he would be likely to do, if he kicked hard against iron bars, for instance. As a further protection to the possible or probable kicker, the lower portion of the divisions may be covered with wood, the grain of which is sometimes placed horizontally, so as to allow the foot of the kicker to glance off the wood more readily than it would do, if the boards were arranged vertically.

Pillars are placed at the entrance of the stall to give a firm attachment to the divisions. I see no use, except the doubtful one of hanging things on them, for tops or heads being placed on these pillars, so as to make them project above the divisions. Mr. Alec Goodman informs me that he has seen 
accidents caused by their presence on occasions when the horse, on being let loose, has swung himself round in a precipitous manner, owing to his having been hit or threatened by the groom; and has accordingly knocked his head with more or less violence against the projection on the top of the pillar.

Divisions of stalls are sometimes furnished with sliding safety bars, which, when not in use, are concealed in tubes let into their respective divisions. When drawn out and fitted into the opposite wall or pillar, they form a useful barrier for blocking up the passage of a horse that may have got loose during the night. When partly drawn out, they may be employed as a temporary bracket for saddlery or harness, which is a practice that is not altogether without danger to horses which are led past the stall, especially in the case of a groom forgetting to replace them after they have served their turn.

As a protection to the feet of a kicker and also to the boards, a thick mat or other suitable contrivance, about $3 \mathrm{I} / 2$ $\mathrm{ft}$. square, is sometimes hung up against the lower end of the division at the foot of the stall. Alternate divisions are in some cases made movable, so that a box, if required, may be converted into two stalls, and vice versâ.

Swinging bails consist of bars of wood or iron which are suspended horizontally from the ceiling, wall, or other convenient means of support, and which serve in the place of divisions for stalls. Apart from considerations of economy of space, cost, and time occupied in construction, they are used in the Army with the object of a simultaneous view being obtainable of all the horses in a line of stalls; and of accustoming the animals to stand quietly close together, as they would often have to do on active service. Various contrivances have been devised for the ready and even automatic release of horses which get their legs over these 
bails. Protection from kicking may be afforded by suspending from the bails a thick mat of rope or other suitable material.

The necessity for the horse's water, corn, and hay being kept apart at watering and feeding times, is recognised by almost every groom, and is self-evident in the case of water. As horses usually prefer corn to hay, they will as a rule endeavour to throw out the latter during their search for the former, if both be given in the same receptacle. Horses will generally go through a similar performance while eating, out of a manger, hay that has been made from too ripe grass, the seeds of which will tend to drop out of their respective ears and to accumulate at the bottom of the feeding vessel. Another objection to a combined corn and hay manger, is that, with such an arrangement, the groom would often have the slight extra trouble of being obliged to remove the remainder of the hay before giving a feed of corn; because a horse as a rule consumes hay far more slowly than oats. The infliction of annoyance on the horse in making him hunt for his corn in a mass of hay is, I think, undesirable, especially in the case of long hay, which offers greater impediment to this search than that which has been cut into short lengths. When animals are fed on short hay or chop, I do not see much objection to the practice of using only one feeding receptacle for the hay and corn; although with long hay I think it is a decided advantage for a hard-worked horse to have these two articles of forage kept separate, so that he can turn from one to the other as he chooses. The manger, besides serving for corn, will be the most convenient feeding utensil for mashes and roots on account of its being generally empty, to say nothing of its size and shape.

The materials used for receptacles for water and food should be strong, non-absorbent, and fairly cheap; and whatever article of either kind is kept constantly in reach 
of the animal, should be of such a nature that he will not be induced to gnaw it, the practice of which habit will be apt to teach him to crib. Iron, whether plain, galvanised, or enamelled, will therefore be the most suitable substance for their construction. I have heard that inferior kinds of enamel often contain poisonous salts of lead, but am unable to say how far the presence of these compounds would affect the health of horses which fed or drank out of vessels lined with such enamel.

It is manifest that the most natural position for $a$ horse's food to occupy when he is eating it, is on the ground. In ordinary cases, it is certainly the one which is most conducive to his health; because it obliges him to eat his corn more slowly; it offers more facilities to the saliva to flow from the salivary glands into the mouth; and it gives more exercise to the muscles of the head and neck than would be the case if the food were placed on a higher level. As the corn which is supplied to a horse is richer in nutriment and can be more easily swallowed by the animal than any kind of forage he would be likely to obtain in the open, and as the digestibility of equine food is largely dependent on its thorough mastication; the natural inducement to eat slowly, offered by the fact of the animal being obliged to hold his head low down, must be an effective aid to digestion. I will not go the length of saying, as some authorities do, that failure to obtain sufficient exercise of those muscles of the throat which are constantly kept at work during the act of grazing, is a cause of roaring; but I feel certain that it must interfere more or less with the due nutrition of the structures which are brought into play by the act of feeding off the ground. Against this practice, we have the objections that some horses which have infirm fore-legs, could not feed comfortably with their forage in this position; that a horse is apt to soil and waste his food by trampling on it and by throwing 
it about, and to consequently make his stall untidy; and that the usual manner of tying up a horse in a stall, makes it inconvenient for him to feed off the ground. As hay is one of the least savoury articles of forage, no useful purpose is served by taking special precautions to make a horse eat it slowly.

The ordinary position for a manger is at the head of the stall, and about $3 \mathrm{ft}$. above the floor. Although the term "manger" is generally restricted to a trough for corn, roots and mashes, it may be extended to a receptacle for both corn and hay (presumably cut in short lengths), when these two articles of forage are given without any attempt being made to keep them separate. The size of the manger should be amply sufficient to allow a horse to eat his food without danger of his spilling any of it, to aid which object, it is well to have the edge of the manger turned a little inwards and downwards. The fact of the sides of the manger sloping downwards slightly towards the centre, and the bottom of the manger being hollowed out, will help the animal to take up his food easily. Among ready-made iron mangers, the intending purchaser will find a large variety to select from. As horses when feeding from mangers which stand out abruptly from the wall are apt to hurt the front part of the fore-arm just above the knee, by suddenly lifting up the leg from impatience, or from some irritation, and as the presence of such a projection is liable to cause a horse to become "cast," if he gets his head under it when he is lying on the ground; the front surface of the manger should slope downwards and forwards, or should be perpendicular. The accident of hitting the leg in the manner just described, is by no means unfrequent, and in hunters and other 'cross-country animals, is usually put down to "chancing" fences. With existing mangers that have the defect in question, it is better to fill up the vacant space with masonry than with wood, which is 
apt to harbour vermin. Any projecting portions of wood in or near the manger should be covered with sheet-iron, zinc, or other suitable material, so as to prevent the horse from gnawing them or cribbing on them.

The hay receptacle should never take the form of the oldfashioned hay-rack, which is placed high up, and which consequently is not an uncommon indirect cause of inflammation of the eyes, from irritating particles dropping out of the hay into them. Besides, with these hay-racks, many horses get into the idle and provoking habit of pulling out the hay, irrespective of their desire to eat it, until all the hay they have not consumed is scattered over the floor, and more or less "messed" about. The idea of a rack (a receptacle formed of open bars) for hay, appears to be altogether wrong; for it will allow any hay seeds which are in the hay, and which are of nutritive value, to fall out. Also, a rack will hold only long hay efficiently. I have therefore refrained in these pages from employing the term "rack," when alluding to a receptacle for hay. The hay holder which I find most convenient to use, is similar in shape to the manger, but is a good deal deeper and is somewhat broader and wider. Its opening is provided with a couple of transverse bars, which are nearer their respective ends than the centre of the opening, so as to stop the animal from throwing out the hay in the manner practised by many horses. This hay receptacle is placed alongside the manger and on a level with it, which is an arrangement similar to that generally adopted by the chief manufacturers of ready-made iron stable fittings. The precautions which I have advised when treating of mangers, against inducements to cribbing, and against accidents to horses from striking themselves, apply equally to hay holders. A net, similar to those used by carters, will often prove useful for holding long hay.

Horses are so fastidious as to the quality of their drinking 
water, and grooms are often so oblivious of this fact, that I feel certain it is a mistake to have, presumably alongside a horse, a fixed water vessel, which, we may be quite sure, will not be cleaned out as frequently as will be necessary. Observation convinces me that when a horse has a bucket or basin of water constantly in front of him, he will unduly slaver into it and foul it, so that its inner surface will soon be covered with mucus and dirt, which will not always be cleaned away by the groom, even if he be careful enough to keep the vessel constantly full. When the receptacle is a fixture, the cleaning out process can be accomplished only with difficulty. The arrangement by which its contents can be tilted into the drain or waste pipe by a mechanism somewhat resembling that used with the revolving covers of silver or plated entrée dishes, facilitates the removal of stale water, but in no way ensures the cleaning of the vessel. Again, the constant presence of water alongside the manger often prompts a horse to play with the water and thus wet his corn in a manner that cannot be good for his digestion. I would therefore advise that instead of a constant supply of water being kept within reach of a horse tied up in a stall, he should be watered by his groom in the manner described in Chapter IV. If, however, the owner prefers the constant supply plan, I would counsel him to get a cylindrical cavity made alongside the manger, so that a sheet iron or zinc bucket without a handle could be placed in it, and to give strict orders that the bucket must be removed, emptied out, re-filled, and replaced at least three times a day; say, first thing in the morning, before the mid-day feed, and last thing at night.

If the wall of the stall is not made of glazed bricks and expense is no object, the appearance of the stall will be greatly improved and its cleanliness promoted by having the portion of the wall above the manger, say, for a height of $3 \mathrm{ft}$, 
covered with porcelain tiles of some suitable colour, such as a light olive green.

Tying-up is the process of securing a horse in a stall in such a way that he will be able to feed, drink, and lie down in more or less comfort, although he cannot quit the spot allotted to him ; and is carried out either by one line placed in the centre of the stall, or by two lines, one on each side. In their most common form, these lines, whether single or double, pass through a ring on the manger, and are attached at one end to the headstall, and at the other end to a weight (log or iron ball). This weight acts in preventing the line from getting free, and in lessening the tendency of that part of the rope which is between the manger and the headstall to form a loop, over which a horse might get a leg (in almost all cases, a fore one), with more or less serious consequences. It is evident that, while fulfilling their special purpose, these lines should be durable; should work with freedom and a minimum of noise; should be arranged so as to offer as little chance as possible to the horse to get a leg over them; and should be readily releasable when this accident occurs. Many ingenious attempts to meet these conditions have been made by manufacturers of stable fittings. In the more elaborate tying-up arrangements, a pulley is usually substituted for the ring, so as to diminish friction and noise, which is always undesirable in a stable. Tying-up lines are generally made of ropechain, or leather. Rope soon begins to fray, chain is noisy, and leather is a tempting substance for a horse to gnaw, but on the whole it is preferable to the other two, except when economy has to be studied, in which case, chain is of course the best, as it is practically indestructible. Some of the more elaborate tying lines have the part which goes over the pulley made of leather, so that it may run freely and make as little noise as possible; and the part next to the horse, of chain, so that he may not injure it with his teeth. It is manifest that the fixed 
point (or ring) upon which force finally falls when the horse hangs back in his stall and pulls on the tying line, should be attached to some immovable object, such as the wall, and not the manger or other receptacle, which in such a case might get pulled down.

The proper length of a single tying line may be taken as a little less than the height of the animal, (say, 5 feet for a horse 16 hands high), which length will enable him to hold up his head in a natural manner when standing with the tying line more or less perpendicular, and the log just resting on the ground. If a freely working pulley is placed at a distance a little more than half way up that height (say, 2 feet 9 inches off the ground for a 16 hands horse), and if the line is of uniform weight and structure, practically no loop will be formed in the tying line when the horse lowers his head. The desirable prevention of the formation of a loop is here secured by the weight of the log, when the log is off the ground; and by the weight of the front portion of the line acting more perpendicularly and being somewhat heavier than the rear portion, in all cases when the log is on the ground and when the formation of a loop might be possible, if there was undue friction between the pulley and the line. If the height of the pulley be somewhat greater than has been stated, the only inconvenience which the horse will suffer, will be the slight one of having to bear, by means of his headstall, the weight of the log more frequently than he would otherwise have to do, when he moves to one side, hangs back, or puts his head on the ground.

The weight of the log should be sufficient to enable it to readily act in all positions off the ground. Consequently, it should be heavier than the tying line. This difference will naturally have to be greater with a ring and coarse rope, than with a friction roller plate and smooth leather strap. If the weight of the $\log$ does not greatly exceed that which is 
required to enable it to perform its special work, the horse will be in no way incommoded by the log being off the ground, when his head is on the floor.

Some horses have the annoying and hurtful vice of endeavouring to get a fore-leg over a line by which they are tied up. Such old offenders can generally be recognised by the presence of a wound, recent or healed up, at the back of a fore-leg just below the knee. I know no cure for this vice, and the only safe preventive measure I can suggest, is the substitution of a loose box for a stall. Cases of horses getting a fore-leg over a tying line by accident are almost always caused by the line being too long in comparison to the height of the pulley, or by the line failing to run freely through the pulley (or ring).

The plan of tying up a horse with two lines, the respective pulleys of which should not be less than $4 \mathrm{ft}$. apart, is far preferable to that of tying him up by a single attachment; for by the former, the animal is much less liable to the serious danger of getting a leg over a line than with the latter. Besides, I am strongly of opinion that if a horse gets cast, he will be much more likely to regain his feet unaided, if tied by two lines, than if tied by only one; for with two lines, the line of the side opposite to that on which he is cast, will be more tense than a single line would be, and will on that account be of more assistance to him when he tries to turn over on his side.

When a horse is tied up with two lines, each of them will obviously have to be longer than when a single line is used. Here the proportion between the length of each line, and the height of its pulley off the ground, cannot be fixed, as it will vary according to the distance between the two pulleys.

A rack-chain (Fig. 26) is used in stall or box to confine a horse within narrow limits, in order, for instance, to keep him quiet when being groomed, and to prevent him from feeding or 
lying down prior to his being taken out for exercise or work. The rack-chain is attached by one end to a ring fixed to the centre of the wall above the manger at a height of about $6 \mathrm{ft}$. from the ground, is passed through the headstall worn by the horse, and is brought back to the ring in the wall. For purposes of attachment, the ends of the rack-chain may be provided with cross bars or spring hooks; the former being preferable to the latter by reason of their being more simple in action and not being so liable to accidentally injure the horse. To admit of the chain being readily shortened, it may have a ring or two, instead of links, at convenient distances from the ends.

Each of the pillars at the entrance of a stall should be furnished with a ring to give attachment to the pillar reins, which are of cord, leather or chain, and are respectively fixed to the rings of the snaffle, when it is required, as might happen in the case of a saddle horse, to keep the animal in the stall ready to be brought out at any moment. For a stall, pillar reins are practically a necessity ; for it is always undesirable to saddle a horse-especially if the stall is narrow and if a side saddle has to be put on-with the animal's head towards the manger. The choice of the material for the pillar reins is a matter of fancy. Steel chain is strongest and lasts a long life time, but does not look well, unless kept bright by constant burnishing. The appearance of a galvanised iron or "never rust" steel chain in a stable suggests the not always pleasant idea of studied economy of labour. White cord, so long as it is kept clean and nicely pipe-clayed, looks "smarter" than leather, which is fairly neat and gives but little trouble to keep clean. Spring hooks are generally used with chain or cord, and billets and buckles with leather pillar reins. When not in use, pillar reins should be looped up out of the way of horses, which have often an unhappy knack of entangling and injuring themselves with loose chains, ropes, 
and spring hooks, not to mention projecting objects of all sorts. In this respect we cannot be too careful, especially with mares.

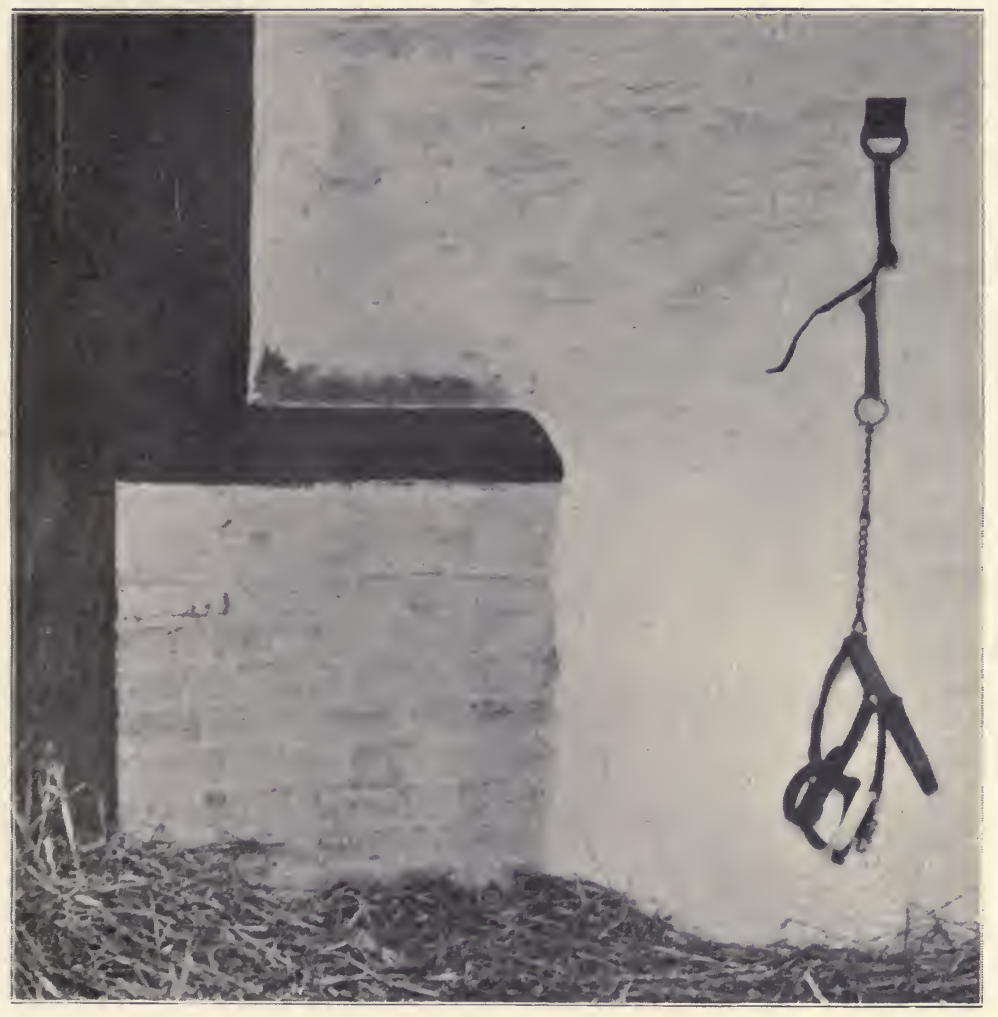

Fig. 26. Rack-chain.

CONSTRUCTION AND FITTING OF LOOSE BOXES.

In the following remarks on loose boxes, it is necessary to allude only to the points in which the arrangements differ from those of stalls (vide preceding section).

In order to obstruct ventilation as little as possible, it is advisable not to carry the divisions of a box or of a row 
of boxes up to the roof or ceiling ; for by doing so, we would convert them into separate rooms. At the same time, they should not be so low as to admit of the horses smelling each other over them, which is a practice that is apt to make even geldings restless and peevish, if not actually vicious. This effect is greatly intensified in the case of mares, and is apt to bring on sexual excitement in them. Allowing an entire to do such a thing, is of course wholly out of the question. A height of 7 feet for the division of a box would be amply sufficient for purposes of separation, and would be compatible with free ventilation; as the height of the ceiling or roof will under ordinary circumstances be at least 9, if not ro feet. As a further preventive against the horses smelling each other, I would advise, even at the cost of a certain amount of obstruction to ventilation, that the side partitions of boxes should be solid, and not with their upper portion made of rails or bars, as is often done. We shall generally find that there is no necessity, except perhaps in the case of entires, of having the upper part of the division at the entrance of the box solid, even when the box has another box or stall facing it.

For full-sized horses, 3 feet from the ground will be a convenient height for the manger and hay-holder, both of which may be of the same respective shape as that advised for use in stalls. To economise space, these two receptacles may be placed, one in each corner, at the top of the box. It is an advantage to have the manger of considerable length, say, 5 or $6 \mathrm{ft}$. long, so that the corn, when given, may be spread out in a thin layer on the bottom of the manger, in which case the horse will be obliged to eat it more slowly, and will be less liable to make it foul, than he would do, if the food was collected in a heap. If the horse is not inclined to soil and throw his hay about, and has no infirmity that would prevent him from feeding easily off the ground, there is no 
need to employ any special apparatus to hold the hay, which, in that case, can be put into a corner for the horse to eat. If a receptacle is needed to hold the hay, and it is not convenient to get a ready-made hay-holder, a cheap and serviceable one may be constructed of wood, which should, of course, be protected by some substance like zinc or sheet-iron, that the horse will not seize with his teeth. If wood be objected to, a brick wall, 3 feet high, may be built across one corner, at the head of the box, so as to leave a triangular opening at the top. A similar structure might serve to hold the manger.

For feeding a horse off the ground, we may use a sheet or large wooden box for the corn, and may put the hay to one side or the other, at the head of the loose box within convenient reach of the animal.

The horse may get his water out of a sheet-iron bucket placed in one of the corners of the box; provided of course that he shows no inclination to play with the bucket and upset it. To avoid accident, it is well to have no handle on a bucket left on the floor in a box or a stall. An arrangement which I have found to work well, is that of suspending to one of the bars of the door or division at the entrance of the box, a bucket of water (Fig. 27), and giving strict orders for the bucket to be kept constantly full, by being, after the animal has drunk its contents, detached from its bar, taken out of the box, filled directly from the water source (tap, pump, cistern, pond, or other means of supply), and replaced, so as to avoid getting the water tainted. No tying-up chains are required in a loose-box; although a rack-chain will be necessary.

SICK BOX.

A sick box is useful in the smallest stable, and is a necessity in a large one. The only thing needed to convert an ordinary 
loose-box into a sick one is the addition of a set of slings, which should be suspended from the roof or ceiling in such a manner that the horse, when the slings are under him, will be in a position to eat comfortably out of the manger, which should preferably be placed at the centre of the wall at the head of the box, with-contrary to what l have advised for ordinary use-the watering bucket or basin and the hay receptacle at its respective sides. The hook holding the block of the chain should be particularly strong, and should be securely fixed to a stout beam overhead. The chain should be of the endless kind and should work in a multiplying block, so that the slings, which should be provided with a breastplate and breeching, can be raised or lowered with ease, safety, and exactness. In order to give rest to the horse when he has to continue standing for a long time-maybe for months-the height of the slings should be regulated so that he can bear his weight on them or not as he chooses; for if he be in any way suspended in them, the resulting pressure on his abdomen will not only be uncomfortable to him, but if continued even for a few hours, will interfere more or less with his digestion. For dressing painful wounds, especially of the limbs, slings are often a valuable means of control, by taking the animal off his legs for the time being. A few rings fixed at convenient positions in the wall and divisions, are useful for the attachment of hobbles, one or more of which can be put on the horse's legs, so as to prevent him from moving them in any undesired direction.

With the possibility of having to treat cases of infectious diseases, it is well to have the sick box far removed and strictly isolated from the other boxes and stalls. This segregation will also be frequently valuable by reason of its guarding the animal from being disturbed by the noises and movements made by other horses and by grooms. 
FEEDING ROOM.

Even a moderately-sized stable will require a feeding room, which should contain a corn-bin for current expenditure; a chaff-cutter; an oat bruising-machine; and a few small

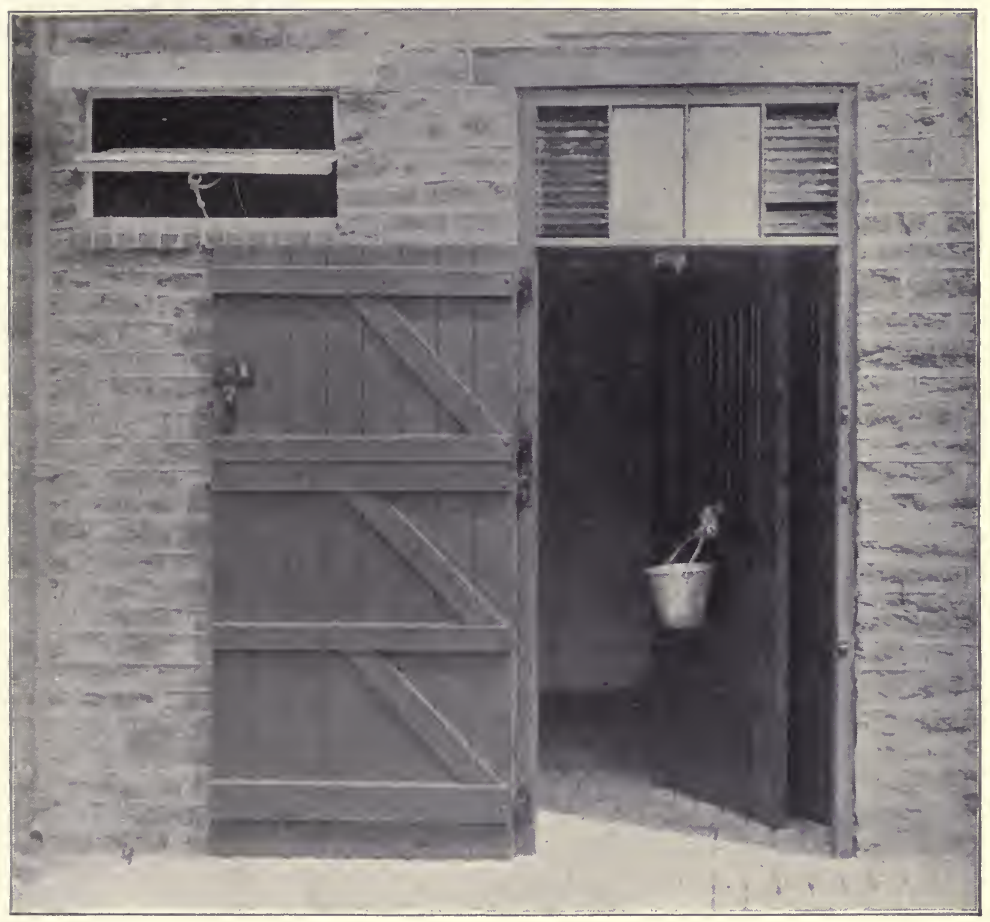

Fig. 27. Water bucket fixed to door of box.

articles, such as a quartern measure, a sieve, a hair-broom, a lantern, and a bucket or two. The feeding room, for convenience sake, may be next to the stalls or boxes.

\section{SADDLE AND HARNESS ROOM.}

If practicable, saddles and harness should be kept in a separate room and not hung up in the stable, as is often done; 
for the damp and ammonia that are given off to a greater or less extent in a stable, would be apt to injuriously affect them (pp. 47 and 48). Besides, a place is required in which to clean and dry the gear, as well as to stow it. As the room should be dry and clean, it is best to have the flooring of cement, and the walls and ceiling lined with match-boarding. If there are many saddles, they are most conveniently kept on brackets that are hung on the walls and have below them semi-circular holders of wood or metal, over which the head pieces of the bridles can be put. A bridle can in this manner remain suspended without the centre of the head-piece acquiring-as would probably happen, if it were hung from a hook-a wrinkle which would be unsightly, and would tend in time to develop into a crack. Harness can also be hung up on brackets, or put in glass cases. If the number of saddles does not exceed, say, six, they may be kept on saddle stands, which have the disadvantage of taking up a good deal of room. In any case a saddle stand is wanted for cleaning saddles, arranging girths and stirrup leathers, \&c. Spare bits can be kept in a bit case placed, like the harness cases, against one of the walls. A cheaper, and, as I have heard, a much better plan, as far as the prevention of rust is concerned, is to put spare bits in a vessel containing paraffin (kerosene) oil. A few cupboards will probably be required, one of which, in a large stable, may be devoted to medicines and a few simple veterinary appliances.

The saddle room should have a good fireplace, which can be used for drying gear, supposing there is no drying room, and, if there is no cleaning and brush room, a boiler for supplying hot water. If it is used as a mess room for the lads, a range of appropriate size will be a great convenience to them. I prefer a good oil lamp, hung from the centre of the ceiling, to gas, which, when lighted, gives off sulphurous fumes that tarnish metals, especially silver 
(forming sulphide of silver), and have a destructive effect on leather.

It is desirable that the saddle room should be connected to the stable, so that the grooms going from one to the other in bad weather may not catch cold. It should not, however, be next to the horses, which might be disturbed by the voices or movements of the men. If there are several lads, as in a training stable, it is well to have their mess room, whether or not it is the saddle room, so far removed from the master's house, that any noise they may make will not be a source of annoyance.

\section{CLEANING AND BRUSH ROOM.}

This room is a desirable adjunct to the saddle room, especially to that of a large stable. In it all washing, brushing, and cleaning of hunting things should be done. It should, if practicable, have a constant supply of water.

\section{DRYING ROOM.}

In large stables it is convenient to have a room set apart for drying clothing and gear, for which object it should have a firepláce and hot water pipes arranged for drying purposes. This room may contain cupboards for storing clothing, bandages, etc.

\section{COACH-HOUSE.}

The coach-house should be separated from the stalls and boxes, so that the carriages in it may not be exposed in any way to the fumes arising from the stable. Not only is damp injurious to a carriage and its fittings, but ammonia, as we have seen (p. 48), destroys varnish. The coach-house should, if possible, face the south or south-west, so as to get a maximum amount of sunlight when required. Like the stable, it should, for purposes of dryness, be raised above the surface 
of the ground, and, like the saddle room, it should have a waterproof floor, and the walls and ceiling lined with match boarding. The coach-house should have a heating apparatus to be used in cold and particularly in damp weather. The best kind is that of hot-water pipes; for the fumes from coal and gas quickly tarnish silver mountings. A hook should be placed high up on one of the walls on which to hang the pole, so that the pole may not become bent, as would be liable to happen if it were placed resting against a wall. In this position, its hook on the swivel head is also apt to become damaged. For each two-wheeled trap there should be a stand on which to rest the shafts. When in use, this stand should be placed at from a foot to eighteen inches in front of the cross-bar. If it is put under the points of the shafts, as is often done, the shafts will in time become bent, and the appearance and balance of the conveyance will become spoiled. The same disastrous result will be obtained by allowing the points of the shafts to rest on the ground. There ought to be a jack or two for raising the wheels when they are to be cleaned; and a whip-rack for hanging driving whips on.

\section{WASH BOX.}

This room or building, which is used for the washing of carriages, should be covered over, preferably with glass, so that it may be well lighted by day; paved with some waterproof material, such as cement-concrete; and supplied, if practicable, with abundance of water under sufficient pressure for the employment of a hose. It should be provided with ample artificial light for night work.

\section{FORGE.}

Every large stable should have a well-appointed forge in which the horses' feet can be attended to without 
incurring the delay and inconvenience of sending the animals to a smithy. There will very rarely be any trouble in arranging to get a blacksmith to come and work in the forge, where he should find everything ready at hand. The great advantage of this accommodation depends on the fact that it is impossible to fit a shoe-especially an ordinary heavy shoe-as accurately cold, as it is to fit it hot.

\section{STABLE-YARD.}

A capital ground surface for a stable-yard, if expense be no object, is one made of hard buff-coloured paving bricks laid on a layer of concrete. Hard blue bricks will be cheaper, but are less resistant to wear and do not look so well. If economy has to be studied, the centre of the yard may be laid down with gravel; and the edges with bricks, say, to a width of $8 \mathrm{ft}$. In a small stable, a space upon which to wash carriages will generally be required, and will be most conveniently placed outside, and at a distance from the coachhouse of say, 5 or 6 yards. This space may be made about I $5 \mathrm{ft}$. square; it should be covered with waterproof material, such as bricks to match the pavement of the yard; and its sides should slope downwards and inwards (say, at a gradient of $I$ in 20) to its centre, at which there should usually be a grating communicating with an underground drain.

Although gravel in the first instance is far cheaper than paving brick, the difference is made up in time by the greater expense and trouble in keeping it in order. Besides it harbours dirt and wet. Cobble stones are noisy and bad for the horses' feet; they retain damp and are difficult to keep clean.

\section{RIDING SCHOOL.}

A riding school is one of the greatest conveniences a hunting man, trainer, or owner of polo ponies can possess ; 
for it is not only very useful for the breaking-in of saddle horses and ponies, but it also supplies its possessor with the invaluable luxury of a dry and comfortable place in which to exercise his animals in wet, snowy and frosty weather. In Illustrated Horse Breaking I have dwelt at some length on the advantages of a riding school from a breaking point of view.

We may take the minimum size of a school as that of the arena of a circus, namely, a circle having a diameter of I 3 metres, which is equal to about $43 \mathrm{ft}$. This length, or 2 or $3 \mathrm{ft}$. more, would be convenient for the side of a square school, which could be used as a square or circular ride, as might be desired. A size large enough for any purpose, would be 60 yards by 20 yards, which is that of a full-sized military riding school.

Supposing that it is intended to have a school, the track of which could be used as a square or circle; we might get constructed a stone or brick building $50 \mathrm{ft}$. square externally (or larger as might be required), and having walls about I $2 \mathrm{ft}$. high. The place should be well lighted by windows, but not by a glass roof, which would make it cold in winter and hot in summer. The lower-portion of the walls on the inside, for a height of about $3 \mathrm{ft}$., should slope inwards at a gradient of about 4 in $\mathrm{I}$, so that when a mounted horse is on the track close to the wall, the rider's legs and feet may be clear of it. It will be convenient to have two doors, facing each other, in the respective centres of their walls, and made to traverse, so that no accident may occur from a door being left on the swing. A width of about Io $\mathrm{ft}$. for the doorways will permit of a horse being ridden from the outside across the school at a fence placed near its centre. Mirrors on the walls of a riding school greatly help to light up the place, besides serving their own special duty.

Although the space in the centre of a quadrangularly 
arranged stable may be utilised for a school, it is much better to have the manège entirely separate from the stalls and boxes, the occupants of which can hardly fail to be more or less disturbed by the noise and presence of the horses at work in the school.

In England the floor of a school is often made by digging out the surface inside to a depth of about $2 \mathrm{ft}$., and then filling it up for about 18 in. with faggots of hazel or birch, and the remaining 6 in. with tan, which has to be renewed from time to time, according as it sinks. This plan entails a great expenditure of tan, and is not necessary; for it is just as good to dig up the ground and cover it with tan, without using any faggots. To either of these methods I much prefer the plan used in circuses and in riding schools all over the Continent, of employing sawdust instead of tan and faggots. To begin with, we may put, on a foundation of clay, a layer of sawdust 2 or 3 in. thick, over which a thin layer of clay is placed, and over that, another layer of sawdust. The feet of the horses will work up the clay and sawdust together, so as to form a soft and fairly elastic surface. On a soil of clay, or of clay mixed with sand, no preparation is needed beyond making the ground level; putting down a layer of sawdust, which should be raked up with the ground underneath; and adding more sawdust as may be necessary. Any excess of sawdust can be removed with a rake, or more added when required. After work, the surface should be raked over, and can be sprinkled with water from a rose. To keep down dust in dry weather, it is well to sprinkle salt (which has a great affinity for water) over the surface, thickly enough to give it the appearance of hoar frost. At first, we might use a pound of powdered rock salt for each square yard, and renew the salt as might be needed. Tan "balls" in a horse's feet, and if left in them, quickly heats and corrodes them, which are objections 
that sawdust is practically free from. Besides, the presence of $\tan$ on the ground makes a building look gloomy. Tan in a quantity sufficient for a school costs far more than sawdust, and does not give such a good result.

\section{LITTER SHED.}

For drying straw litter in wet weather, it is well to have an open shed with a movable protection for any side against which the rain may beat. In fine weather it will be best to dry the bedding in the open air.

\section{WEIGHING MACHINE.}

In large stables it is often a great convenience to have at the gateway a machine for weighing loads of hay, straw, carrots, etc. Bags of oats will generally be weighed one by one with ordinary weights and scales.

\section{STABLE UTENSILS.}

The "tools" for grooming are described on pages 326 to 332.

I refrain from quoting the prices of stable utensils and grooming tools; because they are matters of common knowledge, and are not more affected by quality and the fashionable standing of tradesmen, than those of other articles of commerce. Besides, extra cost has to be allowed for, when horse-owners entrust purchases to grooms, and fail to pay cash.

Each groom, for his horse or horses, should be provided with a bass-broom, birch-broom, stable fork, skep and shovel; and each horse, with a water bucket.

Every stable should possess a corn-bin, sieve, quartern measure, weights and scales for weighing sacks of corn, wheelbarrow, chaff (chop) cutter, oat-bruising machine, saddle-dryer, clipping machine (power or hand, according to the size of the stable), singeing lamp, clipping scissors and combs, 
ordinary scissors, and a hurricane lamp. If maize be used, a corn crusher (kibbling machine) will be required. A wheellifting jack, and possibly a spoke-brush and mop (p. 367) will be needed for a carriage; and a corn cleaning machine (p. I I4) may be added to the utensils of a large stable.

The birch-broom will be for use outside the stable; the bassbroom, inside.

The ends of a stable fork should terminate in round knobs,

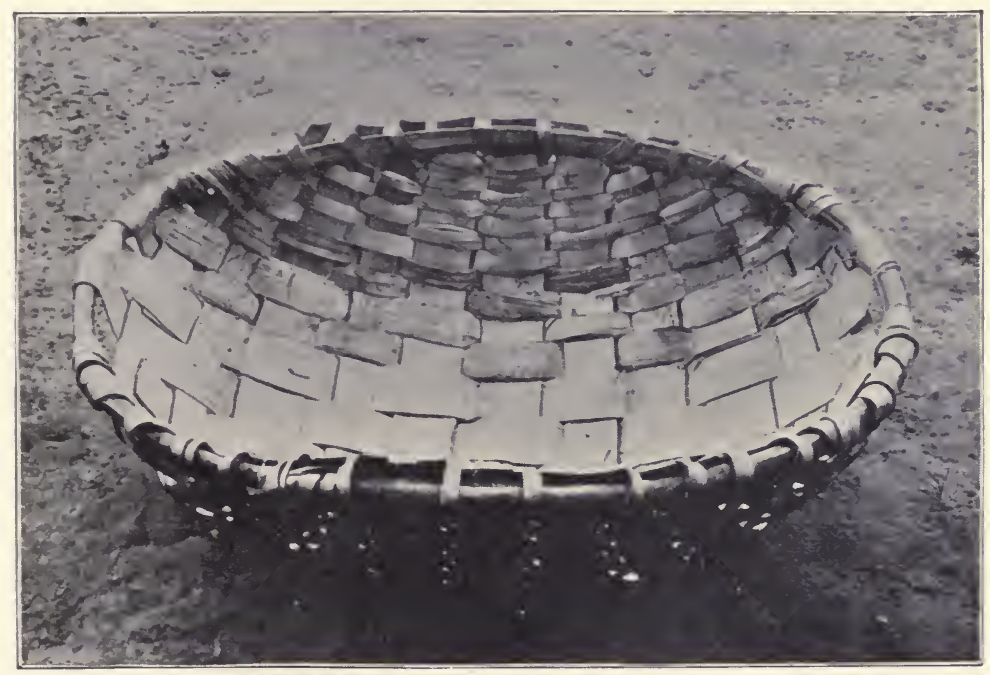

Fig. 28. Skep or dung basket.

so that the horse may not get injured by them, as not unfrequently happens, both accidentally, and through loss of temper. Usually, the handle is much too long, and is more suited for loading a cart with hay or for making a hay-stack, than for arranging bedding.

A skep is either a basket or sheet iron receptacle for dung. I prefer the basket form, as it is not liable to hurt a horse in the event of his knocking up against it. The best kind of skep I have seen is one of wicker work which is made in 
the North Cheshire country (Fig. 28.) This basket is about 7 inches deep, and of an oval shape, the long axis being 24 inches long and the short axis 18 inches.

A wooden bucket, especially if it is of oak and is brass bound, looks better than a galvanised iron one, which is cheaper, cleaner, and more durable. Also, if a wooden bucket is left within reach of a horse, he will be liable to gnaw it, and crib on it.

It is well to have the com-bin made of galvanized iron, so that the corn may be protected from rats and mice. For a small stable, it may be divided into three compartments, to hold respectively, say, eight bushels, four bushels, and one bushel, for oats, bran, and beans. There might be a fourth compartment for salt. The corn-bin should be provided with a lock and key.

A galvanized iron wheel-barrow is cleaner for stable use than a wooden one.

In an oat-bruising machine, the bruising is done by two smooth rollers, the distance between which can be adjusted by a screw as may be required. The corn-crusher is provided with teeth, which break the grain more or less coarsely. In the working of both these machines, a great saving of manual labour can be effected by the adoption of the ingenious method of applying power by means of a tricycle, in the manner devised by Dr. James Roberts, of Melton Mowbray (Figs. 29 and 30).

A pair of clipping scissors with straight blades, and one with curved blades will be useful for trimming parts which cannot be easily got at with a clipping machine.

There are three kinds of spoke-brushes. The ordinary sort is a long narrow brush with a hard back, which is an objection to its use (p. 367). In the second variety, the back is covered with india-rubber, so as to save the paint and varnish on the spokes from getting chipped. In the third form, the bristles radiate from the shaft, as in a lamp brush. 


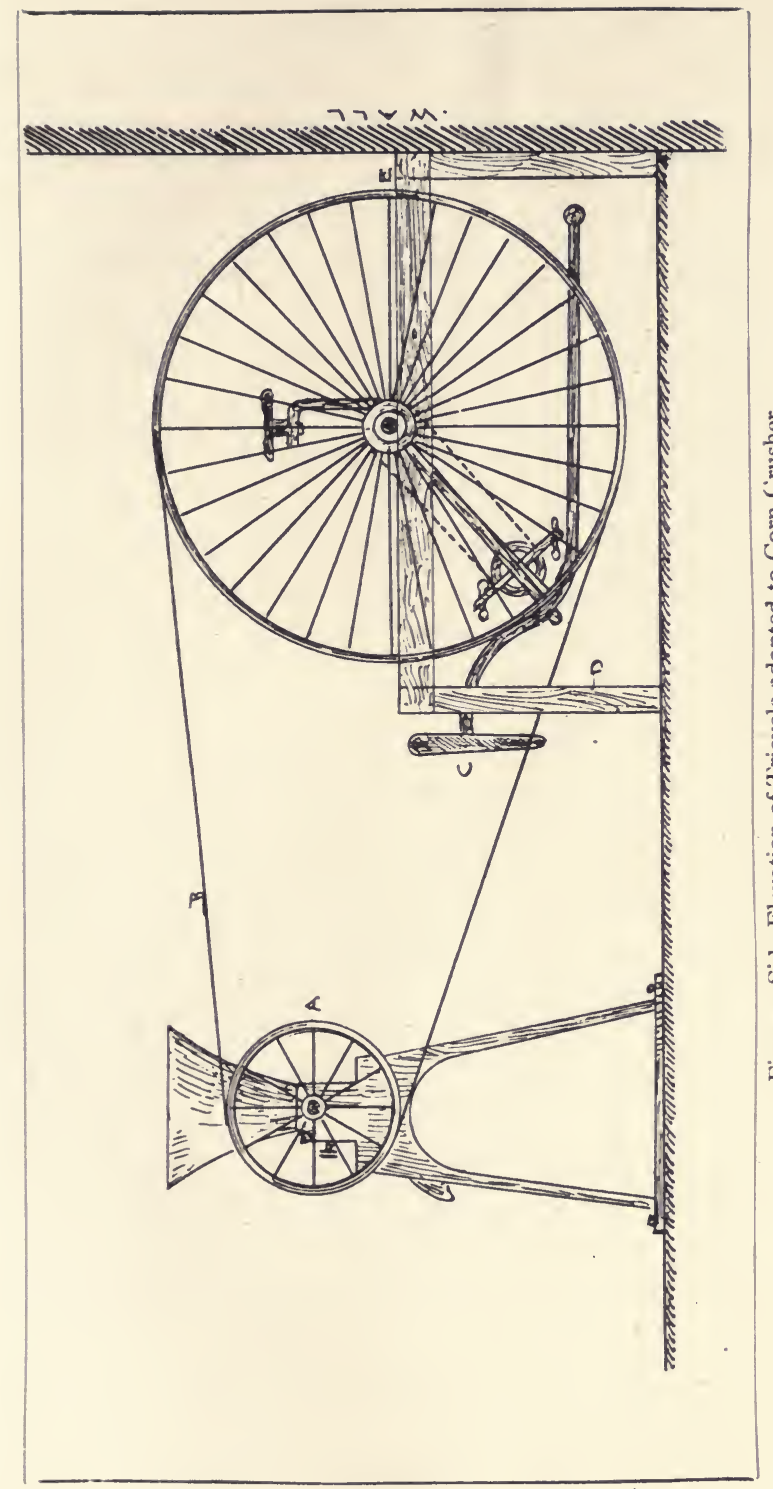

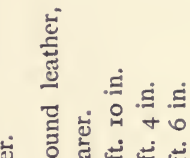

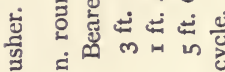

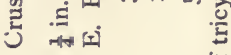

ह ט. $\vdots \vdots \vdots$

๑

ช

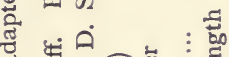

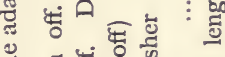

ปั

ड्ड

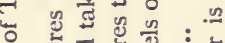

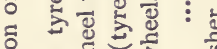

을 플 $\frac{\pi}{3}$ :

उ

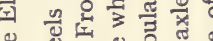

㻤

จ่

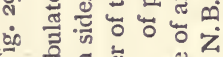

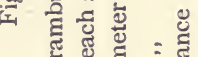

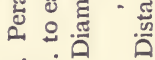

$<\dot{4}$ 


\section{PLANS FOR STABLES.}

The principles which should guide us in drawing out the plan of a stable, are those by which we can obtain healthy stable conditions combined with safety for the horses and convenience for carrying out stable routine. In order to obtain full advantage from the best aspect, the portion of the stable containing the animals should be more or less in a straight line, and should have no objects near it that will interfere with its ventilation, drainage, or supply of sunlight. A quadrangular or three-sided arrangement is often convenient for a large establishment; for, by adopting it, the boxes, stalls, saddle-room, coach-house, and other places can be grouped round a central yard.

With respect to internal arrangement, the conditions in question will best be observed when the horses have only one wall on each side, between them and the outer air, and when they are placed in a single row, with a passage opening by a door at each end between the front wall and the boxes or stalls. If there are more than seven or eight horses, a door may be allowed in the front wall (and also in the rear wall, if necessary) for every three or four horses. By placing the passage next to the front wall, the windows in that wall can be made of any size, or may be placed at any height that may be desired. If the horses stand in two rows with a passage between them, little or no direct sunlight can fall on the compartments occupied by the animals which are next the front wall. The necessity for economising space will, however, often oblige an owner to adopt this tworow arrangement.

The presence of an inside passage is convenient, and by aiding ventilation, especially if a door is at each end, is conducive to health. Want of space would, as a rule, be the only consideration that would warrant its absence. 


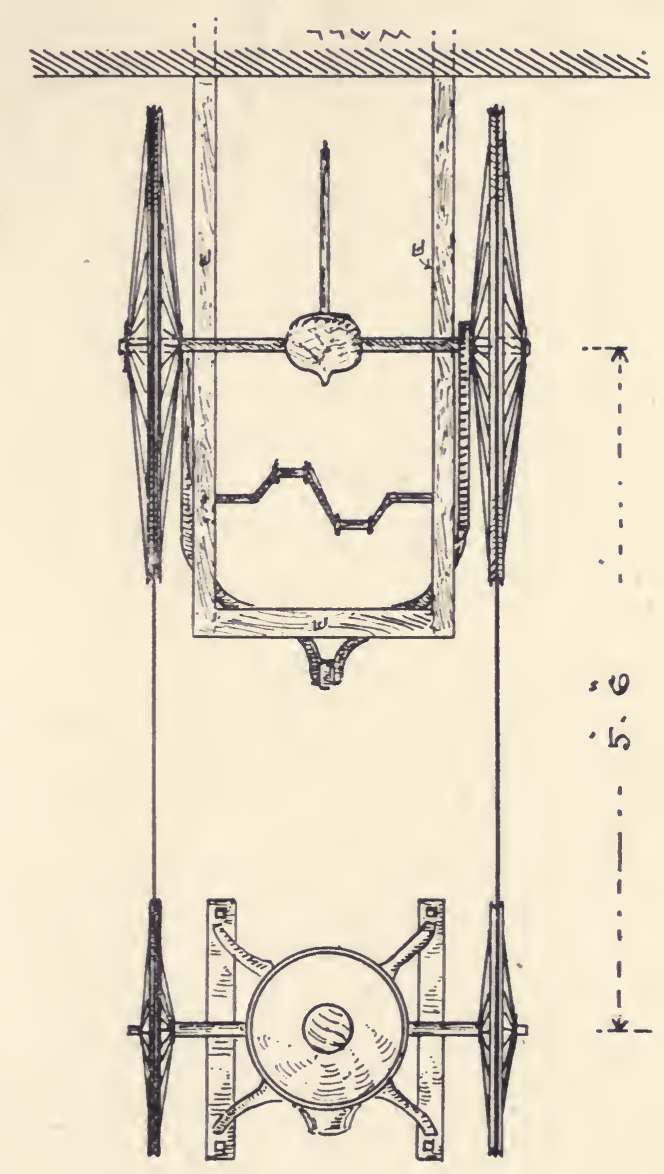

Fig. 30. Ground Plan of Tricycle adapterl to Corn Crusher. 
Thus, supposing that we had available for a line of boxes, a width of only Io or I $2 \mathrm{ft}$, we would have to be content with a series of rooms, to each of which or to each couple of which a doorway would have to be given.

As horses take a great deal of notice of each other, and of noises and movement, the smaller the number of animals which are in a building, the more rest will its occupants obtain. In private stables, the number might with advantage be limited to eight, one or more buildings being added for the horses beyond that number.

When space, expense, the necessity of utilising existing buildings, and other considerations have to be studied, the best compromise which can be made in the circumstances will have to be accepted. Thus we often find in the stables of dealers and large companies in towns, that fairly good results are obtained, even when the boxes and stalls are placed in storeys, one above the other, with inclined planes to serve as stairs.

\section{NECESSITY FOR DRYING NEW STABLES.}

As new stables are always damp, they should not be occupied until they are thoroughly dry. We may hasten the process of drying, by burning charcoal in braziers inside the building. Coal and wood might also be employed, but the smoke given off by their combustion would of course be more or less objectionable.

\section{DISINFECTION OF STABLES.}

Absolute cleanliness is the best form of disinfection, but unfortunately it is not always possible in stables. Comparative purity can generally be obtained when there are no subsoil drains, which require frequent flushing with water to keep them even moderately clean.

A perfect disinfectant should be (I) effective in its action; 
(2) harmless to the occupants of the stable; (3) and free from disagreeable odour. Boiling water is a safe, efficient, and readily procurable disinfectant. Creolin, of which Jay's Fluid is a good form, and fairly pure carbolic acid serve this purpose in an admirable manner, when diluted with about 20 times their bulk of water. Crude carbolic acid is very cheap, but it dissolves only sparingly in water, which is a drawback that can be removed by mixing it with 4 times its volume of glycerine. A solution of sulphate of iron (the impure kind will do) dissolved in a gallon of water makes a capital disinfectant, and fixes ammonia by converting it into the sulphate. Carbolized sawdust is very useful as a purifying agent, for sprinkling in stables as may be required. It can be prepared by taking a solution of equal quantities of crude carbolic acid and water, and adding as much sawdust as will soak up the fluid. Powdered gypsum (sulphate of lime) sprinkled over dung, urine, and contaminated litter, absorbs the evolved ammonia and thus, not only helps to keep the air of the stable pure, but also retains the valuable ammonia for manurial purposes. 


\title{
CHAPTER VIII.
}

\author{
BEDDING.
}

Necessity of Bedding-Varieties of Bedding-Comparative Powers of Absorption of Water by Various Kinds of Bedding-Requirements in a Bedding-Classification of Bedding Materials-Effects of Bedding on Horses' Feet-StrawPeat Moss-Sawdust-Wood Shavings-Tan-Ferns, Fir Needles and MossSand-Combined Bedding-Choice of a Bedding-Bedding down-Muckingout-Disposal of used Litter-Stable Manure.

\section{NECESSITY OF BEDDING.}

THE following are the chief reasons why a stabled horse requires to have an artificial covering for the floor of his box or stall :-

I. The floor is necessarily made so hard that he could not lie down in comfort on it without a bedding. In fact, the absence or deficient supply of bedding is not an uncommon cause, in badly managed stables, of horses getting cut about the points of the hips, hocks, and fetlocks from contact with the floor. We must here remember that when a horse is at grass, he has a large choice of ground upon which to repose, and even then he does not always escape from the injuries just mentioned. Also, it is advisable as a rule to encourage hard-worked horses to lie down during the day, when they are in the stable.

2. For purposes of health, comfort and cleanliness, an animal needs to have some material under him that will soak up or drain off the urine and the moisture 
from the dung, which duty an ordinary floor will not perform.

3. To save the horse from the bad effects of chill, whether generally, or locally in his feet and legs, he needs for lying and standing on, a material which is a bad conductor of heat. Except when the floor is of wood, it is in all usual cases a good conductor of heat. It is true that when a horse lives in the open, his lying down and standing up are performed as a rule on substances which conduct heat with comparative rapidity from objects placed in contact with them; but this disturbance of blood circulation is more or less counterbalanced by the fact that the animal's system is then more resistant-to the effects of chill than that of the stabled horse. Also, when at liberty, he occupies the greater part of both day and night in moving about, chiefly in search of food. The tendency to "fill" shown by the legs of even sound horses which are kept for a long time in a stable, is far greater, if they have to stand during the day on a floor which is a good conductor of heat, like stone, cement, or brick, than if the standing is warm to the feet, as is the case with straw, wood, and peat moss for instance. Frequent movement being one of the natural conditions of equine life, we find that a horse's feet and legs are anatomically badly fitted to bear long-continued rest, especially when standing, in which position gravitation materially helps to retard the circulation of blood in these parts. The ill-effects of this local interference are manifested not only by the legs filling, but also, and far more seriously, by tendency to fever in the feet and navicular disease.

\section{VARIETIES OF BEDDING.}

The principal varieties of bedding are straw, peat moss, sawdust, wood shavings, tan, ferns, sand, and fir needles. 
COMPARATIVE POIVERS OF ABSORPTION OF WATER AND AMMONIA BY DIFFERENT KINDS OF BEDDING.

Muintz and Girard give the following table to show how much water certain kinds of bedding can absorb :-

Times its own weight of water.

\begin{tabular}{|c|c|c|c|c|c|c|c|c|c|}
\hline Sand & - & . & - & • & - & • & • & - & 0.25 \\
\hline Vegetable moul & & . & . & · & . & • & · & - & $0.5^{\circ}$ \\
\hline Fir needles & . & . & - & - & - & . & . & · & 2.00 \\
\hline Dead leaves & $\cdot$ & - & • & • & • & . & . & • & 2.00 \\
\hline Ferns & $\cdot$ & • & . & • & • & . & . & • & 2.12 \\
\hline Wheat straw & . & . & . & . & . & . & . & • & 2.20 \\
\hline Oat straw & . & . & . & · & • & . & . & • & 2.28 \\
\hline Barley straw & - & - & - & - & - & & . & · & 2.85 \\
\hline Moss & . & • & . & . & • & & . & • & 2.75 \\
\hline Sawdust of fir & . & . & - & . & · & & . & · & 4.20 \\
\hline Tan & . & . & & . & . & & . & · & 5.00 \\
\hline Peat moss & . & . & & • & . & & . & . & 6.00 \\
\hline
\end{tabular}

The sample of peat moss experimented upon for the above table, must have been an indifferent one ; because good specimens of this bedding can absorb from 8 to 10 times their own weight of water.

Müntz and Girard have shown by experiment that powdered peat, when moistened with a fluid giving off ammonia (in the same manner as urine does in a stable), absorbs $61 / 2$ times as much ammonia as wheat straw would do under similar circumstances, and 24 times as much as pine sawdust.

\section{REQUIREMENTS IN A BEDDING.}

To fulfil all the conditions of comfort, health, cleanliness, and economy, a bedding should be dry, soft, elastic, absorbent of watery fluids and gases, clean in use, easily procurable, fairly cheap, and free from decomposing matters, disagreeable and unhealthy odours, and corrosive and astringent properties. It should be a bad conductor of heat, and should not be hurtful to the health, if it tempts horses to eat it. For appearance sake it is well to have it of a light colour, so 
that it may brighten up the stall or box by the light reflected off its surface. The possession of a pleasant smell is of course a strong recommendation.

Dryness is essential to the horse's general health and to the strength and soundness of his feet, the horn of which becomes decomposed by the prolonged action of wet. If the bedding, like peat moss, is highly absorbent of moisture, it will aid, as far as its absorbent capacity goes, in keeping the floor dry. But if, like straw, it possesses this property to only a small degree, it will need to be of such a nature that it will readily allow of the downward escape of fluid which falls on it, and it should be of good depth, so that its surface may remain dry. Even then, there will be the difficulty of removing the urine which has drained through the bedding on to the floor.

High capacity for absorbing gases is very useful in a bedding; because it helps to prevent the atmosphere of the box or stall from becoming contaminated by injurious gases which result from the decomposition of urine and dung, and which, in this case, will become imprisoned to a greater or less extent in the material of the bedding, and can then be removed out of the stable.

\section{CLASSIFICATION OF BEDDING MATERIALS.}

An instructive classification of bedding materials can be made by dividing them according to the special aptitude they respectively show for either drainage or absorption. It is evident that the greater the power a substance has of retaining (absorbing) fluid, the less capacity will it have for vertical drainage and vice versâ. In fact, excellence in one implies deficiency in the other. We may therefore, from a practical though somewhat arbitrary point of view, place peat moss, tan, and sawdust under the heading of absorbent bedding; and straw and other forms of litter, which are not more absorbent than it, under that of drainage bedding, if I 
may be allowed the expression. Wood shavings and chips appear to occupy an intermediate position between the two.

\section{EFFECTS OF BEDDING ON HORSES' FEET.}

The various kinds of bedding materials might be divided not only into absorbent bedding and drainage bedding, but also into (I) those which exert an injurious influence on the feet of horses stabled on them; and (2) those which do not exhibit that tendency. In the former we may include all kinds of litter which, like peat moss, tan, and sawdust, are bad conductors of heat, and which are liable to become retained ("balled") in the feet in a more or less compact form. When the feet are allowed to continue in this state, even for a few hours in some cases, the soles and frogs, as we may find on removing the offending material, become unduly heated, with the result in time, if the cause be permitted to remain in action, that thrush will become developed and the heels as a rule will become contracted. When we seek for the cause of the heated condition of the frogs and soles from balling, we find that the retention by the feet of a substance which is a good conductor of heat, does not unduly raise their temperature. For instance, "stopping" the feet with clay, which is a good conductor of heat, has as we all know a cooling effect on them. Frequent picking-out of the feet will keep them sound as far as the bedding is concerned.

The ill effects of balling by means of a bad heat conductor are greatly increased, as we might expect, by the litter in question having corrosive or astringent properties. For this reason tan, which contains more or less tannic acid, has a very heating effect on the feet of horses which, like those in many riding schools, are worked on it, or are bedded down on it.

We have previously (p. 47) considered the bad effect which urine has on horses' feet. 
STRAW.

Old straw is to be preferred to new straw, because it is dryer and more elastic. Its higher price will be more or less made up by the fact of its containing less water, and consequently being lighter bulk for bulk. The more breaking and bruising which straw has undergone, the more will its bulk and elasticity become diminished, and consequently the greater will be the quantity required to make a soft bed. On the other hand, the exposure, by bruising, of the porous material in the interior of the stalks, will render the straw more absorbent than if the stalks were uninjured. The bruising of straw also renders it liable to turn mouldy by breaking the continuity of its hard polished surface, which protects the soft and more absorbent inner substance of the stalk from the action of moisture and disease germs. The foreign straw which is brought over in compressed bales is much inferior to good English straw, chiefly on account of the bruising it has undergone. Wheat straw being tougher than either oat straw or barley straw, is more economical in use than they are, and having a nicer appearance, is justly preferred. The husk of barley is so hard that it sometimes wounds the eyes of horses which sleep on barley straw, and not unfrequently produces grave digestive troubles in animals that eat it. Again, the ears of barley are probably the most common bearers of the fungus which give rise to that very serious, though rare, equine disease, actinomycosis. Persons who have employed it say that rye straw is inferior to barley straw on account of its being harder and rougher. I have found rice straw to be more brittle than oat or barley straw, and consequently to be less economical.

Whatever kind of straw is used for a bedding, it should be of good quality, so that it may be as little liable as possible to cause indigestion or other diseases in the cvent of horses 
consuming it; and it should not be of an irritating nature. Inferior samples of English straw are often full of thistles and other weeds.

The chief advantages of straw used in sufficient quantity, are the ease with which it can be procured; the dry and comfortable nature of the bed which it affords; its freedom from properties injurious to the feet; and its nice bright appearance. On the other hand, we find that owing to its feeble power of absorption, the urine becomes distributed throughout the lower layer of the bedding to an extent incompatible with the united conditions of economy and sanitation. Thus, if we desire to preserve a straw bedding in a thoroughly sweet-smelling state, we are obliged to reject a comparatively large proportion of it at each "mucking-out," and even then we cannot always get rid of the objectionable presence of ammonia from the atmosphere of the stall or box. The plan of selecting and drying the less tainted parts is not altogether a desirable compromise; for having been used under the horse, they will be more or less bruised, and even if they are dried in the sun, they cannot be rendered thoroughly sweet. The fact of straw being "long," increases the wastefulness entailed in cleaning out the floor of the box or stall. To obviate this source of loss, straw is sometimes used in a chopped condition for bedding. Foreign straw is often so long, that it would be well to cut each length into three or four parts. These disadvantages, which longcontinued habit is apt to make us overlook, cause a more or less pronounced smell of ammonia and other products of decomposition to pervade the atmosphere of the large majority of stables in which straw is employed as a bedding.

\section{PEAT MOSS (MOSS LITTER).}

Origin and nature.-Peat is formed in more or less stagnant water, such as that of marshes, by the decomposition of bog 
plants, the chief of which is bog moss (Sphagnum). "Mosses of this genus grow in very wet situations and throw out new shoots in their upper parts whilst their lower parts are decaying and being converted into peat, so that shallow pools are gradually converted into bogs . . . . The formation of peat takes place only in the colder parts of the world. In warm regions the decay of vegetable substances after life has ceased, is too rapid" (Chambers' Encyclopadia). Besides bog moss, we find among peat-producers, cotton-grass (Eriophonum angustifolium) and other sedges, horse-tails (Equisetum), heaths, and bog myrtle (Myrica gale). Drainage kills almost all bog plants. Peat is the first stage in the formation of ordinary coal ; brown coal (lignite) being an intermediate one. The successive changes undergone by woody fibre, peat and lignite in the formation of coal, consist of a " peculiar decomposition or fermentation of buried vegetable matter, resulting in the separation of a large proportion of its hydrogen in the form of marsh-gas $\left(\mathrm{CH}_{4}\right)$, and similar compounds, and of its oxygen in the form of carbonic acid gas $\left(\mathrm{CO}_{2}\right)$, the carbon accumulating in the residue. Thus, cellulose $\left(\mathrm{C}_{6} \mathrm{H}_{10} \mathrm{O}_{5}\right)$, which constitutes the bulk of woody fibre, might be imagined to decompose according to the equation $2 \mathrm{C}_{6} \mathrm{H}_{10} \mathrm{O}_{5}=$ ${ }_{5} \mathrm{CH}_{4}+{ }_{5} \mathrm{CO}_{2}+\mathrm{C}_{2}$ (Bloxam). The conversion of bog plants into peat, somewhat resembles that of wood into charcoal, when it is burned in the presence of a narrowly limited supply of air.

The following table shows the respective percentages of carbon, hydrogen and oxygen in wood, peat, lignite, ordinary coal and anthracite :-

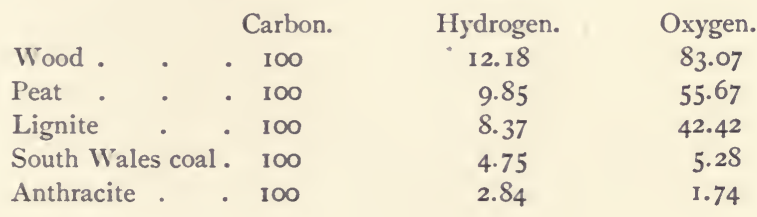


Quality and uses.-From a bedding point of view, the transformation in question is chiefly one of porosity, in which the loosely arranged stems and leaves of the bog plants gradually unite together until at last they assume more or less the character of solid stone. The stage of peat most suitable for our purpose, is an early one (Fig. 31), in which the peat is somewhat similar to wood in composition, very spongy, of a light brown colour, and light in weight. In a later stage of its formation, it is dense, heavy, dark brown in colour, and resembles lignite or even coal in appearance. This inferior peat (Fig. 32) is obtained in bogs of old formation, and contains a comparatively large amount of earthy matter. The best kind of peat for bedding purposes, has only about I 5 per cent. of water, and not more than 4 or 5 per cent. of ash. Peat, like coal, ignites with difficulty as compared to wood or straw ; but when properly arranged as a fire, it burns well, and throws out great heat. To test for the presence of an excess of earthy matter in peat, we may place a small quantity of the peat on an iron shovel and heat it over a fire. A good specimen thus treated will ignite when sufficiently heated; will smoulder, until it becomes gradually consumed; and will leave a light and powdery ash, which is like that of wood and which can be easily blown away.

The special advantage which peat possesses over other kinds of bedding, is its high power of absorption for both liquids and gases-a property which is naturally due to its great porosity. The larger the proportion of earthy matter, the heavier and less porous will the peat become. The presence of earthy matter also renders the peat dirty in use; especially because, when moistened with a fluid like urine, the earthy matter will form mud on the floor. When a good sample of peat is closely examined, it will be found to largely consist of fine fibres, and with no superabundance of cottongrass (Fig. 33), the tufts of which are not very absorbent. In 
many inferior specimens of peat, the chief part of the contained woody fibre appears to be made up of cottongrass.

The value of the highly absorbent properties - as regards gases as well as liquids-of peat moss is shown not only by the comparative absence of ammonia and moisture from the

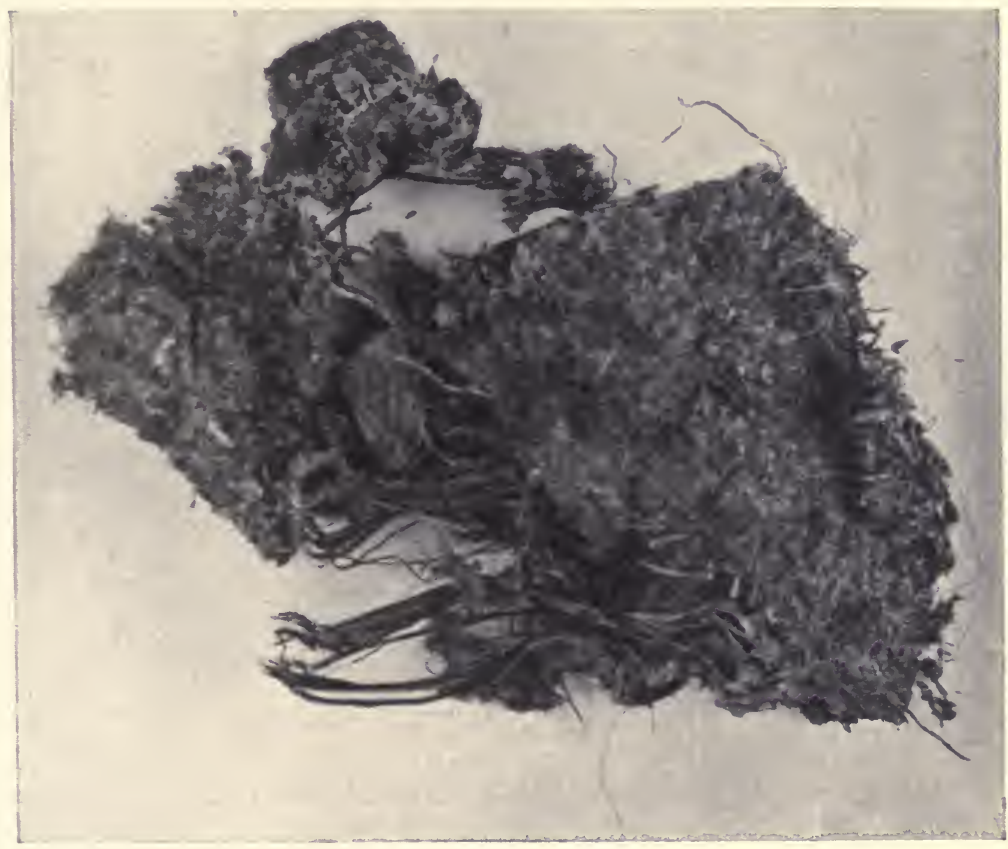

Fig. 3r. Good Moss Litter.

stable in which it is used, but also by the horses bedded on it being far more free from coughs, colds, and epizootic diseases (influenza for instance) than animals on straw, other conditions being equal. The ready absorption of ammonia, instead of being always an advantage as it ought to be, is often, unfortunately, an objection to the employment of peat moss; for careless grooms, failing to notice the hint given to 
them by their organs of smell, are apt to overlook the fact that the bedding requires frequent overhauling, and consequently they omit to remove contaminated portions, which injuriously affect the feet of horses that stand on them, and which sometimes leave patches of damp on the coat or clothing. Besides this, the dark colour of peat moss aids in concealing dirt, both liquid and solid, and on that account, a not very observant groom will be apt to allow a peat moss bedding to become far fouler than a bedding of straw for example. Liability to heat and to rot the horn of the hoofs is undoubtedly the chief drawback to the use of peat moss, which disadvantage can be obviated by extra care in picking out the feet and in removing soiled litter. It sometimes happens that in the use of moss litter by a groom who is careless about picking out the feet and removing tainted litter, that a horse taken out of the stable is apt to soil the yard or other places by peat falling out of his balled feet. In this case, the groom and not the bedding is to blame.

Among other good qualities of peat moss, we may take into consideration its cheapness, portability, ease with which it can be obtained and stored, the small amount of labour required with it for bedding down and mucking-out, its applicability to the use of horses which are inclined to eat their bedding, its noiselessness when trodden on, its usefulness in filling up inequalities, such as those presented by a floor paved with cobble stones, and the difficulty of setting fire to it, as compared to straw or wood shavings. It is said that the coats of grey and white horses do not stain so readily on moss litter as on straw. On the other hand, it balls in the feet, it gives the box or stall a gloomy appearance, and is liable to block up subsoil drains which open under the animals. Peat that contains a good deal of earthy matter will of course be more or less dusty, and will consequently spoil, to some extent, the appearance of the coat for the time being. I have 
been strongly of opinion that peat moss tends to remove the gloss from those parts of the horse's coat with which it comes in contact; but later experience leads me to think that any influence which it might have in that direction, is insignificant from a practical point of view. Some horses eat moss litter, though not to any injurious extent, as far as I have observed

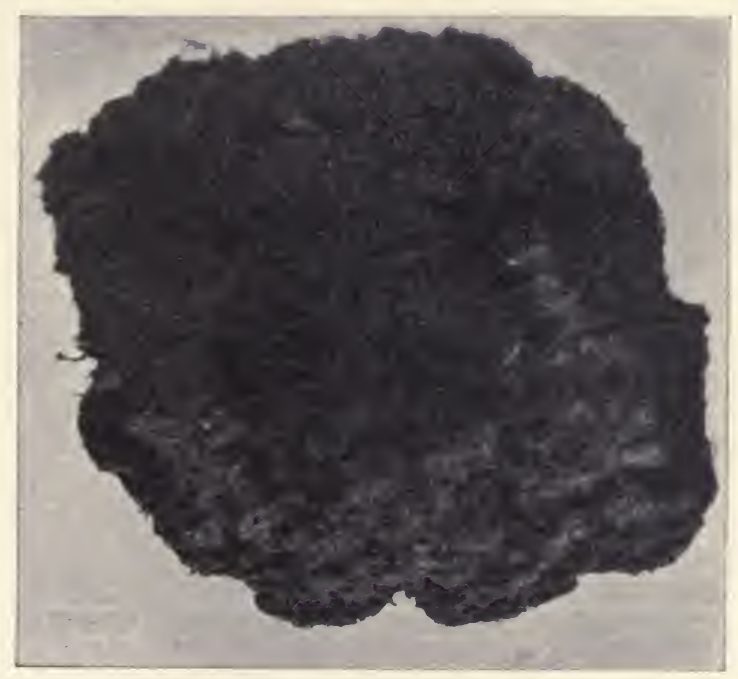

Fig. 32. Bad Moss Litter.

and been able to learn. I therefore think that an objection made against it on that account might be passed over. I have already indicated that if the supply or frequency of change is not sufficient for purposes of absorption, a bed of peat moss will become as foul as that of any other kind of litter.

As peat moss quickly absorbs moisture from the air, it should be kept in bales until just before use. If, however, it has a musty smell, as sometimes happens, the bale should be opened out and dried. 


\section{SAIVDUST.}

Sawdust is generally obtained in the form of sawdust and chips, from which all hard pieces of wood should be removed. The only sawdust fit to be used for horses, is that which is obtained from dry and well-seasoned (usually foreign) wood ; for the sawdust of green wood has but little absorbent power, and is apt to become decomposed. Good sawdust forms an excellent bedding, and as a rule can be bought very cheaply at saw-mills, which unfortunately do not often exist in the vicinity of stables.

We may, with more or less exactness, apply to sawdust everything said in the preceding paragraphs of this chapter about peat moss as regards its applicability to the use of horses that are inclined to eat their bedding, noiselessness when trodden on, protection it affords the coats of grey and white horses from becoming stained by the urine which falls on the litter, usefulness in filling up inequalities on a floor, and tendency to ball in the feet and to block up subsoil drains. It is not so portable, so absorbent, and so easily procurable as a rule as moss litter; but it looks much better, smells much nicer, is cheaper near sawmills, and can be usefully employed for sprinkling over passages and places which have become wet, and which can be improved in appearance by being lighted up by this white covering. It requires far less labour for laying down and mucking-out than straw. When made from fir, it gives a pleasant and healthy odour to the stable. Darbot states that oak sawdust is not a good bedding, on account of the large proportion of tannic acid it contains. A combination of sawdust and carbolic acid (p. 259) forms a handy and valuable antiseptic. 


\section{WOOD SHAVINGS.}

Wood shavings make an excellent bedding, the only drawback to their use being the difficulty of always obtaining them. They appear to be more absorbent than straw, and their curly nature greatly aids in making the bedding soft and elastic, and in promoting downward drainage. Fir shavings have a pleasant and healthy smell like the sawdust

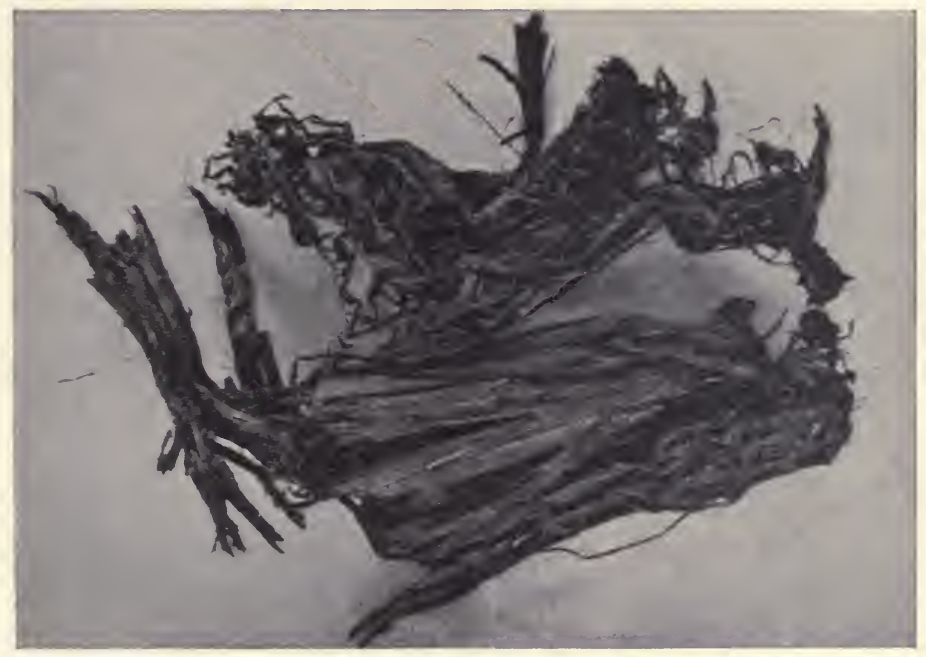

Fig. 33. Cotton Grass in Peat.

of that wood. Unlike sawdust, shavings are free from the objection of balling in the feet. Care should be taken with shavings, as with sawdust, that they do not contain solid pieces of wood or other hard objects which might injure a horse bedded down on them.

TAN.

My experience of $\tan$ as a bedding for horses, is that it is very apt to heat the feet, unless great care is taken in picking them out and in removing wet portions of litter 
without delay. According to some veterinary authorities, $\tan$ forms a favourable ground for the cultivation of the germs of tetanus. We should here take into account the fact that the tan used for bedding is "spent" tan, which contains a considerable quantity of readily decomposable organic matter. The small amount of elasticity possessed by tan, and the hardness of its particles, evidently prevent it from being a very comfortable bedding. The tan which has been used for horses, forms, in combination with the dung and urine, a valuable manure. This appears to be its only recommendation. Horses show such a marked dislike to the smell of tan, especially on approaching tanneries, that I cannot see how it can be regarded as an agreeable bedding for them.

FERNS, FIR NEEDLES, AND MOSS.

I have had no practical experience with any of these bedding materials, which I have heard answer their purpose fairly well.

\section{SAND.}

Horses appear to like sand as a bedding, for they often show a great inclination to roll on it when they find it under them. It makes a cool bedding in hot weather. Sea sand should on no account be used, because horses are liable to eat it. Many cases are on record of horses which were bedded on sand, eating enormous quantities of it with fatal results. The indulgence of this form of depraved appetite is no doubt prompted by the presence of salt in the sand, and was probably strengthened in the cases in question, by the fact that the afflicted animals had previously suffered from deprivation of this essential adjunct to their food. As sand obtained even from inland places may very possibly contain traces of salt, it is evident that if we are obliged to employ 
sand as a bedding, we should be doubly careful to give the horses on it a full allowance of salt in their food.

\section{COMBINED BEDDING.}

Although, as we have seen, the drainage capability of a bedding material varies inversely as its power of absorption, and vice versâ, we can obtain both of these valuable qualities by employing two materials, one being highly absorbent, and the other having good powers of drainage. Thus, a layer of sawdust 4 or 5 in. thick, covered with a sufficiently deep layer of sound wheat straw, would make a nearly perfect bedding. Peat moss would serve the purpose of absorption even better than sawdust; but it is not so clean, and its dark colour is against it. A combined bedding would probably entail more trouble on the groom than a bedding made from only one substance.

\section{CHOICE OF A BEDDING.}

In this selection, the question of economy comes largely into play, especially as regards power of absorption; for although, as we have seen, I lb. of moss litter, for instance, will absorb four times as much water as I lb. of wheat straw; $4 \mathrm{lb}$. of the latter will absorb as much water as $\mathrm{I} \mathrm{lb}$. of the former. Hence, if we can afford to employ an amount of wheat straw sufficient for soaking-up purposes, we shall get a better bed than we could obtain with moss litter; because, in other respects, straw is the superior of the two. We may therefore take for granted that it is the best kind of bedding material for stables in the management of which money is not a great object. For economy combined with efficiency though not with "smartness," peat moss has probably most claims to attention, except, perhaps, where sawdust and shavings can be cheaply obtained. Shavings not being dusty, having no tendency to ball in the feet and being more elastic, 
is a better single bedding than sawdust. The addition of a layer of straw, even if it is not a particularly thick one, over moss litter so as to form a combined bedding, will be a small sacrifice of economy to smartness which few horsemen would grudge. A layer of sawdust under one of straw will in all cases increase the efficiency of the resulting bed without in any way detracting from its appearance. A horse cannot have a much better bed than a combined one of sawdust and straw, or sawdust and shavings.

\section{BEDDING-DOIVN.}

The first thing to do before bedding-down, is to see that the floor is dry and clean. If the floor is damp, and especially if it is evil smelling, we may have it freely sprinkled over with powdered peat moss, sawdust, or even dry vegetable mould, and then swept out with a birch broom. Exposure to air and sunlight, and a sprinkling of sawdust impregnated with carbolic acid (p. 259), will, after drying, be sufficient for disinfecting purposes in all ordinary cases.

With straw, an ample bed may be made for a box having an area of 132 square feet ( $2 \mathrm{ft}$. by I I ft.), with 5 bundles, each of which weighs I4 lbs. An additional bundle or a trifle more every second day, would be sufficient for most horses; but animals which eat their bedding, or which make a practice of walking round and round in their box, would require about an additional 50 per cent. Two-and-a-half bundles would be enough for a stall, with an additional bundle every second day.

The cost of straw bedding may be put at from is. 9d. to 2s. 6d. a week.

Theoretically, the arrangement best suited to utilise the elasticity and drainage power of straw would be to have the bedding composed of layers of single straws, the straws of each layer being all in one direction, and at right angles to 
the direction of the straws of the layer next to them, so as to form a honeycombed structure. Such minute attention to detail could not be carried out in practice. Besides, all useful purposes can be fulfilled by putting, to begin with, half the quantity of the straw evenly over the floor with the direction of the straws running across that of the box or stall, and the other half longitudinally over the lower layer; or vice

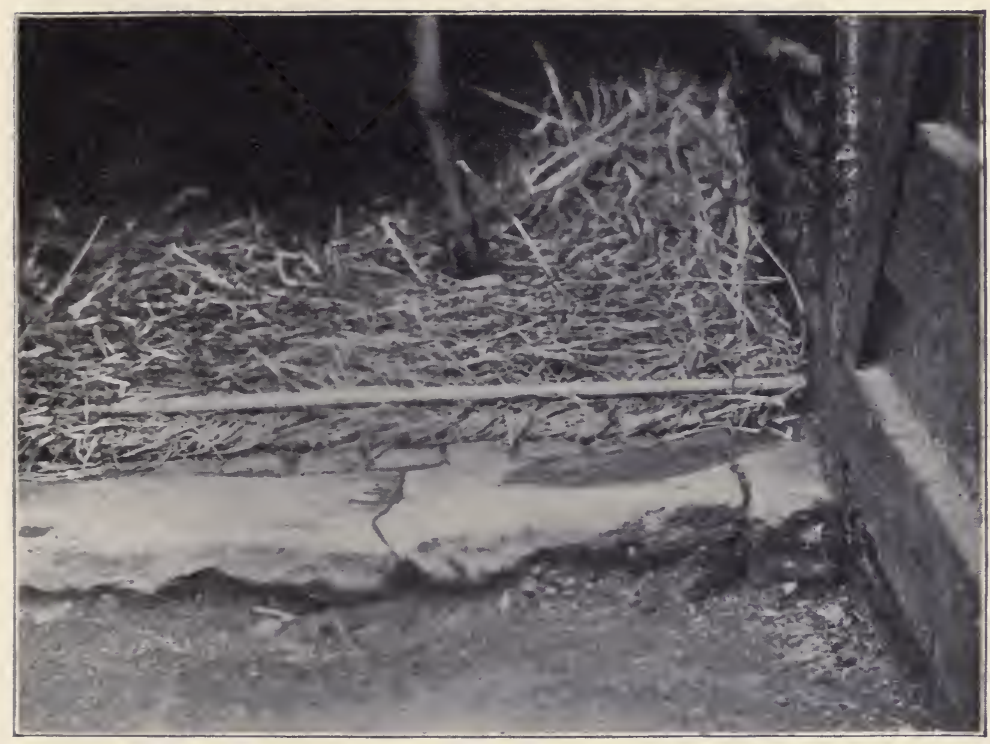

Fig. 34. Ends of straw bedding twisted-in, with stable fork laid across them.

versâ. The groom should spread each layer as evenly as possible, and should go through and work up the whole of the bedding with a stable fork, so as to render the litter as elastic and porous as possible. The straw should be banked up, supposing that the supply is ample, on the side of each partition, and the ends twisted-in at the entrance. The simplest way of twisting-in is to lay the handle of a stable fork across the ends of the straw at the entrance (Fig. 34), 
and while standing on the handle to twist-in the ends underneath. A more elaborate way is to twist-in the upper layer of straw and afterwards the lower layer in the manner shown in Fig. 35. Here the feet keep the straw in place while the ends are being twisted-in by the fingers, and the twisted-in edge can be finished off with a fringe of ears of straw.

From I to $\mathrm{I} / 2 \mathrm{cwt}$. of moss litter will be required for a stall in the first instance; and about double that quantity for an ordinary sized box. The peat moss should be laid down in an even layer free from lumps. A daily allowance of 5 or $6 \mathrm{lb}$. for stalls and 6 or $7 \mathrm{lb}$. for boxes would be ample. The daily cost of such a bedding would vary from $\mathrm{Id}$. to $\mathrm{I} / 2 \mathrm{~d}$.

With sawdust, a horse may be bedded down in the same manner as with moss litter. A bedding four inches deep of sawdust, or a foot deep of shavings would probably be sufficient for health and comfort. As tan and sand are heavier, and of a more compact nature than moss litter and sawdust, a bedding of either of the former materials need not be as thick as one of either of the latter. The cost of sand, ferns, and fir needles will generally be only that of the loading and cartage. The price of sawdust and shavings at their place of production is usually very low.

\section{MUCKING-OUT.}

Whenever a groom sees dung, urine or contaminated litter on the floor of box or stall, he should at once remove it outside; because its retention in the stable will be injurious to the animal's health, by the emanations given off; and to the soundness of his feet, if he happens to stand in such filth. Besides, for economic purposes, the dung and urine should be taken to the midden without delay, and disposed in a manner that will curtail the loss of ammonia as far as practicable. When litter becomes saturated with the horse's droppings, its presence in the stable is not only useless for 
soaking up moisture, but it is also hurtful from a sanitary point of view. The dung and soiled litter are generally removed by means of a skep.

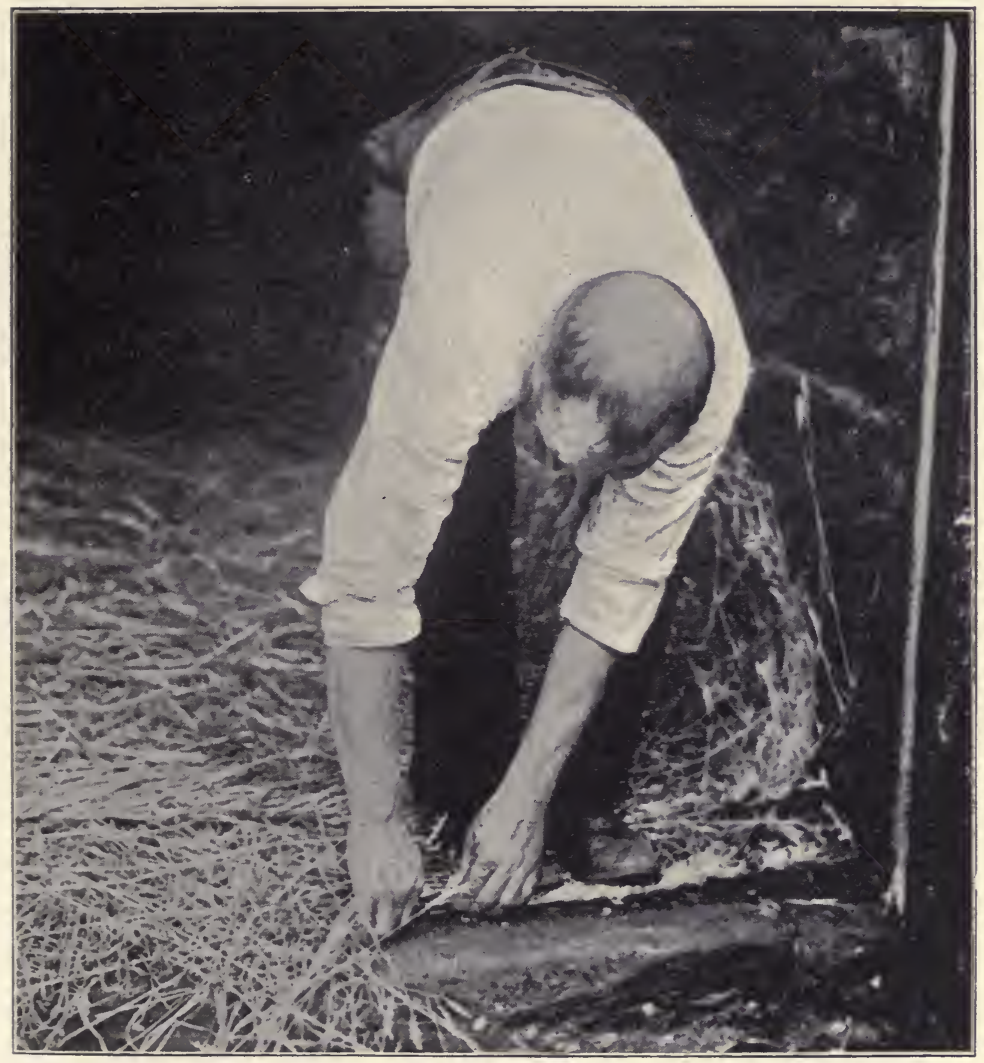

Fig. 35. Twisting in ends of straw bedding.

With straw bedding, the groom places the edge of the skep close to the dung, which he tilts into this receptacle by raising the straw behind it with his right hand, while he holds the skep in the left; or having placed the skep between his legs, and sloping downwards and 
forwards, he gets both hands under the dung and straw upon which it is lying, and cants the dung into the skep. The same procedure may be observed with other kinds of comparatively long litter. If a horse is in the act of dunging, and the groom is within reach, he can, at no loss of dignity and with a considerable gain in cleanliness, receive the dung in his hands, and deposit it in the skep; or, if there is time, he may catch it in the skep in the first instance. In India, the practice among native grooms is to hold an earthen pot under the horse or gelding, and behind the mare, so as to catch the urine the moment they see the animal stretch itself out. The same custom is observed in some places on the Continent, where a pot with a long handle is used. I do not like this plan, because horses which are accustomed to it are apt, if the groom does not hold the vessel for them, to abstain from staling for a long time. This, however, is a mere matter of opinion on my part ; for I have no exact data of any kind, either for condemning this practice or for supporting it.

In regular mucking-out with straw, any dung or soiled portions of litter which are on the surface of the bedding, should be picked up and put into the skep for removal to the midden (dunghill), or in case of only slightly soiled straw, to be dried in the open air or in the litter-shed for future use. All the clean straw is heaped up in two or three corners of the box or stall; the floor swept out with a broom ; all swept-up dirt removed; and, if necessary, the floor dried and disinfected in the manner described. The floor is then allowed to remain exposed to the purifying action of the air, until the bedding is required to be put under the horse, when it is spread with the addition, if necessary, of fresh straw or of slightly soiled straw that has been dried, and is banked up, twisted in and finished off as already stated. Instead of keeping the clean straw heaped up in the box or 
stall, while waiting to spread it, by far the better plan, if there is time and opportunity, is to take it outside, and air and dry it.

Mucking-out with shavings and ferns may be effected in the same way as with straw.

With moss litter, sawdust, tan, fir needles, and sand, we may get all the dung on the surface and all the wet spots removed with a hand-shovel or rake and skep, and the whole of the bed raked carefully over, so as to find all contaminated parts, which should be promptly taken away. When the daily allowance is added, it should be distributed evenly through the remainder of the bedding. The whole of the bedding need not be taken out to be aired and dried and the floor purified oftener than once a week.

\section{DISPOSAL OF USED LITTER.}

The best plan is to remove the whole of the used litter and dung from the precincts of the stable every day, which can be conveniently done by means of a cart lined with metal and made for the purpose, if expense be no great object. If a midden in the premises cannot be dispensed with, it should be placed well away from the stables and the water supply, and should have its foundation and sides of waterproof material, so that the surrounding ground may not become contaminated in any way.

\section{STABLE MANURE.}

Heiden (Storer's Agriculture) states that for each $100 \mathrm{lb}$. of dry matter which the horse consumes, he gives off $210 \mathrm{lb}$. of dung and urine. An ordinary cart horse will produce about $1 / 2$ cwt. of dung and urine in twenty-four hours. The quantity of manure obtained in a stable from the dung, urine, and soiled bedding varies according to the amount of food and bedding, and according to the length of time the horse is in 
the stable. Mr. Porch, F.R.C.V.S., who is in charge of the London Road Car Company's horses, tells me that the weekly quantity of manure produced by each of these animals, averages from $2 \mathrm{x} / 2$ to 3 cwt. a week. They have a daily ration of $3 \mathrm{I} \mathrm{lb}$. of corn and hay, a weekly allowance of $38 \mathrm{lb}$. of peat moss bedding (costing $7 \mathrm{I} / 2 \mathrm{~d}$. a week), and are absent from their stables about three hours out of the twenty-four. When horses are away from their stables for seven or eight hours each day, they will, as a rule, deposit more dung outside, than in the stable; although the opposite of this will be the case with the urine. A friend of mine who has had a large experience among cart horses, puts the average quantity of manure for each horse at about $2 \mathrm{I} / 2 \mathrm{cwt}$.

Müntz and Lavalard have shown that manure resulting from the use of peat moss is of from 15 to 30 per cent. higher agricultural value than that of straw, a fact which is principally due to the great absorbent power for fluids (urine) and gases (ammonia) possessed by peat moss. The manure from peat moss is specially applicable to the cultivation of potatoes and roots, and as a manure for heavy clay land. Straw stable manure suits light (sandy) land. Sawdust and shavings have, as manure, the great disadvantage of taking a long time to rot.

As straw has but little power of retaining ammonia, which is a very valuable constituent of manure, we should try, for purposes of economy, to prevent this loss as far as possible. "The addition of earth (not sand or chalk) to straw considerably increases its power of retaining ammonia. Sprinkling powdered gypsum, superphosphate, or kainite also diminishes the loss of ammonia. . . . Farmyard manure rapidly undergoes fermentation. If placed in a heap, the mass gets very hot, and a large quantity of carbonic acid and some marsh gas are given off. Fermentation is most active when 
the manure lies loosely, more air then coming in contact with it ; it is least àctive when the manure heap is consolidated. When fermentation occurs in consolidated, wet manure, in a place protected from rain, a considerable part of the carbonaceous matter is destroyed, but comparatively little loss of nitrogen takes place; if, however, the manure gets dry, and mould appears, a serious loss of free nitrogen may occur. The losses of nitrogen in the heap may be prevented by introducing a shallow layer of earth each day while the heap is in construction.

"Rotten manure, when well made, is more concentrated than the fresh, having greatly diminished in weight during fermentation without a corresponding loss of valuable constituents. Some of the constituents have also become more soluble. It is often, however, best to cart the fresh manure directly on to the land, and plough it in. Loss in the heap is thus prevented, and the full physical benefits of the manure obtained. Manure heaps in the open field should be protected from waste by covering them with a layer of earth 6 inches thick" (Warington's Chemistry of the Farm).

The British Moss Litter Company give the following directions for converting peat which has been used in a stable, into good manure: "The moss litter after use as bedding should be made into a heap and saturated with liquid manure or water until it will hold no more; then make level on the top and cover up with fine ashes or earth. In about two months it will be quite black and rotten and fit to go on to the land."

Before stable manure can be utilised as a food by plants, a large proportion of its nutritive material has to undergo decomposition by means of bacteria, which convert more or less of its constituents into soluble compounds, and thus perform the office of digestion for the plants. Oxidation, which in this case is a process of destruction, also takes place 
in manure, especially when the manure is in a loose and dry condition. The heat produced by oxidation is liable to become so great as to kill the microbes which are engaged in preparing the manure for the plants. Hence the advisability of keeping the manure damp and consolidated during its preparative ("rotting") period, or of mixing it with earth, which will keep its particles cool and moist, and will absorb the ammonia that is evolved. 


\section{CHAPTER IX.}

\section{CLOTHING.}

Necessity and Objects of Clothing-Nature of Clothing-Amount of Clothing Necessary as a Protection against Cold-Various Kinds of Clothing-Quarter Sheet-Roller-Roller Cloth-Breast Cloth-Rug-Tail Guard-HoodUnder Rug-Head Collars-Halters-Bandages.

THE somewhat arbitrary grouping made in this section has been adopted so as to include all the usual articles which a horse wears in and out of the stable, and which are unconnected with riding and driving.

\section{NECESSITY AND OBJECTS OF CLOTHING.}

In considering the necessity of clothing in a stable, we have to take into account the altered conditions of warmth under which a horse finds himself on being brought into a stable from the open. In a box or stall he is deprived of the frequent exercise which helps to keep his blood at a due rate of circulation when he is at liberty; the thickness and length of his coat become reduced by grooming and clipping, and the dandruff (scaly particles of outer skin) and hair oil, which aid in protecting his body from cold, are more or less removed by grooming. On the other hand, the building in which he resides, shelters him to a greater or less extent from bleak winds and changes of temperature; the air contained in it is usually hotter than that in the open; the bedding, as a rule, affords a warmer couch than the animal could obtain outside; and he is generally better fed. Although circumstances vary so 
much in different cases that it is impossible to make an exact estimate, I think we may say, speaking generally, that a horse without clothing is about as well off in a well-appointed stable as he would be in the open. Seeing that a horse when in the open and in an unclipped condition, is less liable to disease than when stabled and clipped, or stabled and unclipped, we may conclude that as he requires no clothing when unclipped in the open, he will need none when unclipped in the stable. The question of clothing, therefore, appears to resolve itself into one of the horse being clipped or unclipped; clothing being a necessity during inclement weather in the former case, but not in the latter. During warm weather a horse of course requires no clothing to protect him from chill.

The only case in which a groomed horse would usually need clothing outside, is when he is kept standing in cold or wet. We may see from the remarks made about Russian cab horses ( $p .36$ ), that if a horse is unclipped, ungroomed, and accustomed to exposure, he will, as a rule, suffer no ill effects from being kept standing for a considerable time under the influence of a far lower temperature than we have ever experienced in England. Grooming and stabling increase a horse's susceptibility to cold so much, that with an ordinary stabled horse it is always a safe proceeding, when practicable, to put a rug over him when he has to stand in the open if the air is even chilly, and especially if the animal is hot after recent exercise. It would be still better to keep him moving at a rate appropriate to the effect which the coldness of the air has on him, and with or without a rug as the case might demand. To give an idea of what I mean by the air being chilly I would estimate the temperature of such air at from $45^{\circ} \mathrm{F}$. to $32^{\circ} \mathrm{F}$, on the understanding, of course, that the higher the wind, the more severe would be the effect of the cold.

Waterproof clothing put over the ordinary clothing is often 
employed when sending horses by train, and is very useful during wet weather. We have seen (p. 35) that the saturation of the coat with water greatly diminishes its power of keeping the animal warm. When he is out at work, protection against atmospheric damp by clothing should not be obtained at the expense of checking the evaporation of perspiration from the skin; for if that occurs, the coat will become more or less wet from sweat, and the horse will be liable to suffer from chill when the waterproof covering is removed. Hence, such a covering should be permeable to air and vapour. Notter and Firth tell us that "a well prepared waterproof material will permit of a candle being extinguished, when blown through a I-inch pipe at a distance of 6 in." The following method for waterproofing cloth is given in Cooley's Encyclopadia of Practical Receipts: "Rub the wrong side of the cloth with a lump of beeswax, perfectly pure and free from grease, until it presents a light, but even, white or greyish appearance; a hot iron is then to be passed over it, and the cloth being brushed whilst warm, the process is complete."

Clothing is sometimes useful for drying a horse which is brought in out of the wet or which has been washed all over, and when it is not convenient to have him rubbed dry. The process is similar to, though on a larger scale than, the familiar one of leaving an ordinary saddle on the back of a sweating horse for twenty minutes or half an hour, by the end of which time the sweat which was in the hair immediately under the saddle, will have passed into the absorbent panel, and the part in question will be dry. A similar effect would be produced with a felt numnah; but not with a leather saddle cloth, or with a panel covered with leather. We see the same thing occur when a horse's legs which are wet, have woollen bandages put on them. In all these cases, the absorbent material, whether rug, panel, or bandage, should be removed as soon as 
it has served its purpose, and a dry protective covering, applied. After removing the second protective covering previous to work for instance, it is well to stimulate the circulation of the part by friction, so as to prevent the occurrence of chill.

As a rule, clothing is necessary for preserving the cleanliness of a horse's coat in the stable, in the event of his lying down on his droppings or on contaminated portions of litter. In this respect its utility is self-evident.

The judicious use of clothing aids the action of food in maintaining the temperature of the body. A portion of the food digested by the horse is expended in keeping the body at a more or less uniform degree of heat (about $99.5^{\circ} \mathrm{F}$.). As this temperature is considerably higher than that of the atmosphere in cold weather, and as the body undergoes a continual process of cooling by radiation and by evaporation; protection by clothing will help to diminish this loss, and will consequently cause a saving in food. If the weather be warm or if the amount of clothing be excessive, the use of clothing, instead of being economical, will, by over-stimulating the skin, cause loss of weight and possibly debility. We may therefore conclude that the employment of clothing in this respect may be limited to that which will be sufficient as a protection from chill.

Grooms are greatly addicted to the use of clothing for the production of a glossy coat; because this form of polish can be obtained without the expenditure of "elbow grease," which entails more or less hard work. We may be quite sure that the coat which owes its sleek appearance to the effect of an inordinate quantity of clothing, to residence in a hot stable, or to both these influences, will "stare" far worse and much more quickly under the effect of a cold wind, than one which has been produced under healthy stable conditions; because the skin of the former is more susceptible to chill than that of the latter. We may safely conclude that the only legitimate gloss 
on a horse's coat is that obtained by health and good grooming.

We sometimes find that suitable clothing is useful in protecting a horse from the attacks of fies, which are specially irritating during the autumn and in wooded parts of the country. This application of clothing is generally limited in England to the employment in the open of a net to cover the ears of harness horses. In hot countries, eye-fringes and light clothing are in frequent use for this purpose.

The benefit to be obtained by the use of clothing for developing condition is doubtful. I think it is safest in all cases to trust solely to exercise and grooming to stimulate the skin with the object of promoting health and vigour; for, independently of the consideration of the increased susceptibility to chill, we have the fact taught us by practical experience that the stimulation of the skin by clothing, particularly if the clothing is heavy, has a debilitating effect on the animal. In this case, the effect of clothing is similar to that of a long (unclipped) coat.

\section{NATURE OF CLOTHING.}

From the principles already discussed, we may see that the clothing used for protection of horses from cold should be of a material which, like a horse's coat, absorbs moisture readily, and parts with it at a rate which will not unduly expose the animal to chill. These conditions are admirably fulfilled by woollen cloth, which is more absorbent of water than cloth made from cotton, linen, or jute. As a material manufactured from any of these vegetable fabrics is a more energetic conductor of heat, and parts with moisture more readily than a woollen one; it is the more suitable of the two for summer clothing.

As clothing harbours dirt and various kinds of animal and vegetable life, it should be kept scrupulously clean, so that its 
use may not give rise to disease. From neglect of this precaution, clothing is not an unfrequent carrier of mange and ringworm.

Woollen clothing, especially when it is of coarse material and when it is not kept clean, is sometimes a cause of irritation to the skin, in which case it is well to put a cotton sheet between the clothing and the skin.

Clothing should be as light as the performance of its duty will admit, so that it may not inconvenience the animal.

\section{AMOUNT OF CLOTHING NECESSARY AS A PROTECTION AGAINST COLD.}

It is evident that the more the skin is stimulated by exercise and grooming, the more liable will the animal be to suffer from chill in the stable. Hence, racehorses, especially when they are "wound up to concert pitch," as a rule require more clothing than other horses. The objection to the use of clothing on account of its tendency to produce increased susceptibility to chill outside, does not apply as forcibly in their case as in that of ordinary working horses; for during training they are kept constantly on the move when in the open, and besides, they generally wear clothing, though of light material. Even when they are stripped for racing, they are seldom kept motionless, even at the starting post. The case, however, is very different with horses which have to do their work in the open without clothing, and which have often to remain standing for a considerable time in a state of nakedness, exposed to a keen wind, as for instance, at the cover side or in a lady's victoria out shopping. With such horses, we should evidently reduce the quantity of clothing to the minimum required to make up for the loss of warmth caused by enforced idleness in the stable, and by the reduction in the length and thickness of the coat by grooming and clipping. 
In estimating the quantity of clothing that would compensate for the loss of warmth caused by the removal of the coat by clipping, I do not think, except in the case of racehorses, that it would exceed that of a thick woollen rug or quarter sheet, especially when the legs are not clipped. Even when taking during winter well-bred hunters which were clipped and in hunting condition to St. Petersburg, vi $\hat{a}$ Revel, on the deck of a steamer through the North Sea and Baltic, on which occasion the cold was far greater than is ever felt in England, I found a rug and a quarter sheet amply sufficient for purposes of warmth.

\section{VARIOUS KINDS OF CLOTHING.}

A full suit of clothing consists of a quarter sheet, with fillet strings and button loops, breast cloth, roller, roller-cloth, tail-guard, hood, and a set of woollen bandages, with an under rug, if required. The button loops are used to loop up the fillet strings when desired, as in the stable and with mares. A head collar, knee caps, and hock caps may be regarded as accessories. In the clothing of racehorses (Fig. 36), the quarter sheet does not usually come as low down as in that of hunters or carriage horses.

Clothing is generally divided into warm clothing and light clothing, and into day clothing and night clothing. The best warm clothing is made of kersey, or of fawn or striped blanketing, both of which should, of course, be "all wool." The stoutest blanketing is thicker, heavier, and more loosely woven than kersey, and is consequently warmer, though it is not so strong and durable. Light clothing is made of cotton, linen, or jute, and in this country is used only by day. Warm clothing is generally bound with livery cloth. The usual colour for light clothing is check; and for warm clothing fawn or check. With a stable of several horses it is well to have a distinctive colour or pattern for the clothing, so that 
the horses when at exercise can be distinguished by it and that stolen clothing can be recognised. The best and cleanest clothing is generally retained for day duty. Instead of keeping particular sets of clothing for respective day and night use, it is better to divide them into sets which will be used only out of doors, and sets which will be put on only in the stable; for the groom will then be deprived, as far as the clothing is concerned, of the undesirable incentive to tie the horses up during the day. We may study both economy and cleanliness by employing a non-woollen covering (canvas, jute or cotton) for the rugs or quarter sheets used in the stable.

The Quorn Hunt adopt the plan of clothing horses during the season with a kersey quarter sheet and a blanket rug; the former being used over the latter by day, and under it by night. The Quorn quarter sheet is in reality a rug; because it is not provided with a breast cloth (see next page). I have already indicated that this amount of clothing is too much for hunters in England.

\section{QUARTER SHEET.}

The quarter sheet is cut out for the neck, and has a strap to buckle across the breast. Its full length for, say, a I6 h. 2 in. hunter, is $6 \mathrm{ft}$. measured along its lower part. It is provided with plaited fllet strings, which serve to prevent the rear corners of the quarter sheet from flying about when on the horse, and which are looped up when the clothing is worn by the horse in the stable. That portion of the quarter sheet which goes over the withers should be fitted to the part, so that the withers may not become inflamed from undue pressure.

\section{ROLLER.}

The roller is a form of surcingle which helps to prevent the body clothing from becoming shifted out of its proper 


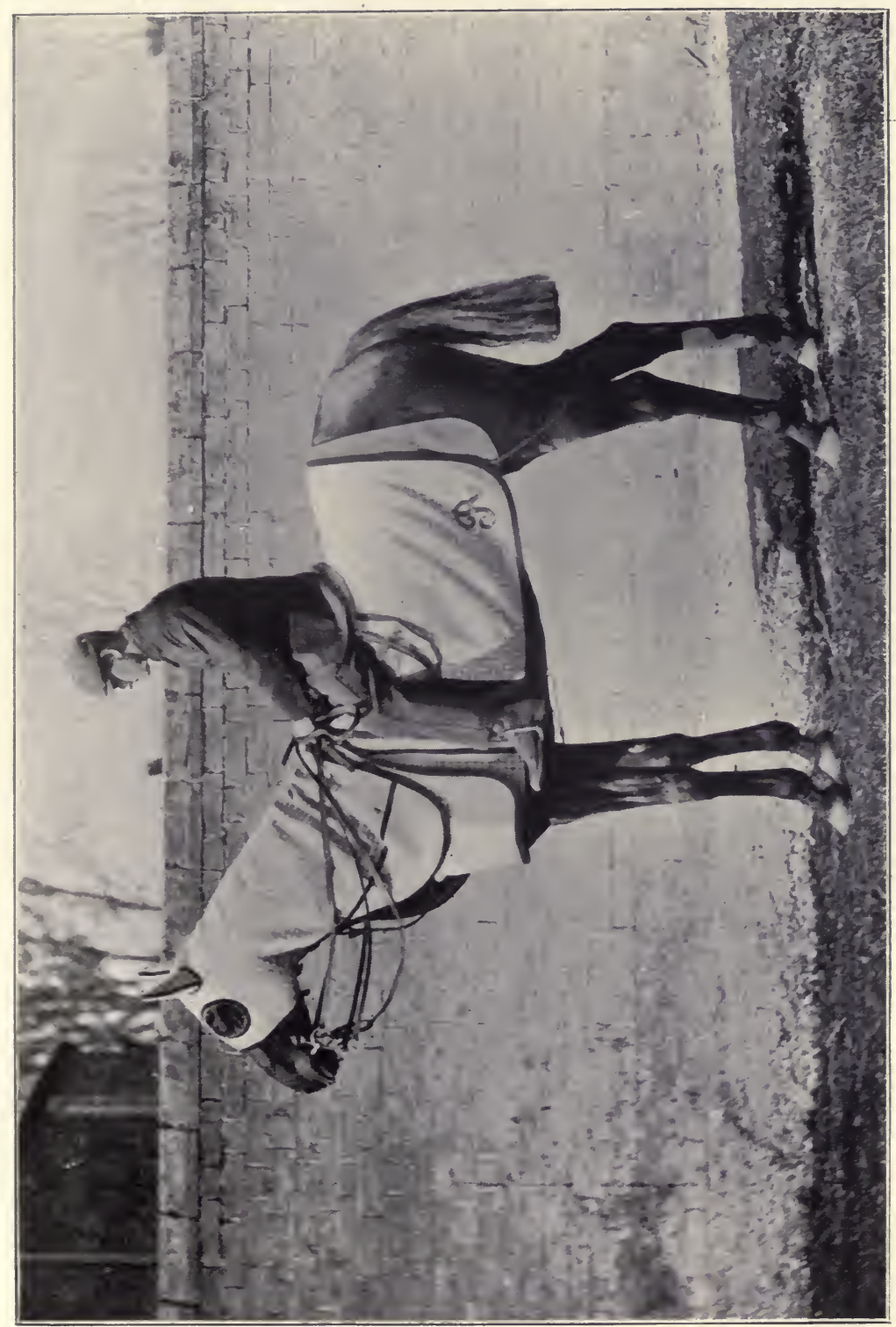

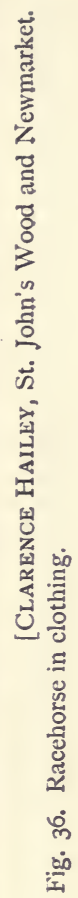

ลे 
position when on the horse. It is well to have the roller provided with a breast-girth so as to obviate the risk of its working backwards. The pad of the roller should be carefully stuffed, in order that there may be no danger of the centre of the pad pressing on the top of the withers, which is an occurrence that is a not unfrequent cause of inflamed withers. Messrs. Champion and Wilton have introduced a very useful plan (Fig. 37) of shaping the front part of the centre of the pad of the roller so as to give additional protection against pressure. Generally, rollers are made either entirely of leather, with the exception of the stuffing; or of webbing. The former are stronger and wear longer than the latter, but as they have less grip on cloth, they are more apt to slip back or round the horse. This objection to leather rollers may be removed to a great extent by making slits in the sides of the roller, and lining the pad with serge.

\section{ROLLER CLOTH.}

The roller cloth plays the part of a saddle-cloth to the pad of the roller, under which it is placed, so as to protect the quarter sheet or rug, as the case may be, from wear.

\section{BREAST CLOTH.}

The breast cloth is the piece of cloth which comes across the breast and buckles on to the quarter sheet near the withers.

RUG.

A "rug" is practically a quarter sheet and breast cloth all in one. The objection that it rubs the hairs off the points of a horse's shoulders may be removed by lining the rug at these parts and under the withers with linen. For economy and convenience sake, a rug is usually provided with a surcingle that is supposed to act the part of a roller, 
which duty the surcingle is unable to properly fulfil on account of its being unprovided with a pad.

\section{TAIL-GUARD.}

A tail-guard is a piece of cloth which is attached to the upper portion of the tail by means of tapes, and is connected

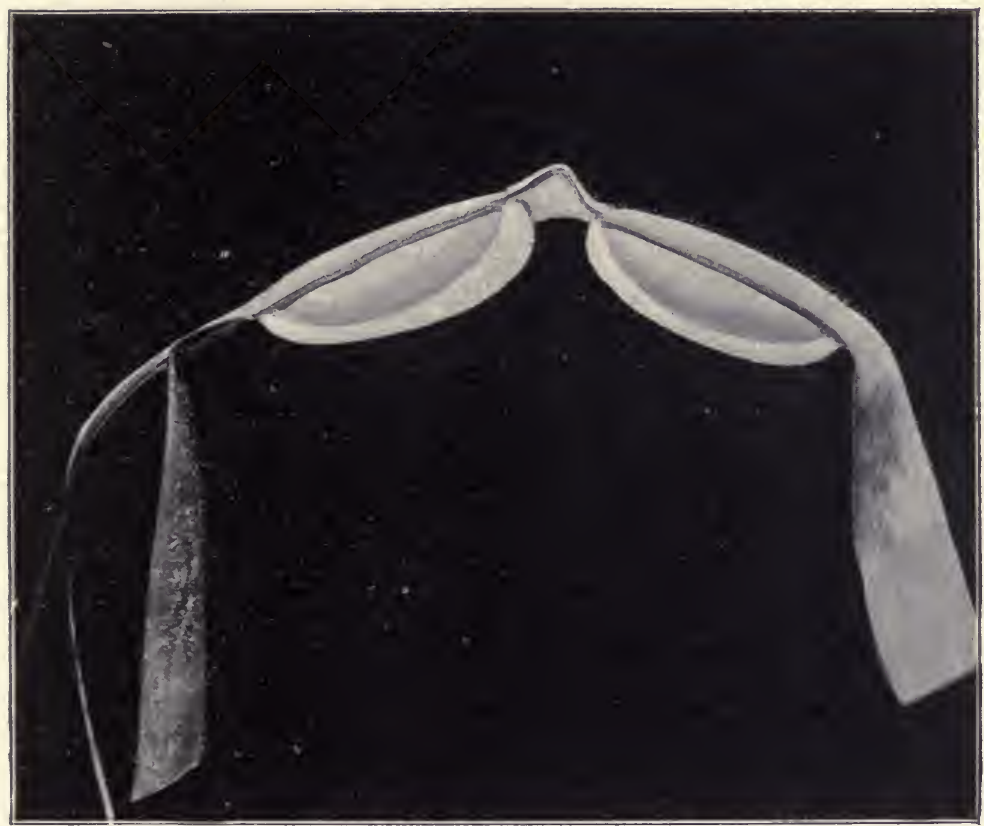

Fig. 37. Arrangement to prevent the Roller pressing on the withers.

to the roller by a crupper. It is used to prevent a horse rubbing his tail. The prevention and treatment of this form of disfigurement are discussed at some length in Veterinary Notes for Horse-Owners.

HOOD.

A hood is attached round the neck by tapes, and is connected to the quarter sheet by a strap and buckle, so that 
the hood may not fall down about the horse's ears in the event of its becoming displaced, as for instance, by the animal lowering his head. Owing to the fact that the length of the neck (by reason of the elasticity of the suspersory ligament of the head and neck) varies greatly according to the position in which the head is carried, it is difficult to arrange a hood comfortably for use at night. Consequently, it is well not to employ ordinary long hoods on horses in the stable. We may get over the difficulty by using a short hood or "nightcap," as it is called. It is probable that the partial protection which a short hood gives, while leaving a large portion of the neck bare, is apt to render the wearer liable to catch cold. A long hood is a useful form of protection when travelling, especially by train and on the deck of a ship during inclement weather.

When a head-collar is worn with a hood, the former should be placed over the latter. If the reverse of this be done, the hood will not fit the animal's head properly.

\section{UNDER RUG.}

An under rug is simply a square or rectangular horse rug. When used for additional warmth it is generally put under the quarter sheet or rug.

\section{HEAD COLLARS.}

An ordinary head collar (Fig. 38) consists of a noseband, two cheek pieces, a throat-latch, a forehead-band (front), an under piece which connects the nose-band and throat-latch together, and a crown-piece which is provided with a buckle, so that it can be lengthened or shortened. The nose-band is divided into three parts, which are connected together by rings that are made square, so as to give rigidity to the nose-band. The ring of the nose-band which is 
underneath the horse's lower jaw, serves as an attachment for the tying-up chain, rack-chain, or leading rein. The under strap is fixed to the lower ring of the nose-band, and its upper end is provided with a loop, through which the throatlatch slides. The throat-latch is generally made round.

The best head-collars are of leather; and cheap ones, of webbing. For stable use, leather head-collars are almost always made of brown leather, except the forehead-band, which may be of pipe-clayed buckskin or patent leather, either white or coloured. The use of pipe-clayed buckskin fronts is generally reserved for horse-show purposes, and

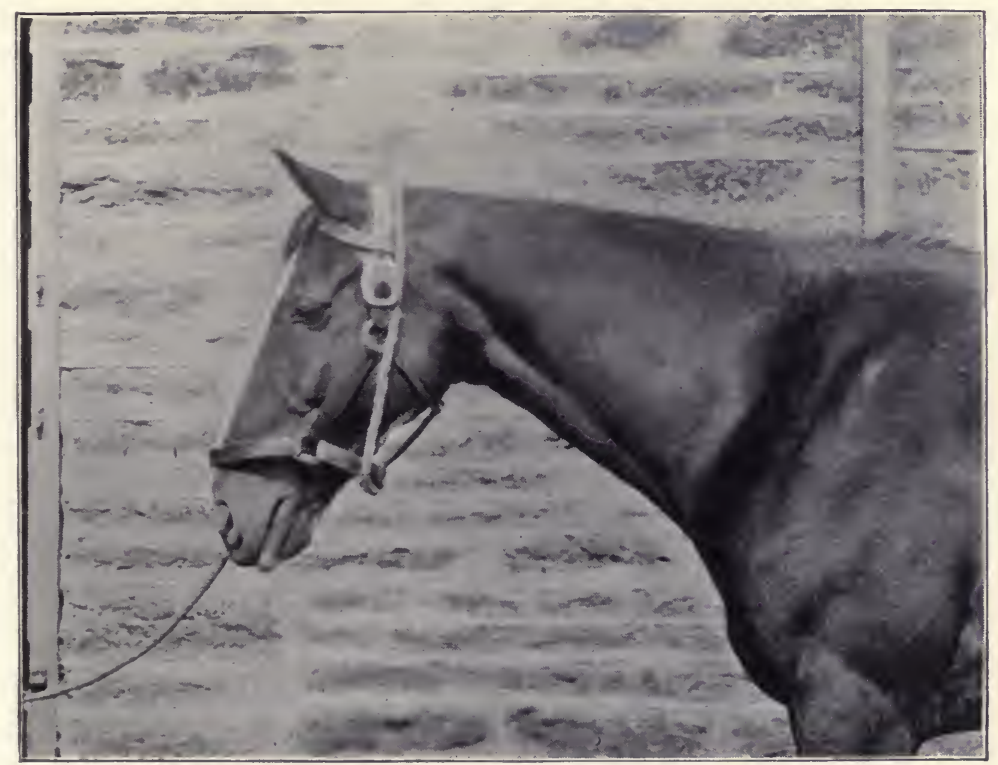

Fig. 38. Manner in which a horse slips his head-collar.

is then as a rule limited to hackneys and cart horses. Patent leather does not wear well, as it is liable to crack.

It is evident that the ring formed by the crown-piece and the throat-latch is greater when the forehead-band is 
employed (Fig. 38) than when it is absent, and when this leather ring is placed more or less at right angles to the horse's neck (Fig. 39), supposing that this leather ring is

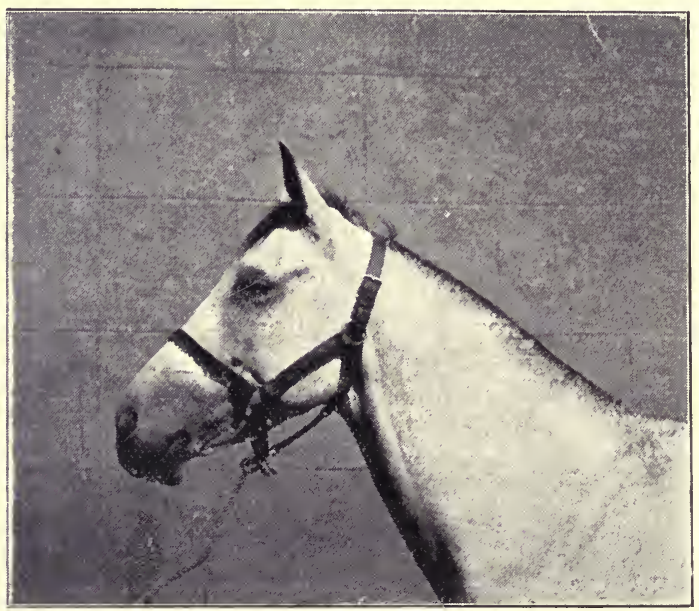

Fig. 39. Head-collar without a front.

equally tight in both instances. Hence, removing the forehead-band, drawing back the crown-piece, and tightening it a few holes, is an effective means for preventing a horse from "slipping his head-collar," which is a trick that some horses are much addicted to. This device has the disadvantage that its adoption causes the mane to become worn at the spot over which the crown strap of the headcollar passes. A more elaborate plan of checking the practice of head-collar slipping is to provide the head-collar with a separate throat-latch, which is passed through the rear loop of a strap that is about 4 inches long, and has a loop at its front end for the crown-piece (Fig. 40). Fig. 4I shows another variety of a head-collar with a separate throat-latch.

Although horses addicted to head-collar slipping are very artful in avoiding observation when they are putting their 
favourite trick into practice, I have succeeded on different occasions in seeing how it is done, and have found that the horse pulled the crown-piece over his poll by means of his tying-up chain or tying-up rope, which, as a preliminary movement, he got over his neck (Fig. 38).

Fig. 42 shows a head-collar which can be easily slipped on and off, and which is consequently suitable for young animals.

\section{HALTERS.}

A halter is a head-collar whose nose-band forms a running loop with the rope or chain to which it is attached. Halters are generally made of webbing. (Fig. 43).

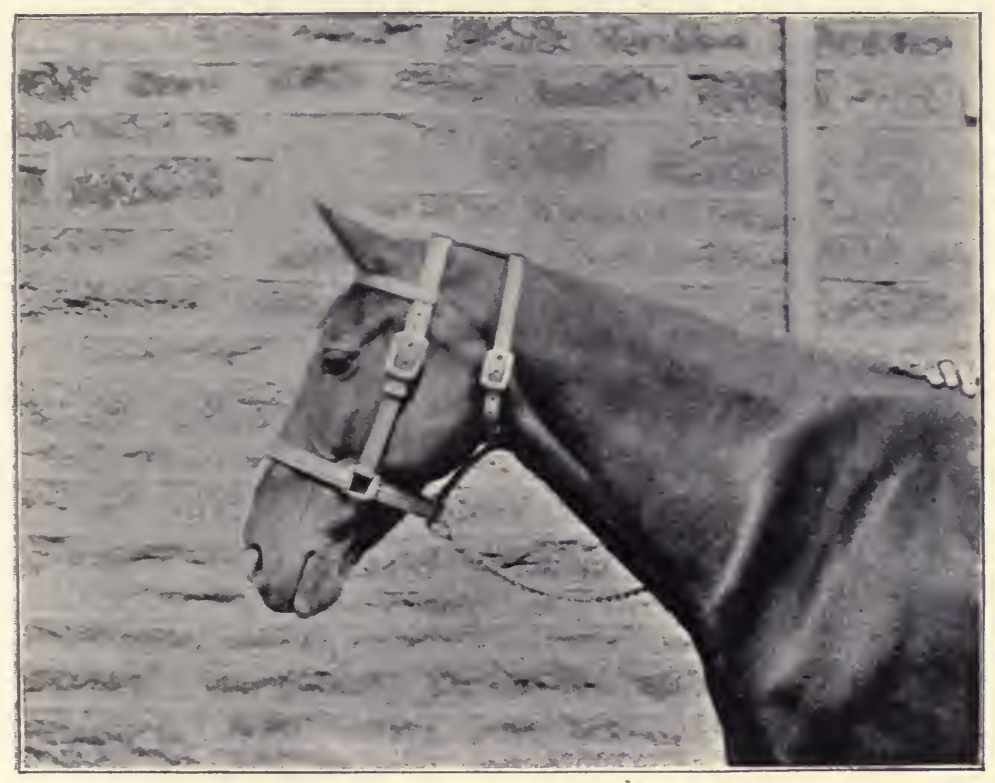

Fig. 40. Anti-slipping Head-collar.

The simplest way to improvise an ordinary halter is to take a rope about half-an-inch in diameter, and about 9 yards long; make it double for about $3 \mathrm{ft}$. 6 in., and put a knot on 
the doubled part, so as to form a large loop, in which make a small loop for the loose end of the rope to pass through. The second knot should divide the large loop, so that the

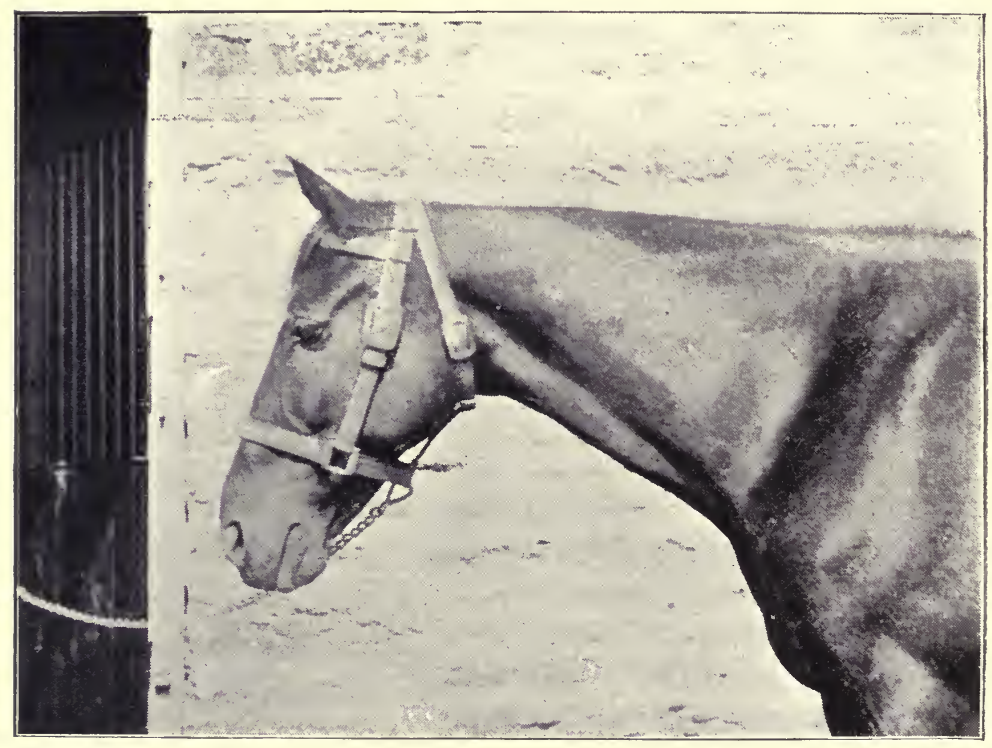

Fig. 4r. Anti-slipping Head-collar.

headpiece may be about twice as long as the nose-band. This halter will now be ready to put on (Fig. 44). The noseband should be made sufficiently long to prevent it from hurting the horse's nose or jaws, when the free end of the rope is drawn tight. Or a knot may be made with that part of the rope which serves as a leading-rein, at the ring through which it passes, so that the nose-band may not squeeze the horse's jaws together (Fig. 45).

Another method, which Mr. Tom Mitchell showed me, is to take a rope of convenient length and thickness, make a small loop at one of its ends and another small loop about 4 in. away from it (Fig. 47), pass the end of the rope through 
the first loop and then through the second loop (Fig. 48). This halter will then (Figs. 46 and 50) fit any horse; but it will require to be kept constantly tight in order for it to retain its position, which difficulty we may get over by making a knot at each of the small loops (Fig. 49).

\section{BANDAGES.}

As I have entered somewhat fully into the subject of bandages in Veterinary Notes for Horse-Owners, my remarks here will be more or less a repetition of those made in that book.

The only bandages which I shall now consider, are ordinary flannel bandages and cotton wadding bandages. The linen

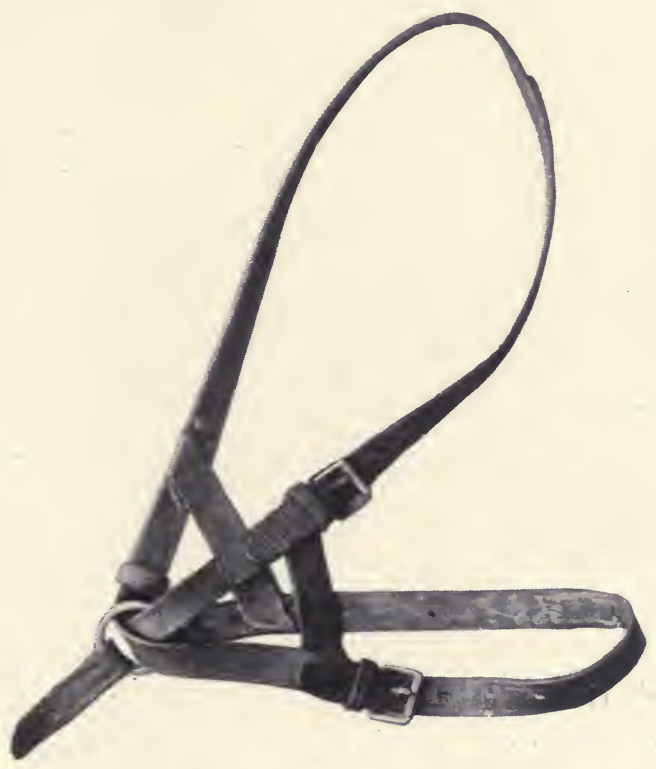

Fig. 42. Foal's Head-collar (oft side view).

and cotton bandages which are used for cold applications in many stables, serve no good purpose which cannot be better attained by other means. 
Flannel bandages for ordinary stable use may be about $8 \mathrm{ft}$. long and $4 \frac{\mathrm{T}}{2} \mathrm{in}$. wide; should have a selvage on each side, and should be made of thick material and of pure wool.

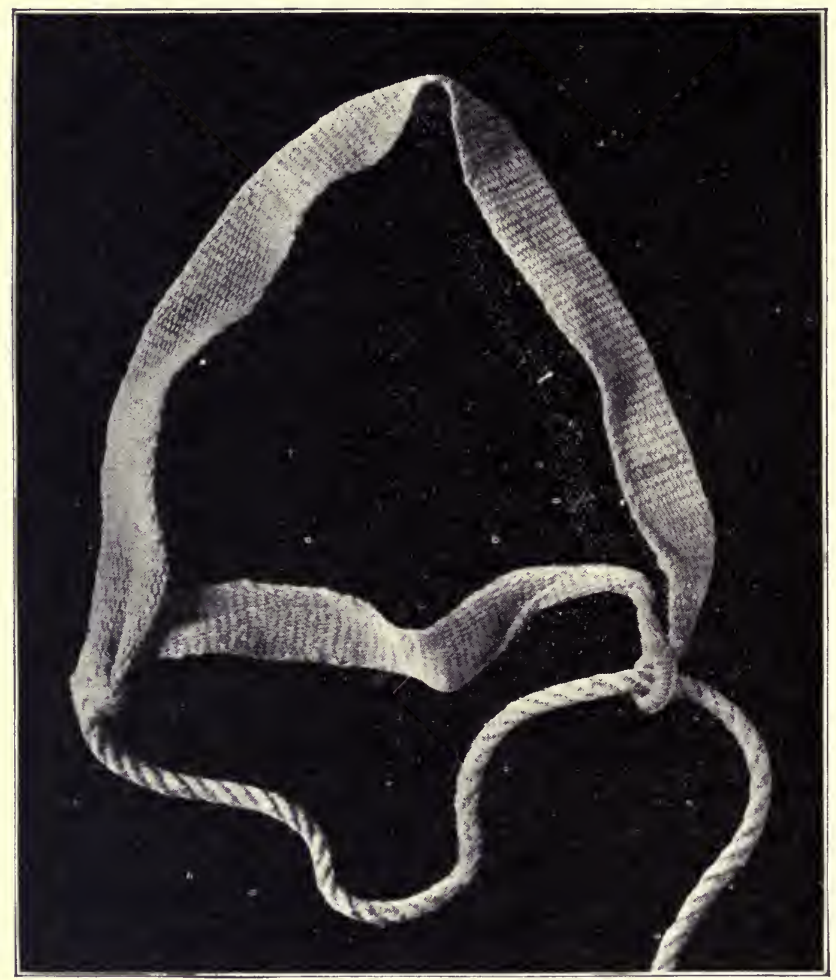

Fig. 43. Webbing halter.

Those which are usually sold are generally too short, too thin, and too wide. A bandage to be ready for immediate use should be wound up with the tapes inside. When about to put it on, we may unroll 6 or 8 inches of it, and lay this loose portion obliquely across the outside of the leg, close to the knee, with the end reaching to about the centre of that joint, and the rolled-up part turned to the outside, and 
directed downwards and forwards. The bandaging should be continued round the fetlock and upper part of the pastern, and brought close up below the knee. The loose end is then turned down, and the folds of the bandage carried over it. The tapes are tied a little above the centre of the cannon bone. By this method, no twists need be taken in the bandage, which will lie close.

A bandage for fast work, as in the case of a hunter or racehorse, requires some nicety of adjustment in order to prevent the loose end of the bandage from getting free. This accident is apt to occur, especially with an elastic bandage, when the animal is galloping, if it is put on in the ordinary manner. When the bandage becomes thus unrolled, and remains attached to the leg only by the tape,

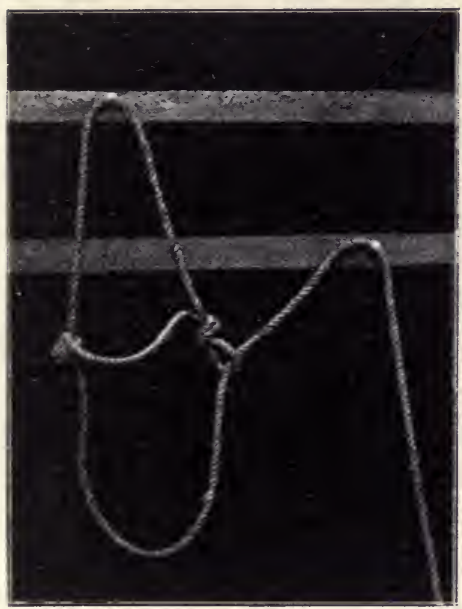

Fig. 44. Improvised halter.

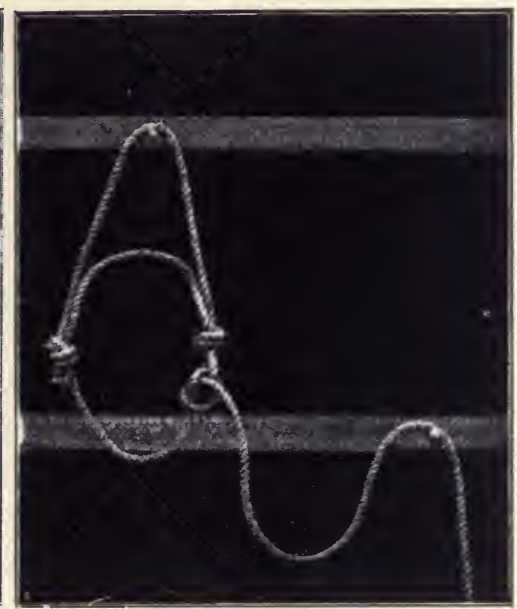

Fig. 45. Improvised halter, with knot on leading rope, so as to prevent it running.

it is liable to trip the horse up if he puts a hind foot on it ; for he would then be unable to advance the leg to which the bandage is tied. To lessen the chance of the bandage 
becoming unrolled, we may put it on in the manner described in the preceding paragraph, except that the end of the bandage in the first instance should be brought two or three

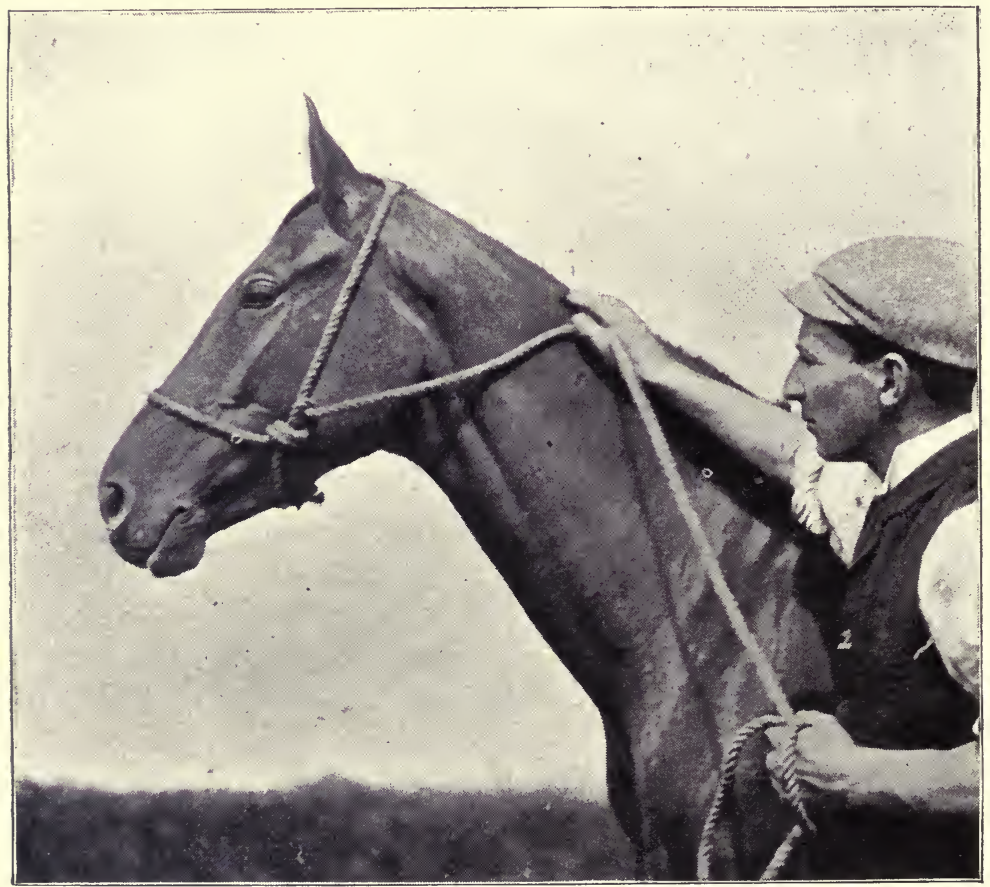

Fig. 46. Improvised halter (near side view).

inches above the knee, so as to allow of a comparatively long free end to be turned down, and to be firmly secured by the bandage being rolled over it; and that no turns should be taken round the pastern with the bandage, the lower part of which should be just clear of the fetlock joint. The loose end will then be firmly secured on both sides between the turns of the bandage.

I have found that the liability of a bandage to become undone while the horse is in movement, is directly propor- 


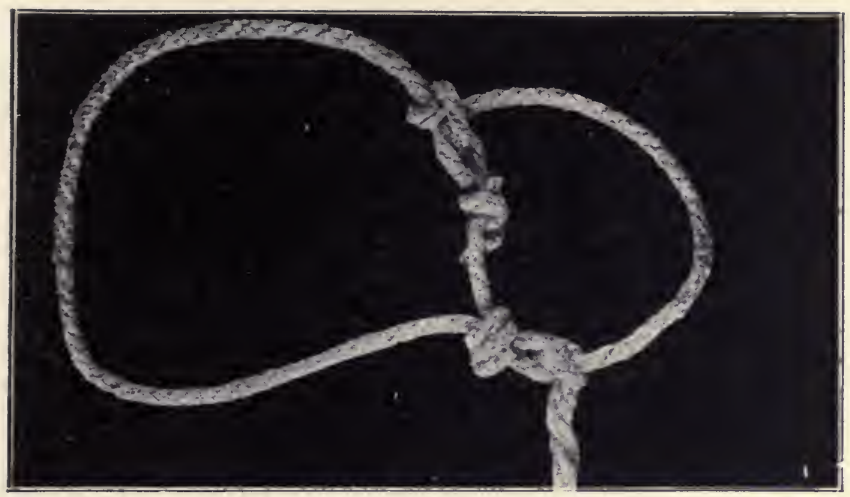

g
이

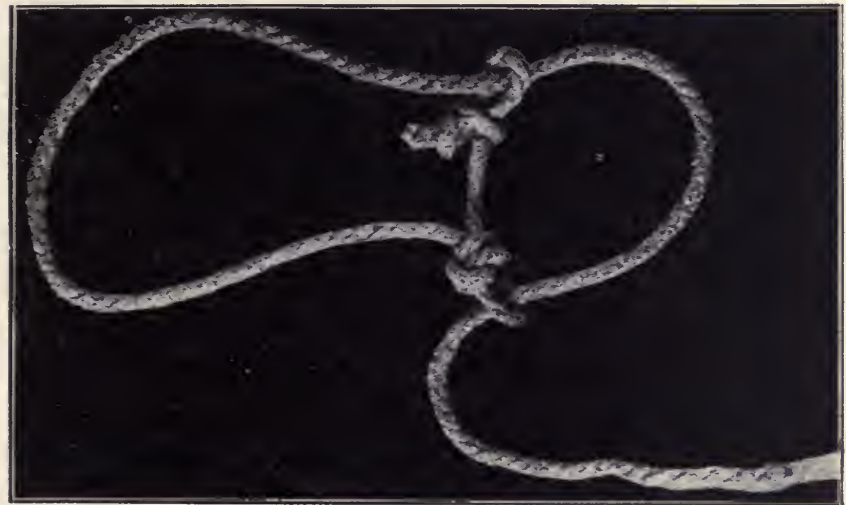

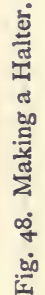

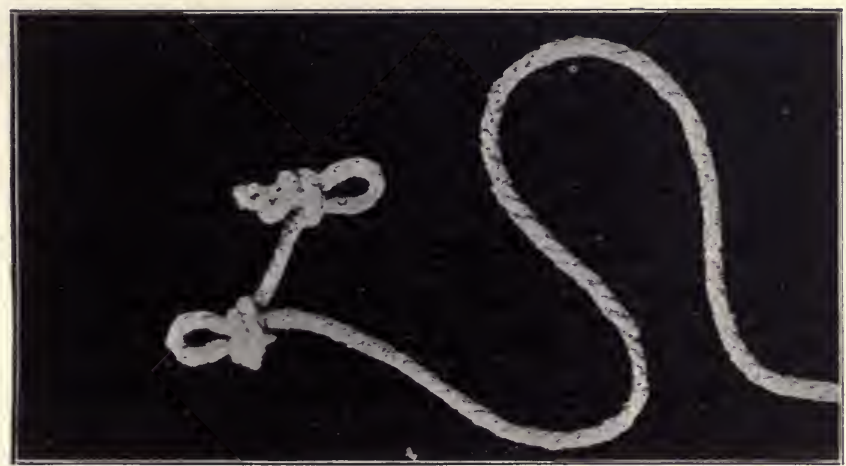

广

오 
tionate, other things being equal, to the difference of the width of the leg at the fetlock and the width just below the knee. When this is small, as is usually the case with well-bred animals, the back tendons run nearly parallel to the cannon-bone, and consequently the turns of the bandage can be put on evenly. If, on the contrary, the width of the fetlock is large, and that below the knee is

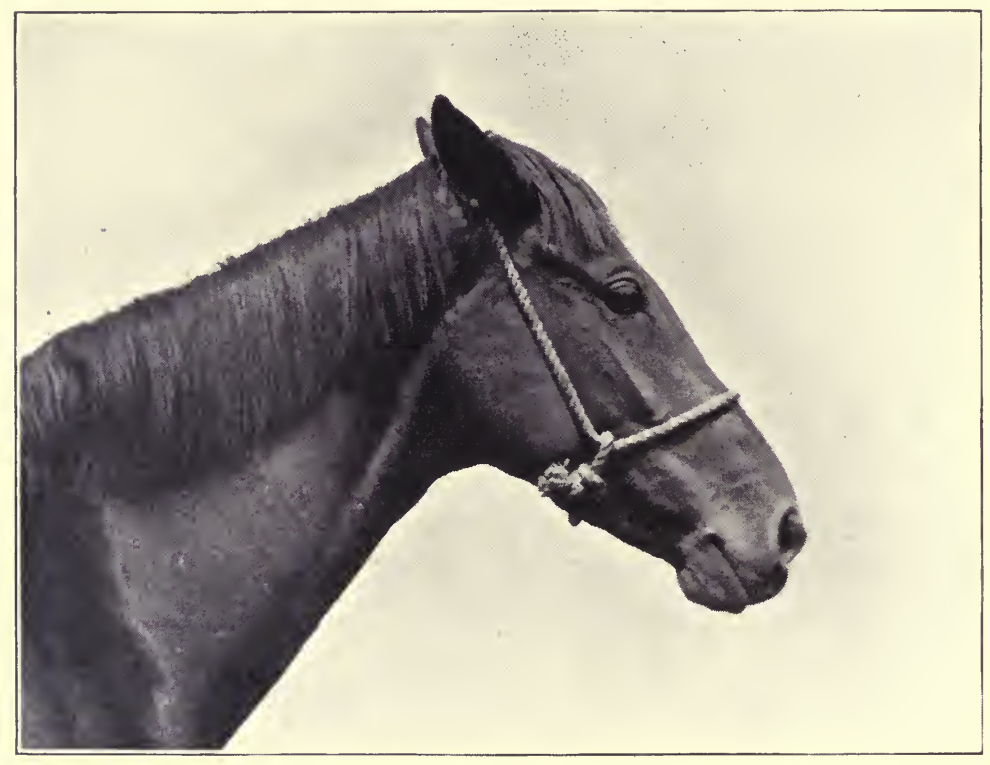

Fig. 50. Improvised halter (off side view).

comparatively small, each turn of the bandage will necessarily be looser at its upper edge than at its lower one, which fact will naturally tend to make the bandage work loose, especially during a long day, as out hunting.

Cotton wadding bandages, the use of which I shall describe later on, are applied in the following manner:-Take two yards of cotton wadding (which can be obtained from any draper), and cut it down the centre, so as to have two pieces 
of wadding a couple of yards long and about Io inches wide. Wrap the leg round with the wadding, one piece over the other; apply round it, rather loosely, a calico bandage (which can be got ready-made from any chemist, or can be constructed out of a piece of unbleached calico) about 6 yards long and 3 inches wide, so as to keep the wadding in place; and tightly apply another and similar calico bandage, so as to afford firm and evenly-distributed pressure on the leg, and secure it by tapes, sewing, or by a safety pin.

With the amount of wadding which has been recommended to be used, there is practically no danger of putting on the second bandage too tightly. It is easier to distribute the pressure evenly with two bandages than with one. If we cannot get cotton wadding, we may substitute $1 / 2 \mathrm{lb}$. of ordinary cotton-wool (the medicated kind will not do so well, because it has lost a great portion of its elasticity), and arrange it round the leg. When using cotton-wool for the object in question, its presence next the skin sometimes gives rise to irritation-probably on account of the pressure not having been properly distributed-which untoward result can be obviated by, in the first instance, wrapping the leg loosely round with a piece of soft cotton cloth, or by putting on an ordinary flannel bandage, and the cotton-wool over it. Irritation of the leg is never caused by the cotton wadding bandage put on in the manner described. I have been the first to introduce into veterinary and stable practice this application of pressure, which has been long known in human practice, and which was first brought to my notice by Dr. Henderson of Shanghai. 


\section{CHAPTER X.}

\section{HANDLING AND LEADING HORSES.}

Influence of the Voice on Horses-Good Temper in Horses-Going up to a Horse-Lifting up a Fore Foot-Lifting up a Hind Foot-Holding up a Fore Leg-Holding up a Hind Leg-Holding a Quiet Horse-Leading a Horse into or out of a Stable-Taking a Horse out of a Narrow Stall-Leading a Horse out of a Stable on Fire-Leading a Horse while Riding another Animal-Leading a Horse through Congested Traffic.

THE proper handling of horses is quite as important a part of stable management as feeding and watering for instance; for faulty handling produces in the animal bad temper, which impairs his usefulness as much as ill health, and is far more dangerous to the groom or owner. I have said so much in Illustrated Horse-breaking about the general handling of horses, that I need not here go into it further than to lightly touch on its main principles. In that book, I have discussed somewhat fully the correction of stable vices, which is a subject that comes more within the province of breaking, than of stable management.

As the voice is the great means by which a horse can distinguish his human friends from his human foes, and can understand our wishes; we should always speak to him when going up to him, and as a rule when wanting him to perform any particular movement, as for instance, coming forward, going back, or moving to one side. As he readily recognises change of tone, but not of words; we should reserve a particular tone for each of our different orders, the number 
of which should be kept as small as practicable, so that ambiguity may be avoided; and we should avoid wearying the attention of the animal by needlessly speaking to him. In fact, we should reserve the use of our voice for occasions on which it is needed to produce a definite effect. A groom who, while he is with an animal, keeps continually speaking to him in a monotonous tone of voice, shows by doing so, that he knows very little about horses.

Experience tells us that to preserve the invaluable quality of good temper in a horse, it is necessary that those who handle, ride or drive him, should possess his confidence, which they cannot do, unless he understands their orders and knows that they will treat him justly. Hence, there should be no teasing a horse, or "venting one's spite" on him. If an animal is difficult to handle, especially about the ears, we may be quite certain that he is or has been in brutal or incapable hands. Difficulty in bridling is another tell-tale fault.

I have found that when going up to an uncertain horse which is held or tied up in the open, it is safest to approach him in the direction of the fore leg of the side upon which we are placed, and a little in front of a line drawn at right angles to the axis of his body, say, at an angle of about $70^{\circ}$ to the direction in which he is standing. Approaching him from his front, or from behind, is apt either to alarm him or to provoke his resentment. 'Having reached his shoulder, near or off as the case may be, we may place a hand or cane on his crest, and scratch his mane, which is a piece of attention he will generally appreciate. When approaching an uncertain horse in the stable, it is well to make him "move over" (turn his hind quarters away from one).

In lifting up a fore foot, I make a half turn to the rear, run my hand (the left when on the near side, and the right 
when on the off) down the back of the fore-arm, grasp the leg just above the knee with the fingers and thumb, turn the elbow in, and press it against the upper part of the forearm so as to make the animal put the weight on the other leg; lift up the leg, and catch the foot, when it is high enough, with the other hand. This is a much easier plan than the usual one of catching hold of the pastern, and is certainly safer with strange animals. If a horse is hairy about the fetlocks, the easiest way to lift the leg is by catching hold of the hair of that part. In lifting up a hind foot of a strange animal, it is usually best to run the hand down the hind quarters; catch hold of the ham-string (tendo Achillis); and seize the pastern backhanded with the other hand. If the animal is "confidential," we may lift a hind leg by running the hand down the limb, and taking hold of the cannon bone with the fingers pointing to the rear. Many badly-trained grooms in England practise the slovenly habit of lifting up either the off fore or the off hind, while standing on the near side of a horse. Such a lazy country-bumpkin proceeding is opposed to one of the first principles of good horsemanship, which enacts that a horse should be the same, as regards mouth and manners, on both sides of his body, which he cannot be, if he is habitually turned, bent and handled only on the near side. In olden days, the custom of mounting from the near side, and of using the left as the bridle-hand became established, because the large majority of riders wore swords, which would get in the way of the horsemen, if the act of mounting was performed from the off side. In civil life we have retained the habit of mounting from the near side; probably because right-handed people are generally leftfooted, in which case it would be easier for them to place the left foot in the stirrup iron, than the right. The picking up of an off foot from the near side is a manifest absurdity; 


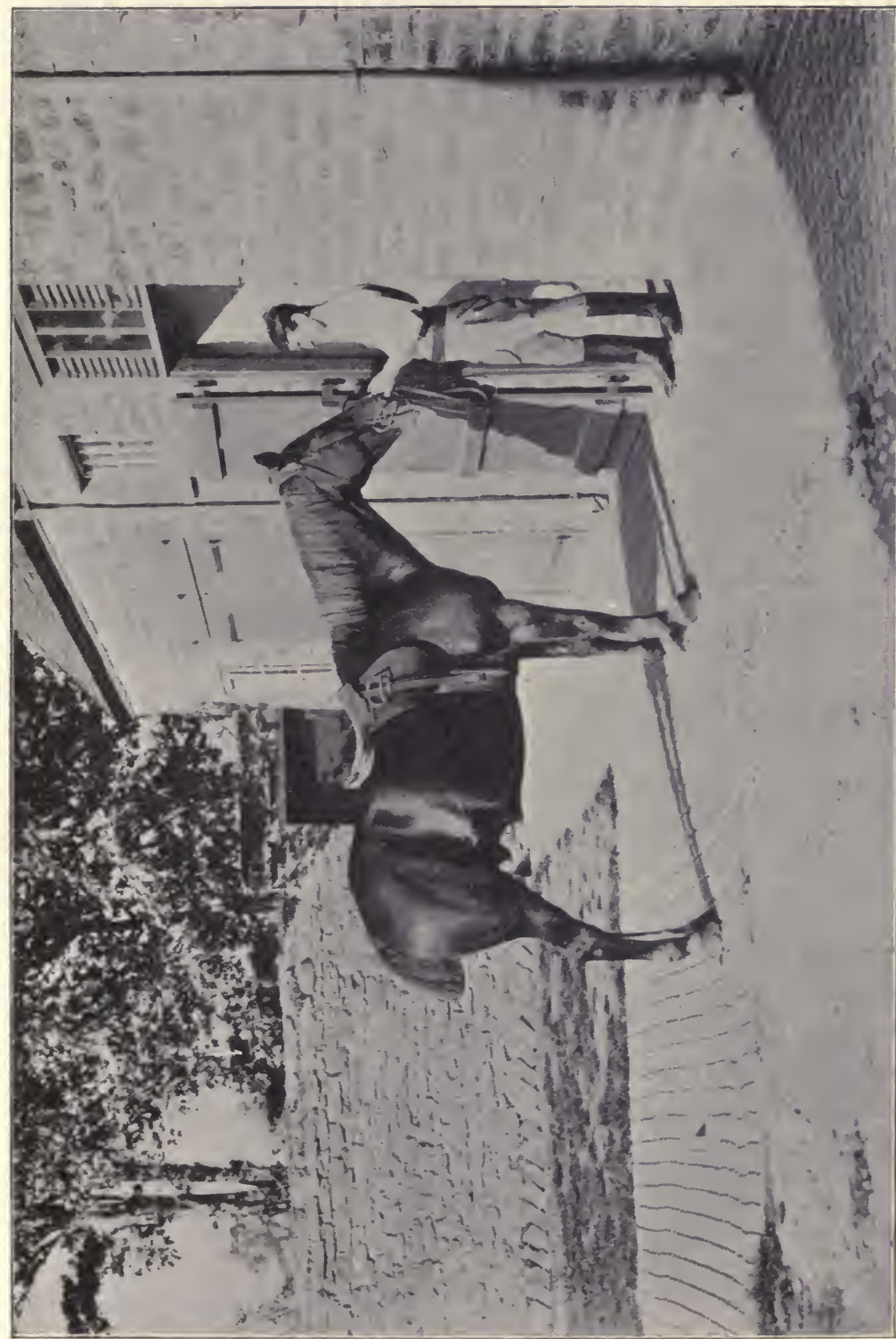

Dू 
because it is more difficult to perform; it is more dangerous, especially in the case of lifting up the off hind; it is less effective, in the event of the person who lifts up the foot wishing to clean or examine the foot; and it places him at a disadvantage in trying to hold up the foot, if the horse makes an attempt to free his leg. We need hardly wonder that the large majority of horses in this country swerve to the left when they refuse a fence, and that thrush is much more common in the off feet than in the near.

If in order to hold up a fore leg, a man passes his hand "under the fetlock or pastern, as is frequently done, the horse, by bearing a portion of his weight on the man's hand, can greatly inconvenience him, and can easily kick with either hind leg. The foot of an unshod horse should on the contrary be held by the spread-out fingers and thumb grasping the front part of the hoof. The shod foot may be held up by the front part of the hoof, under which the fingers pass, while the thumb presses down on the sole. In either of these cases, the animal will avoid placing weight on the man's hand; for by doing so, the joints of the foot would become bent in a painful manner" (Illustrated Horse-breaking).

When wishing to hold up a hind leg for any considerable time, as for instance, in order to dress it for thrush, we should, if on the near side, place the leg on the left thigh, while holding the ham-string with the left hand, and the pastern with the right hand.

"The best way to hold a fairly docile horse while standing at his near side, is to draw the snaffle reins over his head, take them at the centre in the full of the left hand, and catch both reins near the rings of the snaffle with the right hand, having the little finger between them. While holding the reins in this way, we have good command over the horse when leading him. If we wish to hold him for 
examination or for gear to be put on him, we may place ourselves in front of him, catch the off rein with the left hand and the near rein with the right hand, close to the rings of the snaffle; and hold the horse's head up" (Illustrated Horse-breaking).

The best way of leading a horse into or out of a stable, in the event of his being shy of going through a door-way, or

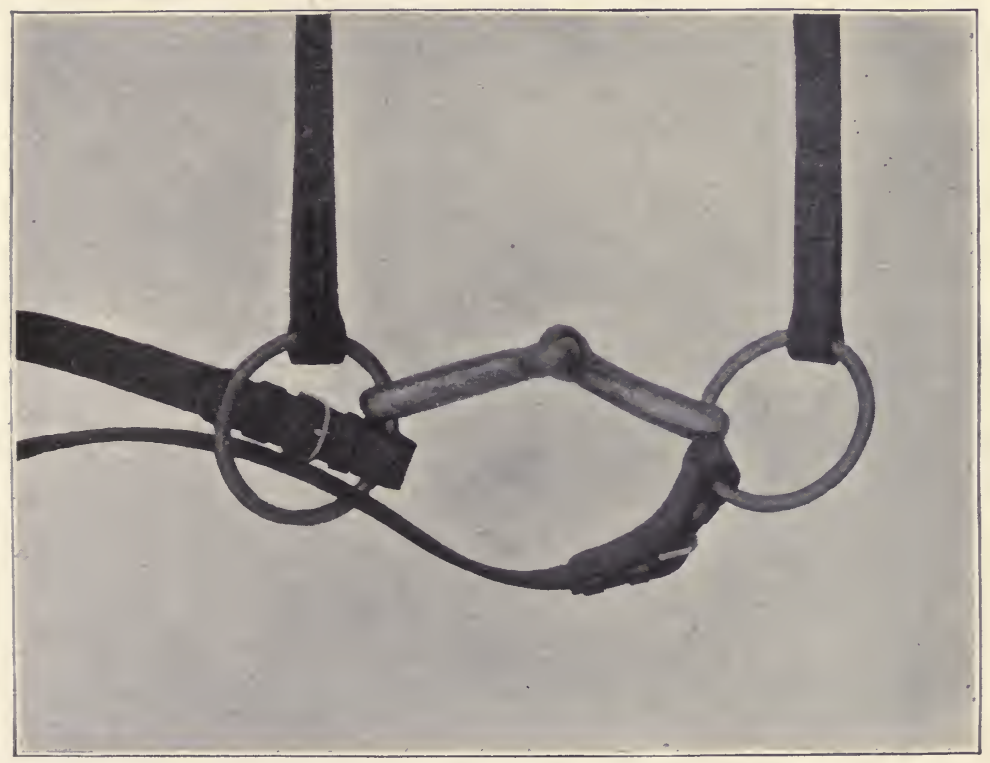

Fig. 52. Adjustment of Snaffle for leading a horse, when mounted.

if the passage is narrow, is to place oneself in front of the animal; hold him as in Fig. 5I ; and lead him forward while stepping backwards.

In taking a horse out of a narrow stall, and especially if he is saddled or is at all stiff in his back, he should be backed out, and not turned round. The practice of saddling a horse in a stall with his head to the manger (instead of putting him on the 


\section{I4 HANDLING AND LEADING HORSES.}

pillar reins) and then turning him round, is a fruitful cause, particularly with side-saddles, of forcing the points of the tree apart, and thus spoiling the saddle. The greater liability of side-saddles to become ruined in this manner, is due to the fact that points of their trees are much longer than those of crosssaddles, and consequently they are more liable to become forced apart in this way. As horses grow old, the ligaments which connect the vertebræ of the back, loins, and croup, show a marked tendency to turn into bone, in which event, the involved portion of the spinal column not only loses the slight lateral play it once had, but also becomes very liable to injury from strain or concussion, as we may see by the comparative frequency of fractures of the back in old horses from casting for operations.

To lead a horse out of a stable on fire is often a difficult matter, on account of the strange reluctance to quit a burning building which horses generally show. After refusing to be led by the head-collar, they sometimes obey when a bridle is put on them. The most effective means of enforcing compliance is blindfolding them, which we may do by throwing a rug over their heads. The stifling effect of smoke can be greatly mitigated by placing a wet handkerchief or other wet thin material over one's nose and mouth, and to a less extent, by using it for this purpose in a dry condition. We might employ the same means for filtering the air breathed by a horse in similar circumstances.

The usual custom when leading a horse while riding another animal, is for the man to keep on the right side of the road; because in this case the led horse, being almost always on the off side of the ridden one, will not be liable to swing round and get hurt by passing traffic. It is evident that this rule could not be carried out in busy cities. In congested traffic, like that of London, it would be out of the question for a man to ride one horse and lead another; in fact, the 
only safe way of leading a horse in such circumstances, would be to lead him on foot, to keep on his off side, and to obey the ordinary rule of the road for carriages.

To lead a horse with a snaffle when mounted, we pass both reins through the near snaffle ring (Fig. 52), if the led horse is to be on our off side; and vice versâ. If the led horse wears a double bridle and both reins are on his neck, we place the snaffle reins outside the bit reins, draw them over the animal's head, and pass them through the near or off snaffle ring, as the case may be. If the reins are off the horse's neck, we place the curb reins on his neck, and adjust the snaffle reins as before described. When leading a horse with a double bridle, it is generally advisable to shorten the curb reins by means of a running knot, as may be required; so that they may not hang down, and get caught by one of the animal's fore legs, for instance. 


\section{H A P T E R X I.}

\section{GROOMING.}

Definition-Necessity of Grooming-Chief Objects of Grooming-Shedding the Coat-Grooming Horses Kept in the Open-Hours of Grooming-Washing Horses-Hand-Rubbing-Grooming Tools and their Uses-Wisping-Time and Help required for Grooming-Details of Grooming-Care of the Legs and Feet-Protection against Flies-Testing the Efficiency of the Grooming.

\section{DEFINITION.}

GROOMING is the process of mechanically cleaning the skin and coat, and of applying friction and massage to them.

NECESSITY OF GROOMING.

The necessity of grooming, as we shall presently see, is created only by the new conditions which are imposed on a horse by civilisation.

\section{CHIEF OBJECTS OF GROOMING.}

I. To prevent chill for the time being, as for instance, when a horse returns hot from work. For this end, the stimulation of the surface of the body by means of friction should be vigorously carried out, though without hurting or irritating the animal in any way, and, if practicable, by at least two men, so as to enhance the efficacy of the grooming. In our own cases, the manner in which shampooing after a Turkish bath, and brisk rubbing-down after a sweat, fortifies the body against cold, are convincing instances of the good effects of the stimulation of the skin by friction in the prevention of chill. 
2. To clean the skin and coat, so as to favour the escape of perspiration and oil from the skin, and to improve the appearance of the horse. We have seen (p. 18) that the scarf-skin, which acts as a protective covering to the true skin, consists of horny scales that peel off as time passes on. From a health, and especially from a training, point of view, we must regard an excess of scarf-skin as so much dirt. The cleansing effect which perspiration, induced by exercise, has on the skin, is well shown by the fact that the skin of a wild animal is as a rule much cleaner than that of a captive specimen of the same species. For instance, a wild pig is one of the cleanest of beasts. A horse in a wild state is not only obliged to take a large amount of exercise in search of food, but has also to use his powers of flight as his chief defence against his enemies.

When the skin, owing to prolonged inactivity, becomes thickly cased with cuticle, the escape of its secretions is proportionately diminished, and the general health will suffer in consequence; to say nothing of disorders in the skin itself, and the increased strain which will be put on the lungs, in the event of the horse being worked. The removal of this unseen dirt, if I may be allowed the expression, is of far greater importance than that of superficial dirt, such as dandruff. As grooms know but little of physiology, and as they find that "eye-wash" generally satisfies their still more ignorant masters, it is not surprising that in the large majority of hunting and other private stables, grooming consists merely in the removal of superficial dirt, and in the straightening of the coat and long hair. This method of slurring over work which is highly conducive to health and bodily vigour, should of course be tolerated only when economy of paid labour is one of the first considerations. An entirely different practice is carried out in good training stables, where the importance of applying an abundance of friction to the skin when a horse 
returns hot from work, is fully recognised. This intelligent view which our best trainers take of grooming, has probably originated, or at least been strengthened in their minds, by the knowledge of the good effect produced by brisk rubbing down, in the similar case of men who are in athletic training, or who are "wasting" for race-riding. Besides, in high-class training stables, the welfare of the horses is not sacrificed for the convenience of grooms or strappers.

3. To give a polish to the coat and to lubricate the skin. The oil which confers this gloss and pliability, is secreted by glands that lie in the true skin close to the hair follicles, from which the hair springs. As a rule, each hair is accompanied by two of these glands, the oil of which is discharged by the opening that gives exit to each hair. Some of these glands open on the surface of the skin independently of the hair. As this oil is brought in the first instance to the surface, its softening action on the scarf-skin will be greatly promoted by friction, which will cause it to penetrate into the scarf-skin more or less deeply. Friction also distributes the oil through the coat. The usual idea that friction brightens the coat and lubricates the skin by stimulating the oil glands, appears to me to be incorrect; because, although exercise brings much more blood to the surface than friction, as we see when a horse sweats from work, it is not nearly so effective for performing the duties in question.

4. To stimulate the action of the skin. The two great natural stimulants of the skin are exercise and atmospheric heat; thus we find that the skin of a horse can be stimulated so highly by fast work, that it will become bathed in perspiration even in the Arctic Regions. The same thing habitually occurs in the Tropics by the influence of atmospheric heat, which is a subject we need not consider here. When a horse performs work which is sufficient for health, but which does not fatigue his lungs, the stimulation of his 
skin by grooming is of no great importance. If, on the contrary, his work demands the highest possible efficiency in his organs of breathing, as in the case of a racehorse or hunter, any relief, however small, which the lungs can obtain from the functional activity of the skin, will of course be an advantage.

When an animal is deprived of a sufficiency of exercise, the lungs will remain more or less inactive, and consequently the skin should be stimulated, so that health may be maintained. As grooming is a useful and thoroughly safe means for stimulating the skin, we should fully utilise it in default of exercise. The richer and more abundant the food, the larger will be the quantity of waste material for the lungs, skin and kidneys to eliminate. Hence, the less the work and the larger the ration of nutritious food a horse gets, the more grooming will he require.

5. To keep the coat short. This can best be done by handrubbing (p. 323).

6. To promote health. This object of grooming, as we have already seen, has special reference to stabled horses which are highly fed and get too little exercise. Even if the work be sufficiently hard to produce fatigue, it will almost always be compressed within too short a period. Consequently, the unnatural deprivation of exercise which a stabled horse as a great rule has to submit to, during a large portion of the twenty-four hours, and the impurities of the atmosphere which he usually breathes, make grooming a necessity to health in almost all cases. Its good effect in this direction is amply proved by experience. I think we may conclude from the foregoing considerations that friction and not brushing is the most important factor in grooming.

\section{SHEDDING THE COAT.}

Nature provides the horse with a fine and a comparatively short coat for summer wear; and a coarser and longer one for 
winter use. The animal sheds the former covering during the autumn; and the latter, during the spring. The hairs of the fore-lock, mane and tail, and the long hairs about the muzzle and eyes are not shed. Good grooming and the use of warm clothing greatly tend to reduce the difference between the summer coat and the winter coat. If, while the coat is being changed in the spring, the brush or other means be employed to hasten the process, the skin will become exposed to undue cold, with the result (p. I8) that coarser hair will be formed than would have been the case had the winter coat been allowed to remain on for its usual period. Hence the summer coat will be rougher than it would otherwise have been, and its appearance may be more or less spoiled. Therefore to prevent any loss of good looks in the summer coat of their animals, grooms who have to study appearances, like those in charge of fashionable carriage horses in the London season, are generally careful to avoid brushing or handrubbing the coat, while it is being shed during the spring. The wisp and rubber, used in the direction of the grain of the coat, will then be sufficient for grooming purposes. With horses which are kept more for use than show, the season of the year should make no alteration in the grooming. Besides, as I have already indicated, the coats of horses which are well groomed all the year round, will vary but little in texture.

The colder the temperature of both the atmosphere and the stable, the greater difference will there be between the summer coat and the winter coat.

\section{GROOMING WORKING HORSES KEPT IN THE OPEN.}

The question of grooming working horses that are kept in the open, is one of atmospheric conditions, clothing, food and state of the coat. We need here consider only animals which are picketted outside, like many troopers on foreign service; because horses that are turned out during their intervals be- 
tween work would require no grooming, except for appearance sake. The protection given by clothing is self-evident. Also, nutritious food fortifies the system against inclement weather. From a wide experience in India with Army horses picketted in the open, I can say that ordinary unclipped animals which are well fed and have a warm rug, are all the better for being groomed, even when the temperature falls to, say, $27^{\circ} \mathrm{F}$. In such cases it is well to know, as we shall presently see, that wisping is not only more conducive to health than brushing, but it also diminishes to a less extent the protective power of the coat. High wind and rain will greatly augment the effects of cold.

HOURS OF GROOMING.

The best time to groom a hard-working horse is on his return from labour; for then appropriate grooming will perform its most valuable office of lessening the danger of chill by preventing the surface from cooling too rapidly. Also, when the skin is warm, it will be easier to distribute the secreted oil over the skin and through the coat, than when it is cold. It is evident that the object of fortifying the horse's skin against cold air outside by grooming, is of no great importance, supposing the animal is put to quick work immediately he leaves the stable. Hence, in most cases (even including those of racehorses), the early morning grooming is of a light description; the serious strapping being reserved until the return home. Even if it were necessary to make a horse look as smart as possible before taking him out of the stable, as would be the case with fashionable carriage horses, we should not neglect to thoroughly stimulate his skin when he comes back, supposing that he had done a fair amount of work outside. When there is plenty of help in the stable, the grooming may generally be carried out in a manner similar to that usually employed with racehorses, namely, a light groom- 
ing in the early morning; a thorough grooming on the return of the animal from work or before his mid-day feed; and a repetition of this grooming in the afternoon. If a horse returns a good deal fatigued after his work, as would be the case with a hunter which had gone through a long day, it would of course be injudicious to fatigue him still further by a long protracted grooming; and consequently the strapping, in this instance, should not exceed that which would be sufficient to guard him from the effects of chill. If a well fed horse does not leave his stable, no relaxation in the grooming should be permitted. When the question of economising paid labour has to be considered, "quartering" (p. 34I), or even "setting the coat" once or twice a day, may have to be substituted for regular grooming.

\section{WASHING HORSES.}

This practice as a rule is injurious, because it removes the natural oil from the skin, and predisposes the animal to chill. The application of water to a horse's skin increases the heatconducting power of his coat (p. 35), and lowers the temperature of the surface by evaporation, and also by conduction ( $\mathrm{p} .30$ ), in the event of the temperature of the water being colder than that of the skin. Besides, water radiates heat with great facility. Although in hot climates, like that of India, a horse may be washed with impunity, provided that he is quickly dried, I do not think that such a proceeding is safe in temperate or cold countries. Even in the Tropics, washing a horse always takes the gloss off his coat, no matter how vigorously the subsequent grooming may be applied, a fact which is certainly a strong argument against the practice in question. If it is imperative to wash, and there is not sufficient help to have the horse rubbed dry without loss of time, we may, after scraping and going over him with two or three dry rubbers, take him out and exercise him at 
a brisk pace, until he gets dry by the exercise, in the same manner as boys often dry themselves in the open after having a swim. We should then walk him about until his circulation regains its normal condition before taking him in. If we cannot give this exercise, we may, after scraping and drying him, put on him a good supply of warm clothing, bandage his legs, and leave him thus to dry under his rugs, which he will do in an hour or less. He should after that be exercised and then well rubbed down, so as to prevent him from becoming chilled. A good plan for getting a horse to dry quickly and safely under clothing, is to cover the animal's back and loins with straw before putting on a rug, so as to utilise the low heat-conducting power of air (p. 32), and to give as little impediment as possible to the escape of moisture.

Water has no power to remove the scales which the outer skin gives off in the form of dandruff; its cleansing effect being confined to sweat, mud, dust and other kinds of adventitious dirt. The practice of washing horses often gives rise to cracked heels and mud fever, which is a form of inflammation of the skin that extends more or less over the legs, and sometimes over the lower surface of the abdomen.

We find from experience that the external application of warm water, especially to the legs, is even more objectionable than that of cold water. This is chiefly due to the fact that warm water more readily removes the oil which keeps the skin soft and pliable, and is more efficient in loosening the layers of scales which serve to protect the true skin from irritation by external influences, than cold water.

\section{HAND-RUBBING.}

In England, the expression "hand-rubbing" is used in almost all cases, only in connection with the legs of a horse. The extension of this process to the body of the animal, in 
the manner practised in India, would make a great improvement in English grooming. It has the special advantage of being in no way irritating to the skin, and consequently it is seldom resented by a horse. I am of opinion that it is a better stimulant to the skin than any other form of grooming.

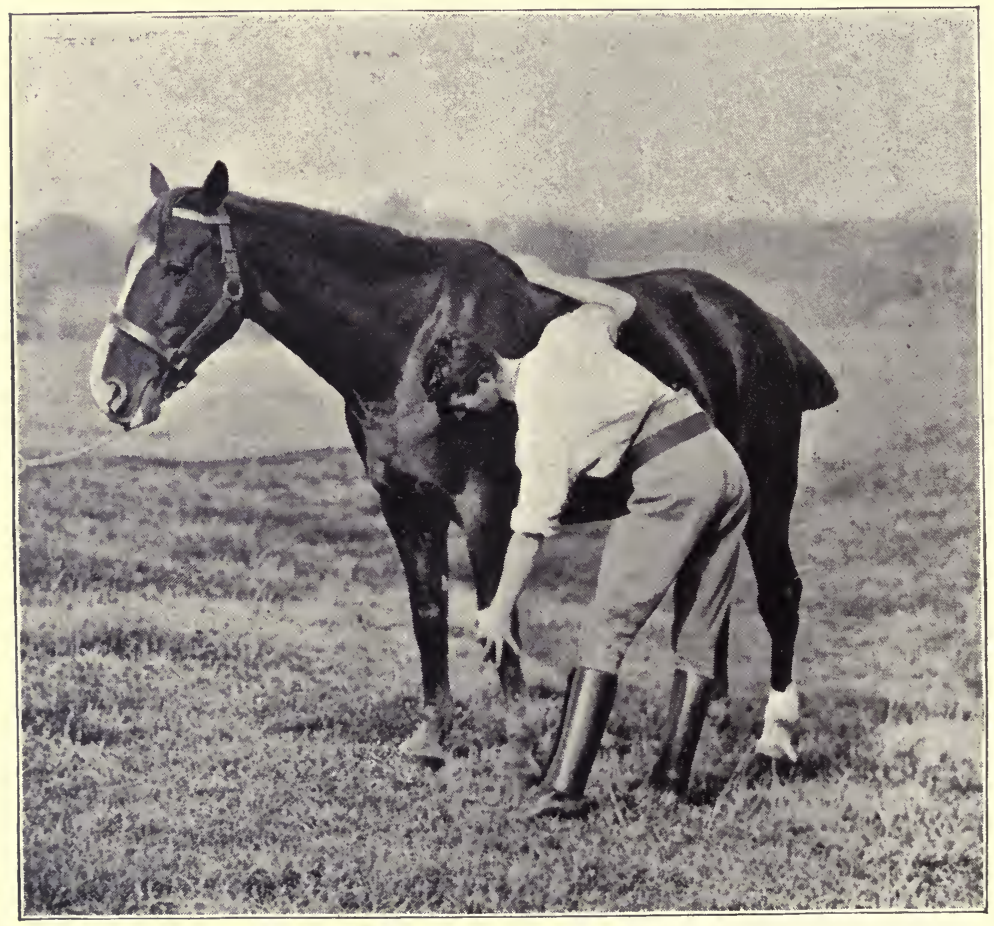

Fig. 53. Hand-rubbing the body.

It is certainly the best means of putting a brilliant gloss on the coat.

In hand-rubbing above the knees and hocks, the stroke should be commenced by bringing the flat of the hand-each hand to be used alternately-well under the belly down the fore-arm (Fig. 53), thigh or gaskin, or between the fore-legs, as the case may be ; and it should then be drawn up with an 
even and firm pressure. As the hand is raised, the elbow should be turned out (Fig. 54), and the under part of the bared fore-arm should be brought into play against the grain of the coat. In doing this, the weight of the body and the strength of the arm should be utilised.

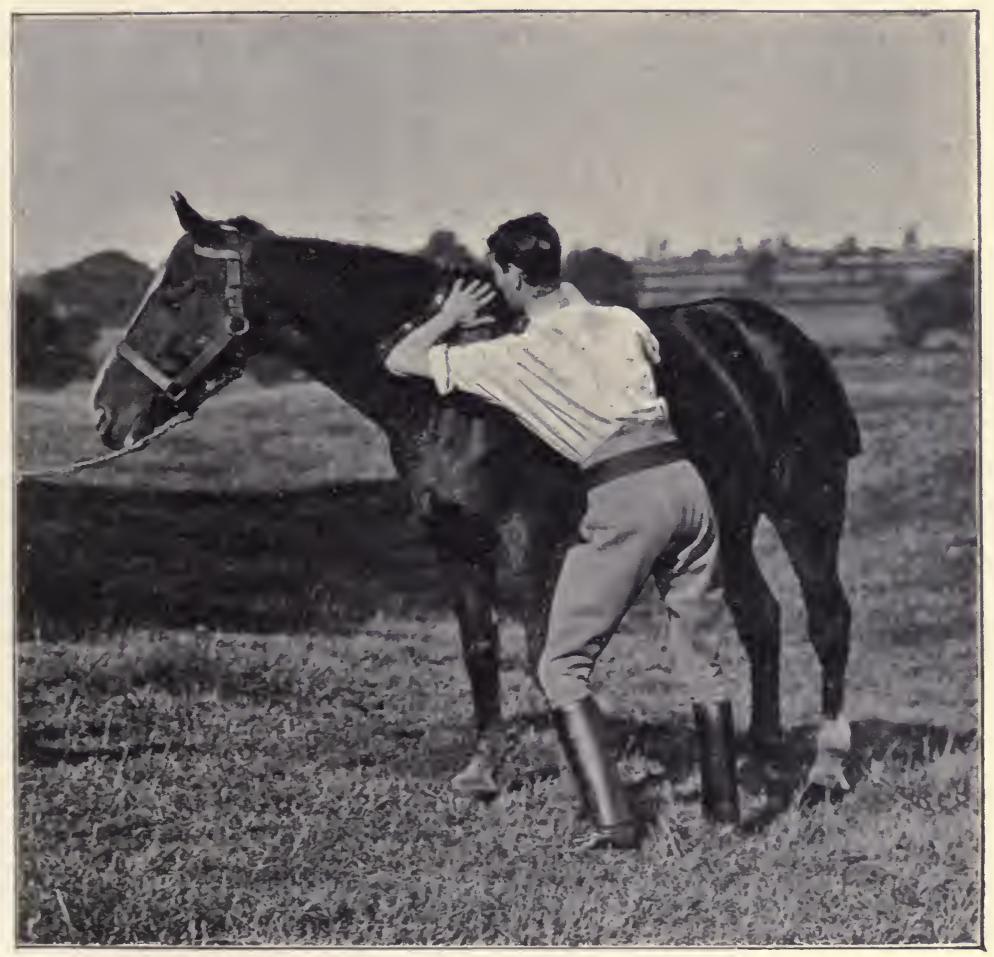

Fig. 54. Hand-rubbing the body.

The usual method adopted for hand-rubbing the legs below the knees and hocks, is to kneel down or sit on one's hams (hunkers) by the side of the leg which is to be manipulated, and make alternate strokes downwards, while grasping the leg between the finger and thumb. When on the near side, the left hand is naturally placed on the front of the leg, and 
the right on the back of the leg. On the off-side, the position of the hands is of course reversed. The pressure exerted by the hands should be firm, but by no means irritating. The skin at the back of the pasterns should be well rubbed, so as to render it as dry and pliable as possible.

Hand-rubbing the legs is a beneficial practice with the generality of stabled horses. It prevents stagnation of blood in the legs and feet; by the pressure exerted, it promotes the absorption of any effusions that may be present about the back tendons and suspensory ligaments; and it helps to guard the skin against "cracked heels" and "mud fever." Although this ordinary hand-rubbing is sufficient for grooming purposes, it is not nearly so effective in cases of sprain as the method of hand-rubbing from the fetlock upwards, while the limb is held up off the ground. That variety of massage, which I have described in Veterinary Notes for HorseOzoners, is not of such easy application as the more common form of hand-rubbing.

Hand-rubbing the body helps to keep the coat short, which desirable effect is increased by damping the palms of the hands with water. If this be done when hand-rubbing the legs, or if the legs be wet when hand-rubbed, their appearance, in the case of well-bred horses, is apt to be spoiled by patches of hair being removed, owing to the moisture loosening the hair. Hence the hair and hands should be kept dry when the legs are hand-rubbed, unless we want to diminish. the amount of hair.

GROOMING TOOLS AND THEIR USES.

The "tools" generally used in grooming (Fig. 55) are :

Body-brush. Water-brush. Mane-Comb. Burnisher.

Dandy-brush. Curry-Comb. Hoof-picker. Scrapers.

To these we must add rubbers, wash leathers, sponges and soap. A hoof-brush would make the list complete. 
Stable brushes, like almost all other brushes, have a large number of tufts (bundles) of bristles or vegetable fibres which are respectively doubled on themselves, passed through holes in the wood and secured behind. The brush is usually completed by a wooden back, which should be screwed (not merely glued) on to the wood that carries the bristles or fibres.

The "hairs" of all stable brushes, except those of dandy-

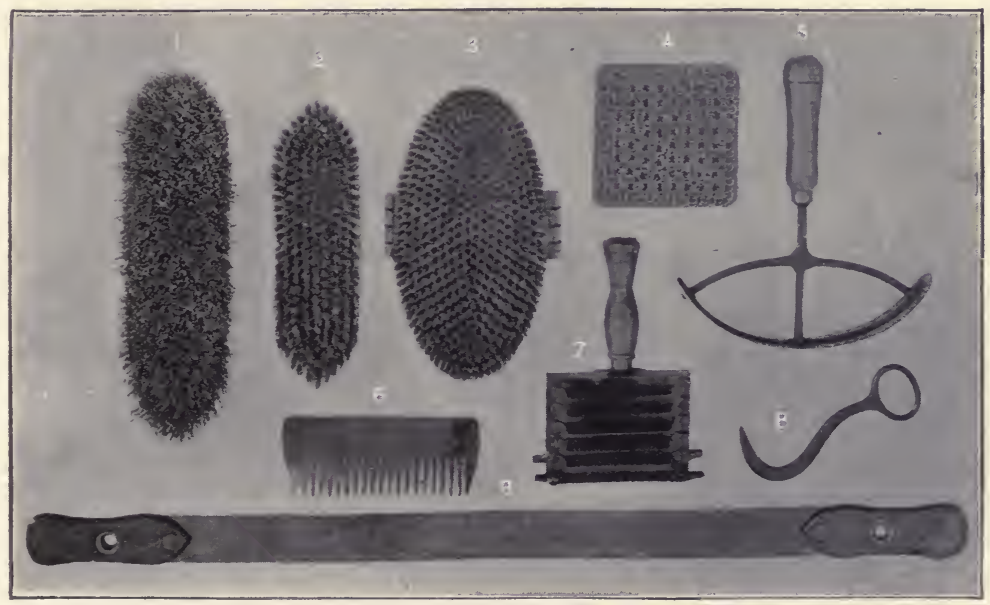

Fig. 55. Grooming Tools.-r. Dandy-brush. 2. Water-brush. 3. Body-brush. 4. Burnisher. 5. Half-moon sweat-scraper. 6. Mane-comb. 7. Currycomb. 8. Hoof-picker. 9. Double-handed sweat-scraper.

brushes, should consist of pigs' bristles, which are usually obtained from Russia. The hairs of inferior brushes are often largely adulterated with vegetable fibres which closely resemble bristles; but the fraud can be easily detected, as $\mathrm{Mr}$. T. U. Clarke, the Rugby saddler, showed me, by applying fire, a lighted match for instance, to the hairs, which, if false, will readily burn. Bristles will frizzle, char, and give off a characteristic odour, but will not ignite. The vegetable 
fibres, which appear to be a kind of grass, stand wear badly, and become soon spoiled by the action of water.

After a brush has been washed or used in a wet state, it should be put to dry with the hairs down, so that the water may not rot the wood or the roots of the hairs.

The hairs of a body-brush (Figs. 55 and 56) should be strong bristles, which are well suited to clean the coat without irritating the skin, and are made of equal length. The shorter the bristles are, the stiffer will they be, the better will they clean the coat, and the more liable will they be to irritate the skin. Hence we may conclude that horses with delicate skins would require brushes with longer bristles than animals with thick skins, supposing that the bristles were of the same kind. These bristles are usually about $3 / 4$ in. long, but one inch would be better for fine skinned horses, for which animals brushes that have been in use for a few months might be reserved; because the bristles get softer in wear, chiefly on account of absorbing oil from the skin. I think it is better to increase the softness of a brush by adding to the length of the bristles, than by using finer bristles.

The brush should be used only in the direction in which the hair lies, and not against it ; because, when it follows the grain, it will more effectually remove the dandruff, which is thrown off by the skin in the form of scales that are pierced by the hairs. The groom should place the brush lightly on the coat, so as to avoid irritating the skin, and should then press on it. He should stand a little away from the horse, so that, while he is making his stroke on the coat with the brush, he may be able to utilise the weight of his body in rendering the pressure effective. After every three or four strokes with the body-brush, he should rub it backwards and forwards once or twice on the curry-comb, so as to clean the brush, and from time to time he should tap the side of the curry-comb on some convenient spot on the ground. In this 
GROOMING TOOLS AND THEIR USES. 329

way, a hard-working groom will leave on the ground a series of small rows of dandruff, the presence of which, at the end of the brushing, will show that he has done his duty in this

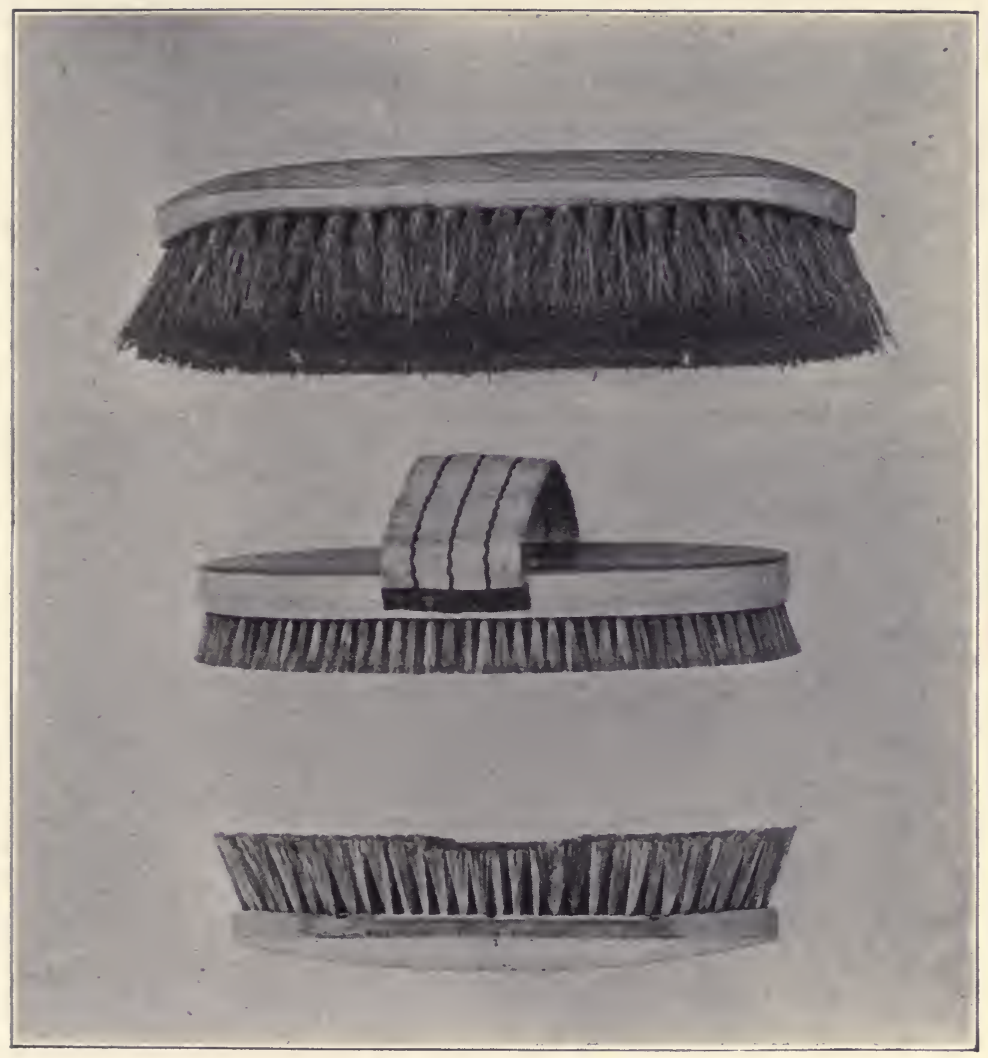

Fig. 56. Dandy-brush.

Body-brush.

Water-brush.

respect. The not uncommon and filthy practice of. blowing the dust out of the curry-comb causes the air of the stable to be more or less filled with particles of floating dandruff. 
Some grooms in their excessive desire to accumulate a large quantity of dandruff for the sake of "eye-ivash," give the curry-comb at least four or five strokes with the brush for every one they bestow on the animal's coat ; in fact, they strap the curry-comb far more than they do the horse. This practice should of course be checked.

The chief object of brushing the coat is to clean it.

Formerly, the fibres of the dandy-brush were often made of whalebone, which now costs too much to be employed for that purpose. A dandy-brush of the present day has stiff whisk fibres, about $13 / 4$ inch long, and is used chiefly to remove mud and other rough dirt, and to save time in grooming horses, especially those with long heavy coats. As it is apt to irritate the skin, and as it possesses no advantage over a body-brush except that of economising labour, it is better suited to common horses than to high-class animals. Cheap dandy-brushes are made of Mexican whisk, and the best ones of French whisk.

A water-brush has the same kind of bristles as a bodybrush, except that they are about $\mathrm{I} / 4$ inch long. It is generally used for straightening the mane, tail and fore-lock, and often for washing the legs and feet. As it is narrower, softer and more pointed than a body-brush, it is admirably suited for the dry brushing of the legs, ears, face and other uneven surfaces. Hence I would advise that a dry water-brush should be kept for this purpose. Water-brushes have generally the bristles in the centres and down the middle shorter than those at the ends in order to facilitate the cleaning of the feet and back of the pasterns. This is a matter of taste. Personally, I prefer the bristles to be of a uniform length.

A hoof-brus/ is a necessary adjunct to the grooming tools, when the pernicious custom of washing horses' feet is not practised; for its use will save brushes that are applied to 
the body, from becoming dirty by contact with the feet. It should have strong bristles, and should be of small size, so as to get into the hollows about the sole and frog. For the sake of convenience, it ought to be provided with a handle, the end of which may be furnished with a hoof-picker.

Each rib of a curry-comb should be made of wrought iron, and for the sake of strength, rivetted to the back. The teeth are generally too sharp, in which case they should be filed down, so that they may not unduly wear out the bristles of the brush. The two front ribs have projecting pieces of iron on each side for knocking out the dust. The cleaning of the body brush is the only portion of the grooming that should be performed with a curry-comb, the teeth of which are of too irritating a nature for application to the skin, except with an amount of care that cannot be expected from an ordinary groom. Although a curry-comb may serve to loosen dirt which has caked on the coat, that work can be done quite as well with a straw wisp, which has the further advantage of stimulating the skin.

Mane-combs are made either of horn or of metal. As horn generally cracks in the course of time, especially in hot and dry weather, mane-combs of that material are liable when they get old, to pull out some of the hairs upon which they are used. Consequently metal mane-combs are safer, and, besides, they are more durable and can be kept cleaner. I fail to see the use of a mane-comb in a well-regulated stable; because it is merely an incentive to a groom to scrimp his work, and to pull out and break the hairs in combing. The dressing of the mane, tail and fore-lock does not consist only in putting the hairs straight, but also includes thoroughly freeing them from dandruff and other dirt, and opening out any knots in them, which is an operation few grooms with an all powerful mane-comb in their hand, would care to spend much time on. It is evident that a mane-comb is of no use 
for cleaning purposes. Experience proves that its action has a very thinning effect on the hair to which it is applied. The dry water-brush or body-brush fulfils every legitimate requirement in cleaning and disentangling the long hairs of the horse, and does not injure them.

A hoof-picker is generally made of iron, and though pointed at one end, it should be rather blunt, so that it may not be liable to hurt the foot when used. Its other end is formed into a ring to enable it to be hung up.

The ordinary burnisher used in stables, consists of a square surface made of small steel rings linked together.

Although an ordinary semi-circular or "half-moon" sweatscraper is more handy to use than a double-handed sweatscraper, it is not nearly so efficient, because it is hard and unyielding to the skin, and its shape cannot be accommodated to that of the surfaces over which it passes. An improved form (Fig. 57), has a piece of india-rubber about a third of an inch thick, placed inside the brass "half-moon," so that either the rubber or the brass can be used on the skin of a horse. The double-handed scraper is very pliable, as it is made of thin copper or brass which can be bent in any way the user desires. Its handles are usually covered with leather.

\section{IVISPING.}

Wisps are generally of two kinds, namely, a straw wisp, which consists of a handful of straw, and a hard hay wisp or hay pad. To these I would add that very useful form of wisp which is made from unprepared hemp.

The straw wisp and the hemp wisp are used for drying the coat and for stimulating the skin, in both of which offices they are far superior to any kind of brush. In this work, a cotton rubber may be used as a wisp. In drying a horse, one or more changes of wisp or rubber will be required. In drying or stimulating the skin, the wisp, whether it be of straw, hemp 


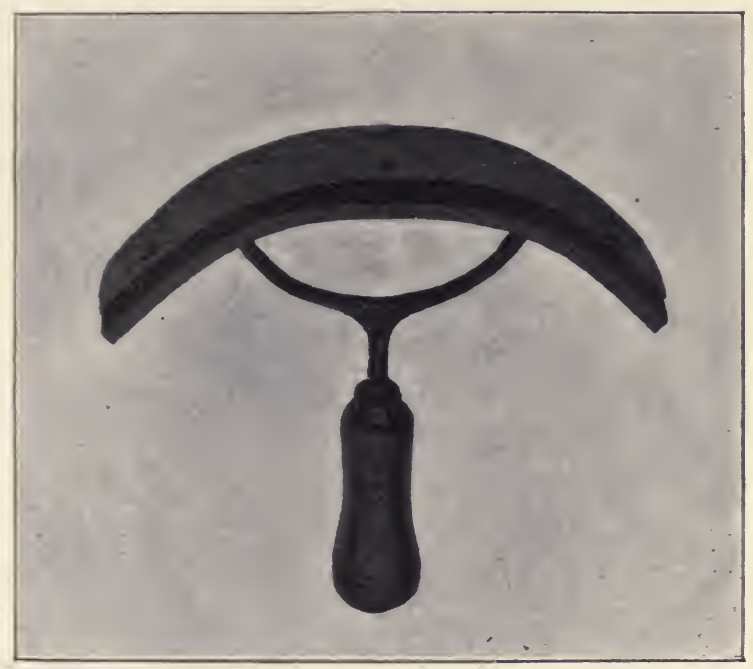

Fig. 57. Half-moon sweat-scraper, with india-rubber band.

or cotton, should be worked backwards and forwards well into the coat, so that full advantage may be obtained from the friction.

The hard hay wisp or hay pad is made by taking a large double handful of hay (Fig. 58), twisting it by one end, while the other is kept fixed between the foot and the ground (Fig. 59), and doubling-in the free end (Fig. 60), so as to form a hard pad (Fig. 6I). This pad is used to "set the coat," after the grooming is finished, by steady pressure applied in the direction in which the hairs lie. It is often used in a slightly damp condition, in order to increase its effect in this respect.

TIME AND HELP REQUIRED FOR GROOMING.

For merely cleaning a horse, one man is enough; but for producing a healthy glow all over the surface of his body, at least two men-one on each side-are required; because one 
man could not possibly do the work with sufficient quickness. To thoroughly strap (groom) a horse, hand-rub his legs, put his clothing straight, and put on his bandages, will take two men at least half an hour; and one man, about double that time. "Quartering" (p. 34I) or lightly grooming a horse will occupy a man from fifteen to twenty minutes.

\section{DETAILS OF GROOMING.}

Let us consider the full grooming of a horse by two men, full grooming by a single-handed man, and finally light grooming or quartering.

If a horse returns hot, and especially wet, from work, and if he is put in a box or stall and is groomed in the ordinary manner, he will run a considerable risk of getting a chill or of "breaking out." A good plan to avert these ill results of bad management, is to loosen the girths, supposing that the animal has been ridden, shift the position of the saddle a little, by moving it a few inches from side to side, so as to relieve any parts that may have suffered from unequal pressure; give the horse half a bucket of cold water to drink; scrape him if he is sweating, and dry him quickly with rubbers, taking care not to neglect the space between the branches of his lower jaw; and walk him about until he is dry, with or without clothing on him, according to the state of the atmosphere, which will also determine the rate at which he should be walked. We may then take him into the stable, remove the bridle, put on a head-stall, give him as much cold water as he chooses to drink, and rack him up, if he is in a box, or put him on the pillar reins, if he is in a stall. If flannel bandages are used with this particular animal, they should be put on the legs loosely, the saddle or harness removed, and the surfaces which previously bore the gear (back or front of the shoulders, as the case may be) examined, so as to find if any swelling has taken place from unequally dis- 


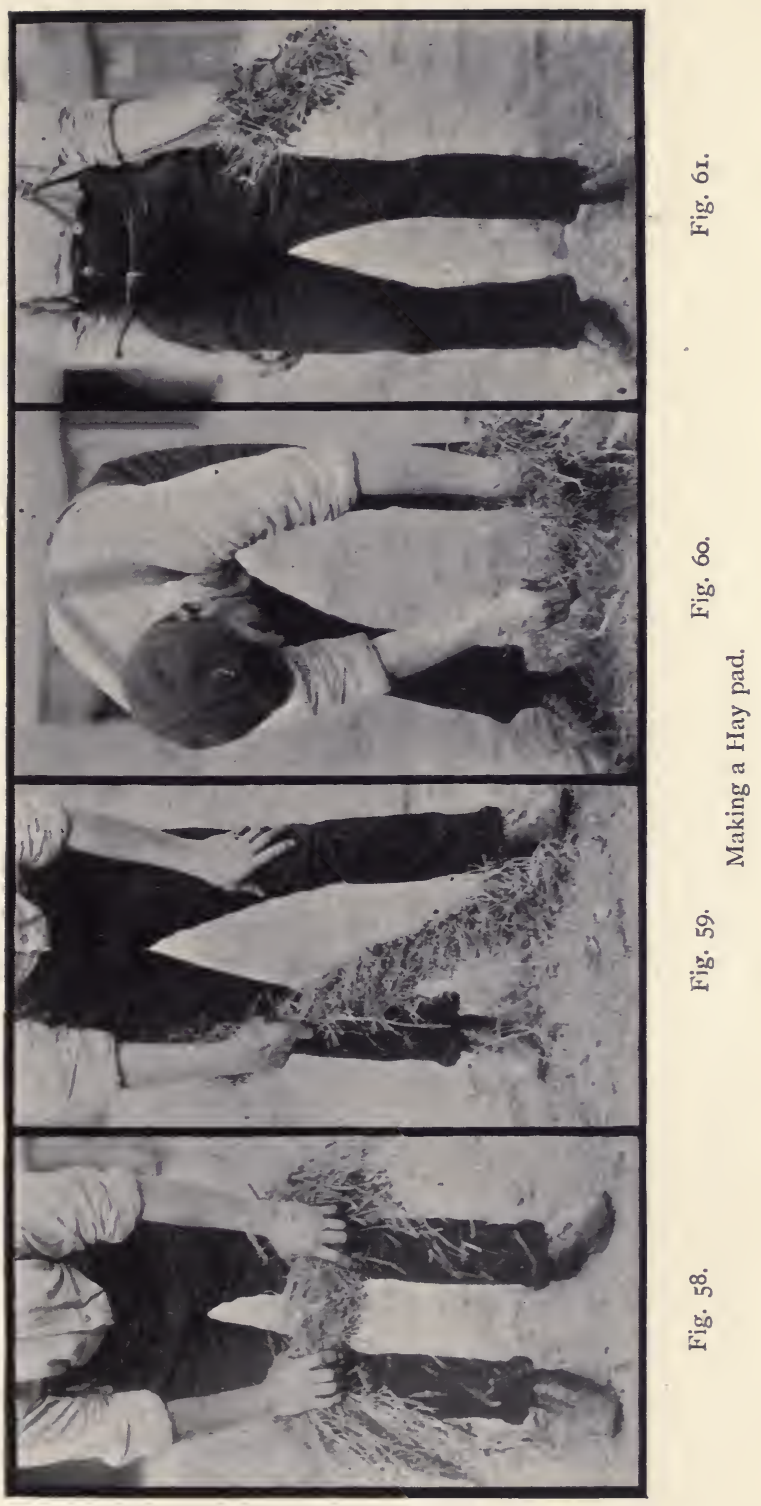


tributed pressure, as is specially liable to occur from the use of a side-saddle. If the skin is not broken, the best way to treat a lump of this kind is to pour into the hollow of the hand a little spirits (whisky or methylated spirits for instance), and rub it into the part with gentle friction, which may be continued for about ten minutes. In any case, the remainder of the back or shoulders should be well stimulated by rubbing with the palms of the hands and a dry rubber for preference. If the skin is broken, as may often result from contact with the girths, Friar's balsam or eucalyptus oil may be applied. In the meantime the groom who is not looking after sore places, should thoroughly go over the coat, from head to hocks, with the wisp, and as soon as the other groom has finished with the bearing surfaces, he should of course join in with his wisp. After the wisping has been completed, the ears should be gently pulled several times between the fingers and palms of the hands ("stripped"), which is a process that always appears. to refresh a horse.

If the beneficial plan of walking a horse which returns heated from work, so as to dry him, is not practicable, he should be taken into the stable, watered, scraped and dried, if necessary; his skin vigorously stimulated by wisping; and the details which have just been described, should be carried out.

If the animal has returned cool from work in clothing, or if he has not left the stable, the hood and breast-piece should be taken off, and the head and neck well wisped. The rug (after unbuckling its breast strap), or quarter-sheet, or both, as the case may be, can be turned back as far as they will go, without undoing the roller, and the breast and shoulders gone over. The roller can now be removed, the remainder of the clothing taken off, and the body and hind quarters wisped. 
If a horse returns wet from work in clothing, as might happen if he had been given a sweat, he should be watered, and the hood, breast-piece and quarter-sheet or rug removed one after another, while the respective parts covered by them should be successively scraped and dried. A single suit of dry clothing may be put on, and the animal walked as before advised. If a walk for drying purposes cannot be given, he should be well wisped. If a horse in clothing comes back only slightly heated from work, he can be walked about, until he is quite cool, before taking him into the stable.

A rider or driver will do well to expedite the grooming, and lessen the chance of the horse getting chilled or "breaking out," by bringing the animal back to the stable cool, which he can generally do by walking him for the last mile or two.

When the wisping has been finished, it is well to give the horse's head, neck, breast, shoulders, body, and legs down to the knees and hocks, a good hand-rubbing.

The horse now being thoroughly dry, a groom on each side (supposing that two men can be spared) should go over the coat with a body-brush. As moisture causes the particles of dandruff to become matted together and to adhere to the skin, no attempt to brush the coat should be made until the horse is dry.

The fore-lock, mane and tail should be cleaned with the body-brush or dry water-brush (p. 330); but not with the dandy-brush, which is apt to pull out the hairs. The groom should begin by brushing these hairs at their ends, and should work upwards as each kink or knot becomes opened out. When the hairs are all separate, they can be brushed, by small locks at a time, from their roots downwards, so as to remove the dandruff. The mane-comb should be used only when it is desired to keep the hair thin, because the hairs get broken and pulled out by it. If the hair of the 
fore-lock, mane or tail does not lie smooth, it may be "laid" by brushing it with a wet water-brush, which should not be done, except for the purpose in question; because wetting the hair takes the gloss off it, and stimulates the production of dandruff.

It is the custom to make the mane lie to the off side; because, as we usually look at a horse from the near side, his neck and shoulders will appear to better advantage than if their lines were broken by the mane. The manes of cavalry horses are made to fall on the near side, with the object of helping the rider to take hold of the mane when mounting. If the mane does not hang down properly, it may be daily wetted, plaited, and small weights attached to its ends; or one of the various kinds of mane-layers may be used. I have found that a thick paste of flour and water plastered over the mane and kept down with a cloth, will make the hair lie flat in a few days. The paste can be washed off before the animal leaves the stable, and it can be re-applied on his return. A plan which is generally successful in removing the irritation which causes a horse to rub his. tail, is to pour on and rub into the part a wineglassful of paraffin (kerosene) oil, and immediately afterwards to do the same thing with a bottle full of water, so as to remove any excess of oil. The oil would in all probability blister the skin, if the greater part of it was not washed off. For convenience sake, we may put the wine-glassful of oil into the bottle, fill with water, shake the bottle, and apply in the manner described. For further information on the treatment of irritation of the tail or crest (portion of the neck upon which the mane grows), see Veterinary Notes for Horse-Ozeners.

The eyes, nostrils, lips and dock should be cleaned, preferably with a damp sponge, each time a horse is groomed. Once or twice a week, the groom should put his hand 
into the sheath of the horse or gelding, gently draw the animal's yard and sponge it clean. Neglect of this necessary precaution is often the cause of a great deal of discomfort to horses which are unable to draw their yard to stale, owing to an accumulation of hard greasy matter (smegma) near the opening of the sheath. The presence of this source of irritation may be discovered by the fact, that instead of the urine being discharged in the usual manner, it escapes by an irregular flow from the sheath.

If there are any stains on the knees, fetlocks, hocks or other parts, as might be caused from contact with the dung or urine while the animal is lying down, they can be removed with a sponge and water-brush. During the performance of this small operation, which as a rule is necessary only with carriage horses, especially those with white markings, as little water as practicable should be used. When these stains are on the legs, it is well to remove them during the early part of the grooming, and then apply woollen bandages over the damp parts, which will soon become dry underneath the flannel.

For purposes of cleanliness and for the groom's convenience, a horse which is in a stall should be taken off the pillar reins and racked up, before his hind quarters are dressed.

The coat may be finished off with a rubber, before applying which, a slightly damped hay pad is sometimes used to set the coat. The clothing is put on, care being taken to throw the quarter-sheet or rug a little way in front of the withers, and then draw it back, so that the coat may not be ruffled.

The feet can be picked out, and, if necessary, cleaned with a dry water-brush, or hoof-brush. If flannel bandages have been put on, they should be removed, the legs handrubbed, and fresh and dry bandages applied.

Trainers often teach their lads to make on the horses' 
quarters, when the brushing is finished, quarter-marks, of which the most common is the "diamond." This mark is made by brushing the quarter with the body-brush, from front to rear in the direction the hair lies; then drawing a stroke with the brush down the centre of the quarter in a perpendicular direction, so as to ruffle the hair; and finally smoothening with the brush the upper and lower portion of the quarter, so as to leave a "diamond," or rather a rhombus with sides about 4 inches long. The rough hair of the quarter-mark will naturally enhance by contrast the brilliancy of the remainder of the coat of that part. The pattern can be varied at pleasure. Some trainers affect particular kinds of quarter-marks, and others pay no attention to such fancy work.

Supposing that there is only one man to strap a horse which has returned hot from work, he should water the animal, and if possible walk him about until he is quite cool. If this exercise cannot be given, the man should slacken the girths, shift the saddle a little, and leave it on for about half an hour, while he proceeds with the grooming of the other parts. After taking off the saddle, he can examine and dress the back in the manner already described. The reason for keeping on the saddle for the time specified, is that it is difficult for one man to dress the back and the remainder of the body with sufficient quickness to avoid chill, and that his labour in this respect can be considerably lightened by the horse's back being allowed to cool down safely, which it will do if the saddle is kept on. When a horse has carried a rider for a long time, especially over a country, the pressure transmitted by the saddle to the back, will have caused a certain amount of anæmia (bloodlessness) in the bearing surfaces of the back. If these surfaces be exposed to the comparatively cold air of the atmosphere by the removal of the saddle, the anæmia will become aggravated, and a sore 
back may be the disastrous consequence. In such a case, the best preventive treatment is obviously stimulation by friction, the effect of which will be much increased by the use of a little spirits, as we have seen. Or we may maintain the heat of the part by allowing the saddle to remain on, in which case the blood vessels will have every facility to rectify the disturbance which has occurred in the circulation. We should here note that cold causes contraction of the walls of the blood vessels, and that heat has the opposite effect. The swelling which is caused by pressure, is due to the fact that the walls of the veins are more compressible than those of the arteries. Hence, when a part is subjected to pressure, more blood is carried to it by the arteries than the veins can remove, and consequently there is an accumulation of fluid, which is made manifest by a swelling. After the rider has dismounted, the bearing surfaces of the back can be further relieved of pressure by slackening the girths, which should accordingly be done without delay.

Quartering is an abbreviated form of grooming, in which the roller is not undone, and the body-brush is not used. When the quarter-sheet or rug is turned back on the roller, the head, neck, mane, breast and fore legs are lightly brushed over with the dandy-brush; the eyes, nostrils and dock sponged out; stains removed, and wet parts dried. The horse, if in a stall, is then taken off the pillar reins and put on the rack chain; the rear end of the rug or quartersheet turned towards the roller; the hind quarters and hind legs lightly brushed with the dandy-brush, and the clothing straightened. In many stables, this constitutes all the grooming that is done, when horses are not wanted for work.

I hope I have said sufficient to indicate the principles that should regulate the economical grooming of working horses, for which the use of the body brush will have to be largely or 
entirely replaced by that of the dandy brush. In these cases, the merits of a straw wisp, or, better still, one of unprepared hemp, should be borne in mind. The washing of horses on which little labour can be expended, is particularly objectionable, on account of the impossibility of thoroughly drying them. Of course these remarks do not apply to valuable cart horses (Shires, Clydesdales and Suffolks, for instance), many of whom are groomed with great care.

\section{CARE OF LEGS AND FEET.}

The alleviation of "filled legs," is one of the most common problems given to grooms to solve. This condition is a chronic ailment which is brought on by stagnation of blood in the limbs from want of sufficiently continued exercise, and from food of too "heating" a nature. It occurs in both fore, both hind, or in all four legs; and presents no acute symptoms, as would be present in sprain, which nearly always takes place, only in one limb at a time. As the hind limbs are farther from the centre of circulation than the fore, they are more liable to become filled than the front pair. This passive tendency of the legs to fill comes on, as a rule, very insidiously. At first it is a temporary sign of confinement to the stable, and quickly passes off during exercise; but in the large majority of cases, it becomes increasingly difficult to dissipate, and impairs more and more the working capacity of the animal. As the defective state of the circulation, of which "filled legs" are a symptom, interferes with the due nutrition of tendons and ligaments, its manifestation by "filling" is usually "the beginning of the end," which is generally attained by means of a sprain or series of sprains. The only proper treatment is removal of the cause, which we can best effect by cotton wadding bandaging (p. 306) and attention to feeding and watering. Suppose we have a 
hunter which is accustomed, after a day with the hounds, to return to his stable with his legs apparently sound, but has them next morning as round as the proverbial bed-posts. Instead of waiting until his legs have filled, before treating them, we should employ the thoroughly sound preventive measure of applying cotton wadding bandages immediately after he comes back from work. If we do this, we may be fairly confident that his legs will be as fine on the following morning, as they were on the previous evening. The efficacy of this new departure which I have introduced into stable practice, has been amply proved by many who have followed my lead, as well as by myself.

With a horse whose legs fill, we should keep the cotton wadding bandages on in the stable, and take them off only a short time before he goes out, and then hand-rub the legs thoroughly. They should be again hand-rubbed and bandaged on his return. This method of bandaging is also an admirable means for reducing the inflammation caused by blows and sprains, in which case it should be a "first aid to the wounded," before calling in a veterinary surgeon.

The groom should be careful to report any change in the size or temperature of the legs and feet, especially after a hard day, or after shoeing, in the event of one foot being hotter than the others. In such cases, he should not wait until the animal is lame; for an ailment of this kind which admits of successful treatment, if taken in time, will often be the cause of permanent unsoundness if neglected. The effects of slight pricks in shoeing and of nails driven too "close," often do not show themselves until a few. days after the animal has been shod, during which time, fluid (pus and serum) due to inflammation, accumulates in the injured part, and finally gives rise to so much painful pressure that lameness is the result. The spread of the inflammation enables the abnormal heat to be felt from the outside.... Slight cuts 
from brushing can he treated by an antiseptic, such as Friar's balsam.

The shoes should be tested every day to see if they are loose. This is best done by holding the foot up with one hand, so as to have the foot more or less horizontal, and then tapping the ground-surface of the shoe all over with the tips of the fingers of the other hand. By this method, even the slightest play which the shoe may have, will be made apparent by the difference in the sound caused by the tapping. We should here note that the looseness in question almost always arises from the giving way, to a greater or less extent, of the clenches of the nails. Persons who endeavour to find out if a shoe is loose, by catching it between their fingers and trying to shift it from side to side, appear to be ignorant of the fact that the displacement is almost always in a vertical, and not in a horizontal direction. In any case, the plan of trying to shift the shoe with the fingers, would succeed only when the looseness was extreme. If a shoe is found to be loose, or any of the clenches started, the animal should be sent to the blacksmith before he is put to work. The groom should also be careful to see that the heels (generally the inner heels) of the fore shoes do not press on the "seat of corn." This faulty bearing of the shoe is particularly liable to occur, when the fore shoes are light and short, as would usually be the case with hunters. The groom should see that the inner edges of the toes of the hind shoes have not become sharp from wear, in which case the injury from an over-reach would be greatly aggravated.

The feet should be picked out at least three times a day, especially if the bedding is of tan, peat moss or sawdust; because neglect of this precaution will be liable to induce thrush and softening of the sole and frog, with consequent impairment of the strength of these parts. The effect of 
bedding on horses' feet has been discussed on page 264 . The presence of thrush can be easily recognised by the foul smell from the frog, and by the open condition of the cleft of the frog, which in health is merely a depression in the middle line of the frog, and does not communicate with the sensitive structures of the foot. Burnt alum is a safe and useful application for thrush. About a teaspoonful of it may be stuffed into the cleft of the frog, which can afterwards be filled up with cotton-wool or tow, in order to keep it clean. It is an instructive fact that the drier the soil upon which horses are reared and kept, the better are their feet. The effect of moisture on horn is to make it soft and weak. Hence we find, that although horses can be moderately worked on unmetalled roads in India and other hot countries during the dry weather, they have to be shod as soon as the rains begin. Horses' feet to be serviceable, should be hard. A horse with good hard feet would be able to trot without flinching, on a road covered with freshly broken stones; he would not go lame if he picked up, even in a fore shoe, a stone which did not project below the level of the shoe; and if he lost a shoe, he would be able to go barefoot for a few miles without becoming foot-sore. It is evident that such an animal will be a much safer conveyance, either in saddle or harness, than a horse which is in any way tender on his feet. We should therefore refrain from having our horses' feet washed. For purposes of cleanliness, the hoof-picker and a dry brush will be sufficient for the frog and sole, and a damp rubber for the outside of the hoof. The argument might be advanced, that it is unreasonable to object to a moderate washing of the feet and legs in the stable; because, during an ordinary day's work, these parts are often kept wet for hours without any harm being done to them. To this I would reply, that the water encountered outside is a necessary evil, the ill effects of which are obviated to a great 
extent by the exercise taken during the time of its action; because the increased blood supply not only warms the skin of the legs and thus helps it to drive off adhering moisture, but it also stimulates evaporation of moisture from the hoof, and especially from the frog. Besides weakening the horn, washing the legs and feet has a strong predisposing influence in producing cracked heels, mud fever, and thrush.

Greasing and stopping the feet.-Although an impermeable covering, like varnish, might do harm to the wall of the hoof by preventing transpiration, I see no objection to the application of hoof ointment or other greasy matter (neats' foot oil, or lanoline, for instance) to that surface, for the sake of appearance. Grease has a good influence on the growth of human hair, although it is unfashionable for toilette purposes; and hair and horn are merely varieties of the same substance (epithelium). Whatever may be the stuff which is put on the hoof, as much of it as practicable should be removed by rubbing, so that it may not soil the hands, if the foot is picked up, and that dirt may not adhere to it. The fact that a horse, after a day's hunting, sometimes returns to his stable with his feet full of clay picked up from the ground over which he had been galloping, might be used as an argument that it is natural for a horse to have his feet stopped with clay. The answer is, that unshod feet do not retain clay in this manner, and that clay is only one of many soils. A blacksmith would naturally like to have a horse's feet stopped with any appropriate filth the night before shoeing him, so that he could reduce the horn with the least possible trouble. Injuring a horse's feet to oblige a blacksmith is a form of politeness I need not discuss.

The only legitimate kind of stopping for the feet appears to be that which is intended to prevent balling of the shoes from snow, for which purpose grease is generally employed. 
Mr. McGavin, M.R.C.V.S., writing on this subject in the Veterinary Record, says: "The best preventive I have found is gutta-percha. After the feet are cleansed with a picker and thoroughly dried, put the gutta-percha (as much as will fill the sole up level with the horse's shoe) into a pan of boiling water for two minutes, or until it is thoroughly softened. Lift it out with a spatula, turning it round for a minute or so till it is dry, place in the sole immediately, dipping your hand in cold water, and squeeze the guttapercha well into the sole before it cools. Hold the foot up for a few minutes; afterwards dip it in cold water, when it will harden in a short time and be fit for the road." However well such a stopping might perform its own particular work, its continued retention would, by checking evaporation from the sole and frog, soon heat the feet so much, that serious injury might be caused. Besides, the fact of gutta-percha being a bad conductor of heat would make its long retention in the feet all the more dangerous.

As the growth of the wall of the hoof can be hastened or strengthened only by stimulating the coronet, which secretes it, no hoof ointment, used as such, can effect either of these two ends.

\section{PROTECTION AGAINST FLIES.}

From June to October, and particularly in August, gadflies or breeze-flies (CEstridæ), seek to lay their eggs on convenient parts of horses during the hottest hours of the day. The female flies of the kind that is most common in England, lay their light orange-coloured eggs, which are about the $\frac{1}{20}$ th of an inch in diameter, chiefly on the breast, front of the fore-arms, and those parts of the shoulders and sides that are in reach of the horse's tongue. They adhere to the hairs by means of a sticky substance which the fly ejects along with them. The eggs on becoming hatched in about 
three weeks (Joly), produce small worms, which irritate the skin by their movements, and thus prompt the horse to lick them off and take them into his mouth, with the result that they gain access to various parts of the alimentary canal, to the walls of which they attach themselves, and are then called bots. During the months bot flies are laying, grooms should be careful to examine their horses after the animals come in, and pick off and destroy all the eggs which they can find.

We may temporarily protect a horse from the attacks of flies by lightly sponging him over with a mixture of I part paraffin oil to Io parts of milk, well shaken up. A better emulsion can be made with similar proportions of this oil and water, and adding a little gum tragacanth. GobbelsCopette (Nos Animaux Domestiques) states that in Canada a mixture of paraffin oil prepared as follows, is used with much success for spraying animals twice a week, in order to protect them from flies: Dissolve $2 \mathrm{oz}$. of yellow soap in a pint of boiling water; add a quart of paraffin; briskly stir up the mixture until it forms a creamy emulsion; and use for spraying purposes, I part of the mixture to 9 parts of water. The Count St. Marsault (Journal d'Agriculture pratique) recommends an ointment (to be applied to the body by means of a rag) made by boiling for five minutes a large handful of laurel leaves in two pounds of lard. A decoction of walnut leaves is said to have a good effect for the purpose in question.

In many hot countries, flies annoy horses so much that special precautions have to be taken against their entrance into stables, which they as a rule invade only during the hot hours of the day. They may be kept out by placing a net across the stable door and windows-which we may suppose are left open for purposes of coolness-provided that light is not let through from the other side. Flies appear to experience no fear in passing through the meshes of a net which is held up 
to the light. Failing a net, screens of various kinds can be used. Dirt in a stable has a great attraction for flies. The smoke of burning dried cow-dung or burning dried horse-dung is often employed in India for driving flies away from horses. The use of peat moss appears to have a good effect in preventing flies from entering stables. I do not know whether this effect is due to the smell of this litter, or to its dark colour.

\section{TESTING THE EFFICIENCY OF THE GROOMING.}

A good plan of finding out if a horse's coat is clean, is to go up to the side of the neck upon which the mane falls, and after turning the mane over to the other side, to examine its roots to see if there is any dandruff present. If the horse stands this test, the roots of the hairs of the tail may be inspected with a similar object. Finally, the point of a fore-finger may be run over the croup and ribs against the grain of the hair. The line or lines thus drawn will leave a streak of dandruff. It is no uncommon occurrence to find in a badly groomed horse, that although the upper surface of the mane and tail may have been neatly brushed down with a wet water-brush, the hairs underneath are full of dandruff. Any roughness at the back of the pasterns, to say nothing of cracked heels or grease, will show that the grooming has been faulty; and the presence of thrush will have to be put down to the debit side of the groom, unless the shoeing smith has allowed the heels to grow much too long, in which case, both men will probably be to blame. A want of gloss on the coat, marks left on the legs by the strings of bandages, and an irregular condition of the mane or tail, will be presumptive evidence that the groom is either lazy or incapable. 


\section{CHAPTER XII. \\ CLIPPING, SINGEING, AND TRIMMING.}

Shortening the Coat-Trimming and Banging.

SHORTENING THE COAT.

IT is evident that the protective power possessed by the coat of a horse is proportionate to its interference with his capacity for work. In fact, a saddle or harness horse with a long coat is like unto a man who wears a warm suit of clothes which he is unable to take off when he engages in physical exercise. This disadvantageous condition in the case of a horse, can, as we all know, be obviated by shortening the coat and supplying him with adequate clothing to be worn when he is not in work. He will then be in the good position of an athlete who can fortify himself against cold by putting on clothes, or prepare himself for work by taking them off; and, besides, his grooming will require much less labour than if his coat was long. When a horse is neither groomed nor housed, he will of course need the natural protection which his coat affords him. The artificial shortening of the coat not only improves the working capacity of long-coated horses, but it also acts beneficially on their general health when they are kept in warm stables. In such cases, it is more reasonable to blame the unsanitary state of the stable, than to praise the good effect of the reduction of the hair. We may conclude that shortening the coat is an advantage with all long-coated horses. 
which are required to be in high working efficiency, or which are kept in warm stables. In these circumstances, the warmer the climate or season, the greater is the benefit obtained from shortening the coat. If clothing cannot be provided in cold weather, as might be the case on some poor farms, the coat should not be removed.

The wearing of a heavy coat by a horse which is doing severe work, distresses him out of all proportion to the amount of "dead weight" he carries; because the moistureretaining power of the coat is so great, that when the animal sweats, evaporation will go on slowly, and consequently, as long as the labour continues, the lungs will fail to obtain adequate relief from the action of the skin, and the amount of evaporation will be insufficient to keep down the internal temperature to a healthy limit. Hence, fatigue thus induced, will be accompanied by more or less feverishness and will be of a more distressing nature, than if the coat was short. It is instructive to note, that the amount of perspiration on the surface of the body is not a correct measure of the amount of evaporation that is taking place, as we see in cases of men respectively exposed to dry heat and moist heat (p. I7). We may therefore reasonably assume that the fact of a thick equine coat being wet with sweat, is no proof that evaporation of perspiration is proceeding more rapidly from it, than from the thin coat of another horse which has scarcely "turned a hair.". I have seen some good instances of extraordinary " reversal of form" in racehorses caused by clipping.

The only objection I see to clipping as a means of shortening the coat, is that it leaves the ends of the hair in a truncated, instead of a finely pointed condition, and that it diminishes the pliability of the hairs. Consequently, skin which is covered by short-cut hair is, as most persons know in their own cases, far more liable to become irritated by 


\section{CLIPPING, SINGEING, AND TRIMMING.}

friction or contact, than if the hair had been left in its natural state, or even moderately long. This fact has often been impressed upon me, when, for purposes of coolness, in tropical climates, I have had the hair of my head cut as close as possible with a barber's machine. On such occasions, I always found that if a fly alighted on my head and walked over the short hairs, it caused great irritation; although such an occurrence would probably have been unnoticed by me, if my hair had been at its usual length. The frequent friction which the hair of the legs and especially of the pasterns endures from objects which it meets when a horse is at work, is no doubt sufficient in many cases to bring on cracked heels and mud fever. Hence the reasonableness of abstaining from running the clipping machine over the legs and that portion of the back on which the saddle rests. Also, the ends of the clipped hairs, owing to their blunt shape and want of pliability, cannot lie in such close contact with each other as unclipped ones would do; and they accordingly "stare," more or less, and cause the coat to be penetrated comparatively easily by water, dust and other foreign bodies. From the nature of its action, singeing is less open to the objections in question than clipping. The best means for reducing the weight of the coat is evidently hand-rubbing (p. 326), which may not always be sufficient for the purpose in view, especially when the coat is heavy and strong, and the groom over-worked or lazy. Even when a coat which has been subjected to a course of good hand-rubbing, appears somewhat longer than if it had been clipped, we must not take for granted that the reduction of weight has been less; because hand-rubbing acts more by thinning the coat, than by reducing its length. Even in a moderately cold climate like that of England, daily good hand-rubbing of the body, which entails more labour than could be spared in ordinary stables, would be sufficient for reducing the coats 
of the majority of well-bred horses; and those of the remainder could be kept short by the occasional help of a singeing lamp. Although clipping is an inferior means of reducing the coat to that $I$ have just mentioned, it is the best one for horses kept in stables which are short of help. If the groom can singe well, I think it will be better for him to keep down the length of the coat by means of the lamp, used, say, every ten days, than by clipping. Keeping the coat thin by means of hot stables and an excess of warm clothing, should not be allowed; because both these means injuriously affect the health of the animal. Whatever way a horse's coat is kept short or thin, his rider or driver should take precautions against his catching a chill, when he is outside during cold weather, by keeping him moving, or by throwing a rug over him, as the case may demand.

As regards expedition, the power clipping machine, of which there are many good varieties in the market, is as superior to the hand machine, as the hand machine is to the old scissors and comb. As far as the health of a horse is concerned, it is an advantage, as I have indicated, not to clip below the knees and hocks, and not to clip that part of the back upon which the saddle rests. In this omission, in order to be consistent, I ought to include that part of the chest over which the girths pass ; but the advantage thus obtained, would perhaps be more than counterbalanced by the uncouth appearance which the resulting band of hair would give the animal. As the hair which is inside the ears, guards these organs from injury by the entrance of foreign bodies; it should not be removed, beyond, perhaps, placing the edges of each ear together, and then cutting off the hair which projects outside the opening of the ear. If it is imperative to clip the legs, and one of them happens to be somewhat more "gummy" than the other, we may adopt the old coping plan of using a thicker comb ( $($ a bone one for instance) when going over the 
sound back tendons and suspensory ligament with the scissors, than when shortening the hair on the infirm leg, so as to give a nearly similar appearance, as regards size, to both legs.

In the clipping of the legs, we should remember that the tuft of hair which falls from the back of the fetlock, acts as a protection to the back of the pasterns, which is a part very liable to suffer from the bad effects of irritation and chill, especially when its natural guard has been removed.

If appearances have to be studied, we may delay the autumn clipping until the coat has attained its full length, say, about the beginning of November. The presence of particularly long hairs ("cat hairs") interspersed through the coat, will indicate the completion of the growth. A premature exposure of the skin will spoil the look of the subsequent coat. The animal will probably require a second clipping before the end of the year.

For singeing, a gas lamp is generally preferred to a mineral oil one ; because its flame can be regulated with greater precision. It has the draw-back of its heat being more intense, and consequently it is more liable to burn the horse than an oil lamp. The heat from the flame of methylated spirits is more feeble than that from burning paraffin oil. The long hair about the lower jaw of a horse may be singed off by means of a lighted candle or taper, such as is used by barbers for singeing.

\section{TRIMMING AND BANGING.}

The hair of the fore-lock, mane and tail is useful to a horse, chiefly as a defence against the attacks of flies. The assistance which the mane gives when mounting, especially if the animal be tall and fidgetty, or when a mishap occurs over an obstacle, should be appreciated by every horseman. A properly developed fore-lock will act as an efficient eye-fringe ; a sufficiently long mane, when thrown from side to side by a 
shake of the head and neck, will guard this part from flies; and an unmutilated tail will drive off these intruders, whose attacks on the genital organs and on the thin skin between the hind legs, have an exceedingly irritating effect. The sides of the abdomen, chest and shoulders, which are not within the protective reach of the tail, are covered by a broad muscle (panniculus carnosus), which, by contracting, has the power of twitching the skin, so as to drive off flies or other small irritating objects that may have alighted on it. This muscle is practically absent in man, but is largely developed in the cat. Although the breast is not provided with a natural fly whisk or superficial twitching muscle, it is within reach of the animal's mouth, which consequently protects it from the invasion of flies. The fact of horses being naturally provided with an efficient system of protection against flies, shows that such protection is needed by these animals, and that it is cruel to deprive them of it.

Unfortunately for horses, the cleaning of horse-hair is a trouble to grooms, who in almost all non-racing establishments are autocrats in the stable. Hence, the vast majority of even hunters have manes that are no use to the horses or to anyone else, and tails that have not much more hair on them, than is to be found on a worn-out scrubbing brush. Luckily for racehorses, the allowance of hair on their tails is fairly effective against flies; considering that they, contrary to the frequent practice with hunters, are not often turned out during the summer.

The mane may be trimmed by pulling out the longest hairs, a few at a time, after having twisted them round a fore-finger or stick. If this annoys the horse, the long hairs may be divided by running a half-shut scissors backwards and forwards across them, in the same manner as hair-dressers trim ladies' hair. The ends are held in the left hand, while the right uses the scissors. 


\section{CLIPPING, SINGEING, AND TRIMMING.}

A space of about an inch and a half broad should be cut out of the mane, just behind the ears, for the crown-piece of the bridle.

When hogging the mane of a pony, it is customary, in order to help the rider in mounting, to leave a lock of hair, which to be effective should be about half-way up the neck. The easiest and neatest way to hog the mane, is to cut it close, running the clipping machine along the top of the crest, and then on each side, so as to make the hair level. The old plan of hogging the mane, so as to leave a bristling ridge of hair, is tedious in execution and has a bad effect, in that, instead of preserving the natural outline of the neck, it gives the part an abnormally thick and high-crested appearance.

A switch tail may be trimmed in the same way as the mane.

The tails of thoroughbreds, which are very rarely docked, are generally banged at such a length that when the tail is pulled down, the ends of its hairs will reach to the point of the hock, or two or three inches higher. "The tails of officers' chargers, troop and detachment horses, are to be cut to such a length as to reach from 6 to 8 inches above the hock. The tails of draught horses will be cut to reach from 8 to IO inches above the hock" (Queen's Regulations).

It is not the custom to dock or bang the tails of Arabs; a fine, thin tail being considered to be one of the marks of high caste among them. The supposed object of banging a horse's tail, is to add to the appearance of strength in his hind quarters.

The following methods may be used for banging the tail:

I. Get an assistant to place his hand under the dock, and to hold the tail in a position similar to that which it would assume when the animal is walking; then cut the hair level at the desired length with a specially made pair of shears, or with a strong pair of scissors. 
2. Bind the tail round with a piece of cord, about six inches above the point at which it is to be divided. Then, with a sharp knife, cut the hair so as to give its ends the required slope.

3. Lay the tail at the desired length, across the edge of a broad adze, and divide the hair by a smart blow with a flat billet of wood. The adze should be held steady, the handle to the rear, the edge horizontal, and the blade sloped, so that the horse may carry his tail level at a walk. Any loose hairs may then be trimmed with a scissors. This is an admirable plan for troopers, with which despatch and uniformity are matters of consideration. For use with a large number of horses, a blade resembling that of an adze, but broader, may be let into a block of wood 4 or 5 lbs. in weight.

The coarse bristles (tentacula or feelers) which are about the muzzle of a horse, proceed from roots that are largely supplied with nerves, and consequently these hairs can act as delicate organs of touch. As a horse is not provided with hands or paws, he is dependent chiefly on his muzzle for purposes of feeling, a fact which is proved by the presence of these bristles on it, and by the great mobility of his upper lip. The bristles on the muzzle no doubt materially aid a horse in the selection and gathering of food. Also, the feelers about his eyes would help to save his eyes from blows when he is moving about in the dark. As all these bristles conduce to his well-being, they should be retained, despite their being regarded by some persons as an eye-sore. Like the hairs of the coat they gradually thin out towards their ends. Consequently, their action as organs of touch would be interfered with by cutting them, which operation would also lessen their pliability. We may therefore conclude, that if the bristles round a horse's muzzle be cut, he will suffer from discomfort, if not pain, when he attempts to feed, or when he is handled about the mouth, as for instance, in bridling him. Besides, clipping them gives a 


\section{CLIPPING, SINGEING, AND TRIMMING.}

horse the disfiguring appearance of being badly in want of a shave. Although there can be no great objection, once in a way, to pulling out one or two of these bristles which may be longer than the others, the frequent practice of thus removing them should not be allowed; because it not only deprives the animal of a useful means of touch, but it also inflicts such severe pain on him, owing to the high sensibility of their roots, that the recollection of the sharp twinges will in all probability make the horse more or less difficult to handle about the muzzle. 


\section{CHAPTER XIII.}

\section{CLEANING GEAR, CARRIAGES, ETC.}

Component Parts of Gear-Brown Leather-Black Leather-Patent Leather and Enamelled Leather-Serge and Linen covered Panels-Steel, Iron and Alloys of Nickel-Brass-Silver and Plated Work-Pipe-claying-Cotton Clothing and Woollen Clothing-Carriages-Blacking Boots-Tops-Leather Breeches -Saddles covered with Buckskin or Rough Leather-Silk Hats-Sponges.

\section{COMPONENT PARTS OF GEAR.}

FOR purposes of cleaning we may divide saddle, harness, and stable gear into brown leather, black leather, patent leather, enamelled leather, serge and linen covered panels, steel, iron, alloys of nickel, brass, silver, plated articles, pipe-clayed leather and cotton, cotton clothing, and woollen clothing. After use, saddlery and harness should be taken to pieces and cleaned according to the nature of their respective parts, or merely gone over with a rubber or brush as may be required.

\section{BROIVN LEATHER.}

The presence of oil or fat in leather is necessary to keep it pliable; for if it is used when it is in a dry state, it will be apt to crack and consequently to become spoiled. When leather was a living substance in the form of skin, its pliability was preserved by the oil that was secreted by the oil glands, which are distributed throughout the skin in countless numbers. Leather therefore has not only to be kept clean, but it must also be kept soft by some oily matter.

Linseed oil and colza oil (rape oil), which are called 
"drying oils," should not be used for lubricating leather; because they become hard and resinous, by absorbing oxygen from the air, and on this account they are employed in paints. An oxidised drying oil is a varnish. Castor oil, olive oil (sweet oil or salad oil), and animal fats and oils do not become dry, and consequently they may be used for softening leather; although their application will have to be renewed from time to time, because the air turns them rancid. It goes almost without saying, that before such renewal is made, the decomposed remains of the previous application should be removed, for instance by soap and water. Cold drawn castor oil and cold-drawn olive oil are much less liable to become decomposed under the action of the atmosphere than when these oils have been obtained by the aid of heat. Vaseline does not dry and does not become decomposed on exposure to air, and is therefore an excellent means for keeping pliable leather which has to be stored for a considerable time. In ordinary cases, soap (p. 48) is sufficient both for cleaning and for lubrication. The soap which has been left on the leather to soften it, will serve on the following occasion to clean it during its more or less complete removal.

If the leather work of a saddle and riding bridle appears clean and pliable without any suspicion of dryness, it need only be wiped over with a rubber to ensure the removal of dust which might not be visible without close inspection. If the leather bears signs of use, such as marks of sweat or mud, the groom should clean the leather with a slightly damp sponge which he has dipped into water (cold or warm), and from which he has squeezed out all the superfluous moisture. He may then give it a thin coating of soap. If he employs soft soap or saddle soap, he should again damp his sponge, which had best be of small size, squeeze'it fairly dry as before; put some of the soap on it (say, $\mathrm{I} / 4 \mathrm{Oz}$.) ; squeeze the sponge in the hand a few times in order to distribute the soap throughout its 
substance, and rub the leather with it. In the case of white or yellow soap, he may rub the damp sponge or damp flannel rag on a piece of soap, so as to raise a lather, and then proceed as already described. After the leather has received a light coating of soap, it should be allowed to dry, which it will do in a quarter of an hour or so, according to the state of the atmosphere. The leather should then be rubbed briskly over with a soft rubber, to cause the oily matter which has dried on the surface to penetrate into it, and to give it more or less of a polish, the amount of which will vary according to the nature of the soap employed, and the amount of "elbow grease" applied.

For saddles and riding bridles, especially if they are new, I prefer yellow soap to soft soap or saddle soap; because it does not darken leather like soft soap (p. 49), and does not make it sticky and dirty to handle like saddle soap. Soft soap is superior to ordinary hard soap for softening leather, on account of the presence of glycerine (p. 49). We may, however, equalise matters, when using hard soap, by supplementing it with a little glycerine, neat's-foot oil, or vaseline, or by employing glycerine soap. For the cleansing of a good new saddle, the owner ought not to grudge the slight extra cost of a soap which contains practically no free alkali. 'Grooms as a rule prefer soft soap to yellow soap; because it is easier to apply, and if it eventually spoils the appearance of the leather, the cost of replacement will fall upon the master, not on them. They naturally favour the use of saddle soap, because it produces a brilliant polish with but little trouble, owing to the beeswax in it. We should here bear in mind that if a saddle is really clean, it will show its stitches clearly; will not soil a clean white pocket-handkerchief that is rubbed on its leather work; and will leave no trace behind, if a finger tip be drawn across its surface. When $I$ was a subaltern in 
a field battery of Artillery, we frequently used these tests at saddle and harness inspections. Although our drivers had no saddle soap, they knew how to deceive inexperienced eyes with a little bees-wax applied by means of a flannel rag. The polish produced by bees-wax, besides dirtying those parts of the rider's clothes which happen to rub against it, is removed by such contact; and consequently a saddle which issued from the stable with this gloss on it, would, owing to its "patchy" appearance, look far worse when the rider dismounts, than if it had been cleaned with white, yellow, or soft soap. If a saddle is not going to be used for a considerable time, the polish in question will no doubt help to preserve the leather from the injurious action of damp, and looks well in the saddle room. I see no objection (rather the reverse) to the use of saddle soap on the leather work of brown harness, except, of course, on those parts of the reins which come in contact with the driver's hands. Also, when the leather of saddles and bridles has become more or less black from the use of soft soap, it is not worth while changing the soft soap for yellow soap.

It is evident that the object of wiping the leather with a damp sponge in the first instance, is to remove dirt, and that the application of the soap is to soften the leather. Instead of soap we might employ vaseline, neat's-foot oil, castor oil, or mutton kidney fat by means of a flannel rag, through the texture of which the lubricant should be well distributed before the flannel is applied to the leather, so that the coating may be even. While fulfilling its softening duty, the greasy material should not be employed for ordinary purposes in such a quantity as to soil the hands or clothes. Hence, after rubbing it well in, so as to make it penetrate the surface as deeply as possible, any of it that may remain should be removed during the polishing process. Before applying the fatty 
matter, especially when the leather is dry, it is advisable to damp the leather; because, when it is in that state, it will absorb the oil or grease much more readily than when it is dry.

The brown leather which lines harness collars, covers the panels of saddles and pads, and serves as saddle cloths, should be sponged over after use, and a little greasy material well rubbed into it to keep it soft. For this purpose, suitable oil or fat (see preceding paragraph) will answer better than any kind of soap; because this leather requires no polish, although no excess of grease should be left on its surface.

\section{BLACK LEATHER.}

As soon as possible after work, black leather should be seen to, and all dirt removed by means of a damp sponge. After the leather has become dry, we may apply a thin coating of black harness composition with a hard brush, polish with a soft brush, and finish off with a soft dry rubber. Harness composition, of which there are a great number of varieties in the market, resembles boot blacking, except that it is of a greasy nature and more or less waterproof. For its application, a double brush-one end soft, the other hard-is often employed, although two separate brushes will be more convenient to use. When a polish is not required, as in rough work, "black oil," which can be obtained from any saddler, is often substituted for harness composition.

\section{PATENT LEATHER AND ENAMELLED LEATHER.}

Patent leather of blinkers, pad, collar, dash-board (guard in front of the driver's legs), splash-boards (guards over the wheels), etc., may, when needing attention, be sponged over, dried with a wash leather, and have a flannel rag moistened with paraffin oil rubbed over its surface, which should be finally polished up with a dry rubber, so as to remove 
all adherent oil. As long as patent leather remains sound it will require no other application than paraffin oil to brighten it up. When it begins to "go," we may employ, as may be required, a little harness composition to renovate it.

Enamelled leather, which is chiefly used in the hood of a carriage, can be treated as patent leather.

\section{SERGE AND LINEN COVERED PANELS.}

These articles, if at all damp, should be carefully dried on a saddle-dryer before a fire or in the sun; or they may be placed on hot water pipes in the drying room, supposing that such conveniences exist. They should then be beaten with a cane and well brushed, so as to soften the panel, and to remove from it as far as practicable the mineral matter which the soaked-in sweat has left behind on evaporating.

\section{STEEL, IRON AND ALLOYS OF NICKEL.}

I may state in passing, that all cast metal articles, such as annealed iron, malleable iron, and the various "never rust" alloys of nickel, are unreliable in use. Although a cast iron bit or cast iron stirrup can be turned out of a factory so skilfully that it would be almost impossible to tell it from a forged steel one, it will soon lose its polish from use, and will be much more difficult to keep bright than a steel article. Getting a high polish on wrought iron is out of the question. Although the alloys of nickel which are used in the trade do not rust, and easily acquire a brilliant polish; their lustre, even under the most favourable conditions, cannot be mistaken for that of steel. With all these forms of metal, it is best after use to place the bits or stirrups in water, so as to loosen the dirt on them. In the case of steel or iron, we may restore the brightness by taking some silver sand 
in the hand, wetting it in water, and scrubbing the article. Or we may do the scrubbing with a wet strip of wash-leather on which silver sand and a little soft soap (to prevent the sand from falling off) has been placed; or with a wet flannel rag rubbed on a cake of "Monkey Soap." Emery powder placed on a flannel rag and moistened with paraffin oil, is useful for removing rust. The article is then dried with a rubber, burnished and finally polished up with a chamois leather, piece of velveteen, or soft dry rubber. Steel, in order to be burnished, should be dry and free from grease, the presence of which will prevent the burnisher from "biting" the steel. Alloys of nickel should not be scrubbed with silver sand, monkey soap, or other gritty applications, which would scratch them. As a rule, they need only be washed in water, and polished with a wash-leather or rubber. To add to their lustre, we may polish them with whiting or plate powder applied on a flannel rag and moistened with methylated spirits.

BRASS.

Brass may be cleaned with powdered rotten-stone (Tripoli powder) and oil placed on a flannel rag; and polished with a rubber, which, when in a greasy condition, will be easier to wash than a greasy wash-leather. Probably a better and a more convenient application than rotten-stone and oil, is "Globe Metal Polish," which is of a greasy nature, and which should be sparingly applied to the surface of brass by means of a rag.

\section{SILVER AND PLATED WORK.}

Put plate powder on a flannel rag, fold the rag so as to enclose the powder; wet each side with methylated spirits, and rub the article with the rag thus prepared. During the rubbing, the plate powder will work through the rag in a 
uniform manner, and will not be liable to fall off the rag. With black harness, it is well to use black plate powder, which will not show as much as the ordinary kind, in the event of particles of it falling on the harness. In the absence of plate powder, whiting may be employed.

\section{PIPE-CLAYING.}

Pipe-clayed articles will usually consist of white leather and white cotton, such as that used for girths, web stirrups, web martingales and web breast-plates. Both leather and cotton may be scrubbed with a scrubbing brush or water brush, so as to clean them. The pipe-clay may be intimately mixed with milk to the consistence of cream, and put on thin with a sponge. When it has become quite dry, it should be beaten off or brushed off.

\section{COTTON CLOTHING AND WOOLLEN CLOTHING.}

Cotton clothing can be washed in the ordinary way. Woollen clothing being liable to shrink to a large extent if immersed in hot water, had best be placed on a table and scrubbed with soap and warm water. Water should be sparingly applied; and after the clothing has been scrubbed, it should be well stretched, so as to help in preventing it from shrinking.

\section{CARRIAGES.}

The floor of the wash-box or other place in which a carriage is cleaned, should be paved, so that mud and grit may not be splashed on to the wheels. When the carriage comes in after use, the cushions and mats should be taken out, and there should be as little delay as possible in removing all adherent mud by means of water. If mud be allowed to dry on any part of the vehicle, it will be liable to injuriously affect the varnish or polish, and then it will not be easy to remove the mud solely by water. We should here bear in mind that in 
attempting to sponge or wipe off mud from a carriage, we are apt to scratch the varnish or paint, on account of the frequent presence of gritty particles in mud. The water had best be applied under a fair amount of pressure. If a hose is not at hand, we may use a Read's pump and flexible tube. Failing these appliances, we shall probably have to content ourselves with sluicing the carriage with buckets of water. The wheels, one after another, should be slightly raised off the ground by means of a jack and carefully washed. I would restrict the use of an ordinary spoke-brush (p. 254) to the tyres, felloes and under-carriage; because this spoke-brush, if employed on the spokes, is apt to injure the varnish and paint, and is rarely narrow enough to get between the spokes at their junction with the nave. The spokes, and indeed the whole of the wheel, can be cleaned with a sponge. When all mud has been removed by water, the remaining moisture may be sponged off, the carriage well dried with a wash-leather, and polished up with a fresh dry leather. Any spots which remain on the panels, etc., may be rubbed over with a flannel rag moistened with paraffin oil or linseed oil. The steel pole-head may be cleaned in the manner described on page 364 , and a coating of paraffin oil, which of course must be removed before burnishing, will prevent it from rusting. The window panes of a closed carriage may be sponged with water in which a little paraffin oil (say, a tea-spoonful in a quart of water) has been mixed and the whole well shaken up, dried with a wash-leather, and polished with a soft duster. The leather, plated work, etc., should be cleaned in the manner already described in this chapter. The cushions and inside lining of the carriage should be brushed, and the mats shaken and brushed.

As a rule, a mop is a lazy man's substitute for a sponge; for, though it is convenient to use, it cannot be applied with lightness and precision. It should be reserved for the under- 
carriage, and in that respect it is useful for two-wheeled traps, the shafts of which can be tilted up. Cotton mops are preferable to woollen mops, because they are not so apt to leave particles of their substance on the carriage.

When the carriage has been cleaned and put away, it should be covered over with a specially made cotton cover, or with sheets, so as to preserve it from dust and damp. If a carriage is not in use, it should be sponged and leathered over at least once a month.

It is a good plan to send the carriage once a month to a coach-builder, who will see that the axles are greased, the washers all right, and everything in order. If this is not done, the coachman or groom will have to look after these details himself. Castor oil may be used for the axles.

\section{BLACKING BOOTS.}

Boots, especially top-boots, to look well, to be easily cleaned and to wear long, should be put on trees immediately after use. The surface should then be cleaned with a hard brush, and if necessary with a sponge or water-brush and a little warm water. When thus made wet, or if they are already damp, the boots should be put away on their trees to dry; because it will be impossible to polish them as long as they are in a moist condition. When all dirt has been removed and the boots are dry, a coating of blacking as thin as possible should be applied, and the boots polished while the blacking on them is still damp. Boots that are in use should be boned at least once a week, and if possible immediately they are taken off the feet; because at that time the leather is soft and pliable by reason of the heat and warmth of the feet. Bottle blacking is better than cake blacking; because it can be put on thinner and more evenly. When cake blacking is used, boots as a rule will require to be frequently washed; because, in this case, the blacking will be apt to cake in 
irregular lumps on the boots. Boning. makes the surface of the leather smooth and compact, and takes out creases.

A little glycerine rubbed into the boots occasionally, helps to soften and preserve the leather, and it also improves the polish.

In the cleaning of top-boots it is a great convenience to have the tops detachable. If they be fixed, the tops will have to be protected while the black leather is being cleaned; and the black leather, while the tops are being dressed. This protection is usually obtained by means of paper, which in one case is placed over the top and is doubled under its lower end; and in the other case, it is put round the upper part of the black leather, and between it and the top.

For blacking boots, a hard brush, a blacking brush and a shining brush are required. There is very little difference between the two last mentioned brushes.

\section{TOPS.}

Probably the best plan is to follow the directions on the box of top powder, which can be obtained at any saddler's shop. After the application of the fluid in which the powder is suspended, the tops are allowed to dry, and are then brushed over with a hard brush made for the purpose.

\section{LEATHER BREECHES.}

White breeches, having been put on trees, should be scoured with a little warm soft water, care being taken that they are not made too damp. If any stains remain, they may be touched with a little benzine or lemon juice, either of which should be washed off. Breeches paste of about the consistency of cream should then be applied in a thin and even coating with a special brush. The breeches should be allowed to dry very slowly, and when they have become quite free from moisture, they should be beaten and brushed, so as to remove all loose particles of powder. They may be carefully finished 
off with a box iron. It is safer to use one of the many excellent kinds of breeches paste (Propert's for instance) that are on the market, than to employ a paste of one's own compounding. The brushes can be bought in sets. Leather breeches of different shades of brown may be cleaned in a similar manner, except that the paste is made from a ball, which can be obtained in several shades. The buckskin or doeskin strapping of cloth breeches, whether white or coloured, may be treated in a similar way.

\section{SADDLES COVERED WITH BUCKSKIN OR ROUGH LEATHER.}

These saddles can be lightly scoured with a damp brush, and treated with breeches paste or coloured ball, in the manner described in the preceding paragraph. When they have become dry, the loose powder should be brushed off.

\section{SILK HATS.}

Go over the hat with a wet sponge, or brush it with a hard wat brush and leave it to dry over night. When quite dry, brush with a soft brush, and finish with a velvet pad. The appearance of the hat will be a good deal improved by ironing it before using the pad.

\section{SPONGES.}

A sponge after use should be rinsed in cold clean water, squeezed tightly between the hands without any wringing, which would be apt to tear it, and dried if possible in the sun or in a windy place. The application of soap to a sponge make it slimy, a condition which may be removed in various ways. Probably the safest plan is to steep it for several hours in a solution of salt and water, which will in no way harm it, as sponges, when living, reside in the sea; rub sand through it ; and finally, rinse, squeeze and dry it. 


\section{CHAPTER XIV.}

\section{MANAGEMENT OF HORSES ON BOARD SHIP.}

Special Dangers-Best kind of Ship-Position of Horses on Board ShipPreparation before going on Board-Taking a Horse on Board-SlingingHorse Boxes-Feeding Trough-Floor-Rough Cocoanut Matting-Cotton Wadding Bandages-Slings-Food-Help on Board Ship-Grooming-Exercise-Clothing-Lowering the Heels-Treatment after Disembarkation.

THE chief special dangers to which horses that travel by sea are exposed are: Injury during embarkation, disembarkation, and while on board; destruction by being washed overboard or by shipwreck; diseases of the organs of breathing, from bad ventilation when the animals are carried below; and laminitis (fever of the feet) from long standing. An attack of laminitis is always a serious affair ; because, even if the patient recovers, it will, as a rule, permanently impair his working capabilities. The probability of this disease being set up, greatly increases according as the duration of the voyage is prolonged. When horses used to be sent viâ the Cape of Good Hope on sailing vessels to India, a large proportion, I would almost venture to say the majority, of them became affected with this grave form of unsoundness as a result of the voyage.

The best kind of ship on which to take horses is one that is fast, steady, roomy, and (when the animals are carried below) well ventilated. Speed in the vessel is of course an advantage; for it reduces the length of the voyage, and consequently its bad effects on the horses. The stability (freedom from rolling) of a vessel largely depends on her 
width of beam, and on the manner in which she has been loaded. As the subject of loading a ship does not come within the province of this book, I will content myself by saying that shippers of horses would do well to avoid vessels which carry railway iron. When there are only a few horses, they are generally put on the upper deck, which is a position that admirably fulfils the requirements of ventilation; but it exposes the animals much more to danger from heavy seas, than placing them below. When horses are carried on the upper deck they should always, if practicable, be provided with boxes, which should be put in a well-sheltered situation. Nowadays sailing vessels are so seldom used for conveying horses that we need not consider them here. Steamers with flush decks and but little "shear" are the worst for horses on deck, and those which are provided with high bulwarks are the best. A ship that is light, and is consequently high out of the water, will naturally be safer for animals on deck than if she were deep. Horses, when in considerable numbers, are usually carried on the main deck, and even on the lower deck. They can then be put in stalls, which should be made particularly strong, and may be arranged in two rows: one on the port side, the other on the starpoard side. It is an advantage for purposes of cleanliness to have the horses' heads facing outwards, with a passage between the two rows of animals. Horses which are below are greatly exposed to diseases of the organs of breathing from defective ventilation, and from their dung and urine being allowed to accumulate under them. Hence the utmost care should be taken to provide them with an ample supply of fresh air, to protect them from chill, and to keep their abode scrupulously clean.

As regards the position of horses on board ship, we may conclude that they should be placed as near midships as practicable; because there is less motion in that part of the vessel than at either end. As the inclination of the deck is 
greater when the ship is rolling than when she is pitching; horses should be put athwart-ship, and not fore and aft.

For a voyage up to, say, ten days' duration, no special preparation of the-animal is required; supposing that the management on board will be carried out according to correct principles. If the journey be considerably longer, as for instance to India or the Cape of Good Hope, it is well, at least three weeks before sailing, to lower the heels and put on tips, so as to strengthen the soles and frogs with the view of these parts having to bear weight; and to cool the animal down by green food. Reducing the slope of the hoofs by means of a rasp is advisable under the circumstances in question; because it takes pressure off the toes to some extent, and thus diminishes the danger of laminitis. It is as a rule better to leave on the shoes than to let the horse go barefoot, in which case he would be apt to break or unduly wear down the wall of the hoofs by pawing and other uneasy movements; and it is not always possible to find a capable blacksmith on landing. As the horse will have to do a good deal of standing, it is of course necessary that his legs and feet should be in a healthy condition.

A horse should be kept without water and food, for, say, four hours before taking him on board, in which case a drink and a feed soon after he has been shipped, will help to reconcile him to his new place of abode. Besides, when his stomach and intestines are comparatively empty, he will not be so liable to be injured, in the event of mishap, as he would be if they were full, especially if he is to be slung. He should wear a particularly strong head-collar, provided with two strong ropes as leading reins. A bridle (snaffle) is necessary only when he is to be walked on board.

Taking a horse on board is usually effected by walking him from the quay or jetty into the vessel; by putting him into a box and lifting it over the side by means of a crane; or by 
slinging him and lifting him in the same manner. When a horse is put into a box, previous to taking him over the side, the ropes on his head-stall should be firmly secured at a proper length to the iron rings that are respectively fixed in the posts at the entrance of the box, and the box should be covered over with sail-cloth or other suitable material, so as to prevent the animal seeing where he is going, while the box is suspended in the air. The fact of his being thus kept in darkness will greatly help in checking him from struggling to get free.

Generally, the safest way of bringing a horse on board is, when practicable, to walk him into the ship by a broad and well-protected gangway, the slope of which should be by no means steep. In this case, the portion of the deck which he has to traverse before arriving at his box or stall should, if possible, be covered by ordinary cocoanut matting or other suitable material, so as to prevent him slipping, which a horse in these circumstances is very liable to do. If cocoanut matting be not available, a layer of cinders will be a fair substitute. The stevedores' men who have helped me on different occasions to walk horses on board, have usually shown a strange liking to fill up inequalities in the horse's path-as, for instance, between the ends of the gangway and the ground or deck-with straw, in order, as they thought, to give the animal confidence to go straight ahead. This practice is certainly founded on a misconception; because, if a horse steps on an inviting surface, and then finds that it concealed a danger, he will generally become alarmed, and will object to again enter into the trap. In all such cases it is best to let a horse see the nature of the obstacles in front of him, so that he may adopt his own method of surmounting or avoiding them. In taking care of himself he requires but little help from us, and no deception.

As slinging a horse with the object of carrying him from 
one place to another is a somewhat dangerous proceeding, especially during the act of placing him on the deck of a ship, it should be done only when economy of time is of paramount importance, or when a box is not available. A box may be thus used for embarkation, even when it will not be required during the voyage.

The inside measurements of an ordinary horse-box are $7 \mathrm{ft}$. long and $2 \mathrm{ft}$. 9 in. wide. This length is sufficient, but the width is at least 3 in. too narrow for a hunter or trooper; because it does not allow enough room for a man to get into the box alongside the horse, in order to arrange his clothing, to pick up a foot, or to perform any other necessary detail. For the conveyance of heavy cart horses, an extra allowance of room should be made. Instead of having a box only just large enough for a horse to stand up in, we might have one sufficiently big (say, $9 \mathrm{ft}$. by $6 \mathrm{ft}$.) for the animal to lie down in if he chooses to do so. I have known such an arrangement to be used when taking valuable horses from Australia to India. It proved very beneficial to the health of the animals thus boxed, but the extra expense would not, as a rule, be justified in ordinary cases.

When two or more horses are taken on the upper deck, it is a good plan to have a box made wide enough for one more than the number intended, and to provide movable partitions, so that any particular horse might be given a compartment of double the usual width, as occasion might demand. Thus, for two horses, the interior width would be $9 \mathrm{ft}$., and for three horses $12 \mathrm{ft}$. The same principle should, if practicable, be carried out with horses between decks.

A box should be provided with doors at both ends, so that the animal or animals may be able to go in or out of it, whichever way it is turned. It should have massive iron rings, placed in convenient positions so as to enable it to be hoisted over the side by means of a crane; and there should 
be placed semi-circular iron bars over the top to give it solidity, and to afford support for coverings. In bad weather, water-tight white canvas covers, properly secured, act well. In very hot weather, an awning may be required. Strong iron rings should be let into the deck, to enable the box to be firmly lashed down.

The inside of the box should be thoroughly well padded throughout its entire extent. Straw padding, covered with canvas, as is generally used, proves ineffective; because it soon gets hard and works downwards, and thus leaves the upper portion of the woodwork unprotected. I would strongly advise the employment of large pieces of felt, to be secured by being laced through holes bored in the planking, so as to dispense with the use of nails of any kind, next to the horse.

The feeding trough or manger which is provided with a sea-going horse-box, is generally much too narrow. It should be at least 13 in. deep and 13 in. wide at the top, and the sides should slope towards the centre, so as to help the animal to reach his food.

With respect to the nature of the floor upon which a horse should stand, whether in box or stall, during a sea voyage, we should bear in mind that the two great dangers from which he is liable to suffer are loss of foothold and laminitis. Such risks as those of shipwreck and being washed overboard do not come within the province of this chapter. The famous Blue Gown, Prince Io, Ossory, who was own brother to Ormonde, and scores of other valuable animals have lost their lives from stress of weather during the short passage across the Atlantic. These accidents usually occur from the horse losing his footing, in which case he will probably either get dashed from side to side, until the life is knocked out of him, or he will struggle till he dies, as horses will do when they get down and cannot regain their feet. As a 
quadruped has a far larger base of support than a biped, he can keep his footing much better on a rocking surface, like the deck of a vessel which is rolling and pitching, provided that his feet do not slip. Yet horses, as a rule, find it far more difficult to keep standing on deck in bad weather than men; because of the small amount of friction that exists between the floor of their box or stall and the ground surface of their feet. The superiority of the four-legged form of support over the two-legged one, is well shown by the ease with which a dog can stand on the deck of a vessel that is rolling in the most desperate manner, because the pads of his feet give him abundance of grip. Therefore, to insure a seagoing horse against the danger in question, we need only place him on a non-slippery surface, as, for instance, thick cocoanut door-matting, into the upstanding fibres of which his feet can sink, and can thus obtain secure foot-hold. I have frequently proved the perfect efficiency of this material during terribly bad weather on voyages with horses between India and England, and also in the North Sea when going to Russia. The best plan for putting down this matting in a box, is to have a piece of it specially made, and to have it a little larger in its width and length than the bottom of the box, so that it could be built up into the sides when the box is being constructed. Then, as long as the box holds together, the matting can not become displaced. If it is not convenient to have a box specially made, we might employ six cocoanut door-mats of the ordinary size (about $3 \mathrm{ft}$. by $\mathrm{I} I / 2 \mathrm{ft}$.) ; five to cover the floor, and one extra, so that the rearmost mat can be taken out every day, cleaned and dried, and the others pushed down in daily succession. With a row of stalls between decks, the matting would have to be fixed to the deck. The old plan of putting battens across the floor is worse than useless; because, instead of using the battens as a fixed point for his toes, in the manner 
intended, a horse will generally place his heels on them, apparently with the hopeless object of digging his toes into the wood beneath, and will thus adopt a position which is well suited to bring on laminitis. Straw is slippery, and consequently should not be employed. Cinders and sand are very inefficient substitutes for rough cocoanut matting; although they are probably the best makeshifts that can be usually found.

With respect to the loss of Ossory and Prince Io, I read in The Spirit of the Times that the man who had charge of them said that he could not keep either straw or sawdust under them, as it got washed away by the water which was shipped. It is evident that no amount of wave-washing could remove properly-placed cocoanut matting. When horses get killed in this outrageous manner, any insurance company that had taken the risk on them, would be right to resist all claims for compensation; because proper precautions had not been taken for the safety of the animals.

I believe I was the first to advocate the use of rough cocoanut matting as a floor for horses on board ship, which I did as far back as the 30th March, I889, in Hayes' Sporting News, which I owned and edited in Calcutta. Also, in

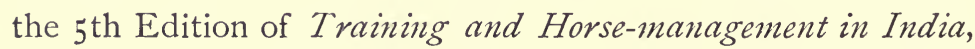
published in 1893, I recommended this kind of matting for the purpose in question.

Rough cocoanut matting not only gives a horse firm footing, but also saves him to a great extent from the danger of getting laminitis, by enabling him to stand on a substance which is a bad conductor of heat, and which causes the pressure on the ground surface of his feet to be well distributed. By using cotton wadding bandages (p. 306) we may further diminish the danger of laminitis; for they are a very efficient help in maintaining the normal rate of blood circulation in the legs and feet. Unfortunately, the idea 
of employing this method of bandages on horses at sea, did not occur to me until within the last three years, and consequently, I have not been able to give it as extended a trial as I would have wished. On two sea trips, of ten days' duration each, I put, prior to embarkation, these bandages on the legs of five or six horses I had with me, and did not remove them until we had arrived at our destination; the result being that when the bandages were taken off, the legs of the animals were free from the slightest suspicion of "fulness," and the feet were cool.

Slings may be placed under the horse in fine weather. They should be so loose as not to press against his belly when he stands up; but tight enough to enable him to rest his weight on them if he chooses. If the sea gets at all rough, the slings should be at once removed. If the slings are so tight as to take any weight off the horse's feet, their. pressure on his abdomen will have a more or less injurious effect on his digestive organs, and the security of his foot-hold will be endangered.

As regards food I have found the following daily ration to be well suited to the requirements of horses on board ship :-

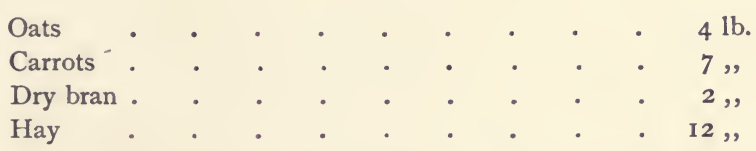

If carrots cannot be obtained, we may double the allowance of bran, and utilise a part of it for a bran mash about every three days. I consider the slightly laxative effect produced by carrots on horses is far superior to that caused by bran mashes. As bran soon becomes musty, it should be obtained direct from a miller and not from a corn chandler.

If any help on board ship be required for the horses, arrangements for obtaining it had best be made with the 
Captain of the ship prior to starting. Liberally paying one's footing on the forecastle has generally a good result.

The grooming of the horse may be limited to sponging out his eyes, nostrils, dock, \&c., and picking out his feet, except when the weather is so fine that he can be taken out on deck; for accidents with horses on board ship are very liable to occur. Neglect to groom an animal that takes little or no exercise is, as I have shown (p. 319), an evil; but as a rule it is a lesser one on board ship than risk of accident.

When taking horses between England and India, I have always managed with safety to lead them out of their boxes from time to time, and give them a little exercise by walking them on ordinary cocoanut matting which I had provided for the purpose. A horse should on no account be allowed to walk on the deck without matting if the deck is at all wet or greasy.

If practicable, the box should be opened morning and evening to enable the attendant to clean it out. On all other occasions it should be kept closed.

If clothing be used, attention should be paid to keeping it straight, so that it may not inconvenience the animal.

If the voyage extends to over three weeks, and there is a blacksmith on board, the shoes should be removed and the heels lowered after the horse has been out for about that time. An experienced man, who is neither a veterinary surgeon nor a blacksmith, might be able to lower the heels properly if the horse was barefoot, or had on tips.

In Veterinary Notes for Horse-Owners, I have alluded to the advisability, on landing a horse after a sea voyage which has extended, say, over eighteen days, to keep him in a loose box and on green food for a few days, so that he may recover the use of his feet before he is gradually brought on to work. A walk of even two or three miles immediately after disembarkation is apt to set up laminitis; although 
previously no symptom of that disease may have been apparent.

From a considerable experience in Calcutta with dealers, horses freshly landed from Australia, Tasmania and New Zealand, I can say with confidence that, as a rule, it takes such animals about three months to recover from their voyage of from four to six weeks' duration, and even then they have to be worked with special care. This statement is in accordance with the remarks on this subject in the Veterinary Record, 26th May, I900, made by Mr. E. E. Martin, who is Remount Veterinary Officer in Calcutta. The horses in question are generally brought over in cargoes of from 200 to 400 at a time; have to stand on bare boards; are packed close together; and get no exercise. The time necessary for recovery of soundness after a voyage, would not be more than a quarter as long, if the management on board ship was conducted according to the principles laid down in this chapter. 


\section{CHAPTER XV.}

\section{STABLE ROUTINE.}

Racehorses and Steeplechasers-Hunters-Carriage Horses-Vanners, Cart Horses, etc.

THE following routine may be observed with racehorses and steeplechasers which are kept in boxes.

The lad enters the stable at 6 in the morning all the year round, or at half-past 5 during summer and at 6 in the winter. If the horse has not had a constant supply of water during the night, the lad draws fresh water, and lets him drink as much as the animal likes, and puts a head-collar on him. He picks out the feet, feeds, collects the dung and soiled portions of litter, puts them into a skep, and deposits the contents on the midden. On returning to the box, he heaps up the bedding, if it is composed of straw, into two or three corners with a stable fork; sweeps out the floor with a broom; and removes to the midden all the swept-up dirt. If the bedding is of peat moss or saw-dust, the mucking-out is effected in the manner described on page $28 \mathrm{I}$. When the horse has finished feeding, the lad racks him up; takes off the clothing by successive pieces while going over him with a straw wisp; cleans any soiled portions of the coat; sponges out his eyes, nostrils, dock, and, if necessary, sheath; dries the wet parts; sets the coat with a rubber; puts on the saddle; and if the weather is cold, places a rug over the saddle, and secures it with a roller. As a rule it is advisable some time before the animal quits the stable, to reduce the clothing as far as can be 
safely done, so as to avoid a violent transition from heat to cold. If the bedding is of straw, it is well to place it outside, so as to dry and air it. When this cannot be done, or when the bedding is not straw, it can be put down in the box and added to as may be required. The lad then goes to breakfast, and has from an hour to an hour and a quarter off duty. After that he goes to the box ; removes the clothing, if it has been put on; bridles the horse; and takes him out at from 8 to half-past 8 , according to the time of the year or the weather. After being exercised, the animal returns to the stable at from half-past Io to I I o'clock. He is watered; well groomed; clothed; bandaged, if necessary; and given his corn and chop, or corn, before getting which he may have a little hay (p. 85). He is supplied with water and hay, and is let loose. If the horse is not given such a large quantity of corn as will prevent him from eating his hay greedily, it is advisable to let half an hour to an hour elapse, after he has finished his corn, before giving him hay. Every facility should be allowed an animal to lie down during the day; and consequently he should not be racked up, except when he is being groomed or when he is being got ready to go out. During the hour or hour and a half which the lad has before his dinner (at I p.m.), he can clean his saddlery, or attend to any of his other stable duties. When a horse has the benefit of a walk in the afternoon, which of course cannot be given unless there is a good supply of help in the stable, he may be taken out and given his walk between 3 and 6 o'clock, according to the season of the year. He should get his third feed before this stroll, and should be watered, groomed, fed, and given hay on his return. If he does not go out in the afternoon, he will get his third feed at about 3 o'clock; his fourth feed, about 6 o'clock; and in any case he should be watered and fed for the last time at Io p.m. or later. When he has been given his third feed, the box 
should be mucked-out for the second time, and the bedding arranged. His second complete grooming will take place on his return from his afternoon walk, or just before his fourth feed, according as he stays in or goes out in the afternoon. It is safer, and no doubt more agreeable to the horse to have his head-stall taken off for the night, than to have it left on. Any dung or soiled litter that is seen at any time, should of course be promptly removed.

Supposing that a riding lad or groom has only one horse to look after, that the stable is opened at $6 \mathrm{a}$.m., the horse is exercised twice a day, and that the animal gets his last feed at ro p.m., the average number of hours which the man would have to work during the day would be about as follows:

$$
\begin{aligned}
& 6 \text { a.m. to } 7 \text { a.m. . . . . . . }=I \text { hour } \\
& 8 \text { a.m. to I p.m. . . . . . . }=5 \text { hours } \\
& 2.45 \text { p.m. to } 5.15 \text { p.m. . . . . . } \quad=221 \text { hours } \\
& \text { Io p.m. to IO.I5 p.m. . . . . . . }=\frac{1}{4} \text { hour } \\
& \text { Total =83 hours. }
\end{aligned}
$$

Considering that out of these eight and three-quarter hours the man spends three and a half in pleasant riding, his work cannot be regarded as unusually hard. If he has got two horses to strap, he cannot be fairly expected to do any afternoon exercise.

If a horse is in a stall, I prefer to rack him up in the morning when he is waiting to go out, than to put him on the pillar reins, which is a position that is irksome to his mouth. In this case it would be better to delay saddling him until his lad has returned from his breakfast; because turning a saddled horse round in a stall is apt to open out the points of the trees, and consequently to spoil the saddle.

It often happens that a trainer has more horses to exercise than lads to ride them, in which case he will usually divide the animals into two batches; the first to be taken out in the early morning, and the second to be worked after the first lot 
is brought home, and after the lads have had their breakfast. The first batch will then be taken out fasting, or will get about half a feed. The second batch will of course be fed first thing in the morning.

The foregoing routine is thoroughly applicable to hunters which are being exercised. On hunting days the feeding may be arranged as described on page 190. When the horse returns, he should be watered, dried in the manner detailed on page 334 , if he is wet; and if he is tired, he should be only lightly wisped over, his ears stripped, and he should get only a light feed of corn, but plenty of hay, and if possible 4 or 5 lbs. of carrots. He should be left as soon as practicable to take his well-merited rest. If he shows signs of fatigue next day, his corn should be decreased, and the difference made up with carrots or other green food. No diminution should be made in his grooming, and his exercise should be continued, but at a slower pace and for shorter periods.

I wish again (p. 227) to draw the attention of my readers to the reprehensible practice, adopted by almost every hunting groom in England, of racking up during the day, horses which are in loose boxes; the object of course being to prevent the animal dunging and staling on various parts of the floor, disarranging the litter, and dirtying his clothing by lying down. To save himself the small extra trouble which consideration for the comfort and health of the horse would entail, the groom racks the animal up, and thus prevents him during the day from lying down and moving about in his box. This arbitrary proceeding on the part of a servant is not only cruel, but it is detrimental to the soundness of the animal's feet and legs, by promoting stagnation of blood in these parts; "filled" legs being the most common result. I was once told by a credulous owner, that his groom had assured him that the practice of racking up hunters during the day was highly beneficial to their health; because it insured them a good night's rest ! 
This gentleman evidently did not take the trouble to find if, on the same principle, the groom refrained from sitting down during the day. It is almost needless to say that this practice is not adopted in racing stables.

With carriage horses, the early morning grooming may have to be of an elaborate character, in order to get them ready for work, and turned out as smartly as possible. With vanners, cart horses, and other working animals, I would recommend a full feed in the early morning, provided that a rest of at least an hour and a half was given after it. If the exigencies of labour will not allow such a long interval, the amount of corn should be proportionately diminished. In all cases, the late feed at night should be given.

When horses do not get a regular supply of carrots or other "green" food, it is advisable to give them a bran mash once or twice a week, say, on Wednesday and Saturday nights. If no work is given on Sundays, and the animals are in strong work and on high feeding during week days, their food on Sundays might consist of $7 \mathrm{lbs}$. of carrots and Io lbs. of bran, with the usual allowance of hay.

For further information on feeding, see Chapter VI. 


\section{CHAPTER XVI.}

\section{SUMMERING HUNTERS AND WINTERING POLO PONIES.}

SUMMERING HUNTERS.

By the first week in April, a hunting man who wishes to keep his horses for the next season, has usually to decide what he has to do with them in the meantime. In such a case, old English custom gives him a choice of a run at grass, or "soiling" either in a loose box or in a straw yard. Turning out to grass is an alternative that restores the animal more or less to his natural state, and is likely to benefit over-worked legs and feet, provided that the ground is not too hard. In soiling, the horse is kept on green food, hay and straw, and can take very little exercise. Consequently, this method of summering is inapplicable to all horses, except those which require veterinary treatment. Besides, the condition of the floor of the box or yard will generally be so unsanitary as to rot the frogs and to produce thrush; and in any case will necessitate constant supervision by a careful and competent man. Mr. Harold Leeney (The Horse in the Stable and in the Field) tells us that the stupidity of farm servants cost him a valuable horse which died from thirst during a time of frost, on account of the otherwise abundant supply of water having been frozen over. In country places I have frequently seen gross cases of cruelty caused by neglect in the supply of water to horses on pasture. The know- 
ledge that sheep can live for months without water is apt to make an ordinary yokel somewhat callous about the drinking requirements of horses. A run on soft damp grass, with no more food than the animal can pick up, is good treatment for inflamed ligaments, tendons and bones; and is certainly a benefit to his organs of breathing. These advantages, however, will be obtained at the expense of his working condition, to regain which he will require several months of hard feeding and strong exercise that cannot be given without taxing the soundness of his limbs. Besides this, horses on grass or in a straw yard during summer cannot fail to become filled with bots (p. 348), and, if docked, to go through a vast amount of irritation from flies. Hence, I would not turn a horse out to grass or in a straw yard, unless economy was of more importance than the animal's health and strength. If the state of his limbs was so bad as to necessitate a long rest, there would of course be no chance of hunting him next season in fast company, although he might do well enough for slow work. I would therefore discard all these old methods of summering sound hunters, except when saving money was the first consideration. Besides, the treatment of unsoundness could be carried out better in a stable, than if the horse was at grass. Soiling in a loose box might be applicable to an infirm animal, which, to get a fair chance of recovery, would as a rule require more treatment than merely standing still and eating green food.

Before turning a horse out to grass, it is as well to take off his shoes, and then rasp round the ground surface of the feet, so as to prevent the walls from splitting. It is generally more important to uncover the hind feet than the fore, because the former suffer more from thrush than the latter, they are more resistant to wear, and are more likely to inflict injury by kicking. When the shoes are taken off, or when tips are substituted for shoes, the question of adjustment of 
weight between heel and toe should be carefully considered, because reduction of the slope of the foot by lowering the heels or thickening the toe, may put undue strain on the suspensory ligament or back tendons. I have discussed this point in Veterinary Notes for Horse-Owners.

I think the best system of summering hunters is to turn them out every day in the late afternoon, as soon as the flies have gone to rest, and take them up, say, about 9 o'clock in the morning, before the flies recommence business. I would give the horses three feeds of corn (total, about $7 \mathrm{lb}$.) daily, first thing in the morning, at noon, and last thing at night; and would let them have as much healthy hacking as practicable.

The management of hunters which are worked throughout the summer as chargers, hacks, trappers, etc., would not of course come under the heading of summering.

\section{WINTERING POLO PONIES.}

As polo ponies are the only working horses which are usually wintered, I shall here refer only to them. Mr. E. D. Miller's Modern Polo contains such an able and full account of this subject, that I need only touch on the general conclusions of that author. The pony may spend the first two months of the slack time from the Ist September to the Ist April, at grass without corn, provided that the "keep" is plentiful, and the animal is young, vigorous and acclimatised. If he finds the exposure trying, he may have a couple of feeds of corn daily. Mr. Miller considers "that the best food for ponies when turned out is $4 \mathrm{lbs}$. of split beans mixed with plenty of old hay cut up into chaff, divided into two feeds, to be given morning and evening, and about ro lbs. of hay in the middle of the day. My ponies thrive better on this allowance of beans than on double the amount of oats." All the ponies should get three 
feeds of corn daily (early in the morning, at noon, and at night), from about Ist November. "Feeding is of more importance than shelter. Even when open sheds exist in the fields, ponies will not as a rule use them. Consequently, these buildings are not of much advantage, unless the ponies are shut up in them at night. It is a curious fact that even in the coldest and roughest nights in mid-winter, the majority of ponies seem to prefer lying out under a hedge or tree, even in the snow, to using the most comfortable shelter provided for them "(Miller). An ample supply of water should of course be given. 


\section{CHAPTER XVII.}

\section{EXERCISE FOR CONDITIONING HUNTERS.}

Length of Preparation-Physic-Exercise Ground-Leading Horses-Riding barebacked-Nature of Exercise-Clothing and Sweating-Daily Distance to be travelled.

I TAKE hunters as typical saddle horses which are to be brought into condition by good stable management and well regulated exercise, and refrain from touching on training for racing, except for the sake of comparison; because it would involve the question of horsemanship, which is a subject outside the province of this book. The exercise necessary to get harness horses into working condition, needs no special description; because, except in the case of match trotters, which need as careful training as racehorses, the powers of these animals are seldom tested so highly as to require a regular preparation. Besides, the urgency of their work is far less than that of horses which follow the hounds.

If a man keeps his hunters during the slack season in exercise, either by hacking or at light trap work, and takes them out cubbing during October, he will seldom need to give them any special preparation before appearing at Kirby Gate on the first Monday of November, or at some less aristocratic opening meet. The majority of hunting men are, however, birds of passage that take their sport like their dinner, without having to prepare it. I shall therefore confine myself in this chapter to remarks which may be useful to stud grooms, or to owners who are their own masters of horse. 
If hunters have been out of work for some months, they will probably require at least August, September and October for getting back their muscle and some of their wind.

Before beginning work, it is generally advisable to give a moderate dose of physic, in order to remove from the system an excess of the poisonous material in broken-up tissue which may not at first be excreted with sufficient rapidity for the requirements of hard exercise, and to get rid of superabundant nutritive material in the body. Feverishness, filled legs, and other signs of a "heated" state of the system, will often result from neglect of the precaution of giving a hunter a laxative before putting him into work. It is evident that a sound horse which has been kept in healthy exercise and has been fed on suitable food, will require no medicine before being prepared for hunting or any other kind of work. A safe and efficient form of physic for the object in question is Epsom salts, which may be given two or three times a day in doses of $4 \mathrm{oz}$. in the food, or $8 \mathrm{oz}$. in one dose as a drench.

There will generally be no trouble in finding fairly good turf on the sides of the road (Frontispiece) for purposes of exercise; and in Leicestershire, the frequent bridle paths afford excellent facilities for this end. Monotony in work is a serious trial to the temper of horses that are being trained for racing, as we may see by the eagerness with which these animals as a rule try to finish their gallops in order to get back to their stables; and it is no doubt a frequent cause of their becoming excitable and learning to pull. Many horses which have been trained and raced, will break out into a profuse sweat if they are brought on a racecourse, and will try to escape from a place which they evidently detest. Hunting, on the contrary, has in the large majority of cases a sedative effect on a horse's nerves; apparently because it is free from monotony, and, when engaged in it, a horse never knows when 
his work will be completed. Although these influences are by no means so potent for spoiling a horse's temper when the work is slow, as when it is fast; we may take for granted that horses like change of scene, and we should if possible humour them in this respect.

If there is difficulty in obtaining ground for exercise by the sides of the roads or by bridle paths, it is well worth while, if practicable, to lay down an exercising track, which need not be more than half a mile round; although for training racehorses we would require one at least I I $/ 4$ mile. An owner who takes a personal interest in the stable management and exercise of his animals will generally find it convenient to have such a track in a place which he can see from his house, and thus observe the work that is being done. The ground I like best for exercise is light sand with a covering of mould (humus), which will yield a soft and elastic surface, and, having a porous subsoil, will not hold rain for a long time like clay. Sand by itself is fatiguing to a horse and makes him slow, by reason of its want of elasticity. Clay is very bad; because it becomes as hard as the proverbial turnpike road in dry weather, and is dangerously slippery in wet weather. Chalk, as we find at Epsom, gets very hard during the summer. The "going" can be greatly improved in most cases, and especially when the ground is porous, by frequently giving it a light dressing of stable manure. Although it is the custom of grooms when mounted, to lead a horse always on the off side of the animal they are riding, there is no doubt that this practice tends to spoil the mouth of the led horse by making the near side softer than the off. I would therefore strongly advise that horses should be led as often on the near side as on the off. To this it might be objected that a horse led on the near side of the mounted animal, and travelling on the right side of the road, as is the custom, might, on becoming startled by passing traffic, swing round and get hurt; but 
the danger of such an accident in the country is too small to outweigh the serious damage done to a horse's mouth by always leading him on one particular side.

As grooms when mounted have rarely any trouble in leading two polo ponies, which are often over 14.3, if not I 5 hands high, and are generally more skittish than hunters; I do not see why they should not exercise two hunters in the same way. There would be no difficulty about doing this on a private exercising track.

A groom should not be allowed to ride without a saddle; because by doing so, he is apt to give the animal a sore back. Besides, being less secure in his seat, he will be more inclined to hang on to the horse's mouth; to say nothing of the increased risk of his falling off, and of the horse getting away and hurting himself.

Adopting the routine given on pages 382 to 385 , as the best for our present purpose, we may give our hunters $2 \mathrm{I} / 2$ hours' exercise in the morning, and one hour in the afternoon. At first the exercise may consist entirely of walking, for which trotting may be gradually substituted within judicious limits. Horses vary so much in their respective capabilities for standing work, that I will venture only to advise that the first hour in the morning should be restricted to walking, and that that pace should be preserved during the afternoon outing. The usual practice of giving all the hunters that go to exercise from any particular stable the same amount of work, is an evident mistake, which generally arises more from ignorance and inability to form independent conclusions, than from indifference and laziness. As many men who have charge of valuable racehorses train them all more or less alike; it would be absurd to expect that an ordinary stud groom would be capable of regulating the work of each of his animals, so as to meet their respective requirements. As few grooms are good horsemen, and as the danger of unsound- 
ness arising from work increases in proportion to the speed ; it is I think best to restrict the pace at which hunters are exercised, to the walk and trot, except when the groom is a thoroughly capable man. If faster work is allowed under such a condition, the ground upon which it is given should be frequently changed, for reasons that have already been explained; and special care should be taken that the animal or animals are extended only up an incline-a gentle one for choice-and on ground that is soft and free from inequalities. An ascent (Fig. 62), by taking weight off the forehand, greatly diminishes the risk of sprain in front, which is an accident that is particularly liable to occur on hard and uneven ground.

I am strongly opposed to the use of clothing for getting down the superfluous fat of hunters; for its effect will be similar to that of a thick coat in causing depression. Such sweating is permissible in a gross racehorse whose legs are too infirm to bear severe work, or whose time for preparation is unduly short; but neither of these conditions should be met with in hunters. If a hunter carries too much "beef," the safest plan is to make him "walk it off," by keeping him out, say, a couple of hours or even longer in the afternoon, as well as by giving him work in the morning.

As a rough approximation, I may say that hunters which are being prepared for the approaching season, may be sent a total distance of from 12 to 16 miles daily. If they are exercised only in the morning, they cannot be expected to do more than 12 miles. 


\section{CHAPTER XVIII.}

\section{STABLE SERVANTS.}

Varieties and Duties-Wages, Board and Lodging-Commission-Allowances and Tips-Livery and Stable Clothes-Qualifications of Grooms and Coachmen-Veterinary Surgeons and Grooms-Respect due from Stable Servants to their Masters.

\section{VARIETIES AND DUTIES.}

UNFORTUNATELY for the harmony which ought to exist between master and man, the terms "groom" and "coachman" are ill defined. Hence, before engaging a stable servant, it is in the highest degree advisable to come to a clear understanding with him as to the exact nature of his duties. If a man is engaged, say, from an advertisement, as a "groom," without any further explanation, he will expect to have some help, and he will not feel called upon to do anything outside his own particular sphere. A "coachman" occupies a somewhat better position than an ordinary groom, and would expect to have a groom entirely under him. If the place is a singlehanded one, that fact should be conveyed to the groom or coachman before engagement. If the master wants the man to fill up his spare time with work outside the stable, he had best engage him on the understanding that he must be willing to make himself generally useful when required. This extra work may include cleaning boots, brushing clothes, cleaning windows, chopping firewood, bringing in coal to the house, going messages, and lending a hand at any outside unskilled labour. Gardening, waiting at table, and cleaning hunting 


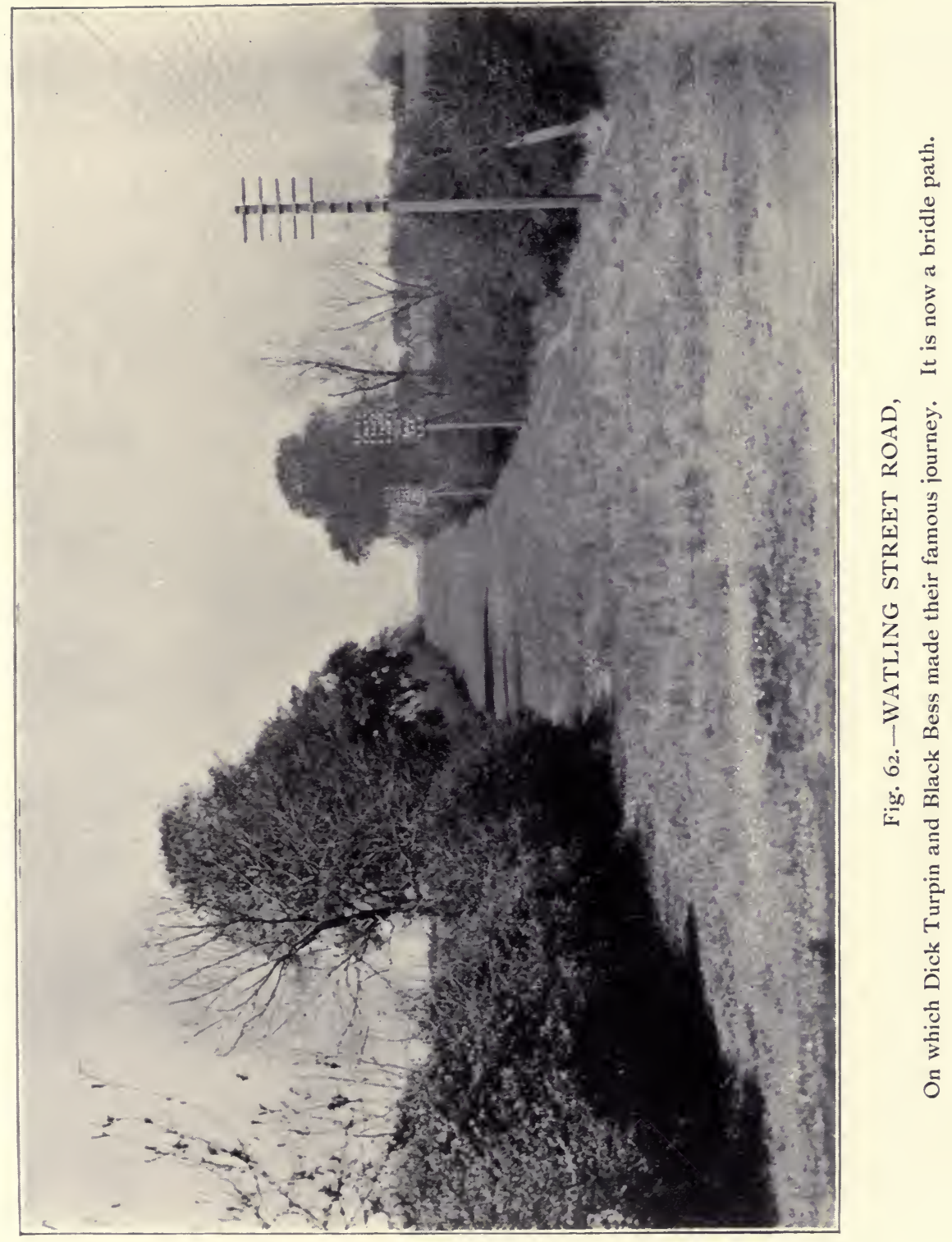



things could not fairly be included in this list. In a small place, say, with only two or three stablemen, the cleaning of boots is generally taken for granted; but in large establishments, that duty would be performed by an "odd man" or boy. A coachman is of course expected to be able to drive single and a pair, but not four-in-hand, unless he is specially engaged for that work, as well as for the more simple forms of driving.

The most humble kind of stable manager is a pony boy, whose labour in the stable is one of many duties. In large places, an odd man will be occupied almost entirely with outside house work, and will have little or nothing to say to the stable, which, in the opinion of grooms and coachmen, should be kept sacred from outside intrusion. We meet among cooks, gardeners, and officials of all kinds, the same dislike to unprofessional inspection. In small establishments, the odd man will probably divide his time pretty equally between the house, stable, and garden.

The groom gardener who has at least half of his time for devotion to the stable, may be reasonably expected to look after a horse and trap, or two saddle-horses, the time occupied in the exercise of which might be regarded as equivalent to that spent in driving the dog-cart or gig. Any driving which the groom-gardener would have to do, would naturally be of an unpretentious character, and he would not be expected to wear livery, beyond a top coat and tall hat. A strapper in a hunting stable and a stable helper under a coachman would be on about the same social standing as a groom-gardener. The strapper is not supposed to ride, and the stable-helper not to drive. Either of these men ought to be able to do three horses well, and also to lend a hand at cleaning saddlery, harness and carriages. In a job-master's yard, in which there is usually the stimulus of tips, more work would be expected, say, that of five, or even six horses; but its execution would 
be of a rough and ready nature. In tram and omnibus yards, a stable-helper will generally have to do ten or a dozen horses in a "lick and a promise" kind of a way.

A single-handed groom or an ordinary groom who is in a subordinate position in a stable, will have a comfortable job in grooming, feeding, watering and exercising two hunters or two polo ponies, which he ought to turn out in first-class style. If he is industrious and has a boy to help him when the ponies are brought on the polo ground for play, he will be able to do three ponies, which he can exercise together by riding one and leading the other two, one on each side. A single-handed or ordinary groom can do all the stable work for three horses which are in work; but he cannot give them a sufficiency of exercise, supposing that he leads only one at a time. The difficulty as to exercise would of course be obviated, if the master or one of his family did all the riding. As a rule, a single-handed groom would not have as much time to devote to the grooming and exercising of his horses, as an ordinary groom; because he would have to do stud groom duties in arranging about fodder, mending of gear, replacement of stable tools, etc. Supposing that a singlehanded groom was not expected to ride or drive, and that extreme smartness was not demanded, he ought to be able to look after a two-wheeled trap and harness, as well as three horses. A carriage groom will do about the same work as an ordinary groom, allowing for the time he may be absent from the stable. His duties are to go out with the coachman, sit beside him on the box, perform the work which a footman would otherwise do, clean harness, and strap.

A single-handed coachman would be able to do a carriage and pair in first-class style, if the turn-out was not wanted oftener than every second day. We must here bear in mind 
that the work on the horses, carriage and harness, and the cleaning of the man's livery, will take about five hours.

A groom or coachman would not esteem a single-handed place as much as one in which he had a man under him. Besides, stable servants as a rule like the society of their fellows, and appreciate a comfortable saddle-room, which is a luxury seldom found in a single-handed situation. Married men, and especially those who are no longer young, often like the independence of a single-handed job.

A groom-coachman generally has some help. He has to ride exercise as well as drive, and can do a couple of horses. $\mathrm{He}$ is simply a groom who has to drive.

A second horseman holds a position about equal to that of a groom-coachman, and in a large stable would be under a head groom. In a stable of ten or twelve horses he might act as head groom; and in one of half that size, as working stud groom. In Leicestershire, a second horseman is generally supposed to do two horses and his own hunting things, which I think is more than he can properly attend to, if he has to go out oftener than three times a week with his master or mistress.

A working coachman would have to feed his animals, look after their shoeing, trimming, clipping, etc., clean the carriage, do one horse or two if there is not much driving, and exercise. The man under him would muck-out, clean harness, cut chaff, bruise oats, and do the larger part of the grooming. Supposing that there were three horses, which would be a full allowance for the two men, if the carriage went out often; the helper would have to do two horses. A working coachman occupies a somewhat better position than a groomcoachman; because he has not to do the rougher part of a groom's work, and is supposed to have a carriage groom or helper under him.

A head groom in a large hunting stable is like a head-lad 
in a racing stable; his business being to see that the orders of the stud-groom are carried out. He would probably have to feed the horses, ride exercise, strap one horse, and superintend the cleaning of saddlery. In a stable of, say, fifteen horses or more, I do not think that he ought to be asked to strap. If the master is his own stud groom, the head groom will usually occupy a more independent position than when he is under a stud groom.

A man who was engaged simply as a coachman ought not to be expected to strap; for the performance of that duty would practically màke him a working coachman. He ought, however, to wash and clean his carriage, do his livery and boots, trim and clip, see to the shoeing, forage, bedding, clothing, harness, stable gear, etc., and superintend all the work done by the men under him, as well as drive. As a rule, when an owner advertises for a coachman with a man under him, he really means a working coachman; because he could not reasonably expect that the stable helper could do all the strapping.

A working stud groom could take charge of a stable of, say, not more than ten horses, one of which he might strap. In a stable of about five horses, the second horseman or coachman might take charge.

A head coachman would be required only in a large establishment, in which there would be also a second and even a third coachman. His duties, like those of a stud groom, would be limited to driving, superintendence and management. A second coachman would have to drive, do the livery and boots of the first coachman, do a carriage, feed and superintend work. The duties of a third coachman would be similar to those of a working coachman.

As a rule, a stud groom would be required only in a large stable, say, of twelve horses or more. He is not supposed to do any manual work, such as strapping (grooming), cleaning 
gear, or even feeding; his business being to make those under him do their work properly, and to attend to the welfare of his animals. He usually engages the other stable servants, buys the fodder, and has a good deal to say to the purchase of the horses.

In a large mixed stable, the head groom might have charge of the hunters ; the coachman, of the harness horses; and the stud groom, of the entire establishment. A smart stud groom in a hunting stable would be expected to break and school, and if need be, to train one or more of his horses for a hunt steeplechase or point to point race.

In a private racing stable we have the trainer, head lad, riding lads, and may be one or more strappers. In a small stable devoted to chasing and timber topping, and owned by a man who would look after entries, etc., the duties of head lad and trainer might be combined. Usually a riding lad will be expected to do two horses; but if he has to ride more than once during the day, he cannot groom more than one horse properly. As a rule, each valuable racehorse in training would have the undivided services of a riding lad. In a large public racing stable there would be two or more head lads according to the number of horses trained. None of these men would be required to do groom's work of any kind, and one of them would probably be selected by the trainer to act for him when he was absent.

\section{WAGES, BOARD AND LODGING.}

The pay of stable servants varies greatly according to locality and place; but out of London, it may be taken generally as follows: Ordinary grooms, strappers and stable helpers, from I 8 shillings to a guinea a week; head grooms, second horsemen and working coachmen, 25 shillings; head lads, working stud grooms, and coachmen who would not have to strap, 30 shillings; stud grooms and head coachmen, from 
35 shillings to 2 guineas; young riding lads, 7 shillings a week and keep; and full-grown lads, I 8 shillings with lodging. Men drawing 25 shillings and upwards would probably get a cottage, fire and lighting. Some liberal employers give vegetables and milk. In London, an ordinary groom ought to get 25 shillings a week, supposing that he has to find his own lodging.

As a rule, a groom can get board and lodging in a private family of his own position in life, for about I2s. 6d. a week in the country; and in London, for about 16 shillings. Lodging in the country would cost about 2 s. or 2 s. $6 \mathrm{~d}$. a week, and 4 or 5 shillings a week in London. I have found that when seven or eight riding lads club together, they can feed well on 6s. 6d. a week, supposing that they get free fire and room, and that one of them does the cooking.

\section{COMMISSION.}

Owing to the ignorance and apathy displayed by the large majority of horse-owners with respect to the conditions under which their animals live; many grooms and coachmen have got into the habit of resenting the slightest interference on the part of their employers with stable details-a state of affairs which is somewhat similar to that which usually exists between mistress and cook. In neither of these cases is the fault altogether one-sided. The impatience of supervision on the part of the servant is chiefly prompted by fear of losing perquisites, and also of being made to do more work. On the other hand, masters as a rule are unacquainted with stable routine, and the ordinary pay of even the head man of a stable, if sufficient for the bare necessaries of life, leaves little or nothing for a "rainy day." Stable servants have no pension to look forward to; they do not grow younger; and in many cases, employers regard the surreptitious presents and commissions received from tradesmen, farmers 
and dealers, as a valuable adjunct to the amount they pay in weekly wages. A story which is both true and instructive, is told of an old stud groom who, on leaving a rich master whom he had served for a long time, asked for a small provision for his declining years. "As I have always given you a free hand in the stable, it is your fault, not mine, if you have not feathered your nest," was the reply the man received. The reason why employers who are aware of the existence of this system of commission, usually ignore it, even if they do not knowingly profit by it; is because they feel that if they took from their servants the privilege of paying bills, their action in this respect would partake of the character of that of the historical dog in the manger; for the presenter of the bill, even if he allowed a commission to the servant, would certainly not give it to the master. I have known several cases in hunting countries, of farmers being unwilling to supply forage to gentlemen, owing to the rapacity of the grooms, who would not deal unless they obtained such an exorbitant commission that the farmer would either have to sell at a price which would not yield him a sufficient profit, or appear by his bills to grossly overcharge his customer. That desirable bond of union which ought to exist between hunting men and farmers, would be much firmer and would be of a far more friendly nature than it is now, if the consumer dealt directly with the producer, who would then have no illegal commission to pay.

In justice to grooms and coachmen, I must say that I have never known any unpleasantness exist between master and man respecting the prohibition of commission, provided that service was entered into on this understanding, and that the owner took an intelligent interest in the affairs of his stable.

In England, the rate of stable commission is not fixed; but 
may be put down roughly at five per cent. on all forage, harness, saddlery, clothing and tools; a shilling on each shoeing, and sixpence on removes. Some men require sixpence on each bushel of oats, or hundredweight of hay or straw. The ordinary commission, or rather present, recognised by dealers is a couple of guineas on the sale of a hunter or carriage horse; although the interest of some grooms and coachmen in their masters' purchases cannot be stimulated under a tenner or even a "pony." Ten per cent. on the bills of veterinary surgeons is not uncommon; and five per cent. is very reasonable according to stable opinion. On the Continent, the recognised commission is ten per cent. all round.

Apart from the moral aspect of the case, it is evident that the two great faults in the practice of stable servants receiving commission, are that it tends to render them slack, if not culpably careless, as to the quality and quantity of the articles supplied; and inclines them to "crab" all forms of stable necessaries from which they do not obtain profit. Thus we find instances of inferior forage being charged at high prices, and good, sound horses turning out unsatisfactorily in the hands of grooms and coachmen whose palms have not been oiled. It is almost needless to tell men and women of the world that, with respect to commission, stable servants are neither better nor worse than the members of trades and even professions in which the secret profit system is practised.

This commission system is so generally and so firmly established, that unless a master has a man upon whom he can thoroughly rely, he will have to accept things as they are, and make the best of them, or buy all stable supplies, horses included, himself, without any reference to his groom. In this case, to be just, he should see that his head man has a comfortable living wage from which he can with economy save a modest provision for his old age. Although the 
intelligent supervision of one's own stable is a source of great pleasure to anyone who is fond of horses; it cannot be successfully undertaken without special knowledge, which it is the object of this book to supply.

\section{ALLOWANCES AND TIPS.}

When a riding lad is sent on a journey with or without his horse, he is usually allowed six shillings a day for his extra expenses. Considering the rapid manner in which the incidental expenses of travelling mount up; this concession might be given to ordinary grooms under similar circumstances.

In some places, chiefly those in the carriage line, the master gives an allowance for extras and tools, which would include brushes, combs, wash-leathers, rubbers, dusters, sponges, soap, silver-sand, oil for dressing leather, harness composition, scrapers, curry-combs, brooms, hoof-pickers, plate powder, boot-top powder, breeches paste and burnishers. Five shillings a week would be a fair allowance to a coachman for three horses, and a shilling a week for each saddle horse.

A shilling may be regarded as the recognised tip to grooms for minor services, such as holding a horse, putting up a horse while the owner is calling at the master's house, going a message, etc. Half-a-crown may be looked upon as a fair tip to the coachman who drives one away, after one has been on a short visit at a friend's place. This might be increased according to additional services rendered. A tip to the stud groom for a mount out hunting in the Shires, might reasonably vary from ten shillings to a sovereign, with, say, half-a-crown to the man who had to strap the horse. It might here be objected that the strapper and not the stud groom should receive the larger tip, as he had to do all the work. We must, however, remember that in establishments in which the master is not his own stud groom, 
the quality of the mount depends to a large extent on the good-will of the stable factotum, whom, on that account, it is advisable to conciliate. Without wishing in any way to discuss the morality of tipping, I must say that the entertainment of visitors and friends puts a good deal of extra work on servants. The mention of hunting may excuse me for going beyond the province of the stable by saying that a fair tip at the end of the season in the Shires to a huntsman would be from three pounds to five pounds, a sovereign to each whipper-in, and a crown to each earthstopper.

\section{LIVERY AND STABLE CLOTHES.}

As a rule, the only stable servants who would wear livery are coachmen (including head coachmen, second coachmen and third coachmen, according to the size of the establishment), carriage grooms, second horsemen, and pad grooms. Their livery would consist of a black silk hat, livery coat (like a frock coat, only single-breasted), waistcoat, breeches and top-boots. Besides these articles of clothing, coachmen and carriage grooms, both of whom are dressed in the same manner, would have a double-breasted top-coat, macintosh, and in some cases a fur cape. All servants in livery should wear a stand-up collar with square ends (not turned down), white cotton (usually piqué) tie, and gloves.

The livery coat. would be of the colour chosen by the master, and the top-coat would be of the same colour, or of drab, which always looks in place with a servant's top-coat. The buttons of these coats would be gilt or plated, according as the harness and mountings of the carriage were brass or plated. Uniformity as to colour and buttons should be preserved in the livery of the other servants.

A master who wishes to avoid the imputation of vulgarity, should bear in mind that the gaudiness of the livery should 
be subservient to the quality of the horses, carriage and harness, and to the smartness with which they are maintained, and that his own get-up should be in keeping with the turn-out. If the carriage, harness and pair would not fetch more than, say, $£ 300$ at auction, black or dark-blue would be the most suitable colour for the livery. The display of a striking colour or colours, to say nothing of a profuse exhibition of gold or silver lace, would naturally attract attention to incongruities of detail, which are often difficult to avoid without great trouble and considerable expense, and which would give rise to no unfavourable comment in the absence of obtrusive ostentation. The same remarks would apply to the painting of the carriage and ornamentation of the harness. An owner cannot err in trying to have his horses too good, his carriage, harness, and the clothes of his servants too well made, and everything turned-out too smartly.

The livery coat of a coachman and carriage groom would be longer than that of a second horseman or pad groom. Waistcoats are as a rule of coloured stripes, and sometimes of a whole colour, such as scarlet. White buckskin cloth (cotton) is generally used for breeches; although real buckskin (leather), which is a good deal dearer, looks better. The colour of servants' tops varies greatly; pink, white, straw, cream, salmon, light-brown and nut-brown being the most common shades. White buckskin gloves look smarter than tan leather gloves, which serve their purpose equally well, give no trouble to clean, and cost about half the price. Driving and riding gloves should be at least two sizes larger than ordinary gloves, so that the action of the hands may be in no way cramped.

If smartness is not aimed at and a special colour for the livery is not assumed, the coachman may with propriety wear plain dark-coloured trousers along with a black or dark- 
blue livery coat. Trousers in this case will look much better than breeches and gaiters, which is a combination that has been handed down from early Christian times. I may point out that a "gaiter" is a combination of a legging and a spat. In winter, even fashionable coachmen often wear trousers and boots of nondescript pattern, so as to save their breeches and top-boots; for as they have not to get off the box until they are within their own yard, the lower part of their body will remain hidden by the apron from public view. As a carriage groom will have to be ready to dismount at any time when out driving, he cannot safely follow the example of the coachman in this respect.

The servants in stables of good class are usually allowed a suit of stable clothes every six months, after which time they are generally considered to belong to the servant. It is, however, more satisfactory to both parties for an arrangement as to the possession of used clothes, both stable and livery, to be definitely fixed before engagement. A suit of stable clothes consists of a coat, waistcoat and breeches of strong tweed and leggings of box-cloth; or coat, waistcoat and trousers, according to the requirements of the particular servant. Some masters allow a pair of lace-up boots (preferably without hooks) along with the half-yearly suit of stable clothes. A good portion of the expense of this concession comes back to the giver by the fact that with a liberal supply of ordinary boot-leather, the servant will not be inclined, as he might otherwise be, to wear his top-boots under his trousers.

The length of time which livery is supposed to last will depend on the degree of smartness demanded by the master. If the family goes up to town every year, a new suit of livery all round will probably be required at the beginning of each season. A second horseman will certainly need two pairs of white breeches to start with. The same allowance might be 
made to carriage grooms and pad grooms, and might be extended even to coachmen. Some masters supply collars and white ties and pay for their washing.

\section{QUALIFICATIONS OF GROOMS AND COACHMEN.}

The average efficiency of men who take charge of horses, is greatly lowered by the fact that no special qualifications are demanded before a man or boy can call himself a groom or coachman. In fact anyone who chooses, can assume either or both of these titles, no matter how ignorant of horses he may be. Instead of stable duties being within the compass of any yokel, their intelligent execution demands quite as much experience, natural aptitude and special knowledge, as are required in navigating a ship for instance. I may briefly state that a capable groom should be acquainted with all the practical details of feeding, watering, grooming, housing, bedding and exercising horses, and of cleaning gear; should be a good sick nurse; should be well up in all the ordinary symptoms of equine disease; should understand the general principles of shoeing; and should be a good horseman and skilful breaker. If he has a fair knowledge of training and schooling, understands the care of brood mares and stallions, knows how to run a hackney, and clean hunting things-so much the better. A coachman should be able to drive single or a pair in town (London) in a smart and capable manner, and not with "a rein in each hand and a whip in the other," according to the usual country practice. Besides his own particular business, he should be competent to fulfil all the duties of a stud groom which are unconnected with riding, supposing that he has to take charge of a stable. We must not, however, expect work worth two hundred a year from a man on a guinea a week.

Above all things, a groom or coachman should be good- 
tempered and patient with horses. A man who is capable of "venting his rage" on a horse, no matter what provocation he may have received from the animal, should never be allowed inside a stable.

\section{VETERINARY SURGEONS AND GROOMS.}

The large majority of grooms and coachmen who are in charge of horses, never like to see a veterinary surgeon within their stable walls, except when they want to shift on his shoulders the responsibility of the approaching death of a sick horse which they have vainly tried to cure by means of their own nostrums. The cause of this impatience to receive professional advice has long been a mystery to me. Formerly, I was accustomed to put it down to fear lest the attendance of the veterinarian might curtail the amount of "perks" to be obtained from bills for medicine run up by the stableman. But since I have found that this antagonism is shared by French, German, Italian, and even Russian stable autocrats, whose all round Io per cent. is in no danger of interference, I have attributed it to the jealousy of ignorance, especially as I have been told by grooms and coachmen of many nationalities, that they know quite as much about the treatment of sick horses as any veterinary surgeon. As they have not gone through the course of study required for obtaining the diploma of the R.C.V.S.; they are manifestly incapable of forming an accurate opinion on the value of such instruction. Besides, if the medical and surgical attainments of veterinary surgeons were not superior to those of grooms and coachmen, who are required to possess no educational qualification of any kind, why should it be necessary, as it undoubtedly is, for veterinary students to devote years of hard theoretical and practical study in order to pass their examinations? I feel that I am specially well qualified to form a sound opinion on this subject; for after 
having spent a large portion of my life in owning, training and riding horses, and in teaching my grooms their stable duties, I became convinced from experience that I could never hope to obtain a thorough knowledge of horses, either sick or well, without studying them scientifically. I accordingly entered the New Veterinary College, Edinburgh, and took out my diploma in due course. During the three years I remained there, I certainly saw a hundred times more practice than I had witnessed in all the previous years I had lived among horses. My subsequent experience proves to me that the time and money which I spent at that college was the best investment I have ever made.

The antagonism which stablemen feel towards veterinary surgeons is a survival of a recent past, in which anyone was at liberty to call himself a veterinary surgeon, and the course of study at the veterinary colleges was of a trivial character. Empiricism not having been leavened with science in those days, veterinary surgeons valued. themselves more on the possession of secret recipes than on their capacity to reason out the causes of disease. No wonder then-say 60 years ago-that grooms and coachmen considered that they knew how to treat the ailments of horses quite as well as the local shoeing smith who called himself a veterinary surgeon, or as the man who had passed through the London College or that presided over by the late Professor Dick. Since then, the veterinary profession has obtained its charter, and has proved itself worthy of it by the enormous progress it has made in learning. Time, however, is needed to remove the taint of previous ignorance, and the prejudice which fathers have handed down to their sons in the stable. In olden times, veterinary surgeons taught grooms to value medicine rather than advice, and even at the present day, there are some who encourage quackery by the use of pink drinks, blue lotions, and similar articles pour épater les pentes. No wonder 
that grooms, knowing that they can get similar drugs from so-called veterinary chemists, often imagine that they can treat the diseases of horses as well as qualified men. The proper attitude of a veterinary surgeon towards a stud groom or coachman in charge, is that of a doctor towards a hospital nurse, who receives directions free from mystery. To make the parallel complete, men in charge of horses should have special instruction, so that they might be able to intelligently carry out the course of treatment laid down by the veterinarian. Until head stablemen are educated up to this point, we cannot hope for much improvement in the care of sick horses.

I believe that those veter nary surgeons who object to disclose to laymen the procedure they adopt in the treatment of a case, are generally actuated by the idea that if they were to do so, they would be taking the bread out of their own mouths on future occasions, by making the laymen as wise as themselves. Here again comes in the fallacy that medicine is all important in the treatment of disease; the fact being that the great merit in a physician is his ability to find what is the matter with the patient. The more employers and stablemen recognise the fact that advice is of far greater value than medicine, the more will they esteem the services of veterinary surgeons and the better will their horses thrive. A wise owner will have his horses periodically inspected by a veterinary surgeon, without whose orders no medicine of any kind should be given in the stable: He may then rest assured that the less medicine his animals receive, the more efficiently are they looked after by their professional attendant; for prevention is better than cure.

RESPECT DUE FROM STABLE SERVANTS TO THEIR MASTERS.

Under this heading I shall include the mistress when speaking of the master, so as to avoid needless repetition. On 
meeting his master in the yard or stable for the first time in the day, or on passing him or speaking to him outside, the servant is supposed to touch his cap or hat, which he does with the forefinger of the right hand. On receiving an order from his master, he should touch his cap and say: "Yes, Sir," "Very good, Sir," or words to that effect, so as to show that he understands what is required of him. If he fails to grasp his master's meaning, he should ask for an explanation in a brief and respectful manner. Some ignorant servants, whose presence would not be tolerated for a moment in a first class establishment, have the provoking habit of receiving orders in silence, in which case the master is left in a state of uncertainty as to his directions being comprehended or not. 


\section{I $\mathrm{N} \mathrm{DEX}$.}

ABDOMEN, 9 I.

Absorbents, 70.

Absorption of fluids, 25.

,$\quad$, , food, $7 \mathrm{I}, 89$.

,, , gases, 26.

Acclimatisation, 44 .

Adamantine clinkers, 2 I3.

Aeration of water, I 3 I.

Affinity, chemical, I I-I 5 .

Age on plants, effect of, I08.

Air bricks, 204.

Air, conductivity of, 32, 33, 34.

Albuminoids, 63 .

Alimentary canal, 69.

Allowances to servants, 405.

Alsike, 62.

Altitude, influence of, 42, I99.

Amides, 63.

Ammonia, 46, 47, 259, 262.

Ammonium carbonate, 46 .

Anæmia, 7 .

Analyses, chemical, 61-63, 66, 67 .

Appetite, 104, 105.

Apples, 63, I69.

Ashes, analyses of, 66, 67 .

Asphalt, 214.

Assimilation, 7 I.

Australia, I20.

Azoturia, 54.

BACK, SWOLLEN, 334 .

"Balled" feet, 264.

Bamboo leaves, I77.

Bandages, 301 .
Bandages, cotton wadding, $306,342,378$

,, , for fast work, 303 .

,, , ordinary flannel, 302.

Bare-back, riding, 394 .

Bare-foot, horse, 345 .

Barley, 62, 66, 69, 72, 80, I I5, I54158,180 .

,, for brewing, 155 .

Beans, 62, 64, 66, 72, I04, I24, I63, I64, 389 .

Bedding, 260-284.

, , absorption by, 262.

, , choice of a, 275 .

,, , classification of, 263.

, , combined, 275.

, , cost of, $276,278,282$.

,, down, 276.

, , eating, I74.

, , necessity of, 260 .

, on horses' feet, effect of, 264.

,, , requirements in a, 262.

, , varieties of, $26 \mathrm{I}$.

Bile, 7 I, 86, 87 .

Birds, gall bladder in, 87 .

Bits clean, keeping, 246.

Black oil, 363 .

Blades of grass, 63 .

Blanketing, 292.

Blistering and epidermal growth, 20.

Blood, arterial, 7 .

, , ash of, 67.

,, , circulation of, 6 .

,, venous, 7 .

Bloodlessness, 7.

Blue Gown, 376. 
Board and lodging, servants', 402.

Body as a machine, 14.

Body-brush, 328.

Body, composition of the, 3 .

Boiling food, II4.

Bone, composition of, II9.

"Bone" in horses, 120.

Bone meal as food, ro3.

Bones, 100.

, , food for strengthening, 103.

Boots, cleaning, 368 .

Bots, 347, 348 .

Box, sea-going horse, 375 .

,, , size of loose, 229.

Boxes, construction of loose, 24 I -244.

,, , merits of loose, 225-228.

Brackets, 246.

Bran, 62, 64, 66, 69, 72, 91, 92, 125, I60, 16I.

, mash, I6r.

Brass, cleaning, 365 .

Breaking grain, 117 .

"Breaking out" into sweat, 23, 334, 337.

Breast cloth, 294 .

,, girth, 294.

Breathing, action of, 91 .

Breathlessness, 55 .

Breeches, cleaning, 369 .

Brewers' grains, $63,64,158$.

Brewing, 158 .

Bricks, blue, 213, 219.

,, , glazed, 220.

, , manufacture of, 217 .

,, , paving, 213.

Bridles, cleaning, 360-362.

Bristles of brushes, 327 .

British gum, 69.

Brooms, 253.

Bruising grain, I 15 , I 16 .

Brush room, 247.

Brushes, stable, 327.

Brushing the hair, 19.

Buckets, 254.

Burnisher, 332.

Bursatee, 42.

Button loops, 292, 293.
CACUM, 71, 87.

Cab horses, London, 184, 191.

Calculi, I I4, 135.

Canal boat horses, I9I.

Capillary attraction, 26.

Carbo-hydrates, 5, 64, 94-96.

Carbolic acid, 259.

Carbonic acid in air, amount of, 202.

", $\quad$ in body, 6, 8, 9, 10, 100 .

,, in water, 132,133 .

", , , poisonous action of, 202.

Carriage groom, 398.

,, horses, grooming, 321 .

Carriages, cleaning, 366.

, , effect of ammonia on, 47 .

Carrots, 63, 64, 67, 72, 168.

Cast, horses getting, 228, 234 .

Cart horses, food for, 184,185 .

Cattle, prehension of food by, 74 .

Cavalry horses, feeding, I83, 184 .

Cerealin, 69. , mortality among, 198 .

Cellular cloth, 33 .

Cellulose, 65 .

Cement-concrete, 2 I I-2I 3 .

Chaff, I74.

,, , Eastern, 154.

Chalk for floors, rammed, 217.

Chalk-stones, 56.

Change of food, craving for, 106.

Chemical affinity, I I-I 5 .

, analysis, reliability of, 68 .

Chest, 9I.

Chewing, 76-82.

Chill, 22-25, 53 .

Chlorophyll, I4.

Chop, 97, I16, I17, I74, I81, 182.

,, , Eastern, 154 .

Clay for floors, 216.

,, soil for stables, 193.

, stopping for feet, $264,346$.

Clean, seeing if horse is, 349 .

Cleaning food, II4.

" gear, etc., 359-370.

,, room, 247.

Clipped horses, 35 .

Clipping, 350-354. 
Clipping the legs, 352.

, under the saddle, 352 .

Clothes, stable, 406.

Clothing, 285-307.

, , amount of, 290.

, , cleaning, 366.

,, , colour of, 292.

, for drying a horse, 287.

, , nature of, 289 .

,, , necessity of, 285 .

, , objects of, 285 .

,, , suit of, 292.

,, , too much, 288.

, , various kinds of, 292.

, , waterproof, 286, 287.

Clover, 62, 64, 65, 66, 102.

Coach-house, 247.

Coachmen, 396.

Coat, horse's, 34-36, 45 .

,, , shedding the, 319 .

,, , shortening the, 350 .

Cob of maize, 97 .

Cobble stones, 216.

Cocoanut matting, 377. meal, 63,167 .

Cold, horses bearing, 36-39.

,, in England, 37.

,, in Russia, 37.

,, weather, 1 5, 18, 37 .

Colour, protection by, 28 .

Combination of foods, 123 .

Commission, servants', '402.

Companionship, 2.

Concrete, 211.

Condiments, 178 .

Conductivity, 32 .

Congestion, 7.

, of the liver, 25 .

,, , ,, lungs, 24 .

Consumption, 199, 200.

Convection, 203.

Corn as a stimulant, 57 .

,, ,, ,, tissue former.

,, bin, 254 .

,, crusher, 254.

, dry, giving, 90.

,, , effect of keeping on, II2.
Corn for maintaining muscle, 93 .

,, for working horses, necessity of, I 18 .

Corns, 20.

Correlation of forces, 1 I.

Corpora nigra, 209.

Corrugated iron for roofs, 221 .

Cotton grass, 267, 268.

, wadding bandages, 306, 342, 378.

Cracked heels, I7.

Creolin, 359.

Crimea, cold in the, 38 .

Cubic contents of stable, 208.

Curry-comb, 33I.

Cuticle, 18, 19, 20.

DAMP, EFFECT OF, 40.

Dandruff, 18, 34 .

Dandy brush, 330.

Dates, 169.

Deli ponies, 4I, 42.

Dextrin, 69.

Dextrose, 5 .

Diaphragm, 9 I.

Diastase, 69 .

Diet, scales of, 182-185.

Diffusion of gases, 203.

Digestibility of food, 72.

Digestion, 7 I.

,, , organs of, 69.

" in the intestines, 86 .

", ,, ,, stomach, 82-86.

Digestive power, 104-106.

Dirt, eating, I03.

Disinfection of stable, 258 .

Disuse, 53,58 .

Door to two boxes, one, 224 .

Doors, 222, 223.

Drainage, 194.

Drains in stable, $194-196$.

Draught, definition of a, 201 .

Draughty stables, 200, 201.

Drinking, see " water."

,$\quad$, action of, 75 .

Drinks, number of times a horse, 139 . 
Dry, giving corn, 90 .

hot climate, I7.

Drying a horse by clothing, 287 .

," new stables, 258.

, room, 247.

Dung, 73 .

,, basket, 253 .

,, in skep, catching, 280 .

", per horse, 282.

EARS, STRIPPING THE, 336.

Economy in food, I80.

Egg albumen, 89.

Eggs, hens', 63, 67.

Electricity, I I.

Enamel, lead in, 233.

Energy, IO-I 4.

Enzymes, 68.

Epidermal growth, 18.

Epidermis, 18

Epithelium, I8.

Excretion, 9, 129.

Exercise, 5I-60, 391-395.

, and grooming, 319.

, , cleansing effect of, 3 I 7 .

,, ground, 193 .

Evaporation, 12, 16, 34, 35 .

Evolution, I.

Eyes, shade for the, 21 .

\section{FASTING, 94, 95.}

Fat, composition of, 4 .

,, , crude, 65.

, in body, decomposition of, 8 .

,, ,, food, i 18 .

,,,,,, , excess of, 122.

,, ," ,, , office of, 92-96.

Fatigue, 55, 59.

Feeding, 179-19I.

,, , frequency of, 84 .

,, , hours of, $\mathbf{I} 88$.

, , regularity in, 185 .

", room, 245.

,, , theory of, 6I-I27.

Feelers, 357 .
Feet balling from snow, 346 .

,, , care of the legs and, 342 .

,, , cleaning the, 339 .

,, , effect of bedding on, 264 .

,, , ,, ,, urine ,, 47 .

,, , greasing the, 346 .

,, , hard, 345 .

,, , not washed, 345 .

,, , picking out the, 344 .

,, , stopping the, 346 .

Fermentation, I I I , I I3.

Ferments, 68, 72.

Ferns, 274.

Ferrets, stomach of, 83 .

Fibre, 65, 73, 96-99, 109, II I.

,, aiding digestion, 84 .

,, , decomposition of, 88 .

, in food, excess of, I2I.

Filariæ, I3I.

Filled legs, 342.

Fillet strings, 292, 293.

Finnish ponies, 19.

Fir needles, 262, 274.

", trees, 194.

Fire, leading horse out of, 3 I4.

First principles, I-50.

Fish in water, $13 \mathrm{I}$.

Flannel shirt, 33, 35 .

Flesh, ash of, 67.

Flies, 289, 347.

Floors, waterproof, 198.

Food at a time, not too much, 186.

,, , daily distribution of, 187 .

,, , effects of too much, I2I.

,, , objects of, $6 \mathbf{I}$.

,, , preparation of, II 4 .

,, , variety in, 106.

Floor, slope of, 196, 197.

Floors for stables, $210-217$.

,, , waterproof, 198.

Flora Temple, 59.

Foot, lifting up a, 309-312.

Forge, 248.

Fork, stable, 253 .

Frogs, breathing by, 9 .

Frost bite, 24, 39.

Fruit, 168. 
GALL BLADDER, 87.

Gamecock, 59.

Gastric juice, 82-86.

Glands, 7 I.

Glare, effect of, 21 .

Glass, windows, 27.

Glasses, coloured, 22.

Glycogen, 5.

Goats not drinking, $\mathrm{I}_{3} 8$.

Going up to a horse, 309.

Go-downs of water, 75 .

Gram, 63, I 15, I 24, I25. I69.

Granite chips, 2 I I.

,, sets, 2 I 4 .

Grape sugar, 5, 8.

Grass, 62, 63, 64, 66, 109, 172 .

,, , turning out to, 387 .

Gravel soil for stables, I93.

Gravitation, I I.

Green house, 28.

"Green meat," 90.

Gregariousness, 2.

Grey horses, 29.

Grinding grain, 117.

Grooming, 316-349.

, and exercise, $3 \mathbf{1 9}$.

,, , definition of, 3 I 6 .

., , details of, 334 .

,, , help required for, 333 .

,, horse hot from work, 334 .

,, , hours of, $32 \mathrm{I}$.

,, , necessity of, 316 .

., , objects of, 3 I6.

., testing the, 349 .

., , time required for, 333 .

., , tools, 326.

,, working horses, 34I.

Grooms, 396.

Ground, feeding off the, 233, 244.

,, for exercise, 393.

Growth of plants, I08.

Guinea Corn, 164, I66.

Gypsum, 259.

H/EMOGLOBIN, 6.

Hair, 19, 20.
Hair, shedding, 319.

,, , trimming, 354 .

Halters, 299.

Hand-rubbing, 323, 354.

, , , , reducing the coat by, 324.

Handling horses, 308 .

Hares not drinking, 138 .

Harness cases, 246.

,, room, 245.

Harvesting, I 10.

Hats, cleaning silk, 370.

Hay, 62, 64, 65, 66, 72, 8o, 97, 98, 99, I02, II0, II2, I18, I19, I72.

,, before corn, giving, 85 .

,, , distribution of, 187 .

, , effect of wet on, I Io.

," "heating," I I I.

,, , long, I87.

,, net, 235 .

,, pad, 333 .

,, rack, 235, 242.

,, receptacle, 235, 242.

,, tea, I74.

Head-collar, slipping, 298.

,, ,, with hood, 296.

Head-collars, 296.

Health, I.

Heat, I I, I 5.

,, apoplexy, 2 I.

, , conduction of, 30-34.

,, in England and India, 40.

,, , latent, 12.

,, , radiation of, 26 .

,, , sensation of, 31 .

"Heating" effect of food, I22, I23, 125.

Hemp wisp, 332.

Herald, 59.

Highflier, 59.

Hindle, 59.

Hippuric acid, 9, 46, 56.

Holding a horse, 312.

,, up a leg, $3 \mathbf{1 2 .}$

Hood, 295.

Hoof-brush, 330.

,, picker, 332. 


\section{INDEX.}

Hoofs, effect of bedding on, 264 . , , , , , urine on, 47.

Horn-parings in food, 96.

Horns, 19.

Horse-box, sea-going, 375 .

Horse, going up to a, 309 .

,, , holding a, 312 .

, , leading a, 313-315.

,, sickness, 42.

,, , sleeping, I89.

Horses, barefoot, 345 .

,, by day, racking up, 227.

,, , canal boat, I9I.

,, , feeding, 179-19I.

,, , grey, 29.

, , handling, 308

,, , light-coloured, 28.

,, , white, 29.

, , young, 2, 102, 109, I I 8-1 21, I 54 .

Hunger, I 25 .

Hunters, 24.

,, , exercising, 391.

, , feeding, I80, I90, I91.

, , soiling, 387 .

, , summering, 387-389.

Hunting men, 391.

Hydrochloric acid, 5, 82.

ICE MELTING, PREVENTING, 3 I.

India, heat in, 40.

Indian horses, I9.

Influenza, I98, 199, 269.

Inlets and outlets of air, 206.

Insects, breathing of, 9 .

Internal temperature, I 5, 21 .

Intestinal juice, 87 .

$$
\text { ,, glands, } 71 \text {. }
$$

Intestines, 71 .

,, , digestion in the, 86 .

Iron, cleaning, 364 .

, in the body, 5 .

, in food, 99 .

\section{JACKSON, 59.}

Jay's Fluid, 259.
KAFFIR CORN, I64-I66.

Kelley, Harry, 59.

Kersey, 292.

Kicking, 226, 230, 231.

, at night, horses, 210.

Kidneys, 8.

Kiln-drying oats, I I 5, I 48 .

Kirgis steppes, 3 .

Kulthee, 63, I I 5, I70.

LAMINITIS, 37 I.

Lead in enamel, 233.

, , water, 134 .

Leading horses, 313-31 5, 393, 394.

Leather, cleaning, 359-364.

,, , effect of ammonia on, 47 .

Leeches, I3I.

Leg against manger, striking, 234 .

,, , holding up, $3 \mathbf{1} 2$.

,, over tying-up chain, getting, 237, 238.

Legs, care of the feet and, 342 .

,, , clipping the, 352 .

,, , filled, 342 .

Lifting up a foot, 309, 3 I0.

Lignin, 65.

Lime as a manure, 109.

, in bricks, 218 .

,, ,, food, 102.

,, ,, soil, 120, 136.

,, ,, the body, 4 .

,, , phosphate of, 68.

,, , quick, 12.

,, , slaked, $\mathbf{2} 2$.

,' stone soil, 120.

Linseed, 62, 162.

,, and bran mash, 162.

,, cake, 62, 64, I63.

,, meal, 162 .

Lips in feeding, action of, 74 .

Liski, 200.

Litter, disposal of, 281.

," shed, 252.

Liver, 7 I.

, , congestion of the, 25 .

Livery, 406. 
London cab horses, I37.

,, Road Car horses, I84, 282.

Lucerne, 62, 66, I02, I21, I75.

, , cultivating, I 76 .

Lungs, congestion of the, 24 .

Lymphangitis, 54, 122.

MACHINE, ANIMAL, I4.

Maize, 62, 64, 66, 72, 92, 97, 102, I04,

I I 5 , I I 8, I 24, I25, I 5 I-I 54 .

,, , cob of, $\mathbf{1} 53$.

,, , manner of giving, 153.

Malt sugar (maltose), 69.

Mane, cleaning the, 337 .

, comb, $33 \mathrm{I}$.

,, , trimming the, 355,356 .

Manger, striking leg against, 234 .

Mangers, 232-234, 242.

Manure, fermentation of, $282,283$. ,, , stable, 28I.

Master, respect from servants to, 4I 2.

Mastication, 76-82.

Matting, cocoanut, 377 .

McKinnell's method of ventilation, 207.

Melanosis, 29.

Middlings, I6r.

Milk, 63, 67, I I9, I 72.

Millet, 63, 66, I64-I66.

Mineral matters in body, 4 . ,, , , , food, 65, 99 .

Monday morning disease, I 22.

Montana, cold in, 38 .

Moong, 63, I7I.

Mop, 367 .

Moss as bedding, 262, 274.

Mosso, Prof. 94.

Mote, 63, I 7 I.

Motion as energy, I I.

Moulting the coat, 319.

Mounting on near side, 3 Io.

Mucking-out, 278.

Mucous membrane, 69.

Mud fever, $\mathbf{1 7}$.

, walls, 220.

Muddy water, drinking, IO3.
Muscle, composition of, 4 .

,$\quad$ twitching, 355 .

Muscular development, 54 . power, variation in, 49 .

NAPOLEON I. IN RUSSIA, 38.

Nature, state of, I.

Navicular disease, 54 .

Near side, handling on, 3 Io.

,, ,, mounting on, 3 Io.

Negroes bearing heat, 29.

Net for hay, 235 .

Nickel, cleaning, 364 .

Night caps, 296.

, , feeding at, I 88.

Nitrogenous food, benefit of, 93 .

,, matter in food, excess of, I 22, 123 .

,, matter in food, office of, 93.

,, matter of body, 4 .

,, , , ,, ,, , decomposition of, 8 .

,, $\quad$ matter of plants, 63, I25.

, waste, effect of exercise on, 92.

waste, poisonous, 56 .

Norfolk, breeding horses in, I2O.

Norwegian stove, 3 I.

Nutritive ratio of food, IO3.

,, values of foods, IO7-II3.

OAT BRUISING MACHINE, 254. ,, fodder, 62, 66.

Oats, 62, 64, 66, 68, 72, 80, 97, 99, I02, I03, I04, I46-1 51.

,, , dust in, I47.

,, , husk of, I47, I48, I49.

,, , kiln drying, I I 5, I48.

,, , measuring, I 50.

,, , old, 148 .

, , tests of quality, I47.

,, , weight of, I48-1 5 I.

Oil for leather, 359,360 .

,, of the skin, I7, 318 . 
Omnibus horses, food for, 184,185 .

Ossory, 376.

Oxygen in body, 6 .

,, ,, water, 132 .

Oxyhæmoglobin, 7 .

\section{PAD, HAY, 333.}

Paddy, 63, 66, I24, 166.

Pancreas, 71 .

Pancreatic juice, 86.

Panels, serge and linen covered, 364.

Panniculus carnosus, 355.

Pantiles, 221.

Paralysis of the loins, I93.

Parching, I 5 .

Parkes' method of ventilation, Dr., 204.

Parsnips, I68.

Passages in stables, 225.

Pay of grooms and coachmen, 401 .

Peas, 62, 64, 65, 66, 163 .

Peat moss, 262, 264, 266-271, 275, $278,28 \mathrm{I}$.

Pepsin, 82.

Peptone, 82.

Perspiration, 12, I5, 16, 34 .

Phosphate of lime in food, IO2, II9.

Phosphoric acid in body, 5 .

Physic, 392. ,, ,, food, 99.

Picker, hoof, 332.

Picking out feet, 264, 344 .

Pigment, 29.

Pigs bearing heat, 30 .

,, , feeding, 93, 103.

Pillar reins, 24I-244.

Pink-eye, 198.

Pipe-claying, 366.

Plants, composition of, 6. , , food of, 13 .

Plaster, horses licking, I03.

Plated work, cleaning, 365 .

Plums, I69.

Poisonous nitrogenous waste, 56 .

Polo ponies bearing cold, 36 . ,, , , food for, 184 .
Polo ponies, wintering, 389 .

Portland cement, 212.

Potash in the body, 5 .

$$
\text { ,, ,, food, } 99 .
$$

,, ,, soap, 47, 49.

Potatoes, 63, 67, 167 .

Prehension of food, 74 .

Preparation of food, II4.

Pressure and epidermal growth, 20. ,, , swelling from, 34I.

Pricks in shoeing, 343 .

Prince Io, 376.

Proportions of food, I79.

Proteids, 63.

Pumpkins, 63, I69.

QUARTER MARKS, 340.

, sheet, 293.

Quartering, 34I.

Quorn horses, clothing of, 293.

RABBITS NOT DRINKING, I38.

Race horses, clothing of, 292.

,, , , feeding of, I84, I90.

Rack chain, 240.

Racking up horses by day, 227, 385 .

Radiation of heat, 26.

Rays of the sun, 27 .

Reaction, 22, 23.

Regal, 59.

Reindeer, 59.

Respiration, 6.

Rest, 54 .

Rice, 63, 66, 166.

,, meal, 63, 64, 166.

, water, I 66 .

Rickets, 100.

Riding school, 249 .

Roads, exercising on, 392.

Roaring, I99.

Roofs, 221.

Roller, 293.

, cloth, 294.

Roots, I68.

Routine, stable, 382-386. 
Rugs, 3I, 32, 35, 294.

Russia, cold in, 37 .

,, , horses in, 36, 37, 44 .

,, , watering horses in, I 37 .

Russian cab horses, I37.

,, remount depôts, 199 .

, stables, I99.

Rye, 63, 66, I67.

SADDLE AFTER WORK, LEAVING ON, 340.

Saddle, clipping under, 352.

,, , lumps on back from, 334 .

,, , opening out trees of, 3I4.

,, , riding without, 394 .

,, room, 245.

Saddles, cleaning, 360-363, 370.

Sainfoin, 62.

Salicylate of soda, 57, 123.

Salicylic acid, 57.

Saliva, 7 I, 79-8I.

Salivary glands, $7 \mathrm{I}$.

Salt for keeping down dust, 251 .

,, ,, melting snow, 39 .

, in food, 99-102.

Salts, Epsom, 392.

Sand as bedding, 262, 274, 278.

Sandy soil for stables, 193 .

Sawdust as bedding, 262, 264, 272, $275,278$.

,, , carbolised, 259.

,, for riding school, $25 \mathrm{I}$.

Scissors, clipping, 254 .

Second horseman, 399.

Servants, stable, 396.

Sharps, I6I.

Shavings, 273, 275, 278.

Sheath, cleaning the, 339 .

Sheep not drinking, 138 .

Sheringham's air inlet, 205.

Ship, horses on board, 37 I-38I. ,, , ventilation on board, 208.

Shire horses, soil for, I 2 I.

Shoeing, 343 .

Shoes are loose, seeing if, 344 .

Shorts, I6I.
Sick box, 244 .

Signorina, 59.

Sikhs, I9.

Silica in body, 5 .

Silver, cleaning, 365 .

Singapore, I7.

Singeing, 353, 354 .

Skep, 253 .

Skin, 8, 9, I 5-20, 70.

Slates, 22 I.

Sleeping, horse, I89.

Slinging horses, 374, 379 .

Slings, 244 .

Slipping head-collar, 298.

Slope of floor, I96, 197.

Soap, 48-50, 360-362.

Soda, bicarbonate of, I23.

, , in body, 5 .

,, ,, food, 65, 99, roo.

,, ,, soap, 47, 49.

Soft soap, 49 .

Soiling hunters, 387 .

Soils for stables, 193.

Soja beans, 63 .

Snow, 32, 35, 36, 39, 346.

South African chaff, I 53 .

Speed, 58, 59.

Spoke-brushes, 254, 367.

Sponges, cleaning, 370.

Stable impurities, 45, 201.

,, routine, 382-386.

,, utensils, 252.

,, yard, 249 .

Stables, 192-252.

,, , aspect of, I93.

,, , cubic contents of, 208.

,, , damp, 198.

,, , disinfection of, 258 .

,, , draughty, 200, 201.

,, , drying new, 258.

, , floors for, 2 IO-2I 7.

,, , ground surface of, 2 Io.

,, , hot, 197-200.

, , in storeys, 258.

,, , lighting of, 209.

,, , necessity of, 192.

,, , plans for, 256 . 
Stables, site of, 193 .

, , temperature of, 197 .

,, , walls for, 21 7, 220.

Stains on horses, removing, 339.

Stalls, construction of, 230-24I.

", , merits of, 225-228.

,, , size of, 229.

,, swinging bail, 226, 227, 228, 230, $23 \mathrm{I}$.

Starch, animal, 5 .

, in food, $64, \mathrm{II} 8, \mathrm{I22}$.

," , plants, formation of, 13 .

Starvation, 92, 94, 95.

Steam, 12.

Steaming food, II 4 .

Steel, cleaning, 364 .

Stomach, 70, 82-86.

Stone thrown in air, II.

Stones, cobble, 2 I6.

Stopping the feet, 346 .

Storeys in stables, 258.

Stowage of forage, 113 .

Stripping the ears, 336 .

Straw as food, 62, 64, 65, 67, 72, I 74, I $81,182,183$.

,, ,, bedding, 262, 265, 275, 276, 280.

Sugar for starving animals, 94.

, , cane, 64, 169.

,, grape, 5, 8, 64 .

Sulphuric acid, 122, 123.

Summering hunters, 387-389.

Sun-cure, 4 I.

, protectors, 22.

,, , rays of the, $13,14,27$.

,, stroke, $2 \mathrm{I}$.

Sunlight, effect of, 4I.

Supply, bodily, 7 .

Sweat, 16, I7.

,, , cold, 16.

,, scrapers, 332 .

Swedes, 63, 67 .

Swelling from pressure, 341 .

Swinging bail stalls, 226, 227, 228, 230, 231.

TAIL, BANGING, 356, 357 .
Tail, cleaning, 337 .

, guard, 295.

,, , rubbing, 338 .

Tasmanian natives, 2 .

Tan, 262, 264, 273, 278.

,, for riding school, 35 I.

Tea, I09.

Teeth, 74, 76-78, 100.

Temper in a horse, good, 309.

Temperature, extremes of, 36-40.

$$
\text { ,, , internal, 15, 21, } 52 .
$$

,, of stables, 197 .

Tentacula, 357.

Thirst, 56, 125.

Thorley's food, 178.

Thoroughbreds, bone of, I 9 .

Thrush, 54, 345.

Tibben, 154 .

Tibet ponies, 19, 42 .

Tiles, $219,221$.

,, , porcelain, 236.

Tips to servants, 405 .

Tobin tube, 204.

Tommy Tittlemouse, 59.

Tools, grooming, 326.

Tops, cleaning, 369 .

Tram horses, food for, I84, I 85.

Tricycle for corn crusher, 254 .

Trimming hair, 354.

Tuberculosis, 172 .

Turnips, 63, 64, 67.

Twisting-in bedding, 277 .

Twitch, 74 .

Tying-up, 236-240.

," horses by day, 227.

UNDER RUG, 296.

Urea, 9, 10, 46, 56.

Uric acid, 56, 123.

Urine, 8, 10.

,, in pot, catching, 280.

,, , receptacle for, 196.

Urud, 63, I 7 I.

VARNISH, EFFECT OF AMMONIA ON, $47,48$.

Vasculose, 65 . 
Vaseline, 360.

Ventilation, 201-208.

Vetches, 62, 65, 66.

Vet. Surgeons and grooms, 410.

Voice, 3, 308.

\section{WAGES OF STABLE SERVANTS,} 401 .

Walls for stables, 21 7, 220:

Warburton, Choppy, 59.

Wash-box, 248.

Washing horses, 322, 345 .

Waste materials in body, 8, 9 .

Water, I6, 53, I28-145.

,, , æration of, I3I.

,, as a food, 89.

", brush, 330.

, , change of, 140.

,, , cold drinking, I37.

, , colour in, 136 .

,, , conditions of drinking, I 3 I.

, , conductivity of, 32, 35 .

, , cooling effect of drinking, 128 .

, , destination of drinking, I 30.

,, , drinking muddy, ro3.

, in body, 3 .

,, for digestive juices, 88 .

,, , hard, 133-1 36.

,, horses drink, quantity of, I38.

, in food, too much, I2I.

,, , stables, 236.

, , mineral substances in, 133 .

, , necessity of, 24 .

,, , objects of, I28-1 30.

, , odour in, 136 .

,, , rain, 132 .

,, , spring, I 32 .
Water, soaking grain in, II 5 .

, , , soft, I33.

,, , Thames, I33.

,, , warming drinking, I37.

Watering after feeding, 86.

," before ,, , I4I.

,, after work, I44.

,, during work, 143 .

,, horses, I 28-145.

,, , , rules for, I40-I45.

Waterproof clothing, 286, 287.

Weasels, stomach of, 83 .

Weighing machine, 252.

Wells, I94.

Wheat, 62, 64, 66, 159 .

Wheel-barrow, 254.

White walls, 209.

Wholesomeness of food, 72.

Wild animals clean, 3 I 7 .

Williamson, 59.

Wind, cooling effect of, 34 .

Windows, 200, 206, 224.

Wisping, 332.

Wisps, 332.

Wood, ash of, 67 .

,, ashes as food, I03.

,, for floors, $2 \mathrm{I} 4$.

,, ,, walls, 220, 22 I.

Woody fibre, formation of, 13 .

Work, I0, I23.

, , food in relation to, 117 .

,, , unit of, Io.

Working horses, food for, 93, I 84 , I 85 .

YARD, STABLE, 249.

Young horses, I02, IO9, II8-I2I, I54. 
I3, Great Marlborough Street,

LoNDON, W.

\section{BOOKS ON HORSES}

BI

M. HORACE HAYES, F.R.C.V.S.

(Late Captain "The Buffs").

Now Ready in I vol., Demy 8vo., Cloth. Price I6/- nett.

\section{Riding and Hunting.}

By CAPT. M. H. HAYES, F.R.C.V.S.

Fully lllustrated with upwards of 250 Reproductions of Photographs and Drawings.

Now Ready in I vol., Demy 8vo. Price $12 ;-$ nett.

\section{Stable Management and Exercise.}

A BOOK FOR HORSE OWNERS AND STUDENTS.

BY CAPT. M. HORACE HAYES, F.R.C.V.S.

Illustrated by numerous Reproductions of Photographs taken specially for this work.

"Captain Hayes-who may justly claim to be the first authority now living on all matters connected with the horse-is always welcome, and the more so because each succesive volume is a monument of "the reason why.' "-County Gentleman.

LONDON: HURST \& BLACKETT, LIMITED. 
Second Edition. Super-Royal 8vo., Cloth, Gilt Top, Price 34/-

\section{Points of the Horse.}

A FAMILIAR TREATISE ON EQUINE CONFORMATION.

\section{By CAPT. M. HORACE HAYES, F.R.C.V.S.}

The present Edition has been thoroughly revised and contains numerous additions, including specially-written Chapters on the Breeds of English and Foreign Horses, with over Two Hundred beautiful Illustrations reproduced from Photographs, the larger number of which were taken by the Author and have never before been published.

"An elaborate and instructive compendium of sound knowledge on a subject of great moment to all owners of horses, by a writer of established authority on all matters comnected with the horse."-Times.

"We hail the advent of a work on the subject by such a pastmaster of the arts hippic as Captain Horace Hayes, late of 'The Buff's' and a Fellow of the Royal College of Veterinary Surgeons, the author of several of the most simple and thoronghly instructive treatises upou riding, breaking, and veterinary treatment of the horse."-Land and Water.

Demy 8vo., Cloth. Price Io,6 nett.

\section{INFECTIVE DISEASES

$$
==\text { OF ANIMALS. }
$$

Being Part I. of Friedberger and Frohner's Veterinary Pathology,

With a Chapter on Bacteriology by Dr. G. Newman, D.P.H.

\section{Translated and Edited}

By Capt. M. H. HAYES, F.R.C.V.S.

"Whether considered as a work of reference for busy practitioners, as a text-book for" students, or as a treatise on pathology in its widest significance, this volume meets every requirement, and is an invaluable addition to our literature."-Veterinary Record.

"With great satisfaction we welcome the appearance of this translation, which for the first time places in the hands of English-speaking readers a worthy version of one part of Friedberger and Fröhner's great work. Captain Hayes' reputation is sufficient warrant for the excellence of the literary portion of the present issue. It would be presumptuous on our part to arld one word on the value of the work as a source of information. Every one bows to the authority of the authors."-The Vterinarian. 
Fifth Edition. Revised and Enlarged. Large Crown 8ro. Price 15/-.

\section{Veterinary Notes for Horse Owners.}

AN ILLUSTRATED MANUAL OF HORSE MEDICINE AND SURGERY, WRITTEN

IN SIMPLE LANGUAGE.

By CAPT. M. H. HAYES, F.R.C.V.S.

This Editinn is revised throughout, considerably enlarged, and incorporates the substance of the Author's "Soundness and Age of Horses."

The chief new matter in this edition is-articles on Contracted Heels, Donkey's Foot Disease, Forging or Clicking, Rheumatic Joint Disease, Abscess, Dislocation of the Shoulder Joint, Inflammation of the Mouth and Tongue, Flatulent Distention of the Stomach, Twist of the Intestines, Relapsing Fever, Cape Horse Sickness, Horse Syphilis, Rábies, Megrims, Staggers, Epilepsy, Sunstroke, Poisoning. Castration by the Ecraseur, and Mechanism of the Foot (in Chapter on Shoeing). Field.

"Is a thoroughly practical work and may be recommended with confidence." - Ihe

"Is a valuable addition to our stable literature; and the illustrations, tolerably numerous, are excellent beyond the reach of criticism."-Suturday Revien.

"Leaves nothing to be desired on the score of lucidity and comprehensiveness."Veterinary Journal.

"A necessary guide for horse-owners, especially those who are far removed from immediate professional assistance."-The Times.

\section{The Horsewoman.}

By MRS. HAYES. Edited by CAPT. M. H. HAYES.

A PRACTICAL GUIDE TO SIDE-SADDLE RIDING.

With Numerous Illustrations and Drawings from Photographs by OSWALD BROWN.

"A large amount of sound, practical instruction, very judiciously and pleasantly imparted."-The Times.

"This is the first occasion on which a practical horseman and a practical horsewoman have collaborated in bringing out a book on riding for ladies. The result is in every way satisfactory, and, no matter how well a lady may ride, she will gain nuch valuable information from a perusal of 'The Horsewoman.' The book is happily free from selflaudatory passages." - The Field.

Large Crown 8vo. Price 1o/6 nett.

\section{Among Horses in Russia.}

By CAPT. M. H. HAYES, F.R.C.V.S.

With Fifty-three Iliustrations from Photographs taken chiefly by the Author.

LONDON : HURST \& BLACKETT, LIMITED. 
Imperial 16mo. Second Edition, Price 21/-.

\section{ILLUSTRATED . . $H O R S E=B R E A K I N G$.}

By Capt. M. H. HAYES, F.R.C.V.S.

This Edition has been entirely re-written; the amount of the letterpress more than doubled; and 75 reproductions of Photographs have been added.

"' It is a characteristic of all Capt. Hayes' books on horses that they are eminently practical, and the present one is no exception to the rule. A work: which is entitled to high praise as being far and away the best reasoned-out one on breaking under a new system we have seen."-The Field.

Fifth Edition. Revised. Crown 8vo. Price 6/-.

\section{Training and \\ Horse Management in India.}

By Capt. M. H. HAYES, F.R.C.V.S.

"A useful guide in regard to horses anywhere. Concise, practical, and portable."-Saturday Review.

"We entertain a very high opinion of Capt. Hayes' book on 'Horse 'Training and Management in India,' and are of opinion that no better guide could be placed in the hands of either amateur horseman or veterinary surgeon newly arrived in that important division of our empire."-Veterinary Fournal.

Crown 8vo. Price 5/-.

\section{AMONG HORSES . . \\ - IN SOUTH AFRICA.}

By Capt. M. H. HAYES, F.R.C.V.S.

LONDON: HURST \& BLACKETT, LIMITED. 



\section{DAY USE}

RETURN TO DESK FROM WHICH BORROWED

\section{LOAN DEPT.}

This book is due on the last date stamped below, or on the date to which renewed.

Renewed books are subject to immediate recall.

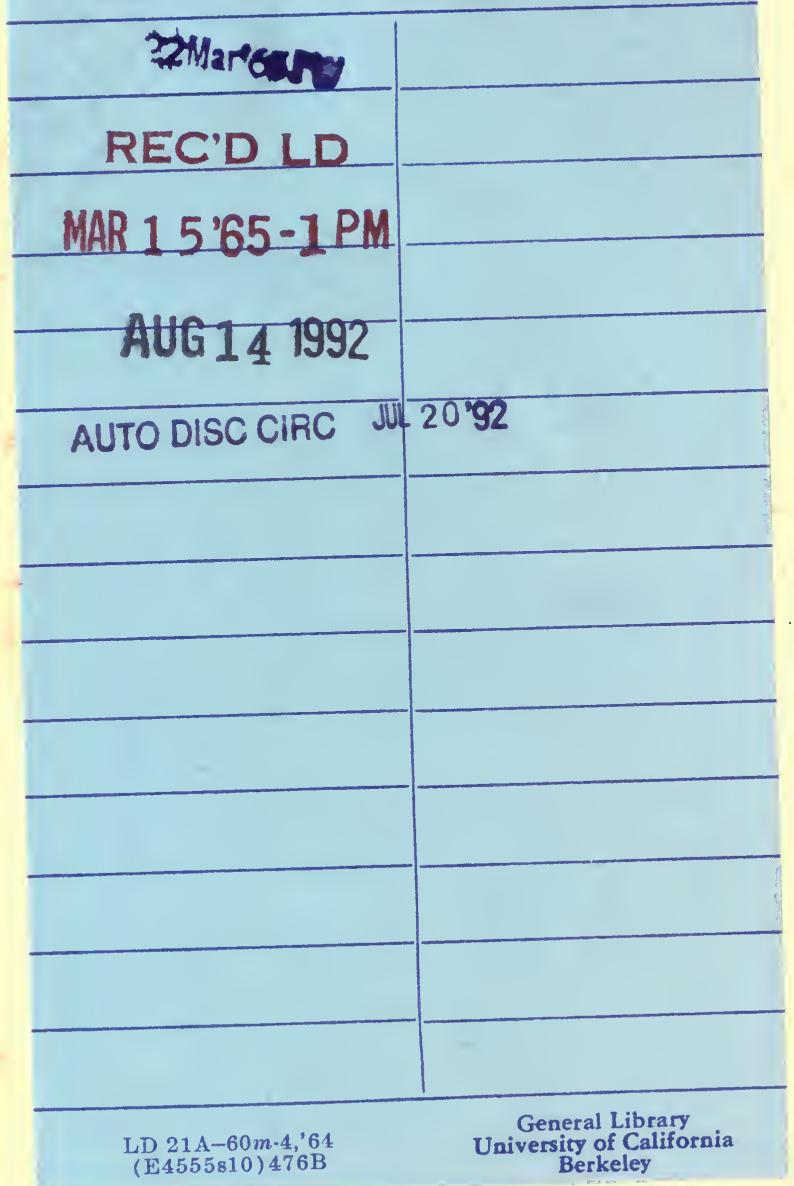




\section{$\mathrm{C} 041206975$}

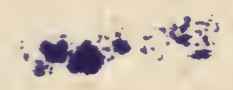

4Avo 
